\title{
A FRAMEWORK FOR DETERMINING THE IMPACT OF DEFERRED MAINTENANCE AND/OR OBSOLESCENCE OF A HIGHWAY SYSTEM
}

\author{
by \\ Allan D. Chasey \\ Dissertation submitted to the Faculty of the \\ Virginia Polytechnic Institute and State University \\ in partial fulfillment of the requirements for the degree of \\ DOCTOR OF PHILOSOPHY \\ in
}

Civil Engineering

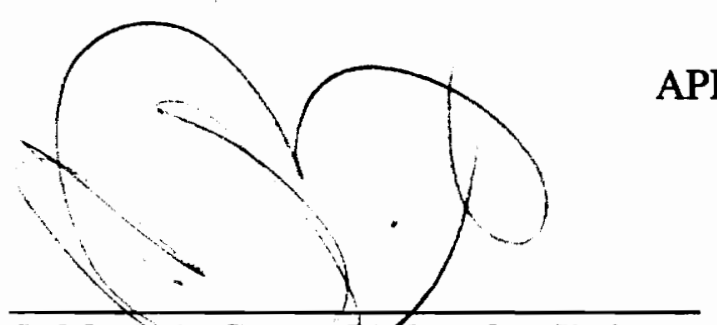

J. M. dè Garza, er.D., Co-Chair

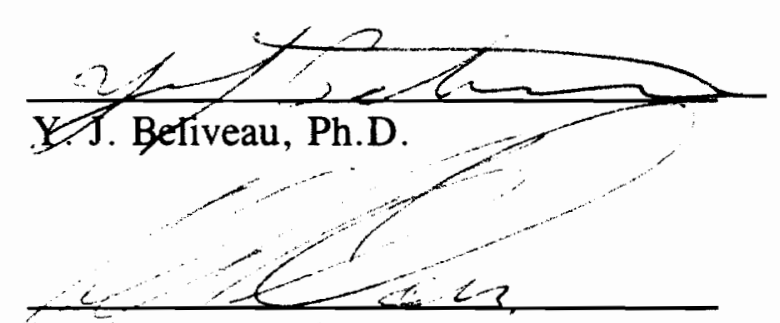

M. C. Vorster, Ph.D.
APPROVED:
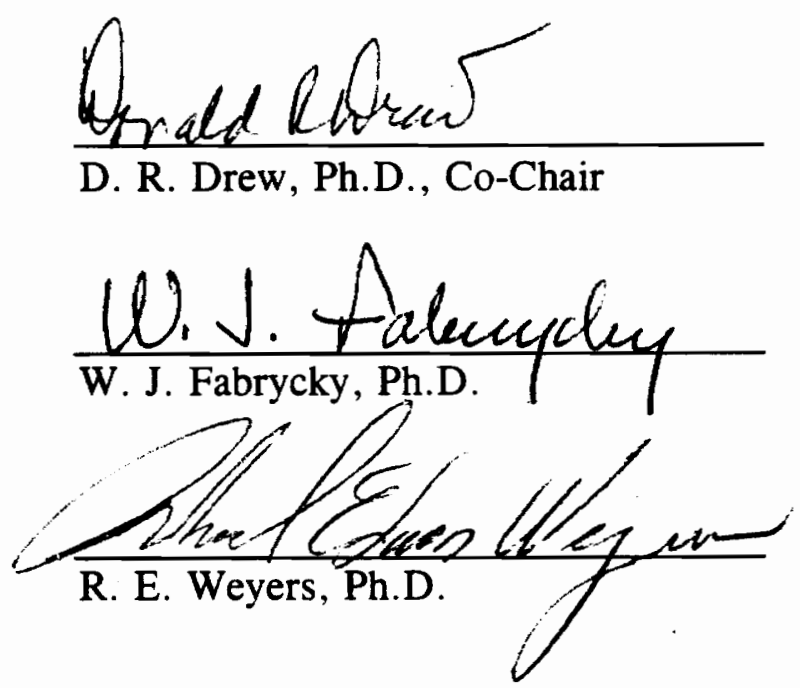

March, 1995

Blacksburg, Virginia 
0.2

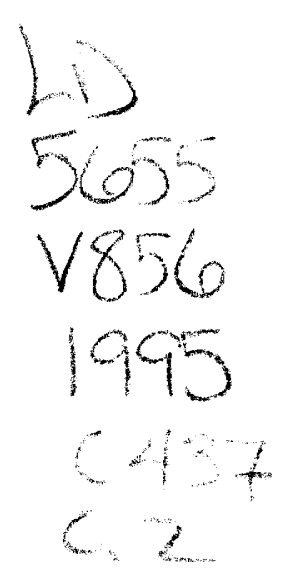




\title{
A FRAMEWORK FOR DETERMINING THE IMPACT OF DEFERRED MAINTENANCE AND/OR OBSOLESCENCE OF A HIGHWAY SYSTEM
}

\author{
by \\ Allan D. Chasey \\ Dr. J. M. de la Garza, Co-Chair \\ Dr. D. R. Drew, Co-Chair \\ Department of Civil Engineering
}

(ABSTRACT)

In the early 1980 's, the decline in the U.S. infrastructure was highlighted by a report entitled America in Ruins: Beyond the Public Works Pork Barrel. A series of reports followed trying to assess the condition of the infrastructure. One of these reports, Fragile Foundations, assigned grades to the various infrastructure systems and concluded that "the quality of America's infrastructure is barely adequate to fulfill current requirements and insufficient to meet the demands of future economic growth and development."

This research develops a framework to account for the impact of deferred highway maintenance and/or construction on user and non-user benefits. This will aid the decision-making process and help guide the effective use of scarce financial resources. The framework proposes the concept of a Comprehensive Level of Service for highways using a combination of both maintenance (Level of Operation) and capacity (Level of Availability) indicators. Highways, like equipment, are affected by deterioration and obsolescence, obsolescence being the inability to function as designed. Deterioration, defining the physical level of service, comes from the aging 
of physical materials over time. Obsolescence, defining the functional level of service, comes from increased usage. Together, they result in overcrowding, congestion and increased economic costs to both users and non-users.

A mathematical model is developed that allows simulation of the impact of deferred highway maintenance based on the concept of a Comprehensive Level of Service. System dynamics is the simulation methodology utilized as it allows incorporation of social, technical, economic and political issues into a laboratory setting to analyze change. The framework, permitting evaluation of the future implications of current policy decisions, is demonstrated through scenario analysis. The scenarios include an analysis of various highway maintenance investment levels and of the trade-off between highway maintenance and highway improvement. These scenarios demonstrate the impact of maintenance and construction investments on a highway system through a user and non-user benefit analysis. 


\section{ACKNOWLEDGMENTS}

I would sincerely like to thank my advisors, Dr. Jesus M. de la Garza and Dr. Donald R. Drew for their patience, advice and support for this dissertation. Their constant encouragement and guidance helped me during those times of greatest need.

I would also like to thank others on my committee, Dr. Yvan Beliveau, Dr. Wolt Fabrycky, Dr. Mike Vorster, and Dr. Richard Weyers, for their time and assistance in this endeavor.

My greatest thanks goes to my wife Susan for her sacrifice in allowing me to return to school and complete this degree. Her hours of encouragement and cheerfulness in time of need will never be repaid. In addition, I would like to thank my daughter Alisha for standing by me during this time and my parents, Dr. and Mrs. E. F. Chasey, for their love and support and their faith in my abilities. 


\section{Table of Contents}

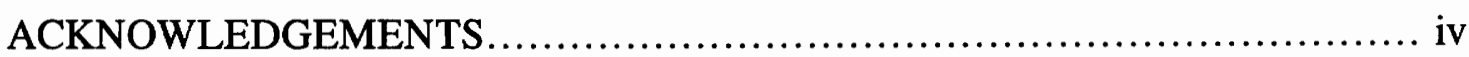

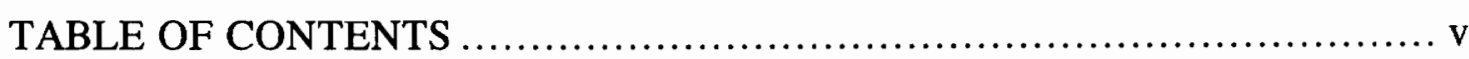

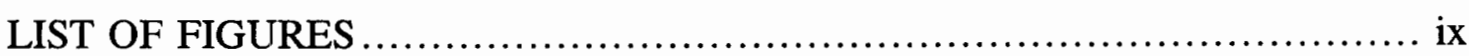

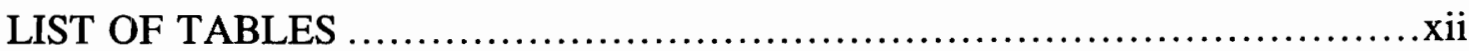

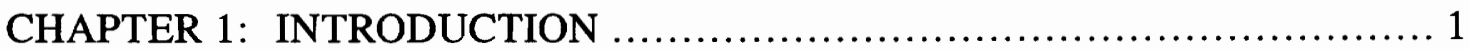

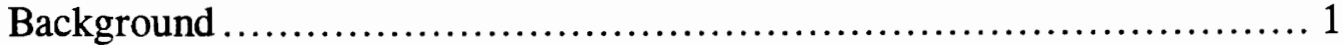

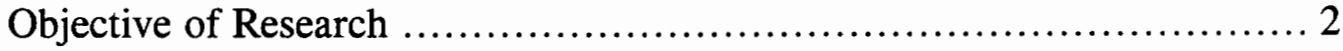

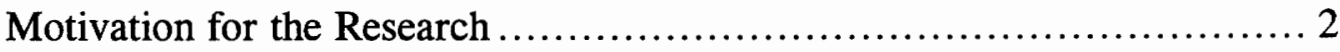

Scope and Limitations of the Research .............................. 4

Level of Service and the Infrastructure System Framework ............... 4

Contribution to the Body of Knowledge............................. 7

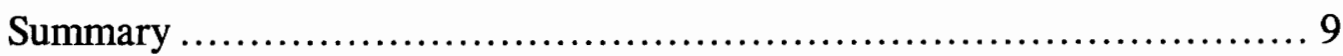

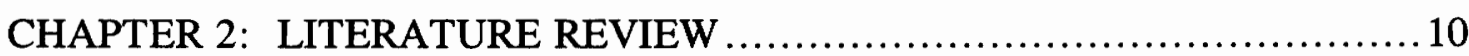

Introduction......................................................... 10

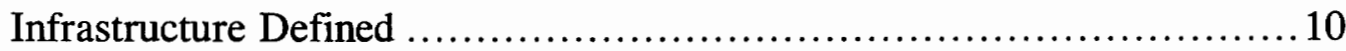

Infrastructure Problem Statement ..................................... 11

Infrastructure Financial Problem Expanded ............................ 13

Capital Budgeting .................................................. 15

Infrastructure and Economic Links.................................. 16

Effects of Infrastructure Deterioration................................ 17

Impact of Degraded Infrastructure ................................. 18

Productivity Effects ................................................ 18

Quality of Life Effects .............................................. 19

Regional Economies .................................................. 19

Importance of Highway Maintenance ...............................20

Consequences of Deferring Maintenance .............................22

Effects of Maintenance on Pavement Performance......................23

User Perception of Road Quality .......................................24

Effects of Deterioration and Obsolescence..............................25

Life-Cycle Cost Analysis Applied to Pavements and Bridges ................28

Budgets and Transportation Needs ..................................... 31

The Effects of Budgeting on the Deteriorating Infrastructure .............. 32 
Dynamics of the Budget Process........................................ 34

Revenues and the Budget Process ....................................... 36

The Federal Highway Trust Fund ........................................... 39

The Politics of the Highway Trust Fund ..............................41

The State Role in Highway Funding .................................42

Current Related Research ............................................43

Summary: Public Works and Performance .............................44

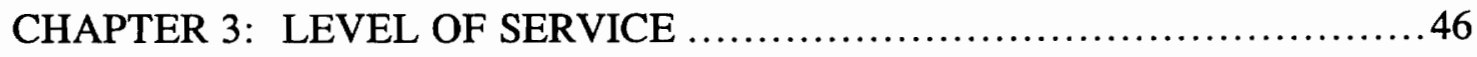

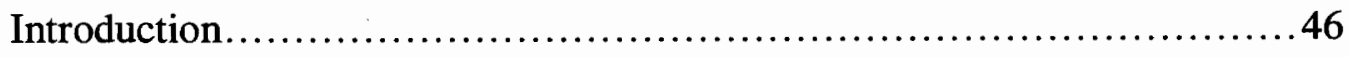

Highway Capacity .................................................... 46

Capacity Level of Service ............................................. 51

Measurement of Level of Service ....................................53

Maintenance Level of Service .............................................6 60

Maintenance, Obsolescence and Level of Service .........................62

Comprehensive Level of Service Definition .............................64

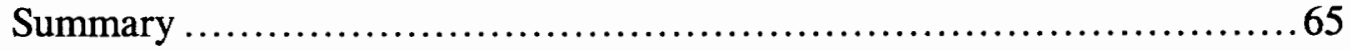

CHAPTER 4: SYSTEM DYNAMICS MODELING .........................68

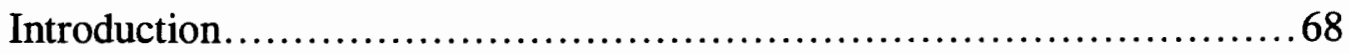

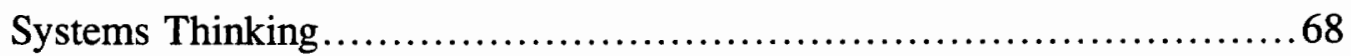

System Dynamics and Feedback Structures ........................... 72

System Behavior ............................................. 72

Closed-Loop Structures ........................................ 73

Positive Feedback Loops ...................................... 73

Negative Feedback Loops....................................73

Conserved Systems......................................... 74

Dynamic Modeling Forms ............................................. 75

Verbal Models ............................................. 75

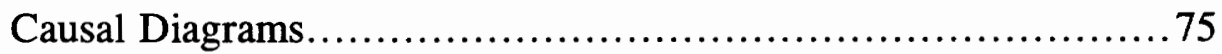

Mathematical Formulation ...................................... 78

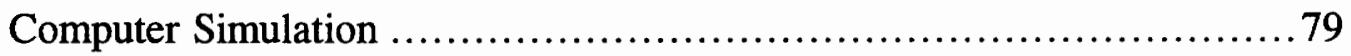

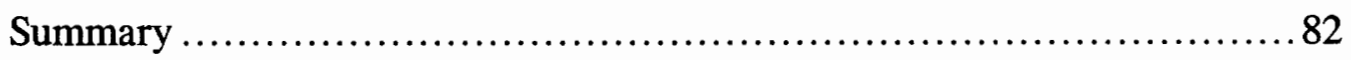

CHAPTER 5: DEVELOPMENT OF SYSTEM DYNAMICS MODELS .........84

Introduction ........................................................... 84

Development of Maintenance Level of Operation Simulation Model ........84 
Development of a Construction Level of Availability Simulation Model ...94

Development of Comprehensive Level of Service Simulation Model..... 101

DYNAMO Simulation of Comprehensive Level of Service Model ....... 102

Model Parameters and Initial Conditions ........................ 103

Simulation Results and Analysis ............................... 105

Summary ......................................................... 107

CHAPTER 6: EQUILIBRIUM ANALYSIS OF SYSTEM DYNAMICS

MODELS ..................................................... 109

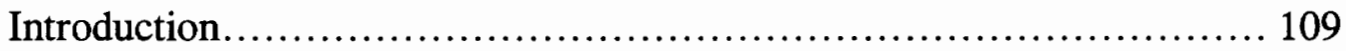

Equilibrium Analysis of Level of Operation Model..................... 109

DYNAMO Maintenance Model Results .............................. 117

Equilibrium Analysis for Level of Availability Model .................. 118

Comprehensive Level of Service ................................... 122

Summary .............................................................. 123

CHAPTER 7: USER AND NON-USER BENEFIT ANALYSIS .............. 125

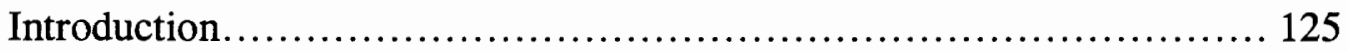

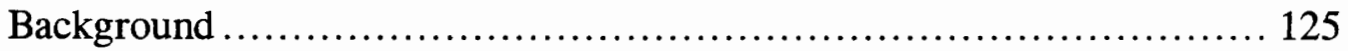

Benefit-Cost Ratio Analysis ...................................... 126

Continuously Compounded Benefit-Cost Ratio ........................ 130

Maintenance, Obsolescence and User/Non-User Benefits ............... 132

Model Approach to the Simulation of User/Non-User Benefits........... 132

Model Development for User/Non-User Benefits ...................... 136

Model Development for Benefit-Cost Analysis

of User/Non-User Benefits ..................................... 142

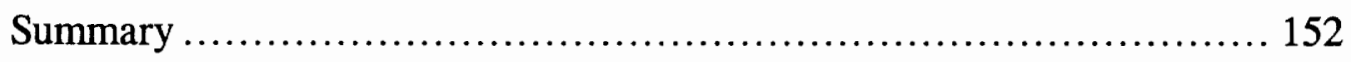

CHAPTER 8: MODEL VALIDATION................................... 155

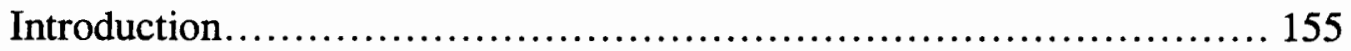

System Dynamics Model Validation ................................. 155

Testing Confidence in a System Dynamics Model ..................... 157

Tests for Model Structure and Behavior Suitability .............. 157

Dimensional Consistency Verification......................... 158

Model Behavior and Parameter Sensitivity ..................... 159

Tests for Model Consistency ................................. 165

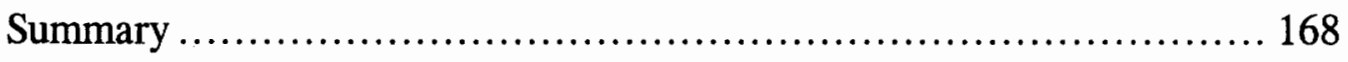

Table of Contents $\quad$ vii 
CHAPTER 9: MODEL IMPLEMENTATION ............................. 171

Introduction....................................................... 171

Management Information Systems.................................. 171

Scenario for Maintenance Expenditure Rates......................... 172

Analysis of Maintenance Effects Simulation Results.................... 175

Scenario for Highway Maintenance vs Highway Improvement ........... 177

Analysis of Highway Maintenance vs Highway Improvement

Simulation Results........................................... 180

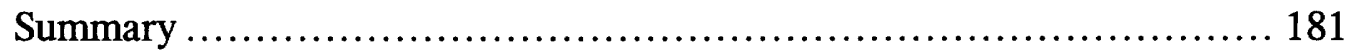

CHAPTER 10: SUMMARY AND RECOMMENDATIONS ................... 182

Introduction.......................................................... 182

Summary of Research .............................................. 182

Recommendations for Future Research............................... 185

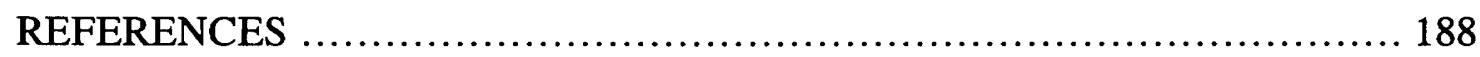

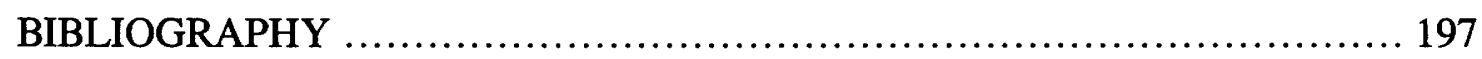

APPENDIX A: LEVEL OF OPERATION MODEL ............................. 203

APPENDIX B: LEVEL OF AVAILABILITY MODEL ........................ 208

APPENDIX C: COMPREHENSIVE LEVEL OF SERVICE MODEL ......... 210

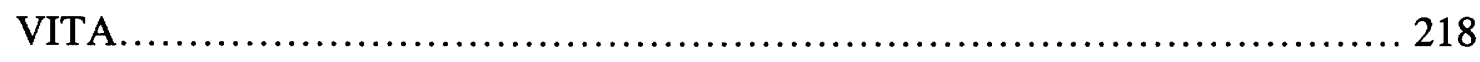

Table of Contents $\quad$ viii 


\section{List of Figures}

Figure 1.1: The System Effect of Deferred Maintenance

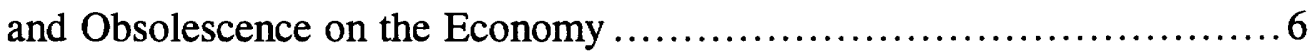

Figure 1.2: Population, Business, Industry Sector $\ldots \ldots \ldots \ldots \ldots \ldots \ldots \ldots \ldots \ldots \ldots \ldots$

Figure 2.1: Significance of Present Rideability Index (PRI) for Effective Pavement Management 26

Figure 3.1: Relationships among Speed, Density, and Rate of Flow on Uninterrupted Flow Facilities

Figure 3.2: Speed-Flow Relationship for a Six-Lane Freeway

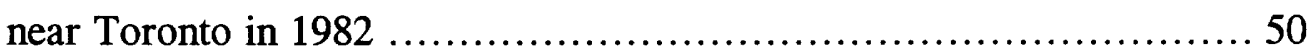

Figure 3.3: Level of Service A and F ......................................... 52

Figure 3.4: Quantitative Approach to Level of Service Using the Total Energy-Momentum Analogy ............................. 55

Figure 3.5: Comprehensive Level of Service Matrix ........................... 66

Figure 4.1: Closed-Loop Concept .......................................... 73

Figure 4.2: Positive Feedback Loop Behavior .................................. 74

Figure 4.3: Negative Feedback Loop Behavior .................................. 74

Figure 4.4: Levels and Rates ...................................................... 76

Figure 4.5: Auxiliary Variables...................................................... 77

Figure 5.1: Causal Diagram for Highway Maintenance Model ..................... 86

Figure 5.2: Causal Diagram for Highway Construction Model ...................... 96

Figure 5.3: Revenues Less Expenditures vs UMHE and UCHE Simulated over 10 Years ............................................. 105

Figure 5.4: Revenues Less Expenditures vs UMHE and UCHE Simulated over 15 Years 106

Figure 5.5: Revenues Less Expenditures vs UMHE and UCHE Simulated over 20 Years 107

Figure 6.1: Level of Operation vs Unit Maintenance Highway Expenditure for Steady State Analysis

Figure 6.2: Revenues Less Expenditures vs Unit Maintenance Highway Expenditures for Steady State Analysis. 
Figure 6.3: Revenues Less Expenditures vs Unit Maintenance Highway Expenditures Simulated over 25 Years Using DYNAMO Simulation ...117

Figure 6.4: Level of Availability vs Unit Construction Highway Expenditure for Steady State Analysis

Figure 6.5: Comprehensive Level of Service vs Unit Construction Highway Expenditures vs Unit Maintenance Highway Expenditures

Figure 6.6: Lane-Mile Condition vs Unit Maintenance Highway Expenditure at Equilibrium

Figure 7.1: Highway User Cost and Benefit Relationships Single Facility 134

Figure 7.2: Highway User Cost and Benefit Relationships Alternate Facilities

Figure 7.3: Vehicle Operating Costs vs Level of Operation 136

Figure 7.4: Total Net Benefits vs UMHE and UCHE

Simulated over 10 Years 140

Figure 7.5: Total Net Benefits vs UMHE and UCHE

Simulated over 15 Years

Figure 7.6: Total Net Benefits vs UMHE and UCHE

Simulated over 20 Years

Figure 7.7: Total Net Benefits per Capita vs UMHE and UCHE

Simulated over 10 Years

Figure 7.8: Total Net Benefits per Capita vs UMHE and UCHE

Simulated over 15 Years

Figure 7.9: Total Net Benefits per Capita vs UMHE and UCHE

Simulated over 20 Years

Figure 7.10: Benefit-Cost Ratio (Annual Equivalence) vs UMHE and UCHE

Simulated over 15 Years

Figure 7.11: Benefit-Cost Ratio (Annual Equivalence) vs UMHE and UCHE Simulated over 20 Years

Figure 7.12: Annual Equivalent Total Benefits

Figure 7.13: Benefit-Cost Ratio (Continuous Compounding) vs UMHE and Construction Investment Simulated over 15 Years

Figure 7.14: Benefit-Cost Ratio (Continuous Compounding) vs UMHE and Construction Investment Simulated over 20 Years 154 
Figure 8.1: Effect of Unit Maintenance Highway Expenditures on Travel Time.

Figure 8.2: Parameter Sensitivity for Ordinary Maintenance Cost in the Maintenance Model.

Figure 8.3: Parameter Sensitivity for Maintenance Replacement Cost in the Maintenance Model.

Figure 8.4: Parameter Sensitivity for Highway Aging Time in the Maintenance Model.

Figure 8.5: Parameter Sensitivity for Highway Deteriorating Time in the Maintenance Model. 164

Figure 8.6: Extreme Condition Test for Maintenance Model Travel Time on Physically Sufficient Roads

Figure 8.7: Extreme Condition Test for Maintenance Model Comprehensive Level of Service for Physically Sufficient Road

Figure 8.8: Extreme Condition Test for Maintenance Model

Travel Time on Physically Deteriorated Roads

Figure 8.9: Extreme Condition Test for Maintenance Model

Comprehensive Level of Service for Physically Deteriorated Roads..... 169

Figure 9.1: Total Net Benefits per Capita vs UMHE vs FEOM

Simulated over 20 Years

Figure 9.2: Revenues Less Expenditures vs UMHE vs FEOM

Simulated over 20 Years

Figure 9.3: Benefit-Cost Ratio vs UMHE vs FEOM

Simulated over 20 Years

Figure 9.4: Total Net Benefits per Capita vs UMHE vs UCHE

Simulated over 20 Years

Figure 9.5: Revenues Less Expenditures vs UMHE vs UCHE

Simulated over 20 Years

Figure 9.6: Benefit-Cost Ratio vs UMHE vs UCHE

Simulated over 20 Years 


\section{List of Tables}

Table 3.1: Levels of Service as Established by Energy-Momentum Concept .......................................... 56

Table 3.2: Illustration of Level of Service Quantification........................... 57

Table 5.1: Initial Construction Variable Values

for Comprehensive Level of Service Model .......................... 103

Table 5.2: Initial Maintenance Variable Values

for Comprehensive Level of Service Model ............................ 104

Table 5.3: Initial Model Parameters for Comprehensive Level of Service Model.... 104

Table 6.1: Initial Values for Level of Operation Index

vs Unit Maintenance Highway Expenditure

Table 6.2: Initial Values for Revenues Less Expenditures

vs Unit Maintenance Highway Expenditure 116

Table 6.3: Parameter Values for Level of Availability Index

Steady State Analysis

Table 8.1: Summary Table of Tests for Building Confidence

in System Dynamics Models....................................... 156

Table 8.2: Parameter Sensitivity Analysis for Maintenance Model .................. 160

Table 9.1: Initial Values for Maintenance Effects Scenario ........................ 173

Table 9.2: Initial Values for Highway Maintenance vs Highway Improvement Scenario 177 


\section{CHAPTER 1: \\ INTRODUCTION}

\section{Background}

"The road to a stronger national economy is not found in clogged streets and highways, slowing traffic to a crawl ... or in water shortages, open garbage dumps and polluted streams. Instead national strength will come through the provision of those everyday facilities whereby industry, commerce, and agriculture can thrive and citizens can enjoy the benefits of our national way of life" (Grigg 1993, p. 52).

These words were spoken by William Hardenbergh, an early public health engineer, as part of a keynote address to the American Public Works Association in 1954. These same words ring true today as we face a deteriorating infrastructure.

In the early 1980 's, the decline in the U.S. infrastructure was highlighted by a report entitled America in Ruins: Beyond the Public Works Pork Barrel by Choate and Walter (Barker 1984). Articles in Newsweek (August, 1982) and U.S. News and World Report (September 27, 1982) further heightened the public's awareness of the deteriorating condition of the nation's public works. A series of reports throughout the country tried to assess the condition of the infrastructure. One report, Fragile Foundations, even assigned grades to the various infrastructure systems and drew the conclusion that "the quality of America's infrastructure is barely adequate to fulfill current requirements and insufficient to meet the demands of future economic growth and development" (NCPWI 1988).

Since the hard-hitting exposé of the decaying infrastructure, emphasis has been placed on the need to rebuild American public works. The importance of maintaining what has already been constructed has been highlighted by several studies such as Fragile Foundations: A Report on America's Public Works, by the National Council on 
Public Works Improvement (NCPWI 1988), and Delivering the Goods, Public Works Technologies, Management and Financing by the Office of Technology Assessment for the United States Congress (OTA 1991). These and other studies (DHS 1987; OTA 1990; Vaughn 1984a, 1984b) indicate that maintenance must be a priority item if the infrastructure is to carry on its primary purpose of economic development.

\section{Objective of Research}

The objective of this research is to gain an insight and understanding of the interrelationships between maintenance and construction activities on a transportation system's Level of Service and their impact on user and non-user benefits. This analysis will also provide a framework for public works' decision-makers to be able to make more structured policy decisions regarding budgeting and funding allocations and to understand the impact of those decisions on the user and non-user benefits.

\section{Motivation for the Research}

The prohibitive cost of rebuilding the infrastructure and the search for an intelligent comprehensive approach has prompted the National Science Foundation's (NSF) development of a research initiative to approach the infrastructure issue from a systems perspective instead of the "band-aid" approach of the past. NSF's research is seeking to build on the current, infrastructure-component research efforts and look at system behavior, deterioration, assessment, and renewal. The goal is to enhance infrastructure performance by seeking new knowledge in deterioration science, assessment technology, and renewal engineering from a systems perspective. The challenge set forth is to study "optimal system performance rather than individual components." (NSF 1993, p. 4). 
Deterioration science is an understanding of why facilities deteriorate. Understanding deterioration will allow for assessment technology to estimate the remaining useful life and to determine the state-of-health of a segment of infrastructure. Renewal engineering seeks to rebuild the aging infrastructure that has suffered the effects of deterioration and lack of maintenance or is functionally obsolete based on the assessment technology estimates. Within these research areas, the systems perspective is evident. Within the assessment technology area of research is included system evaluation and the interdependence of infrastructure systems and social and economic effects. The renewal engineering area of research is seeking knowledge regarding system performance criteria, system modeling, design for system performance, and the future demand, reliability, functionality and longevity of new systems.

In a politically-oriented system as in this country, the budget process is used to set policy and determine priorities for government. Priorities have shifted from supporting economic development to developing a social "safety net" and Congress has chosen to emphasize capital programs instead of maintenance since new construction is more visible to voters and more easily remembered at election time. This change has created a lack of financial resources for infrastructure maintenance. With the lack of adequate available funding for performing the necessary rebuilding, maintaining, or required new construction, spending priorities will have to be established. Within the renewal engineering phase, different strategies for upgrading, maintaining, or disinvesting in infrastructure will need to be evaluated and prioritized. This research will seek to develop a framework that will account for the impact of deferring maintenance and/or obsolescence on the infrastructure as indicated by user and nonuser benefits to aid in the decision-making process. 


\section{Scope and Limitations of the Research}

A mathematical model development and computer simulation is the emphasis of this research. This is seen as the first step in the evolution of a framework to determine the effect of maintenance and/or congestion on an overall highway Level of Service. According to the system dynamics paradigm, a formal, quantitative mathematical model represents some slice of reality and as such allows the modeler to gain an understanding of the complex relationships between variables. By repeated experimentation in the laboratory, assumptions can be tested and the model can lead to an understanding of the feedback interactions (Richardson 1981). The causal diagrams presented within this dissertation are a graphic way of illustrating the verbal model, and are easier to understand and display the hypothesized relationships. The computer simulation model will demonstrate the effect in an infrastructure system context. The simulation will then illustrate the economic impact in terms of user and non-user benefits of a lack of maintenance and/or congestion of a highway system.

\section{Level of Service and the Infrastructure System Framework}

Civil infrastructure systems must be considered from a total systems perspective. No one part of the nation's public works can be singled out as the most important. And no one part of any particular subsystem, such as highways as part of the transportation system, can be considered alone. All pieces are interconnected. The growth of a city is dependent upon the transportation systems, power systems, communication systems, water and waste systems and educational/governmental administration. Businesses and industries go where the physical infrastructure will support profit for the company. The growth of businesses will attract more employment which will require increasing the infrastructure capacity as well as maintaining the existing to required high Levels of Service. If the infrastructure declines or 
fails to maintain an adequate Level of Service, business profits can sag, eventually to a point where industry may relocate, severely limiting the tax base of a community.

The description of a system flow chart, Figure 1.1, illustrates how the Level of Service can affect the businesses and population in a region in terms of user costs. As the fraction of dollars spent on transportation costs increases, less money is available for other purposes. Consumers have less to spend on discretionary items. Businesses and industries have less to spend on capital investment. One of the user costs is safety. Decreasing Levels of Service will increase the dollars spent by the population on accident loss, both in property and human life.

Beginning at the population-business-industry block, the types of businesses, industries, and the population in a region affect the demand placed on a highway. The larger the population, business, and industry, the greater the transportation demand. The demand on the highway affects the condition of the road and the capacity needed. The more demand, the more the road wear. The more road deterioration, the lower the pavement quality, the lower the Level of Operation. As the Level of Operation decreases for the road, the Level of Service decreases. User costs will increase in areas such as vehicle operating costs, travel time, safety costs, and the degree of driver discomfort and inconvenience. The lower the Level of Service of a network and the greater the user costs, the less attractive a region will be to new business or industry. The demand will also affect the capacity need. As the demand increases, the capacity need increases. As the capacity need increases, the Level of Availability of the roadway decreases. With more vehicles on the road, the ability to maneuver safely decreases. As the Level of Availability decreases, the Level of Service decreases, user costs increase, and the attraction to the region for business and industry is diminished. 


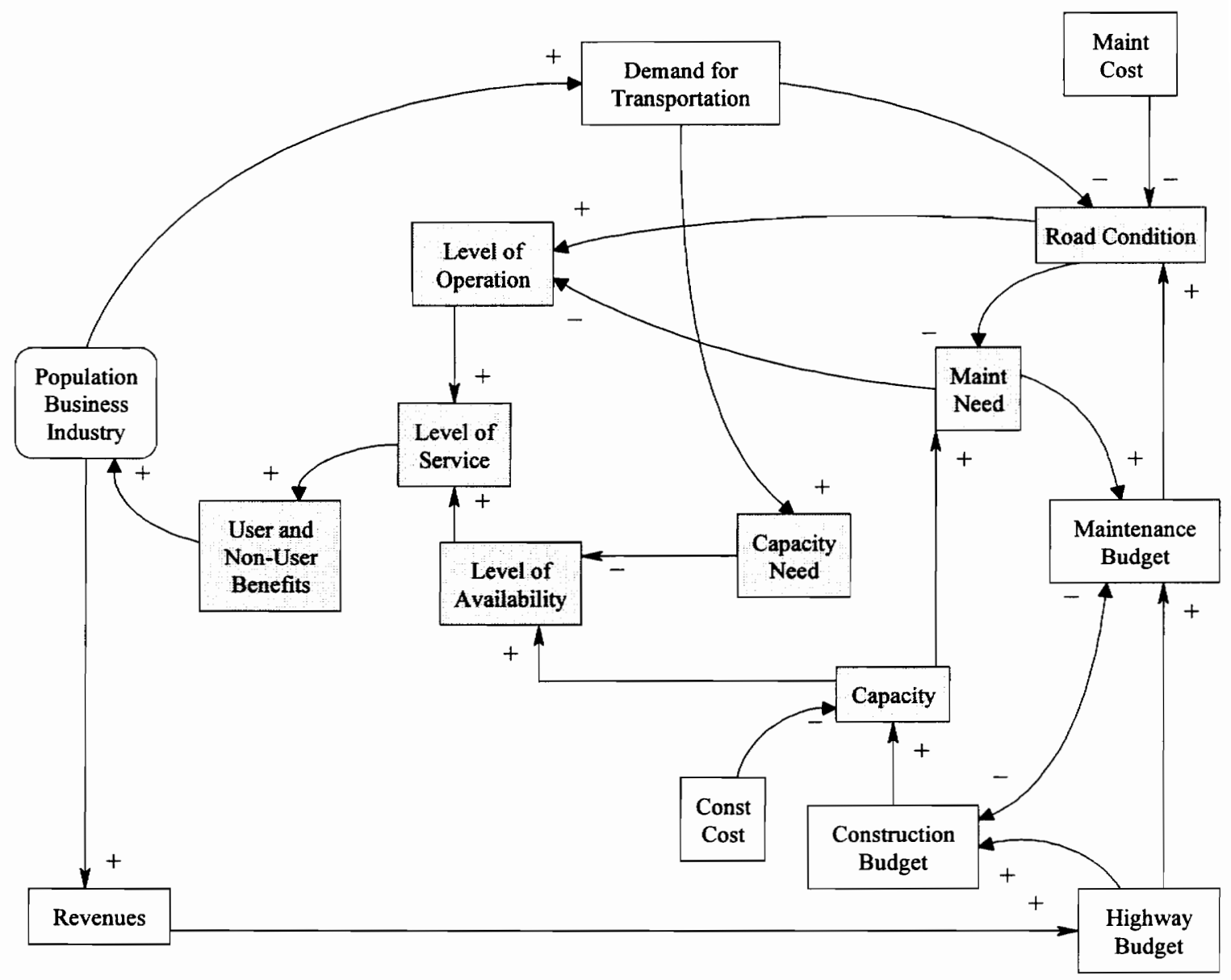

Figure 1.1: The System Effect of Deferred Maintenance and Obsolescence on the Economy

Note: The shaded areas indicate the emphasis of this research in simulating the Level of Service within the total systems framework.

Population, business, and industry also affect the amount of tax revenues available for maintaining and upgrading the highways. The greater the population, the more revenues are available for the highway budget. The more money spent on construction for capacity upgrading, the less money is available for maintenance. Maintenance affects the road condition, and construction affects the upgrading of the capacity of the network. The maintenance that can be accomplished is affected by the 
amount of the maintenance budget and the actual cost of the maintenance required. As maintenance costs increase, less maintenance can be done for the same amount of funding. Similarly, to increase capacity, the amount of work that can be accomplished is affected by construction costs. As the construction costs increase, the amount of capacity increase is reduced within the available funding. As the capacity increases, the Level of Availability increases and the Level of Service increases, decreasing the user costs. Travel time is reduced and a greater freedom to maneuver is available. As the road condition improves, maintenance needs go down requiring less expensive maintenance costs to provide a good riding surface. As the maintenance needs are reduced, the Level of Operation improves. As the Level of Operation is improving, the Level of Service is improving. As the capacity is increasing, the maintenance need will be increasing as the added capacity will also require maintenance. As the road condition deteriorates, more maintenance funding is required.

Previous work by Huang (1990), as diagrammed in Figure 1.2, illustrates how this dissertation could fit into an even larger systems context. The feedback loops from the economy, society, technical and political systems all affect the construction, use, and maintenance of the public works. Even those privately owned and operated support systems, such as telecommunications, are subject to many of the same social, economic and political pressures.

\section{Contribution to the Body of Knowledge}

This research represents a first step in the development of a framework for combining the impact of maintenance and construction on infrastructure systems. This is accomplished by proposing a Comprehensive Level of Service that joins both 


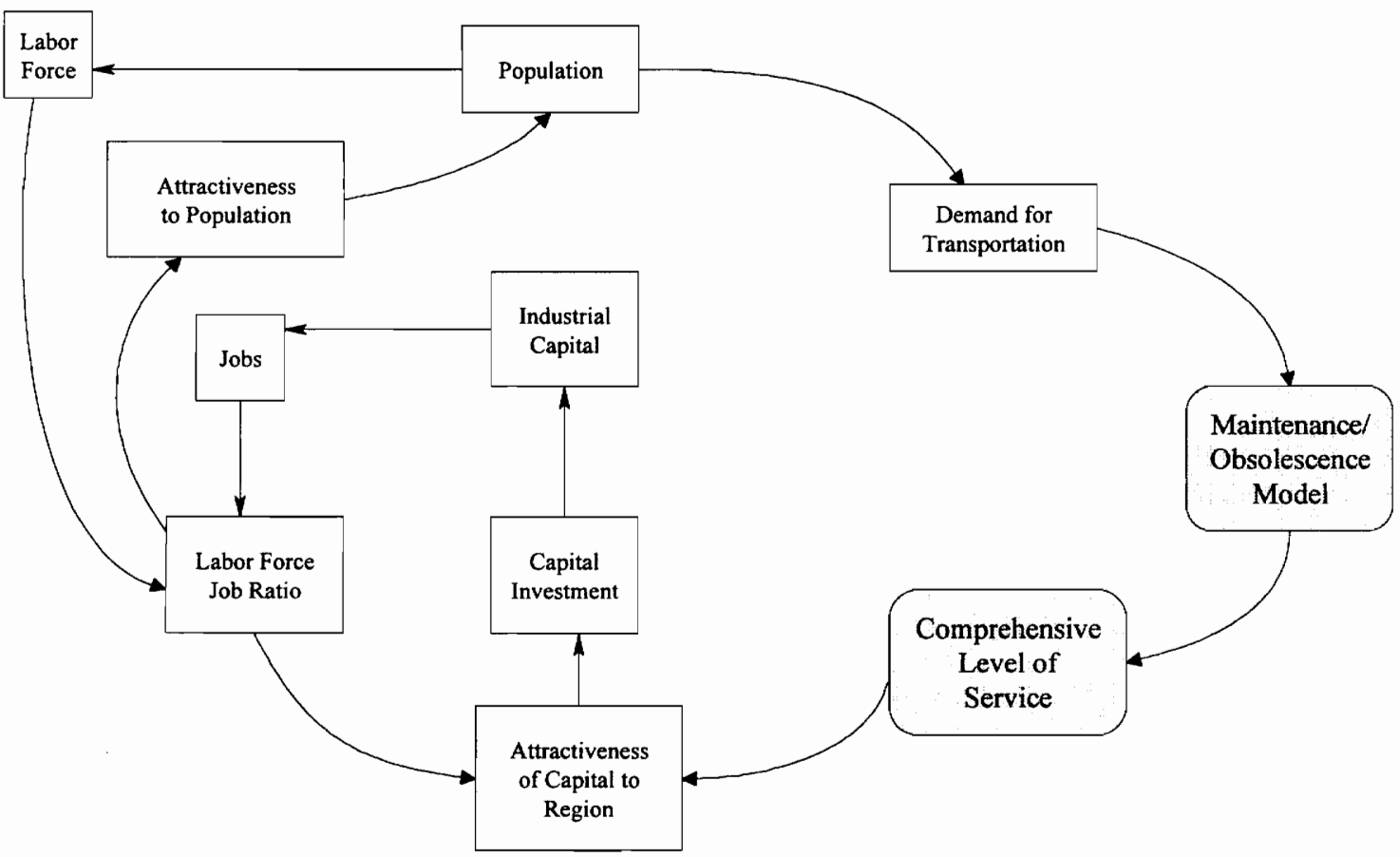

Figure 1.2: Population, Business, Industry Sector (Huang 1990)

Note: The shaded areas represents the inclusion of this framework in a broader systems context.

maintenance and construction indicators into a single measure. Within the transportation arena, capacity analysis, representing the impact of construction, assumes good pavement condition. Maintenance work does not consider the impact on capacity but is accomplished when a threshold deficiency level is reached.

This research is also a beginning for developing a framework and methodology to quantify the impact of deferring maintenance and/or construction expenditures and the effect on user and non-user benefits. Louisville, Kentucky Mayor Jerry Abramson said, "It's hard to run for re-election on the theme of 'I've kept your sewers from falling apart'" (Perry 1989, p. 96). With this framework, more structured decisions can be made on how to utilize the scarce resources available for providing for an area's 
total infrastructure needs. Policy decisions regarding deferring maintenance and increasing construction can be viewed for their impact over time, thus affecting the political system's decision-making process.

\section{Summary}

Levels of Service are important to all who use the transportation system. As the Levels of Service improve, user costs decrease affecting the economy in many ways. Unfortunately, it does not appear that a method exists to quantify the overall Level of Service for the transportation system. Users want a high Level of Service, but no comprehensive quantification system is available that explains how it affects the rest of the socio-economic structure. This research is the development of the framework for understanding these relationships. When this framework is expanded, Levels of Service can be determined for the Nation's transportation system or any other type of infrastructure, and the impact of deferring maintenance or allowing obsolescence to persist can be graphically portrayed. 


\section{CHAPTER 2: \\ LITERATURE REVIEW}

\section{Introduction}

The nation's infrastructure is deteriorating according to the several reports in the 1980's (Barker 1984, NCPWI 1988). Even now, a quick survey throughout the United States will confirm that the infrastructure is still in trouble. Bridges are in need of repair, roads are falling apart, water lines are leaking, and large cities' public facilities require extensive rehabilitation. Many facilities are exceeding their design lives and will require substantial rebuilding (Barker 1984). In the opinion of the U.S. Department of Transportation, over $40 \%$ of the nation's 575,000 bridges are structurally deficient or functionally obsolete and will require over $\$ 67$ billion to rebuild or replace to current standards. Also, the same report states that over $10 \%$ of the nation's 3.8 million miles of roads were classified as deficient because of the potholes, cracks, and washboard ridges (OTA 1991).

\section{Infrastructure Defined}

According to Webster's New World Dictionary (1986), the infrastructure is the "basic installation and facilities on which the continuance and growth of a community, state, etc. depend, as roads, schools, power plants, transportation and communication systems." The physical infrastructure actually goes deeper as it serves the "social purposes of health, safety, economics, employment and recreation" (Rainer 1990). Usually, the infrastructure is taken to mean the public works and buildings of a nation. Many classifications of these public works have been made, but in general, six categories are prevalent: roads, transportation services, water, waste management, buildings, and energy (Grigg 1988). The National Science Foundation (NSF) has proposed a 
research program concerned with Civil Infrastructure Systems. Within that document, a classification of infrastructure was presented that considers infrastructure as systems rather than specific components. That classification of systems as identified in the NSF Civil Infrastructure System research initiative will be used within this research (NSF 1993, p. 9).

\section{Infrastructure Problem Statement}

The problems listed above can be related to a decline in capital investment. Federal, state, and local governments are reducing construction expenditures in new infrastructure and in maintenance of existing infrastructure to meet the growing demand for increased social services. Facility maintenance is often deferred due to this lack of funding. Some facilities are stretched beyond their designed capacity resulting in early deterioration. Design standards have changed to improve safety, leaving many structures functionally obsolete. For example, many bridges are too narrow for today's larger volume of traffic and need to be widened. The need for repair or rehabilitation of aging structures has been ignored (Barker 1984). Many public facilities have outlived their estimated design lives and will require extensive rework to keep them functioning.

The political system can sometimes hamper infrastructure repair. Elected officials sometimes have short political vision and can be tempted to defer spending on a repair project that would have a greater future payoff in favor of a more highly publicized expenditure now in new construction. New facilities are much more noticeable than water line replacement contracts. Pay raises for teachers or additional police manpower have more political returns than sewer line repairs (Vaughn 1984b; DHS 1987). Dollars that could have been spent on maintenance or repair are often shifted to 
more obvious products. Unfortunately, new facilities built for political visibility will also require future maintenance. Existing infrastructure systems are left alone and additional requirements are added. As a result, more funding will be required in the government's budget for the added maintenance requirements. No existing infrastructure problems have been solved. Instead, they have been postponed, and very likely the cost of future repairs will have increased due to the deferring actions of the politicians. Several funding policies of the Federal Government also precipitate deferred maintenance. For example, Federal grants will pay for 75 to $90 \%$ of new construction and major rehabilitation of highways and bridges. Consequently, state and local government officials admit letting structures deteriorate to qualify for increased Federal funding which allows the use of local funds for other pressing problems (Barker 1984).

Lastly, the societal implications of a deteriorating infrastructure are numerous. Deteriorating infrastructure directly affects the economic health and quality of life of a nation's citizenry. The urbanization in the late 1800 's, due to the industrial revolution in the United States, brought about the need for better living conditions prompting the growth of the infrastructure (Rainer 1990). A study from 1983 to 1985 revealed a definite correlation between the amount of investment in infrastructure and the growth of productivity (Novick 1990). Many communities now are unable to revitalize their economies because the basic public works of roads, water, and sewer systems are too limited, obsolete, or in such disrepair to sustain a modern industrial economy (Barker 1984). A report by the National Council on Public Works Improvement entitled Fragile Foundations concluded "that the quality of America's infrastructure is barely adequate to fulfill current requirements, and insufficient to meet the demands of future economic growth and development" (NCPWI 1988). 


\section{Infrastructure Financial Problem Expanded}

The amount of work required to bring the infrastructure back to a serviceable condition has been estimated to cost from $\$ 40$ to $\$ 150$ billion (Rainer 1990) to $\$ 2.5$ trillion (Vaughn 1984b). These estimates are vague since the actual condition of much of the infrastructure is unknown. Recent estimates of increased funding for public works of $\$ 20$ billion per year will put a strain on an already deficit-ridden Federal budget. Unfortunately, the budget deficit continues to increase with more requirements being added each year for new facilities.

Many articles have been written to suggest different ways of providing the required funding for future infrastructure construction, operation, and maintenance (Vaughn 1984a; Allen 1991; Perez 1988; Grigg 1988; NCPWI 1988). Probably the most common method of financing infrastructure is through taxation. Property taxes, sales taxes, and income taxes all generate funds for government use. Special tax districts have been used to identify a geographic area that will specifically benefit from a particular project. Special assessments have been levied for primary beneficiaries. For example, property owners in a neighborhood will be assessed by the local government for construction of a new sidewalk in their area since they directly benefit by the new construction. Impact fees or development exactions are also used to finance new infrastructure for an area. For example, a housing developer will be required to install roads, water lines, and sewer lines in order to develop the property for sale. This relieves the local government from having to obtain funding for the new work (Perez 1988).

User fees are also becoming a necessary method of financing the infrastructure works. Toll roads are being planned or constructed in 17 states including Texas, California, and Colorado. These funds will be used to help with the initial construction 
expense as well as future maintenance. In Colorado, funds are also being generated through an added motor vehicle registration fee (Allen 1991). User fees can also include added taxes on motor fuel or bus fares for the municipal transit system. Sewer fees or metered water use pass on operating and maintenance costs of the utility company to the users. Tuition fees at state universities are a user-pay type of fee. Unfortunately, user fees alone are many times not sufficient to fund all the costs and will not attract private investment monies due to a lack of economic return (Agee 1993).

Another financing method that has been proposed is the issuance of taxable municipal bonds that would receive a subsidy for part of the interest from the Federal Government. These bonds would have a much broader market for sales and would generate more income for the treasury. Much of the current tax-exempt interest goes to high-income bond holders, not municipalities (Vaughn 1984a).

An even more interesting proposal to increase funding for infrastructure construction and maintenance involves allowing private sector investors the opportunity for monetary gains from increased tax revenues generated as a result of infrastructure investment. This proposal would allow the private sector marketplace to help determine the types of projects that would increase economic growth. The funds could be used alone or in conjunction with government funding. This way, the financial market would assist in determining future economic growth potential of infrastructure projects, especially if direct project revenues (tolls, taxes, etc.) could not provide sufficient returns (Agee 1993).

One similarity in the conclusions of all these articles has been the consensus that facilities should be self-sustaining. That is, the cost of operation, maintenance, repair, 
and rehabilitation should come from the beneficiaries of the project, although the weariness of user fees may go the way of the tax revolts of the 1980's (Flanagan 1993).

\section{Capital Budgeting}

Most current capital budgeting processes consider only the basic design and construction costs of a project. The operating and maintenance funds are usually included in the government's operating budget after the project is completed. Since municipalities are funding the majority of these costs, maintenance is often deferred because of a shortage of funds.

Since the early 1980's, the creation of a national capital budget that would include the cost of operation and maintenance has been suggested (Barker 1984; Vaughn 1984b; Choate 1981). A survey done by the General Accounting Office (GAO) in 1982 concluded that few states assess the effect of a public works project on future operating budgets. Even the Federal Government budget process was labeled as a "collection of haphazard practices." If lawmakers realized the impact of a new facility on the operating budget, they might rethink new expenditures (Vaughn 1984b). The Rebuild America Coalition and the National Council of Public Works Improvement have both reiterated the need for a national capital budget (Poggemeyer 1989). Specifically, a national capital budget would consist of three components, "current and projected capital needs and expenditures, current and projected operations and maintenance needs and expenditures, and sources of funding" (Choate 1981, p. 25). One of the primary reasons for this type of budgeting is to prioritize the capital needs of the nation and identify the sources of funding. 


\section{Infrastructure and Economic Links}

"The end result of economic activity is the production of goods and services and the distribution of those goods and services to the members of society" (Drew 1984, p. 134). Infrastructure, whether it is transportation, power, water, or waste, is a part of that system. Without a distribution system, goods produced cannot be efficiently delivered. Without power, manufacturing plants cannot produce sufficient quantities to supply the population. Fresh water supply and waste disposal systems have helped improve the health standards of society, thus ensuring a healthier labor force.

Great concern has been expressed in recent years about the deterioration of that infrastructure in the United States. Bridges have collapsed, the aging water system in Chicago flooded the business district and caused millions of dollars of losses to business and government. One study reported in the national press has shown that the industrial countries that continue to invest in public works have shown steady increases in productivity. The study went on to say that one-half of America's productivity problems are due to neglected infrastructure (Friedman 1991).

Whether or not there is such an explicit link between low spending and low productivity, most economists agree that the infrastructure is vital to the U.S. economy. Consider the just-in-time inventories system being used throughout manufacturing corporations because of the reduction in warehousing, inventories, and waste. Fewer personnel are needed in the storage area, less storage space is required, yet production is not decreased. This helps increase profits for companies, but relies on a transportation infrastructure that will get the goods to the manufacturer on time.

Consider Airborne Express as another example. Airborne Express is a package delivery company. Delivery trucks must arrive at the airport on time for their shipping and receiving flights in order to meet their deadlines. When the trucks are delayed due 
to congestion or poor roads, employees are standing idly by, translating into decreased productivity (Friedman 1991). Profits are less and prices could increase.

Infrastructure has impacts beyond the manufacturing sector. The construction process alone involves millions of dollars of materials and employs hundreds of thousands of individuals. In 1980 , the $\$ 223$ billion construction industry was $24 \%$ public works (Grigg 1993). Even now, it is estimated that a $\$ 1$ billion investment in rebuilding infrastructure would create 30,000 to 50,000 new jobs (Friedman 1991).

\section{Effects of Infrastructure Deterioration}

If we accept the interconnection of the infrastructure and the economy, what then is the impact of the deterioration of that infrastructure on the economy, quality of life of the citizens, or the industrial productivity? How are we to view the neglect of the infrastructure and the policy of deferring maintenance to pay for social services? What Level of Service should be provided so the productivity or regional economics are not affected?

Economic models have been developed that represent the relationships between economic development and transportation, for instance. These models look at the impact of transportation on a region from the planning aspect, such as highway improvement, corridor development, or a high occupancy vehicle-lane provision (Huang, 1990). Other methods look at project alternatives for resource allocation using benefit-cost ratios and cost-effective users analysis (Reinke 1983). Even with these models available, the principles of transportation pricing and investment analysis are poorly understood resulting in an impediment to policy analysis (Grigg, 1993). 


\section{Impact of Degraded Infrastructure}

Using the transportation system as an example, deterioration of the system can manifest itself in several ways on the productivity of industries, the quality of life of the citizens, and the regional economy. Reduced levels of maintenance, deferred maintenance, increased usage due to shifts in population, or deterioration due to heavier trucks on the roadways can all lead to degraded service levels. Physical deterioration of the road surfaces or bridges, as well as traffic congestion, are indicators of this decreased performance level. Traffic slows, time is wasted, and prices escalate. Vehicles can wear out sooner or require more maintenance and vehicle miles traveled are reduced. Even though this may reflect an increase in one segment of the economy, car repair or fuel, the opportunity to invest or spend in other areas is lost. Changes in highway expenditures and funding also affect the construction industry directly. Supplies are not purchased and construction workers are unemployed.

\section{Productivity Effects}

Most every segment of the economy is affected by a deteriorated condition of the nation's highway. Goods transported by motor carriers are delivered more slowly which increases the cost to consumers. One study in $1978-1980$ estimated that $11 \%$ of the nation's total wage-hours were spent in business travel. As travel is slowed, either through congestion or deteriorated surfacing, the percentage of business-travel hours will increase with no increase in value to the company (Butler 1984). Many large corporations, like the Campbell Soup Company, are increasingly making transportation a central consideration in their business decisions (Friedman 1991). Their just-in-time inventory system depends on a viable transportation network to keep a smaller supply of fresh ingredients on hand, cutting down on waste, storage, and expensive handling. 
In our service-oriented society, every express-delivery truck delayed from an ontime delivery, every truck detoured around a restricted bridge, every plumber caught in traffic, every employee late to work because of traffic tie-ups represents lost productivity (Drummond 1991).

\section{Quality of Life Effects}

Degradation of infrastructure also affects the quality of life. As roads or freeways become crowded, time is wasted waiting in vehicles. Additional fuel is consumed and higher levels of pollutants are added to the air from idling cars. The Federal Highway Administration (FHWA) estimates that Americans spend 2 billion hours tied up in traffic costing $\$ 35$ billion annually in lost interstate commerce (Friedman 1991). Truck delays add another $\$ 7.6$ billion a year to the cost of goods that Americans buy according to the American Association of State Highway and Transportation Officials (AASHTO) (Drummond 1991). Vehicle-travel mileage is expected to increase by onethird in the 1990's over roads which an estimated $60 \%$ need some form of rehabilitation according to estimates of the FHWA and AASHTO (NB 1990). The Road Information Program (TRIP), an organization of industries and groups dealing with highway transportation issues summarized the problem like this, "Unless America can increase her investments in maintaining and improving roads and bridges, the country will suffer. The cost of doing business will increase, traffic safety will be in danger, traffic congestion will worsen, and America's national and local economies will deteriorate" (Drummond 1991, p. 26).

\section{Regional Economies}

Regional economics are affected by degraded infrastructure. Businesses prosper when deliveries are faster, industries expand when power and sewer resources are 
plentiful, and exports increase when deep-water harbors are available (Hage 1992). How to pay for the repair of infrastructure is still under debate. The Federal Government will face $\$ 300+$ billion in deficits each year. The slowdown of the economy puts less tax revenues into the Federal coffers. As the deficit increases, higher interest payments are required on the debt which decreases the amount of money available for other programs. An increase in taxes or user fees will take moneys away from individuals and further reduce discretionary spending. This lack of discretionary spending will hurt other businesses.

The money spent on infrastructure, however, will provide jobs for construction industry workers and suppliers. This will generate some tax revenues and also increase spending in other service-related industries. The easier movement of goods and services will add profits which will also generate increased tax revenues. The increased profits can also lead to business expansion which translates to more jobs and additional tax revenues. All of the increases have effects on other parts of the economies as support industries follow to provide the services required for the industry and the population.

\section{Importance of Highway Maintenance}

Maintenance of highways is considered one of the primary responsibilities of local governments (NCPWI 1988). However, due to budget pressures, maintenance has often been deferred resulting in a physical decline of the nation's roads and highways. The lack of maintenance funding has resulted in a deterioration of the physical assets of the transportation network and has contributed to the obsolescence of the roadways as the capacity has been degraded. 
According to the 1993 Report on the Status of the Nation's Highways, Bridges and Transit, the overall condition of the highway network has improved. For example, in 1991 , only $23 \%$ of the urban interstate miles were considered poor or mediocre compared to just over $32 \%$ in 1983 . Even with this improvement, the report stresses increased traffic loads will continue to deteriorate pavements and require substantial resurfacing and rehabilitation programs to maintain the surface in acceptable condition. That annualized cost to maintain the present condition of the nation's pavements is now estimated at $\$ 51.6$ billion, compared to the 1991 related outlay of $\$ 32.1$ billion (FHWA 1993).

Without significant increase in funding, the maintenance backlog will continue to grow. Currently, the maintenance backlog estimate as of December 31, 1991 is $\$ 212$ billion, an increase of $\$ 7$ billion over 1989 figures. Of that amount, $42 \%$ is related to pavement cost.

Maintenance activities for highways had been classified in several ways. Currently, the following definitions are being proposed for standardization (Smith 1992, p.16):

- Routine Maintenance: This is localized maintenance activity such as pothole patching, spot sealing, and other repairs not funded for specific planned treatments for identified pavement segments.

- Programmed Maintenance consisting of Preventive and Corrective:

- Preventive: Treatments are applied to preserve the existing pavement integrity and reduce the rate of deterioration. Examples include programmed joint and crack sealing, chip seals, slurry seals, fog seals, and rejuvenator applications (including minor surface preparation).

- Corrective: Treatments are applied to an existing pavement to maintain surface characteristics (surface friction restoration and moisture penetration resistance) and the structural integrity for continued 
serviceability. Examples include programmed joint sealing with partial depth patching to repair joints, slurry seals, chip seals, friction courses, thin asphalt overlays (1.25 in. and less) (including minor patching and shape correction) applied to correct surface friction problems or repair surface cracking.

- Rehabilitation consisting of Restoration and Major Rehabilitation:

- Restoration: New surface layers and repairs are intended to restore the pavement structure to a level approximately equivalent to that which was originally present. Examples include joint replacement, fulldepth slab replacement, full-length overlays with minor repairs to the existing pavement, and surface treatment with major shape correction and selective deep patching.

- Major Rehabilitation: Lane-width, full-length layers are added to the existing surface to increase the structural strength to handle future traffic loads. Examples include overlays with selective deep patching and recycling one or more pavement layers.

- Reconstruction: This is lane-width, full-length removal and replacement of pavement, mostly on existing alignment including rehabilitation of associated structures generally to improved standards.

Types of distresses in the pavement will determine the types of maintenance procedures required to return the pavement to an acceptable Level of Service.

Depending on the Level of Service desired, different levels of maintenance costs will be required. Since $100 \%$ maintenance funding is never achieved, the level of funding obtained versus the Level of Service desired will reflect a difference that will be absorbed either through increased vehicle costs, loss of productivity, increased accidents, pollution, noise, etc.

\section{Consequences of Deferring Maintenance}

The impacts of deferring maintenance have been studied in relationship to future maintenance costs. Sharaf, Shahin, and Sinha (Sharaf 1988) sought to quantify the 
effect of delaying pavement maintenance by determining the life-cycle cost as the pavement condition deteriorated. Relating cost to condition provides a way to determine how much more rehabilitation would cost than maintenance because of delay. The results indicate that maintenance action performed on "good" pavement was approximately one-fourth as expensive as would be necessary on "poor" pavement. These costs were related to strictly maintenance costs and other costs such as safety or users' costs were not included. This work did develop a method to relate condition to pavement age.

Similarly, a Utah Department of Transportation Study (NCHRP 1979) indicated an approximate three-fold cost increase if pavements were allowed to fail before applying a rehabilitation effort of an overlay. The Utah study used the Present Serviceability Index (PSI) as its basis for action.

\section{Effects of Maintenance on Pavement Performance}

Pavement performance depends on the effects of traffic load, environment, age and prior maintenance work (Al-Suleiman et al 1991). Using information from maintenance work done in Indiana, a relationship between pavement age and maintenance work was developed by Al-Suleiman et al, 1991. They concluded that changes in roughness, through the use of the Present Serviceability Index (PSI), could be used as an effective measurement of pavement deterioration for relating maintenance effectiveness to pavement age and traffic loading. The study was used for predicting effectiveness at a network level for planning and budgeting purposes as opposed to specific project-level information for a particular maintenance action.

Another study accomplished by Fwa and Sinha (Fwa 1986) sought to predict the performance of pavement with different levels of maintenance. This research adopted a 
measure defined as the PSI-ESAL loss, Present Serviceability Index (PSI) versus equivalent 18-Kip single-axle loads (ESAL), as a means of quantitatively defining pavement performance over time. The PSI-ESAL loss depends on the homogeneity of the pavement section as well as a uniform maintenance policy. This study concluded that a positive correlation exits between the levels of pavement performance and the levels of pavement routine maintenance. In other words, low pavement performance was associated with low pavement maintenance expenditure.

\section{User Perception of Road Quality}

Pavement performance is usually determined by highway agencies and maintenance departments. Another study by Fwa and Sinha (Fwa 1992) developed two distinct values for pavement components, one for the highway agency, and another for the users' value perception. Highway departments are concerned with preserving or improving the road condition as indicated by the Present Serviceability Index (PSI), while users are concerned about pavement performance as measured by travel distance and quality of road condition. As a result, the users' performance measure indicated that the further the distance traveled, the more the user was willing to pay for better roads. On the other hand, the highway agency's performance measure was the condition of the pavement. Accordingly, the highway agency looked at the performance from an engineering standpoint and not as a motorist.

In this study (Fwa 1992), the researchers defined various pavement conditions. A PSI of 1.5 was considered a poor pavement that gives a very rough ride, has many cracks, potholes, repair patches, and requires continuous repairs to keep the pavement from a total breakdown. A PSI of 2.5 was fair pavement that gives an average ride quality. The pavement has visible surface defects such as cracks, potholes, and repair 
patches, and requires constant repair and maintenance to keep the pavement in its present condition. Good pavement, considered a PSI of 3.5, gives a good smooth ride, has few surface defects, and needs only minor maintenance. The best rating was a PSI of 4.5 for very good pavement. This pavement gives an extremely smooth ride, has no visible surface defects and requires hardly any maintenance.

From this statistically-analyzed survey study, an interesting item to note is that state highway officials were willing to spend approximately $60 \%$ more in project costs to increase pavement ratings from PSI $=3.5$ to PSI $=4.5$. For the same PSI increase however, the users' value of pavement performance, measured in willingness to pay a toll fee, only increased from approximately $\$ 0.75$ to $\$ 0.85$ per 100 -mile trip.

An earlier study by New York developed a measuring system for evaluating the pavements in terms of their functionality, that is, how well they functioned in providing an adequate traveling surface for the highway user. The degree of functionality was expressed by means of a Present Rideability Index, PRI. As can be seen in the Figure 2.1 (NCHRP 1979), as the PRI decreases, the effects of the deterioration become significant to users. This demonstrates the implications of pavement restoration or correction based on the user's perception of pavement quality.

\section{Effects of Deterioration and Obsolescence}

The life of equipment or infrastructure is affected by deterioration and obsolescence. Deterioration comes from the aging of the physical over time. As weather, traffic load, and environmental forces work on a pavement, the road will begin to show signs of wear or deterioration. Maintenance is required to keep the pavement in a usable state. Deferring maintenance will contribute to faster deterioration. 


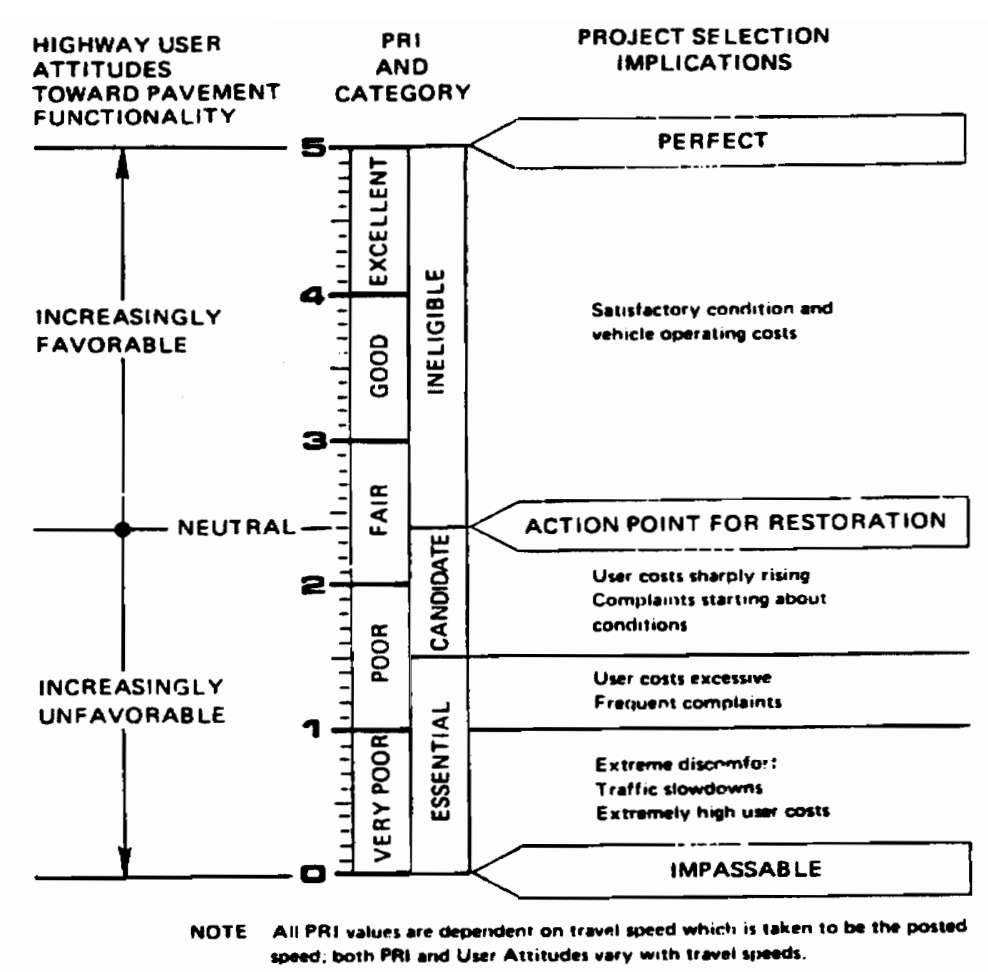

Figure 2.1: Significance of Present Rideability Index (PRI) for Effective Pavement Management (NCHRP 1979)

Another factor affecting the pavement life is an obsolescence factor. Traffic increases due to population growth, shifting of traffic patterns, new industry, etc., and the transportation network can no longer handle the amount of traffic imposed on the road. Overcrowding and congestion result and the road is obsolete in the respect that it can no longer do what it was originally designed to do.

Taylor (1980) discussed this two-edged sword in relation to the economic life of equipment, but the concept is similar for the infrastructure. Taylor defines deterioration as "the lowering of the engineering efficiency compared to that existing when the equipment was new." Similarly, highway efficiency is lowered as evidenced by the PSI rating decrease. As machine deterioration results in increased maintenance 
and labor costs, similarly, road deterioration results in increased maintenance and user costs.

Obsolescence is defined by Taylor as "the lowering of the engineering efficiency of equipment when new, compared to the best engineering efficiency currently available." Equipment would be compared on a technology basis, but infrastructure should be considered on a requirements basis. The engineering efficiency of infrastructure decreases over time due to increased demands placed on the system, even if the system were maintained within operating parameters. For example, a transportation network will only handle so many vehicles before speeds and volume are reduced below a maximum point, even though the road surface is in excellent condition. This obsolescence is a lowering of the engineering efficiency of the system when new compared to what is now required.

A similar concept of effects of costs due to lack of availability and downtime of equipment was explored by Vorster and de la Garza (1991). This research was to define the consequential costs for an organization if the equipment needed was not available or broke down during use and different equipment was used to complete the task. They outlined several cost impacts, some of which are analogous to infrastructure cost. They defined a lack of readiness cost, which was due to not having the piece of equipment ready when needed for a project. They also discussed a service-level impact cost as an expense due to breakdowns that resulted in using other equipment, not necessarily the most efficient, to maintain a given Level of Service.

These can be paralleled with transportation network costs. Maintenance is required to keep the system at a given Level of Service. Deferring that maintenance could result in decreasing the Level of Service as indicated by a reduction of PSI (Present Serviceability Index) or PCI (Pavement Condition Index). This required 
maintenance then, is a level of operation cost. The reduction of capacity (obsolescence) is a result of a lack of readiness or lack of availability cost. This impacts users, manufacturers, and industry as costs increase with the transportation systems' inability to handle the required traffic volume.

\section{Life-Cycle Cost Analysis Applied to Pavements and Bridges}

Engineering economics is not a new concept. Believed to have started in 1847, the idea of the cheapest not necessarily being the best was first started by Gillespie in his Manual of the Principles and Practices of Road Making (Peterson 1985). The 1920 's saw the first major emphasis on highway economics with the beginning of the automobile era.

The use of the term, "life-cycle cost analysis," has been relatively recent and is becoming increasingly popular. Life-cycle cost (LCC) is basically a method of defining and analyzing all costs of a facility or product for the life of that facility or product. The use of life-cycle costing for pavement design is well documented in National Cooperative Highway Research Program (NCHRP) Synthesis of Highway Practice 122, Life-Cycle Cost Analysis of Pavements (Peterson 1985). This synthesis explores the costs associated with each design including initial design and construction costs, operating and maintenance costs, rehabilitation costs, and user and salvage costs over the expected life of the item. Various alternatives are compared through a discounted cash-flow analysis to provide the least life-cycle cost alternative. As defined by Dell'Isola and Kirk in NCHRP Synthesis of Highway Practice 122 (1985), the steps of life-cycle cost analysis are:

1. Selection of a study area,

2. Generation of alternatives, 
3. Evaluation of designs, including identification of each alternative's cost,

4. Selection of design alternatives.

Life-cycle analysis has also been applied to the decision for the repair, rehabilitation, or replacement of bridges by Weyers et al (1993). An application manual was prepared that extensively detailed methods of repair or rehabilitation and provided a methodology to compare these costs to bridge replacement on a life-cycle basis. The object of the life-cycle analysis is to provide guidance in minimizing the annual equivalent life-cycle cost while maintaining the bridges in a cost-effective manner. Life-cycle costing also allows the various alternatives to be compared on the same basis of equivalent annual costs as demonstrated in the manual.

The outcome of any economic analysis is based on a prediction of uncertain events. The required maintenance needs are influenced by the pavement or bridge performance. The cost of pavement maintenance or bridge repair is affected by the type and extent of work performed and the estimated time intervals of the maintenance treatment. In other words, the service performance of a particularly facility is unknown; consequently, the type of maintenance required, when to accomplish the maintenance, and how long the maintenance treatment applied will be effective are uncertain. Delaying prescribed maintenance activities will further influence future maintenance costs requiring additional work to be performed.

A system perspective is needed for the decisions made on a transportation system's construction and maintenance activities because a system life-cycle process will consider all facility costs from planning through salvage. Low initial cost does not necessarily mean that the best dollar value has been obtained. Also, keeping the system quality at a consistently higher level will reduce users' costs which will improve the life-cycle cost of the system (Fabrycky 1991). 
In order for LCC analysis to be useful, information such as pavement or structure performance predictions, estimated remaining service life, recommended maintenance efforts to improve the service life, cost of the maintenance recommendations, and affected users' costs are required. Pavement or bridge performance models are necessary to determine when a minimum acceptable Level of Service or performance is anticipated to be reached so necessary maintenance or repair activities can be accomplished. Different maintenance options will impact the treatment costs and the length of time required until retreatment. Users' costs will relate the effects of surface roughness to vehicle operating costs through such items as tires, fuel consumption, vehicle maintenance, etc. Another source of users' costs that should be considered is the delay caused by construction and maintenance activities.

In a study done by Fwa and Sinha (1991) on pavement performance and life-cycle cost analysis, they indicated that the serviceability performance level of pavement is not considered explicitly in current life-cycle cost analysis approaches. Their alternative approach was directed towards the serviceability over time as compared to a minimum level PSI at which time a maintenance intervention is considered for cost analysis. This approach also considered the difference between road-user performance values and highway agencies' points of view. The highway agency approach is one performance measure based on the Pavement Performance Quality Index (PPQI) which is a weighted average PSI computed with respect to the equivalent single-axle load (ESAL) for the analysis period. A higher PSI-ESAL capacity value means better overall pavement performance.

Weyers et al (1993) developed a "Value Management" index to guide the decision for repair and replacement based on a life-cycle analysis. The VM index is a comparison of bridge repair or rehabilitation versus bridge replacement. A positive 
value indicates the structure should be repaired or rehabilitated. A negative value indicates the structure should be replaced. The size of the VM is a measure of the amount of savings available.

As the various alternatives are considered and the least-cost alternative selected, the life-cycle cost analysis can then be used to provide a basis for required funding for a transportation network. The initial construction cost will determine the final constructed product. This final pavement or structure will impact the types of maintenance work required and influence the frequency of maintenance to keep the roadway or bridge in a serviceable condition. Routine and preventive maintenance activities, which are usually less cost intensive and done in shorter time intervals, will keep the pavement or bridges at a higher quality level for a longer period of time. If the life-cycle cost analysis is to be useful, the planned maintenance activities must then be accomplished, or a higher cost will inevitably result due to the deferring of the lifecycle maintenance plan recommended.

\section{Budgets and Transportation Needs}

Maintenance of public facilities is dependent on dollars allocated to perform the needed tasks. A NCHRP report on formulating and justifying budgets (Kelly 1981) states that highway budgets rarely, if ever, provide sufficient funds to meet standards of maintenance. The current maintenance backlog of $\$ 212$ billion nationally (FHWA 1993) reiterates the fact that the need is greater than the source of revenue.

The budget process brings together the sources of revenues and the requested expenditures. Most states use dedicated resources to support highway activities. Motor vehicle fuel tax, license fees, and vehicle-weight tax are a few sources of revenues. Changes in fuel consumption patterns through increased miles-per-gallon 
efficiency, and ride-share programs have reduced available revenues. Intrusion on the utilization of user fees to support other programs, such as mass transit, has also reduced available funding (Kelly 1981).

With this reduced funding, Pavement Management Systems have become an important element in determining priorities for maintenance activities in trying to accomplish the most within the funding provided by legislative actions. The need to develop an economically sound request, and defend that request, is an important part of the highway department's job, showing in part what work cannot be accomplished due to insufficient funds. Many times, budget reductions are attempted by looking to reduce the Level of Service on highway maintenance activities. A properly defended budget request will show the impacts of deferred maintenance, not just the work that cannot be accomplished. A better budgeting tool will assist all budget players in making appropriate decisions.

To help define the work required, some states have developed levels of service maintenance that provide guidelines for work quantification. For example, Pennsylvania has five Levels of Service, from M1, which is road maintenance at the highest level (recommended standard) to M5, which is just keeping the road open. Each drop in service level (which indicated less available funding) will affect the usefulness of the road and will incur greater costs at a later date, impact safety, and affect the capital investment (Kelly 1981).

\section{The Effects of Budgeting on the Deteriorating Infrastructure}

"Budgeting is governing; its processes determine how power is shared; its policy decisions allocate scarce resources; its politics shape the electoral debate on the nation's values and future" (Kee 1991). Budgets are powerful tools as they represent 
the policies of those in political office. Priorities are established as to what will be accomplished and how much will be spent to obtain the results. Choices are made as to what services the government will or will not provide. These decisions often have economic consequences since most decisions by the lawmakers become local, i.e. what monies can be returned to their own legislative districts. Budgets also reflect the way citizens are taxed to support the policy decisions and the different levels of taxation to various groups. A budget can become an effective tool for accountability as the people know where the dollars are to be spent and can thus become the reference point for citizen changes that can put new policies into effect with different elected officials (Rubin 1993).

A budget is a method of allocating scarce resources to different objects of expenditures within a decision-making framework. Funds are limited, but potential areas for expenditure are not. The decision process involves the agreement of those controlling the budget on the overall goals or objectives of the government and on the allocation the resources to achieve those agreed upon goals.

As is the case with most public budgets, many people and organizations have different objectives and perspectives. People are looking for different services from governments. The constraints or restraints on the budget may be legal or public opinion. Some forms of taxation may have legal limits, such as the maximum tax rate imposed by the state on local governments, or the amount of taxation may be more than the public will accept resulting in "taxpayer revolts" as witnessed in California in 1978 (Gleckman 1988).

The budget process and type of budget will influence the budget outcomes as will the involvement of various interest groups. Public budgeting has five characteristics that differentiate it from other forms of budgeting (Rubin 1993); 
1. Public budgets have a variety of participants who have different priorities and different levels of power over the budget outcome.

2. Public budgets have a distinction between those who pay taxes and those who decide how to spend them.

3. Public budgets are a document that can become a means of public accountability.

4. Public budgets are vulnerable to the economy or changes in public opinion.

5. Public budgets are incredibly constrained.

\section{Dynamics of the Budget Process}

The budget process is not just a technical arrangement to ensure the timely flow of decision making. It is also a highly political process. Participants want control over the process to guide policy (where and how funds are spent) and to determine the relative size of the various programs carried out by government. Control over the budget allows public officials the opportunity to satisfy constituents' demands and build a power base, power that can be traded as a resource to gain support for their budget outcomes. Because of the power sought by the various budget participants, the process is divided among many committees and subcommittees (Rubin 1993). For example, appropriation bills originate with the House Appropriations committee and its 13 subcommittees. These committees effectively control spending because funds cannot be spent, even though authorized, until the monies are appropriated. Specifically with regard to the Nation's public works, almost one-half of the 303 committees and subcommittees of the 101st Congress claimed jurisdiction over some aspect of public works. Sixteen committees worked on highway legislation, with three committees authorizing major programs, five committees authorizing special programs, and two 
committees appropriating funds. This kind of fragmentation reveals the divisions of power and how it impacts the ability to set firm long-range policy (OTA 1991).

With participants seeking control over the budgeting process, change is continually sought. These changes have led to the very complex budget arrangement used today with the following characteristics;

1. Balance is sought between the executive and legislative branches. The budget must be agreed upon by both the executive and legislative branches. Slow economic growth, rapid increases in social entitlement programs, and increasing budget deficits have created an atmosphere for budget change and balance between the policies of the Congress and the President. The Budget Enforcement Act (BEA) of 1990 helped provided an atmosphere of no-fault budgeting. During the 1980's, Congress and the President were engaged in lengthy budget battles, each seeking to lay blame for the increasing deficit on the other. The Democrats were looking to expand social programs. The Republicans were seeking to limit or reduce domestic spending and increase defense spending. The threat of withholding authorized/appropriated funds was used to leverage Congress to negate budget outcomes. The 1990 BEA has removed that leverage significantly, and the blame for the deficit increase will be difficult to assign to anyone (Doyle 1991). A balance is now more available because of the three discretionary spending targets (defense, domestic, and international) which fit the two parties better.

2. A top-down instead of bottom-up budgeting process is in place. This allows more centralized financial control and is conducive to a policy-oriented review process. As the different participants seek to gain control over the budget process, the growth of deficits, and the desire to implement policy, 
the budget has become a more top-down approach where limits are set by the budget on what can be spent for various programs. Spending targets are a top-down approach.

3. The budget is highly constrained. The budget is constrained by the amount of revenues available and the expenditures planned. As the budget deficit grows, more pressure is applied to reduce the deficit by either limiting spending or increasing revenues, both politically unwise as people do not want tax increases nor do they want less government service. Parts of the budget are pre-determined each year in the form of entitlements that are uncontrollable without legislative action. As economic conditions change, these entitlements can grow and revenues decrease, making the deficit worse. As deficits grow, borrowing increases and the portion of the budget linked to the interest on the debt grows. The portion on the budget that is uncontrollable was estimated at $75 \%$ in 1982 . Prior multi-year commitments, general operating expenses, and personnel salaries are all included in the budget and without massive restart of government, the estimated portion of the total budget open to change is less than $10 \%$ (Lynden 1983). The BEA of 1990 has further constrained the budget by setting spending limits and with a "pay-as-you-go" sequester on direct entitlements.

\section{Revenues and the Budget Process}

Public agencies are funded primarily through the imposition of taxes. The authority for Federal taxation comes from the Constitution, Article 1, Section 8 which states "Congress shall have the power to lay and collect taxes, Duties, Imports and Excises, to pay Debts and provide for the Common Defense and General Welfare of 
the United States." States assume all powers not delegated to the national government and not specifically prohibited. Local governments are legally subordinated to and dependent upon the states for their authority (Lynden 1983).

For the Federal government, most tax revenues are from personal income taxes, corporate income taxes, and payroll taxes, and support the general obligations of the governments. Earmarked revenues, from payroll taxes for social security and from fuel taxes for the Highway Trust Fund, support specific programs. At the state level, the use of sales taxes and personal income taxes support most state programs with earmarked funds from fuel taxes for the highway operation and maintenance. For local government, the revenues come primarily from property taxes and sales taxes (OTA 1990).

From 1929 to 1980, the Federal expenditures have increased from 15\% to almost $50 \%$ of all government expenditures, with almost $60 \%$ of the funds originating at the national level (Lynden 1983). The revenue increases to support these growing expenditures have resulted in increased taxes. Broad-based taxes, such as the income tax, have changed from an elite tax on the rich (7\% top rate over $\$ 500,000$ in 1913) to a mass tax (28\% top rate over $\$ 29,750$ for 1988 and after) (Cranford 1989). As taxes increased, tax breaks for special interest did also. An additional 29 tax preferences were added to the tax code between 1975 and 1981 alone. Tax breaks are used to help design Federal policy in pursuit of national goals. The granting of tax breaks can be used to stimulate business or the economy or to enhance the political support for a program. During the 1970 's, tax breaks were given to businesses and the wealthy as a way of stimulating business and personal investment. Tax breaks for municipal bonds created a large pool of tax beneficiaries while seemingly reducing the borrowing cost for local governments (Rubin 1993). 
As increasing taxes became more politically dangerous, several tactics emerged to sell the idea of increasing revenues to the governments. Two of the basic strategies were earmarking, tying a tax to a specific need, service or capital project, and raising more revenues than needed and distributing the excess to various groups for their support. Earmarking has been a particularly successful method as taxpayers feel they know where the dollars will be spent. One of the most successful earmarking programs has been the fuel tax for construction of the interstate highway system. Since the inception of the highway program in 1956, the Highway Trust Fund has been utilized to build and now help reconstruct the nation's system of over 44,000 miles of interstate and 785,000 miles of Federal-aid primary, secondary, and urban roads which provide vital links to the Interstate System (OTA 1991).

The Intermodal Surface Transportation Efficiency Act of 1991 (ISTEA) has recently been enacted that will change the focus of the Government in relation to the highway system. The ISTEA legislation will allow more flexibility for State Departments of Transportation in the way funds can be spent. This bill creates a National Highway System, which includes the Interstates, and seeks to put more emphasis on the intermodal connections through the highways. Construction and reconstruction are still the primary focus, although a new category for Interstate Maintenance (IM) is authorized. IM funding is $\$ 17$ billion over six years which will allow the funds to be used for preventive maintenance when a state can demonstrate that the maintenance activities are cost effective for extending pavement life (FHWA 1993a).

The distribution of Federal funding has changed significantly over the years as Federal programs and policies have changed. Particularly in transportation-related areas, the distribution of Federal aid to state and local governments has dropped from $42 \%$ in 1960 to $15 \%$ in 1989 . At the same time, health benefit-related social services 
rose from $3 \%$ to $30 \%$. During the changing policy years of the Depression through the Johnson era, government increases in social programs provided large sums of monies to state and local governments to initiate programs. Many were in the form of categorical grants direct to home districts, allowing Congress to send money home and minimize state interference (OTA 1990).

With the decrease of Federal funding for social programs from the 70's and particularly the 80 's, many state and local programs were put in chaos. Rather than eliminate popular social programs, many transportation projects were deferred or cut. Since highway maintenance is a state and local responsibility, maintenance was easily deferred. Even though maintenance funding was still available at approximately the same level in many areas, the double-digit inflation, increasing wages and prices made less "real" monies available for transportation-related work. Overall, the share of Federal, state, and local governments' budgets devoted to public works dropped from $12 \%$ in 1960 to below 7\% in 1987 (OTA 1990).

\section{The Federal Highway Trust Fund}

The Federal Highway Trust Fund (HTF) was established in 1956 as a way of financing the Interstate System. This "pay-as-you-go" financing system relies on user fees in the form of motor fuel taxes to raise funds for expenditures. Funds not expended are invested in Treasury Securities with the interest being credited to the balance of the Trust Funds. Since its establishment in 1956 until 1989, the fund has accumulated $\$ 220$ billion, including interest, and made available $\$ 209.5$ billion to the states (OTA 1991). The Byrd Amendment, a part of the original authorizing legislation, ensured expenditures would not exceed revenues. 
The HTF distributes funds for the Interstate and Federal-aid highway construction (primary, secondary, and urban), and $80 \%$ for bridge replacement and rehabilitation. Unfortunately, almost 3 million miles of local roads are not eligible for any Federal funding, and Federal funds could not be used for maintenance of any road surface, including Interstate and Federal-aid highways. Maintenance was to be $100 \%$ state funded. The Federal grant program for reconstruction, resurfacing, rehabilitation, and restoration (4R Program) provided funding for the Federal-aid system, up to $75 \%$ for the required work. However, less than $25 \%$ of the available funds have been used for that purpose. To be eligible for Federal grants, projects had to conform to grant requirements which encouraged states to tailor their priorities to Federal requirements (OTA 1991).

Under the provisions of ISTEA of 1991, the Federal share for Interstate work remains at $90 \%$, with an $80 \%$ share for the National Highway System, a 155,000 mile yet to be determined system of connecting highways. Funding for the Surface Transportation Program in the ISTEA legislation allows any road to qualify for Federal funding, up to an $80 \%$ share, as long as the road is not specifically designated a local or rural minor collector. The flexibility in the program comes from the opportunity to use highway funds for transit capital projects instead of road work (FHWA 1993a).

The motivation for Congress to protect the highway spending from competition with other programs was obvious from the start. The trust fund provided revenues that were earmarked for the specific purpose of road construction and have survived attempts through the years to utilize the funds for other purposes. In 1990, the first real opening of the trust fund was accomplished. The budget required $2.5 \mathrm{c}$ of the $5 \mathrm{c}$ a gallon fuel tax increase to be spent on deficit reduction (Rubin 1993, OTA 1991). 
Again in the FY93 budget, a portion of the fuel tax increase was set aside for deficit reduction.

Many states have similar trust funds that set aside fuel tax revenues for use on highway operation and maintenance. Tax increases have been evident in the States during the last decade in an attempt to generate dollars for transportation-related programs. Unfortunately, trust funds are coming under increasing attack to provide funding for other programs. In 1987, the Texas Highway Fund loaned $\$ 280$ million to the State general fund for education (OTA 1990).

\section{The Politics of the Highway Trust Fund}

The Highway Trust Fund is a capital program and as such is subject to all the political maneuvering of any capital program. Members of Congress seek to control the spending and decide where the dollars will be spent. Since the Fund represents a transfer of monies from one level of government to another, the politics of grants plays an important part in the process. Finally, the politics of revenue increases play a role in determining how to pay for the requirements of the program.

When the Interstate program was originally developed in Congress, the Public Works committees had major jurisdiction. With the funding mechanism established as a trust fund, the House Ways and Means Committee took over control of the funding portion while the Public Works Committee retained control over the highway program. The normal two-step process for the authorization and appropriation of funds was successfully by-passed by the Public Works Committee by awarding contract authority as part of the authorizing process. This meant that the Public Works Committee had control over the size and scope of the program and the House Ways and Means Committee had no real role except to pay the bills when presented. When the program 
was in serious financial trouble by 1959 , the House Ways and Means Committee had to figure out how to raise the additional revenues required to fund the program. A temporary increase in fuel tax rates occurred in 1959, with it being made permanent in 1961. The program's completion time was also lengthened to 1971 in an attempt to ensure sufficient revenue availability for the Interstate completion (Rubin 1993). The authorization of the Interstate program has continually been lengthened as the completion time changed because of cost increases.

Other political events such as the Vietnam War and the Oil Embargo of 1973 put additional pressure on the Trust Fund. The war changed spending priorities and the oil embargo put an emphasis on the mass transit program, allowing some flexibility in use of Federal funds for mass transit and eventually the use of $1 \mathrm{c}$ of the Federal fuel tax for mass transit projects. Except for minor incursions, the Highway Trust Fund has been used to fund the Federal-aid Highway and Interstate systems. Now that the system is essentially complete, Congress will decide how to re-define the Federal role in highway maintenance (Rubin 1993, TRIP 1990, Parker 1991, OTA 1991). The Intermodal Surface Transportation Efficiency Act was that attempt to re-define Federal policy. Maintenance is now a small portion, but the major emphasis is still on construction and reconstruction of the National Highway System, those roads designated to be the most important to interstate travel and national defense (FHWA 1993a).

\section{The State Role in Highway Funding}

State and local governments are basically responsible for construction and operation of the highway system in this country. Of almost four million miles of roads, three million are specifically local in nature. Of the $\$ 75$ billion spent in 1991 on highway construction, operation and maintenance, only $41 \%$ came from Federal 
sources. The remaining 59\% came from state and local revenues (FHWA 1993). Most states have similar funding arrangements, imposing from $8 \mathrm{c}$ to $22 \mathrm{c}$ per gallon state motor fuel tax, averaging 16c in 1989 (OTA 1990). Unfortunately, as fuel efficient vehicles have become more popular, the user-fee revenues have dropped almost $50 \%$ even with an increase in vehicle miles traveled (OTA 1991). Also, the cost of construction and maintenance has risen steadily over the years, requiring more funds just to stay even.

\section{Current Related Research}

The Transportation Research Board of the National Research Council is a major contributor to highway research. They are presently reviewing a draft copy of National Cooperative Highway Research Project 2-18, Research Strategies for Improving User Cost-Estimating Methodologies (Hickling 1993). The purpose of the report is to examine the current methods used in determining highway user costs and identify areas needed for improvement. The areas reviewed included vehicle operating analysis, vehicle operating costs, safety-related costs, and environmental costs. Of special interest were the findings and conclusions related to this research.

1. Speed is an important variable in all user cost-estimation models as it affects fuel consumption, travel time, vehicle emissions, and other vehicle operating costs. Speed does contribute to noise and accident severity.

2. Existing speed/density models do not accurately reflect today's roadway dynamics, particularly for congested conditions.

3. Vehicle operating costs, as quantified by MicroBENCOST, a computerized version of the AASHTO Manual on User Benefit Analysis, are disaggregated into various cost elements including uniform speed costs and 
pavement-condition excess costs. Data used to develop the costs is obsolete and requires improvement.

4. Safety-related costs are generally taken as the value of life and the value of non-fatal accidents and property damage. Most models have been developed on special situations and may not reflect a general-purpose cost framework.

5. The Highway Performance Monitoring System (HPMS) data base and modeling procedures do not take pavement condition, traffic, or traffic composition into account when projecting accident rates.

6. Panels of experts were convened to discuss the various user-cost issues of importance. They felt that cost models should reflect pavement condition/vehicle cost relationships, although there may not be enough variability among pavement conditions to be able to obtain comparable flows for data acquisition.

\section{Summary: Public Works and Performance}

The literature reviewed has provided the background on the importance of maintenance and the impact of budgeting on the availability of maintenance dollars. Proper maintenance in a timely fashion is the key to preserving a safe, functional transportation network. Deferring maintenance has a negative effect on future costs of repair and serviceability of a highway as well the perception of the users as to the quality of the transportation system. Increased usage affects the ability of the system to provide the service originally intended making the system obsolete. The combination of deferring maintenance, causing accelerated deterioration, and increased usage, causing obsolescence, needs to be considered to determine infrastructure reliability. 
The importance of infrastructure lies in the service it provides. The demand for infrastructure services comes from businesses, households and governments, including Federal, State, and local. Demographics, individual preferences, production techniques, mobility and distribution of costs affect the demand. Supply is determined by the condition of the existing facilities, the usage of the facilities, or the additional facilities added to the public works. The difference between the supply and demand is the quality of service provided. As maintenance is deferred or usage is increased, service levels can be reduced, thus affecting the economy of a region. 


\section{CHAPTER 3: \\ LEVEL OF SERVICE}

\section{Introduction}

This chapter discusses the current practice regarding a transportation system's Level of Service. The concept of a Comprehensive Level of Service based on both maintenance and construction activities is introduced as a way of integrating both of these functions into a single Level of Service indicator.

Level of Service for infrastructure systems is a way of measuring the ability of that infrastructure to support the social, economic, and quality of life needs of a community, region or nation. Transportation Level of Service is specifically a measurement of the capacity-carrying capability of a particular roadway. Maintenance and highway traffic flows are not considered at the same time to indicate an overall ability of the system to perform the function required. This chapter develops the Level of Service concept as now utilized in the transportation industry and proposes a new definition that will combine both aspects of maintenance and construction to determine a Comprehensive Level of Service for infrastructure systems.

\section{Highway Capacity}

The transportation network has been built for the purpose of moving people and goods. A report, Delivering the Goods (OTA 1991), indicated that even though the present transportation system has excess capacity, it is not available on the busiest routes when most people want to travel. These periods of heavy demand create "peaking" problems as the demand fluctuates. Current highway designs are usually a trade-off between the costs of delay and congestion versus the costs of building, 
operating, and maintaining the roadway. When the demand exceeds the supply, delays (congestion) and safety problems occur (OTA 1991).

Capacity, as defined by the Highway Capacity Manual, is "the maximum hourly rate at which persons or vehicles can reasonably be expected to traverse a point or uniform section of a lane or roadway during a given period of time under prevailing roadway, traffic, and control conditions" (TRB 1985, p.1-3).

Many conditions will affect the capacity of a section of highway as noted by the capacity definition above including roadway conditions, traffic conditions, traffic control, and weather. Roadway conditions refer to the geometric characteristics, that is, the alignment of the road on either level or rolling terrain. Traffic conditions refer to the traffic stream characteristics including the mixture of trucks and busses. Control conditions refer to the types of traffic regulation devices on a particular highway, such as traffic signs or traffic signals. Weather conditions could include sunny and dry weather or icy, winter driving conditions, each having an effect on the speed, thus affecting the traffic flow. The current capacity definition assumes that both good weather and good pavement conditions exist.

Capacity is determined by three related parameters and is the expected maximum rate of flow of traffic on a section of highway as measured in vehicles per lane per unit of time. These parameters are:

$$
\begin{array}{ll}
\text { volume }(q): & \text { the number of vehicles per hour (vehicles/hour) } \\
\text { density }(k): & \text { the number of vehicles per mile (vehicles/mile) } \\
\text { speed }(u): & \text { the number of miles per hour (miles/hour). }
\end{array}
$$

This gives rise to the classical speed-flow relationship:

$$
q\left(\frac{\text { vehicles }}{\text { hour } / \text { lane }}\right)=k\left(\frac{\text { vehicles }}{\text { mile / lane }}\right) * u\left(\frac{\text { miles }}{\text { hour }}\right)
$$


As illustrated in Figure 3.1 below, flow rates, or traffic volume, can vary under two very different conditions, high speed and low density or low speed and high density. At the one extreme, with no vehicles on the road, speed, flow and density would be zero. As the number of vehicles on the road increases from zero, the flow rate or traffic volume will also increase, but the speed will begin to decrease because of the interaction of the vehicles. As the density continues to increase, the speed will continue to decrease, until capacity is reached. At this point, the speed will drop dramatically, while the density continues to increase and the traffic volume or flow rate decreases. At the other extreme, with the maximum density of vehicles on the road, the speed and flow are zero as the traffic cannot move. This is the well-known phenomenon that can occur during rush hour on a freeway when traffic stops because of the density of vehicles. The point of critical speed and critical density are thought to occur at the capacity of the highway, the peak of the speed/density/flow curves. The high density, low speed side of the curve represents an unstable flow situation, while the low density, high speed side of the curve represents stable flow.

From the curves presented in the Highway Capacity Manual and the speed/flow relationship, speed does have an effect on the maximum rate of flow. As the speed decreases, the maximum rate of flow will be lower, thus affecting the performance of the highway. Three studies by McFarland, Hazu and Zanewski indicated that pavement roughness, as measured by Present Serviceability Index (PSI), can drop speeds significantly (Cleveland 1987).

The shape of the speed/flow curve, however, is still being researched. Persaud and Hurdle (1988) suggest that the upper part of the curve may be relatively flat indicating that higher speeds remained relatively constant with an increase or decrease in volume. As the flows start exceeding 1800 vehicles per hour per lane, speeds began 


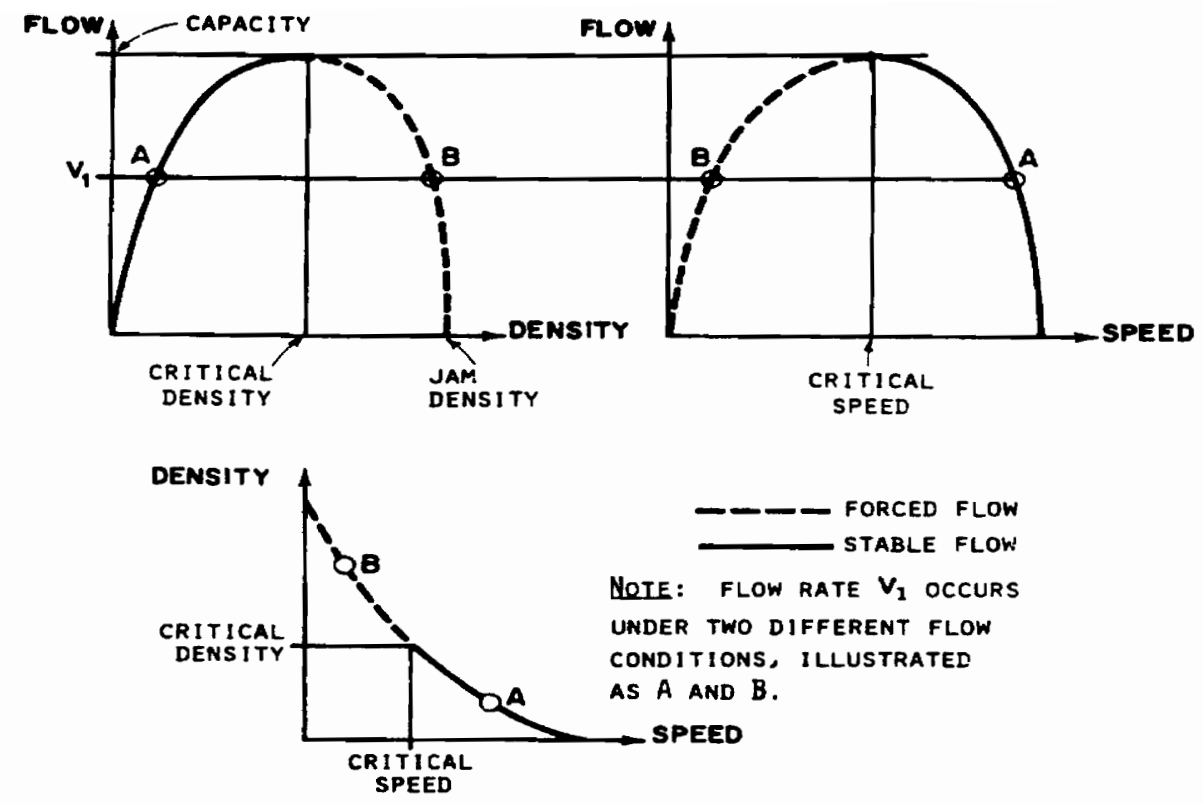

Figure 3.1: Relationships among Speed, Density, and Rate of Flow on Uninterrupted Flow Facilities (TRB 1985)

to fall off gradually, but not as sharply as indicated by the Highway Capacity Manual. The missing relevant information according to this study is the bottleneck and queue locations. Earlier studies by Hurdle and Datta (1983) indicated that the presence or absence of an upstream queue ahead of the restriction, such as at the bottleneck created by blocking a lane for maintenance work, is a more important variable than flow in predicting speed. When there is a queue upstream, speed is primarily a function of the distance from the data collection point to the beginning of the queue.

The shape of the speed/flow curve is also unknown at the capacity point. Figure 3.2, reproduced in the Highway Capacity Manual (TRB 1985) and discussed by Hurdle and Datta (1983), shows five possible curve shapes for the data they collected. They concluded that the flow characteristics of the freeway seemed to indicate that the speed of the traffic was unaffected by the flow rate until the volume reached approximately 
1500 vehicles per hour. At that point several different speed/flow curves could be hypothesized. Curves A and B were drawn using the average capacity flows observed. Curve $\mathrm{C}$ was drawn using the maximum flow observed to determine the capacity break. Curve D fits the data and would come from someone without a prior knowledge of the expected shape of the speed/flow curve as defined by the usual traffic engineering studies. Curve E fits the data better than the conventionally drawn curves, but no explanation could be offered for the sudden drop in speed at the 1800 passenger car per lane per hour. Further work by Persaud and Hurdle (1988) question then, where is the break point in flow and what is the shape of the speed/flow curve?

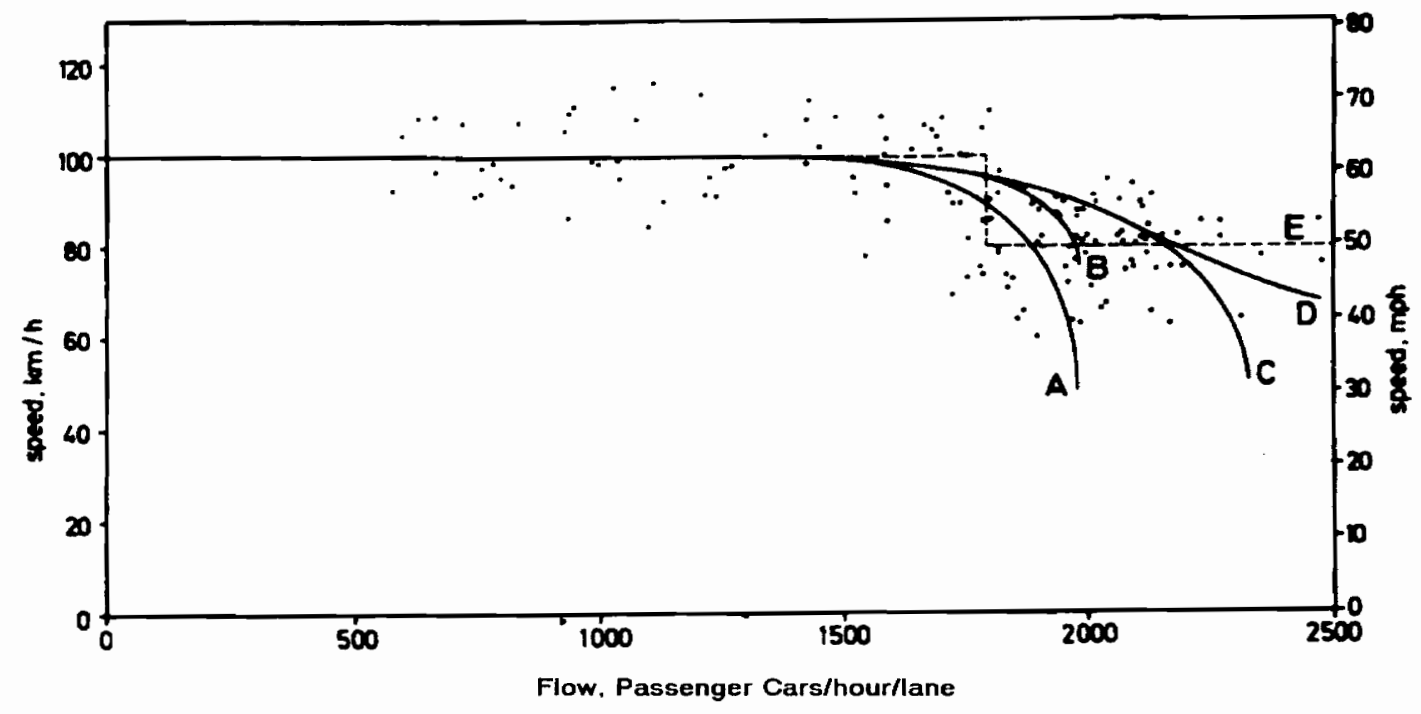

Figure 3.2: Speed-Flow Relationship for a Six-Lane Freeway near Toronto in 1982 (TRB 1985).

Another study by Banks (1989) agreed with the conclusion of Persaud and Hurdle (1988) regarding the slight drop in speed as density increases during free-flow 
condition. This research also indicated that an inverted $\mathrm{V}$ is a more acceptable model for flow versus density as opposed to the inverted $\mathrm{U}$ more commonly described.

The question of the definition of capacity is still unresolved. Hall and Agyemany-Duah (1991) question when capacity is reached. Since capacity is not the maximum flow observed, but what can reasonably be expected to be achieved day in and day out, they argue that it is better to distinguish between capacity and a type of facility than the capacity of a specific facility. Their research suggested that capacity drops in a bottleneck, that the capacity before a queue and discharge from a queue are different, yet both meet the HCM requirement for sustainable flow. The research also suggests that the numerical value for capacity may be higher than currently defined by the present Highway Capacity Manual.

These and other studies, such as Polus, Crans and Livneh (1991) looked at the flow/capacity/speed relationship, but none of the studies indicate the condition of the road surface and if it had any effect on the speed/density recorded. As earlier mentioned, the capacity analysis is based on the assumption that the pavement is in good condition. Within the capacity analysis, the condition of the pavement should be evaluated for effect on speed.

\section{Capacity Level of Service}

The Level of Service concept was introduced in the 1950 version of the Highway Capacity Manual (HCM) through the idea of the traffic-carrying capabilities of a road surface. The term "practical capacity" was used to define empirically the maximum number of vehicles that could pass a point under prevailing conditions when reasonable operating conditions were maintained. The 1965 update to the HCM specifically defined Level of Service (LOS) as "a qualitative measure of the effect of a number of 
factors, which include speed and travel time, traffic interruptions, freedom to maneuver, safety, driving comfort and convenience, and operating cost" (Roess 1984, p. 1).

The 1985 Highway Capacity Manual continues the definition as a qualitative measure describing operational characteristics as perceived by motorists (Figure 3.3). Six Levels of Service are defined ranging from LOS A, which is generally an uninterrupted free flow where drivers are unaffected by the presence of other drivers and have a feeling of freedom to maneuver at will, to LOS F, characterized by stopand-go traffic which is very unstable (TRB 1985).

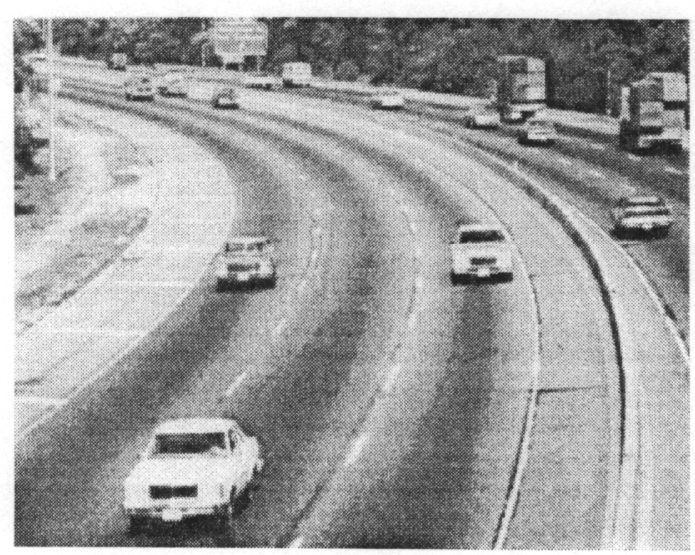

Level of Service A

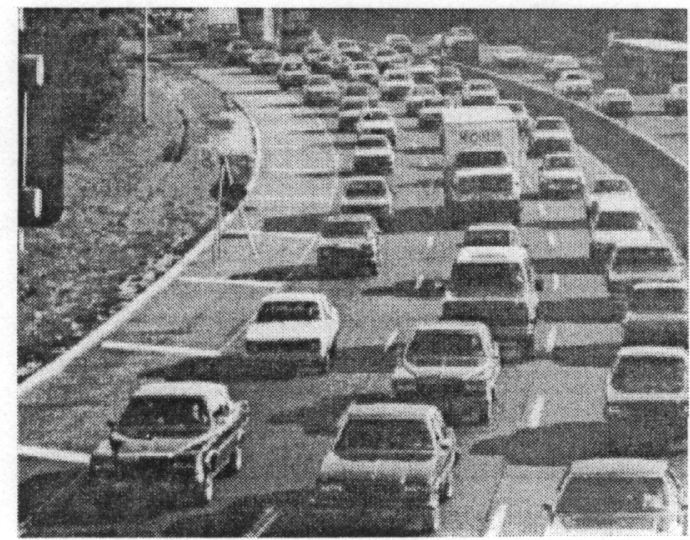

Level of Service F

Figure 3.3: Level of Service A and F (TRB 1985)

These Levels of Service are generally defined for uninterrupted flow (typical freeway conditions) and will vary for individual user's perceptions. In an attempt to quantify the Levels of Service, measures of effectiveness have been established which best describe the operating characteristics of a particular traffic facility. For example, for the basic freeway segment, the measure of effectiveness is density in passenger cars per mile per lane $(\mathrm{pc} / \mathrm{mi} / \mathrm{ln})$ in which boundary conditions have been set which identify 
a change from one Level of Service to another. For LOS A, the density is defined as equal to or less than $12 \mathrm{pc} / \mathrm{mi} / \mathrm{ln}$. For $\operatorname{LOS~B}$, the density is defined to range from greater than 12 to less than or equal to $20 \mathrm{pc} / \mathrm{mi} / \mathrm{ln}$. Truck and bus volumes are converted to passenger car equivalents using table values in the HCM (TRB 1985).

For computational purposes, either for operational analysis or design, the current Level of Service Index is a volume to capacity $(v / c)$ ratio which indicates the volume of traffic flow to the "ideal" capacity. This $v / c$ ratio is used to calculate a Mean Service Factor (maximum vehicles per mile per lane) that with various correction factors provides the expected flow rate for the specified conditions. The $v / c$ ratio is developed for ideal conditions of good pavement, no traffic incidents, and good weather. Correction factors are provided for the effects of restricted lane conditions, heavy vehicles, and driver populations.

\section{Measurement of Level of Service}

The measurement of the Level of Service has been difficult because Level of Service is qualitative in nature. For the 1965 HCM, Level of Service (LOS) was defined in terms of two parameters, operating speed and the volume to capacity ratio. Unfortunately, no correlation existed between the operating speed and the $v / c$ ratio. An existing $v / c$ ratio does not guarantee an operating speed (Roess 1979).

Since the LOS was a qualitative measure, the update to the HCM in 1985 sought to define more of the Level of Service in terms of what the driver experienced. Density replaced volume as density better reflects the driver's freedom to maneuver in traffic. Speed is still an important variable for freeway sections. From 1965 to 1985 however, the speed variable changed from an operating speed, defined as the maximum safe speed, to the average travel speed, a statistical parameter that can be obtained from 
sample observations as the time to travel a given section of road. Even though the two LOS measures are speed and density, volume and speed are the two parameters measured, with density being a computed value (Roess 1979, TRB 1985).

Some research has been done to quantify the qualitative LOS measure through the relationship of "acceleration noise" and the traffic measures of speed, volume, and density (Drew 1968, Croft 1985). Acceleration noise is the driver's natural speed changes due to the nature of the traffic flow. Acceleration noise can be natural, due to the geometry of the roadway, or it can be imposed due to the traffic density. Acceleration noise is measured by the number of positive and negative $2 \mathrm{mph}$ speed changes that occur during the running time of a specially-equipped test vehicle over a given highway section. The "natural" noise is determined when traffic volume is low to eliminate the traffic interference. The results of this research indicated again that the critical parameter for Level of Service is density.

This research (Drew 1968, Croft 1985) provided a method to quantitatively assess Level of Service by using the energy-momentum analogy for traffic flow. The efficiency of a system is the ratio of the maximum energy to total energy, $E / T$. Optimum operation is when the lost energy, I, is at a minimum. For a traffic system, this concept of efficiency can be illustrated by maximizing the motion of the traffic stream (E/T) and minimizing the lost energy or acceleration noise (I/T). This point would be the critical Level of Service. Using the classic speed-volume relationship,

$$
\begin{array}{ll}
q=k u, & \\
\text { where: } & \mathrm{q} \text { - volume or rate of flow (vehicles/hour/lane) } \\
& \mathrm{k} \text { - density (vehicles/mile/lane) } \\
& \mathrm{u} \text { - speed (miles/hour) } \\
& \mathrm{u}_{\mathrm{f}} \text { - free flow speed (miles/hour) }
\end{array}
$$




$$
\mathrm{u}=\mathrm{u}_{\mathrm{f}}\left[1-\left(\frac{\mathrm{k}}{\mathrm{k}_{\mathrm{j}}}\right)^{(\mathrm{n}+1) / 2}\right], \quad \mathrm{n}>-1 \text {, }
$$

and normalizing for $\mathrm{q} / \mathrm{q}_{\mathrm{m}}\left(\mathrm{v} / \mathrm{c}\right.$ ratio) and $\mathrm{u} / \mathrm{u}_{\mathrm{f}}$ (speed/free speed ratio), specific levels of service can be quantified as illustrated by Figure 3.4 for $n=1$.

The Levels of Service are quantified in Table 3.1 and an illustration of the quantification is shown in Table 3.2, assuming a road has a lane capacity, $\mathrm{q}_{\mathrm{m}},=2000$ vehicles per hour, and a free flow speed, $\mathrm{u}_{\mathrm{f}},=70$ miles per hour. The lower limits for the Levels of Service can then be quantified for other computational purposes.

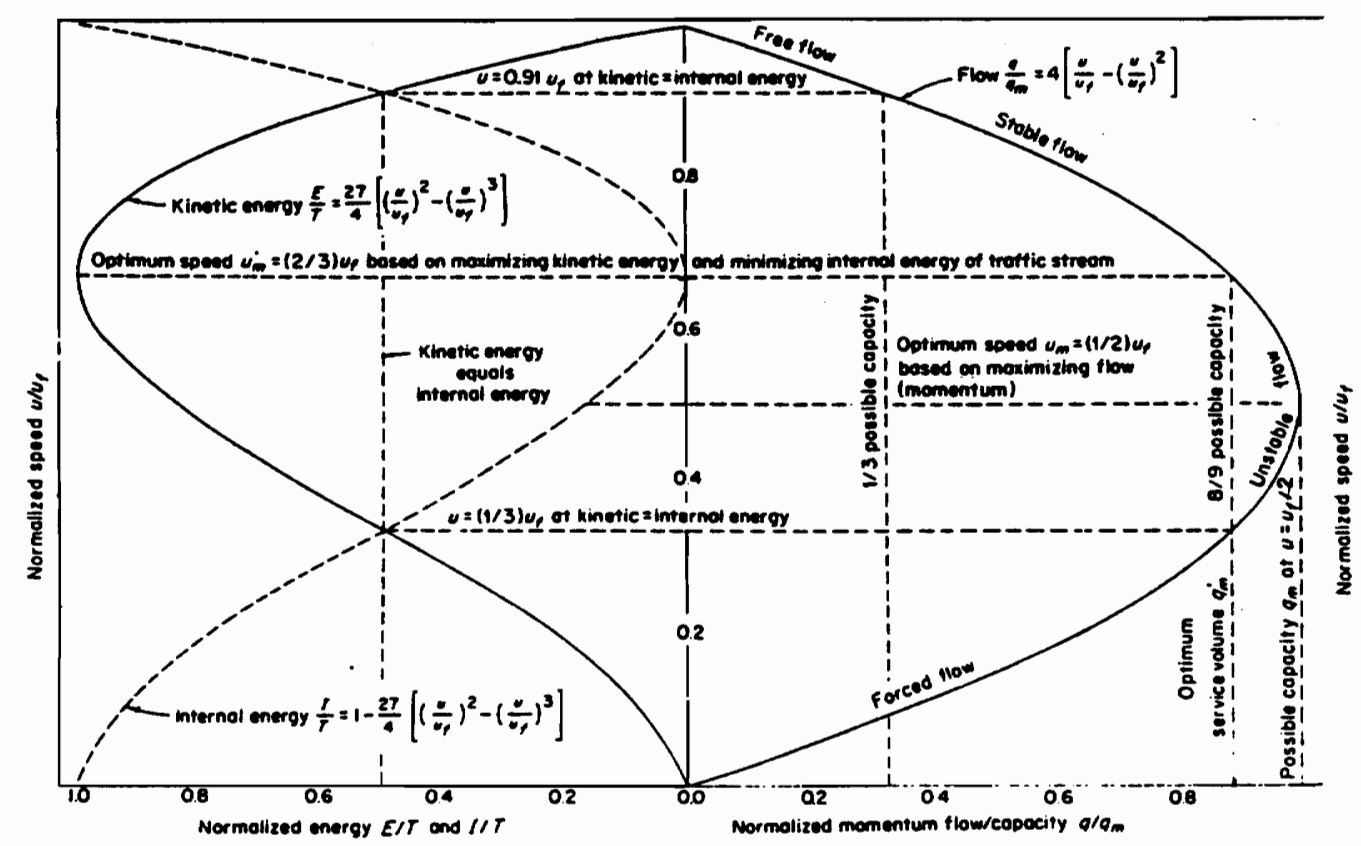

Figure 3.4: Quantitative Approach to Level of Service Using the Total Energy-Momentum Analogy (Drew 1968)

Other methods to define Level of Service for specialized types of traffic facilities have established measures of effectiveness relevant to that facility. For example, for a 
two-lane highway, the HCM defines speed, capacity use, and percentage of time delayed as the LOS measures. Morrall and Werner (1990) introduced the concept of overtaking as another measure. Here, the Level of Service is perceived by the driver as the ability to overtake and pass slower vehicles, which would depend on the opposing traffic stream and the road geometrics (i.e., sight distance). Toll Plaza Level of Service was investigated by Woo and Hoel (1991). Even though the Level of Service is specialized, density was still a major factor in defining the operating capabilities of the facility.

Table 3.1: Levels of Service as Established by Energy-Momentum Concept (Drew 1968)

\begin{tabular}{|c|c|c|c|c|}
\hline \multirow[b]{2}{*}{ Level-ol-service } & \multirow[b]{2}{*}{ zone } & \multicolumn{2}{|c|}{ Zone limits* } & \multirow[b]{2}{*}{ Description } \\
\hline & & Upper & Lower & \\
\hline \multirow[t]{2}{*}{ Free flow: } & $\lambda$ & "s & $0.01 u_{s}, 0.35 q_{m}$ & $\begin{array}{l}\text { Speeds controlied by driver } \\
\text { desires and physical rosdway } \\
\text { conditions. This is the type } \\
\text { of service expected in rural } \\
\text { locations }\end{array}$ \\
\hline & $B$ & $0.91 u_{s}, 0.3 \mathrm{sm} m$ & $0.83 u_{s}, 0.55 q m$ & $\begin{array}{l}\text { Speed primarily a function of } \\
\text { trafne density }\end{array}$ \\
\hline \multirow[t]{2}{*}{ Stable flow: } & $r:$ & $0.8311,0.35 \times 1 \mathrm{~m}$ & $0.75111,0.75 \mathrm{~m}_{\mathrm{m}}$ & $\begin{array}{l}\text { The conditlons in this zone ore } \\
\text { acceptable for freeways in } \\
\text { suburbon locations }\end{array}$ \\
\hline & l) & $0.7511,0.75 \mathrm{~kg} / \mathrm{m}$ & $u_{m}^{\prime} q_{m}^{\prime}$ & $\begin{array}{l}\text { The conditions in this zone are } \\
\text { acceptable for urban design } \\
\text { practice. The lower limit } \\
u_{m}^{\prime} q_{m}^{\prime} \text { represents the critical } \\
\text { level of service }\end{array}$ \\
\hline Unstable flow: & $H_{1}$ & $\eta_{m}^{\prime} \cdot q_{m}^{\prime}$ & $n_{m,}, q_{m}$ & $\begin{array}{l}\text { A small increase in demand } \\
\text { (now) is occompanied by } \\
\text { large decrease in speed } \\
\text { leading to high densitles and } \\
\text { internal friction }\end{array}$ \\
\hline & $b:$ & $11 m, 9 m$ & $0.33 u_{f}, q_{m}^{\prime}$ & $\begin{array}{l}\text { This type of high.density opera. } \\
\text { tion cannot persist and leads } \\
\text { inevitably to congestion }\end{array}$ \\
\hline Forced flow: & $F$ & $0.33{ }^{\prime}, q_{m}^{\prime}$ & 0 & $\begin{array}{l}\text { Flows are below capacity and } \\
\text { storage areas consisting of } \\
\text { queues of vehicles form. } \\
\text { Normal operation is not } \\
\text { achieved until the storage } \\
\text { queue is dissipated }\end{array}$ \\
\hline
\end{tabular}


Table 3.2: Illustration of Level of Service Quantification

\begin{tabular}{|c|c|c|c|}
\hline Level of Service & Lower Limit & $\begin{array}{c}\text { Density in } \\
\text { Vehicles/Mile/Lane }\end{array}$ & $\begin{array}{c}\text { Speed in } \\
\text { Miles/Hour }\end{array}$ \\
\hline \hline LOS A & $.35 \mathrm{q}_{\mathrm{m}} / .91 \mathrm{u}_{\mathrm{f}}$ & 11 & 64 \\
\hline LOS B & $.55 \mathrm{q}_{\mathrm{m}} / .83 \mathrm{u}_{\mathrm{f}}$ & 19 & 58 \\
\hline LOS C & $.75 \mathrm{q}_{\mathrm{m}} / .75 \mathrm{u}_{\mathrm{f}}$ & 29 & 52 \\
\hline LOS D & $.89 \mathrm{q}_{\mathrm{m}} / .67 \mathrm{u}_{\mathrm{f}}$ & 39 & 47 \\
\hline LOS E & $.89 \mathrm{q}_{\mathrm{m}} / .33 \mathrm{u}_{\mathrm{f}}$ & 77 & 23 \\
\hline LOS F & 0 & $>77$ & $<23$ \\
\hline
\end{tabular}

Polus and Tomecki (1986) went further to establish a Level of Service framework for evaluating traffic capital investment alternatives by suggesting a broad range of variables be combined by utility theory. Utility theory would allow the definition of a utility function for such qualitative areas as aesthetics and comfort along with quantitative values of volume and travel times. Each of these areas would then be weighted by a panel, representing such diverse areas as planners, engineers, and users, to determine a Level of Service function. This final LOS function was then defined by the assigned weight and a measure of effectiveness, such as vehicle delay, vehicle occupancy, level of emissions, energy consumption or traffic volumes determined appropriate by the panel. The main emphasis of this type of Level of Service evaluation was to provide input from a cross section of interested parties to help determine how Level of Service might vary with capital investment alternatives.

Sufficiency ratings used by many state DOTs for funding allocations are, in effect, a Level of Service index. The sufficiency rating subjectively measures road conditions, traffic volumes, and safety and assigns a numeric index of the adequacy (inadequacy) of the road. This system measures and weighs such items as road condition (foundation, wearing surface, maintenance), safety (accidents, hazards, sight 
distance), and service (ride quality, shoulder width, pavement width). Being a subjective rating, often the rating cannot be reproduced. Differences exist between states on the criteria to use and the weight to assign to each criterion (Humphrey 1981, Mercier 1988). The rating system seems to provide a relative score and not an absolute score that indicates when a pavement must be upgraded or repaired due to the overall score. Weighting of individually rated items can also affect the final index.

The Highway Performance Monitoring System (HPMS) is a Federal Highway Administration computer program that uses data provided by the states to determine the performance characteristics of the highway system and the effectiveness of the Federal highway programs. This system uses information regarding pavement condition, capacity, road geometrics, and operating characteristics to calculate a sufficiency index to evaluate highway condition, safety and service on a section-to-section basis or on a system-wide basis. This sufficiency index can then be used for deficiency analysis and a deferred-cost analysis. Several other models within the HPMS allow for policy analysis of capital investments for the highway system. One of the major uses of the program is to develop the information for the annual report to Congress entitled The Status of the Nations' Highways, Bridges, and Transit: Conditions and Performance and to provide information on the current transportation system performance and funding necessary to maintain or improve that performance (Kittell 1984, FHWA 1993).

One interesting item to note, the physical condition or maintenance level of the road surface is not a consideration in all of these methods for Level of Service or capacity analysis, but speed is. Karan and Hass (1976) studied the effect of pavement roughness on vehicle speeds and concluded that speeds of motor vehicles are significantly affected by pavement condition. By not including the pavement 
conditions' effect on speed, a higher Level of Service may be expected than actually is available. Sufficiency-type indices are usually subjective in nature and vary from user to user, not providing a consistent measure of the Level of Service of a highway system.

Levels of Service have also been used in an attempt to control growth in certain cities. The capacity Levels of Service were implemented as policy standards with the idea of controlling traffic in a congested area. The thought from the elected decisionmakers was that controlling traffic would eliminate the unwanted side effects from traffic congestion while improving economic development. The result was a de-facto no-growth policy which is what most cities do not want (Dowling 1989). These types of Level of Service policies are still concerned with the new construction aspect of Levels of Service and do not consider the impact of maintenance as part of the policy.

Transportation service standards were espoused by Ewing (1993) in an effort to move away from speed as the primary measure of Levels of Service. Replacing the measure of speed as a definition influencing Level of Service, Ewing suggests mobility, accessibility, livability and sustainability. These measures would relate the ability of the population to move with ease over a determined distance with acceptable travel time and/or cost. "Whereas levels of service relate to facilities, 'mobility' pertains to population, 'accessibility' to land uses, 'livability' to environments, and 'sustainability' to communities" (Ewing 1993, pp. 11-12). The underlying concept behind this idea is that the traveling experience of the motorist should relate to the entire trip, not on the delay at an intersection or the congestion on a particular road segment. Even trying to move the Levels of Service away from just a capacity measure as related to speed and/or density, the impact of maintenance is still not in this definition, even though the maintenance of a highway network will influence all of these added concepts. Rough, 
potholed, or patched surfaces will help determine the motorist's perception of the travel experience.

\section{Maintenance Level of Service}

One of the difficult tasks in maintenance management is to determine what level of maintenance is required for a transportation network. Multiple and often conflicting factors must be considered such as safety, riding comfort, protection of investment, and economics. An early study by Kulkarni in 1980 determined that maintenance levels were often subjective based on the experience of the personnel involved in the maintenance activities. Having no systematic method of determining a level of maintenance leads to inefficient use of limited resource dollars.

Kulkarni's research continued on to provide guidelines for developing maintenance Levels of Service defined as "a threshold deficiency level that should trigger an appropriate maintenance action" (Kulkarni 1980, p. 5). Each level defined was based on opinions of department specialists to determine "ideal" and "barely tolerable" maintenance levels with a spectrum of in-between levels. Through various weighting techniques, value functions for each level of maintenance on various attributes (safety, aesthetics, etc.) were developed. The final objective was to find the optimum level of maintenance for roadway conditions in the system that maximized the user benefits subject to the resource constraints. Unfortunately, the levels of maintenance were not connected to a functional Level of Service such as defined by a relationship to capacity. The Levels of Service were subjective alternate levels of maintenance described after reaching a threshold condition requiring action.

Maintenance Levels of Service were researched by Kulkarni in an attempt to effectively use maintenance dollars. These Levels of Service were user-oriented in 
terms of keeping the roadways safe and usable for the motoring public and to preserve the highway system. For example, the State of Virginia publishes a Maintenance Policy Manual that defines Maintenance Levels of Service and states when action is to be taken to correct a deficient maintenance condition that is considered unacceptable. These Levels of Service are identified as Levels A, B, and C, and are not connected to the capacity-oriented Levels of Service, but are threshold levels that should trigger maintenance activities. Level A is considered the minimum funding level necessary to protect the investment in the highway and provide reasonable levels of safety while Level C provides a higher level of comfort and convenience (VDOT 1991). From a definition standpoint only for Virginia, the Maintenance Levels of Service are directly opposite the Capacity Levels of Service with the best level at Level $C$ and the minimum Level of Service at Level A.

Maintenance does have an effect on the Level of Operation of the transportation network since pavement roughness has been connected to vehicle speed, thus affecting traffic volume. Pavement roughness will affect user vehicle-repair costs and will also contribute to the user perception of poor riding comfort, a measure of the HCM Level of Service. Research was accomplished by Janoff, et al, (1985) which attempted to correlate a subjective opinion from a panel of users for needed road repair based on "ride quality" with an objective physical measure of roughness determined by instrumentation, for example, a Mays ride meter. One of the conclusions of the study indicated that for rougher roads, slower travel would seem to make the ride more comfortable to the panel of riders. If pavement roughness does cause motorists to slow down for a more comfortable ride, then again, Level of Service may be lower than determined by the normal capacity analysis. One of the maintenance trigger levels for 
the Virginia Department of Transportation is roughness. Does the level of roughness trigger point affect the capacity of the system?

\section{Maintenance, Obsolescence and Level of Service}

Maintenance of any sort, whether it is preventative or routine maintenance, will affect the ability of a highway to fulfill the functional requirements. Deferring maintenance can lead to earlier deterioration, eventually resulting in an unusable pavement. As the road condition deteriorates, the Level of Operation decreases and the maintenance need increases. As the maintenance is kept at the required level, the Level of Operation improves. According to the 1990 Highway Statistics published by the Federal Highway Administration (FHWA), 59.0\% of the nation's urban interstate freeways have a Present Serviceability Rating (PSR) between 3.5 and 5.0 and 32.3\% are rated between 2.6 and 3.4 (Larson 1990). The PSR system, first developed by Carey and Irick at the AASHO road test in 1960, was a subjective rating that was the numerical average rating determined by a panel of individuals who would test ride a section of pavement and independently rate it as to its rideability and serviceability. The PSR ranges from 0.0, indicating impassable pavement, to 5.0 indicating a perfect pavement (Baladi 1991). The subjective PSR has been correlated with specific road defects, such as roughness, patching and cracking, to determine a Present Serviceability Index, PSI. This allows objectively predicting a subjective measure. The question here is: How much does this PSR for an urban interstate of 4.0 compared to 3.0 affect the Level of Service of that freeway since the PSR is a subjective indication of pavement condition?

Also, based on the 1990 information, over $30 \%$ of the urban interstate has an International Roughness Index (IRI) of greater than 126 inches per mile (Larson 1990). 
The IRI is a cumulative measure of longitudinal surface profile of a road representing the vibration induced in a typical passenger car by the road roughness. As the roughness increases, how does the increase affect the Level of Service of the highway? In this research, the effect on the serviceability of a road will be defined as the "Level of Operation" and defined by a Level of Operation Index (LOI).

Obsolescence can occur because of increased usage, revised criteria of acceptable performance, or better ways of accomplishing the same task. According to the 1993 Status of the Nation's Highways, congested peak-hour travel has continued to increase at an average annual rate of $3 \%$ since 1983 . In 1991 , over $70 \%$ of the rush-hour travel on urban interstates was accomplished under congested or severely congested conditions. A Texas Transportation Report in 1989 indicated that the 1989 cost of congestion in the 50 urban areas studied was $\$ 39.1$ billion of which $85 \%$ of that cost was due to delays (FHWA 1993). As the capacity of the road is increased, the Level of Availability is increased. As the capacity need is increased, the Level of Availability is decreased. As the capacity is increased with additional road construction, more maintenance work is required because of the additional pavement. For this research, the effect of obsolescence (congestion) will be defined as the "Level of Availability" and defined by a Level of Availability Index (LAI).

The Level of Operation and Level of Availability directly influence the Level of Service. If the Level of Operation and Availability vary in a downward direction, meaning the pavement is deteriorating and the traffic is becoming congested, the carrying ability of a section of highway will be reduced as well, indicating a degraded Level of Service for the road.

Degraded Level of Service is manifested physically through traffic congestion and/or rough and deteriorated pavement surfaces. When the Level of Service 
decreases, users' costs increase, which means that vehicle operating costs and vehicle repair costs are increasing. Decreasing Levels of Service also mean an increasing cost for industry to operate. As vehicle operating and repair costs are increasing, the ability of an area to attract new business or industry is decreased.

\section{Comprehensive Level of Service Definition}

Comprehensive Level of Service for this research will be a combination of two areas, Level of Operation, defining the maintenance (deterioration) characteristics and the effect on traffic flow and Level of Availability, defining the capacity (obsolescence) characteristics of the roadway. The definition will be one that reflects the impact of maintenance on the desired qualities of Level of Service (LOS) as defined by the current Highway Capacity Manual, a qualitative measure describing operational conditions such as speed, travel time, freedom to maneuver, comfort, convenience, and safety within a traffic stream and the motorist's perception of those conditions (TRB 1985). This definition of Level of Service will be used because of its familiarity in the transportation design, construction, and maintenance sectors.

The Level of Operation will define the physical condition of the roadway which will indicate the system level of deterioration. Present Level of Service calculations in the Highway Capacity Manual assume good pavement conditions, but provide no "adjustment" factor for deteriorated pavement.

The Level of Availability will define the obsolescence of the roadway and will be measured by the system congestion. The rate of traffic flow is defined by the number of vehicles per lane per hour in a traffic stream. When this rate of flow is compared to the maximum rate of flow or roadway capacity, it will indicate the Level of Availability or degree of obsolescence. Current operating capacity calculations seek to 
estimate the traffic speed and density, thus Level of Service, based on the road alignment, the physical road construction features such as lane widths or distances to obstructions, and the percentage of trucks and buses in the traffic mix.

Both Level of Operation and Level of Availability affect the transportation systems' Comprehensive Level of Service. If a road is well maintained, but crowded, the Level of Service is low. Users' costs are increased by lower speeds and increased travel time. Motorists' convenience is less, and traffic interruptions are increased. If a roadway has very few vehicles, but the surface is rough, potholed, and/or patched, the Level of Service is still low. Users' costs are increased through excess vehicle repairs. Travel is uncomfortable because of the rough road. Speed will be reduced to try to make the road seem smoother which will increase travel times and vehicle operating costs. For industries, transportation-related costs such as these will be included in the pricing of the goods produced increasing the prices to consumers.

Increasing the Level of Operation of a road surface may not increase the Level of Availability. For example, re-paving a congested highway may provide a smoother surface for motorists, but will do nothing to increase the overall Level of Service. Similarly, increasing the Level of Availability by constructing new roads and not maintaining the existing system may not increase the Level of Operation. A state DOT or local official should understand where a particular road lies within the Comprehensive Level of Service Matrix, Figure 3.5, to make the best investment of scarce resource dollars.

\section{Summary}

Research has been accomplished for several years concerning the speed/flow relationships for traffic flow on different types of highway facilities, only to conclude 
Level of Availability

High

Low

Level of

Operation

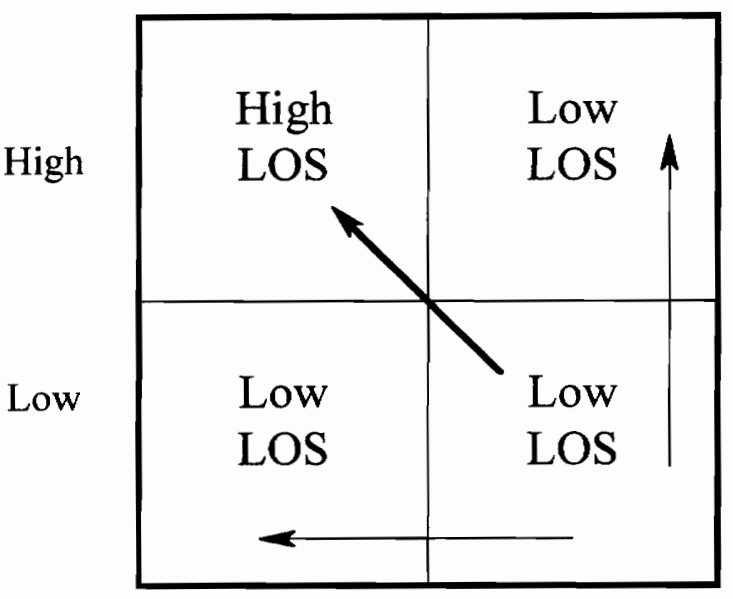

Figure 3.5: Comprehensive Level of Service Matrix

that no one is quite sure of the exact relationships. Speed and flow are related, but maybe not to the degree traditionally considered, particularly at higher speeds. The relationship is important because without an understanding how speed and flow vary, the Level of Service of a roadway becomes difficult to determine.

Level of Service has also been investigated in several different situations, only to have no quantification system established. Maintenance and capacity are looked at in different ways. Capacity Level of Service is concerned with the speed and density of traffic, not considering the condition of the pavement. Maintenance Level of Service is concerned with the condition of the pavement but not the impact of the pavement condition on the traffic carrying capabilities of the roadway.

A Level of Service indicator is very important to the transportation industry. As noted, the Level of Service definition includes several areas of driver comfort, economics, and reliability. With the current definition, maintenance is not considered, 
yet the maintenance efforts will have a direct impact on the Comprehensive Level of Service of any highway system. The maintenance, or lack of maintenance, will directly affect the qualitative measurements of the Level of Service. Rough roads, potholes, and slick road surfaces, as well as congestion, narrow travel lanes, and winding roads will contribute to decreased driver comfort and convenience, speed and safety, and increased density, traffic interruptions, travel time and operating costs, which are all identified as providing a Level of Service to the motoring public. Both areas of maintenance and construction activities must be considered when Level of Service is determined. 


\section{CHAPTER 4: \\ SYSTEM DYNAMICS MODELING}

\section{Introduction}

This chapter describes the system dynamics methodology utilized to model and simulate the impact of deferred maintenance and obsolescence of a highway system. The information is condensed from Drew 1993, Richardson 1981, and Bala 1994.

System dynamics is a methodology whose purpose is to assist in the understanding of complex problems and provide an approach for representing the dynamic relationships between variables in a system. This understanding allows testing policies and/or assumptions to gain insight for problem solutions, or at least, a minimization of the potential outcome. As a modeling tool, system dynamics is based on the use of dynamic relationships (quantities that change over time), feedback, and control theory. "The goal of the modeling effort is to improve understanding of the relationships between feedback structure and dynamic behavior of a system so that policies for improving problematic behavior may be developed" (Richardson 1981 p. 38). This type of modeling complex problems over a period of time permits decision makers the opportunity to evaluate the future implications of present decisions as an analysis of change.

\section{Systems Thinking}

The problem of infrastructure deterioration and management does not lend itself to a simple solution. Interaction of the social, environmental, economic, technical, and political realms seen in most problems does not lead to a single solution to satisfice all, or any, of those involved. The growing tightening of the interaction between the subsystems makes it even more important that we start thinking in a systems 
orientation, that is, the dynamics of the system feedbacks are key in understanding how "reality" really works.

The multiple feedback loops found in any problem are beyond the ability of most individuals to be able to sort out. This leads to cognitive overload as most people cannot think in multiple tracks at the same time, particularly with time series ideas (Richmond 1993). The following seven critical systems thinking skills from Richmond (1993) are summarized here to express the importance of systems thinking in regard to the problems of infrastructure deterioration and its interaction with the economy.

First, dynamic thinking provides the ability to envision behavior patterns rather than focus on or seek to predict events. Within the reality of life, patterns are developed over time depending on the closed-loop processes developed. Feedback systems will tend to reinforce a development or tend to move towards an equilibrium state. To be able to visualize the pattern over time is to think dynamically. For example, maintenance on roadways should improve the surface condition over time. Similarly, lack of maintenance will allow deterioration to occur. This does not indicate what the surface condition would be at any time, only that the maintenance will have an effect over time.

Second, closed-loop thinking will move people away from the regression formula type of one-way relationships into a set of on-going interdependent processes. Closed-loop thinking moves toward behavior of systems instead of looking for outside forces that cause the behavior. With the system causing the behavior, the burden for improvement moves to the decision makers in the system instead of trying to locate and control some outside force. For example, highway maintenance will improve road conditions which will increase user and non-benefits. This increase in benefits will improve the attractiveness of a region to support industry. Additional industry will 
increase the population which will provide additional tax revenues. A growing tax revenue base will allow more maintenance to be accomplished. This is a closed loop, back to the original variable of highway maintenance, that puts the responsibility on the decision makers to promote highway maintenance activities instead of only looking to promote new industry.

Third, generic thinking allows the thought process to be applied to almost any situation. People tend to think of events and specifics, yet history has shown that nations appear to go through a cycle (feedback loops) that can be traced as certain behavior. These skills come from structures that can be developed by growth, decay or oscillation cycles. For example, system thinking can apply to highway systems, economic systems, or physical systems. It can be useful for any area by researching the problem definition and seeking the closed loops.

Fourth, structural thinking is more disciplined in that the units of measure must be consistent throughout and have a basis in reality. For example, highways can be measured in lane-miles. The rate of new construction can also be measured in lanemiles per year. The causal diagram for the increase of highway lane-miles would indicate a continued growth if left unchecked. The situation of decreasing construction of lane-miles per year does not indicate a decreasing total number of lane-miles, only a decreasing rate at which the lane-miles increase. In structural thinking, this distinction must be made.

Fifth, operational thinking means thinking in terms of how a system actually operates. In the realm of operational thinking, one can discover how the system functions and this will provide insight into those factors that can be decision variables in a system, something that really manages the process. For example, highway budgeting is many times accomplished from the top down, by pre-determining how 
much funding is available for maintenance, instead of letting the maintenance requirements of the system determine the highway expenditure budget. This kind of operational thinking can help visualize how a system currently works in order to provide alternatives to change to the way a system should work.

Sixth, continuum thinking involves using a continuous, as opposed to discrete, modeling technique. Discrete functions tend to assume no change in process until a certain point is reached when in reality the process will change over time in reaction to the developing process. For example, road maintenance accomplished when a certain preset standard is reached neglects the impacts or changes that may occur before the maintenance is accomplished. It assumes that the traffic flow will continue as normal until the maintenance is accomplished or will not continue if the maintenance is not accomplished. In reality, the traffic behavior changes over time in response to the road condition, either slowing down or finding alternative routes until the road is repaired. Continuum thinking is the ability to see these connections and interdependencies and not consider them as boundaries.

Finally, scientific thinking has more to do with quantification than measurement. Measurement will indicate how rough a road is or how many lane-miles are in what condition, but scientific thinking will quantify the impact of that road quality. For example, a Comprehensive Level of Service of 0.0 means "in the absence of any service" while 1.0 means "maximum possible service." It does not mean that the exact quantities for any intermediate Level of Service are established, or a convention for thinking about the dynamics of the variables involved. Now the question can be asked, what variables keep the Comprehensive Level of Service from reaching or going beyond 1.0? With a continuous model available, one variable at a time can be 
manipulated to determine what variables have the most impact and can be tested for change.

These system thinking ideas are part of the underlying concepts in which the system dynamics methodology is rooted. Being able to understand the system behavior will lead to the fundamental feedback loops inherent in closed-loop systems.

\section{System Dynamics and Feedback Structures}

System dynamics is concerned with the understanding and management of complex systems in order to provide a desired performance. Based on the foundation of decision making, feedback analysis and simulation, systems can be defined and modeled that will allow experimentation in a laboratory setting. Decision making relates to how action is taken. Feedback deals with the way information is used in the decision-making process, and simulation permits decision makers to view the implication of their decisions over a future time. This is the power of system dynamics. By varying those variables within the direct control of the decision makers, various policy scenarios can be quickly investigated for discussion, critique, revision, and reapplication.

\section{System Behavior}

Feedback loops within a model determine the dynamic behavior. Recognizing the type of behavior in the problem being modeled will provide insight into the type of feedback structure at work in the system and lead to approaches for policy implementation to change the system's behavior. Several interconnected feedback loops will make an analysis more difficult even though the implications of an isolated loop are relatively obvious. This interconnection of several feedback loops is particularly amenable to computer simulation. 


\section{Closed-Loop Structures}

The primary feature of a closed-loop structure, Figure 4.1, is the feedback into the system. The action taken is dependent on information provided from the system. The result of that action provides additional information to the system for another action at a later time. This is an example of a heating control system. The information received from the space temperature determines the action of the heating system.

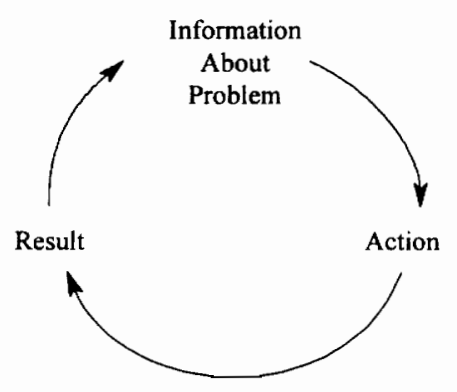

Figure 4.1: Closed-Loop Concept

\section{Positive Feedback Loops}

Positive feedback loops, such as picutred in Figure 4.2, are demonstrated by systems that exhibit an exponential growth or decaying behavior. The variable in this type of feedback loop is continually feeding on itself to reinforce its own growth or decline which gives rise to the "vicious circle" or "snowball" effect. When a system is showing a constant growth or decline, a positive loop is dominate in the model structure.

\section{Negative Feedback Loops}

Negative feedback loops, Figure 4.3, on the other hand tend to seek an equilibrium position. This type of feedback loop will attempt to counteract any deviation from an equilibrium point or goal state in a self-regulating manner. A system 


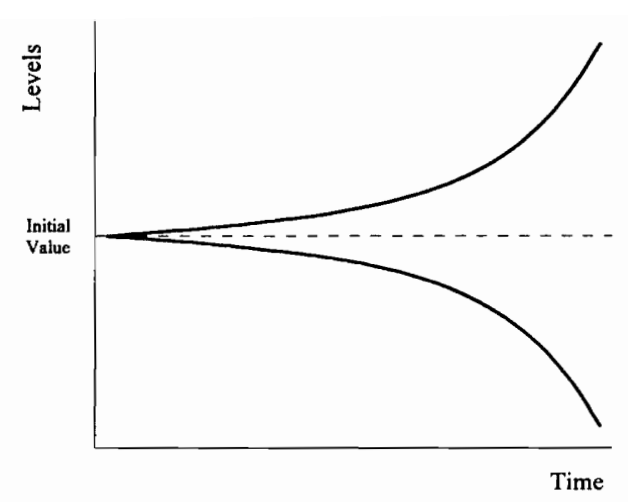

Figure 4.2: Positive Feedback Loop Behavior

that is moving toward a steady state has a negative feedback loop. In a system with both a negative and positive feedback loop, the dominate loop will determine the overall system behavior. Using this knowledge of feedback loops, a positive feedback loop that is to be controlled, must have a negative loop added working on the same state or level variables that will dominate the continuous growth. The negative loop would provide a policy decision opportunity for the decision makers.

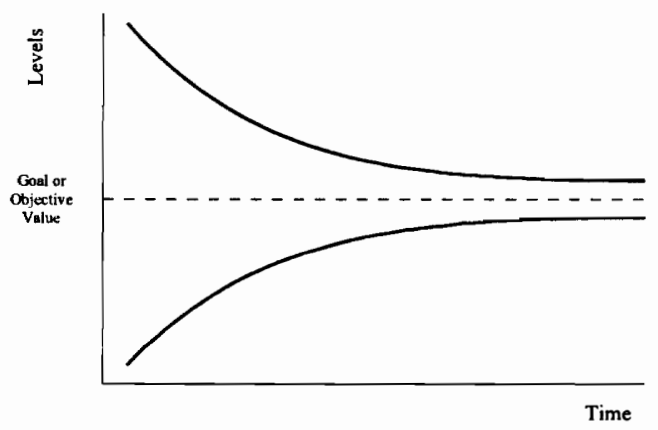

Figure 4.3: Negative Feedback Loop Behavior

\section{Conserved Systems}

In some systems, the total amount of the state or condition variables does not change. For instance, in maintenance of highways, the condition of the surface varies 
between different physical states, but the total number of lane-miles of highway does not increase or decrease. This says that the total of the initial values of the surface conditions equals the total values of the surface conditions at any time. This is known as a conserved system and is an important concept for mathematical analysis of the variables as shown in Chapter 6 detailing the equilibrium analysis of the maintenance model.

\section{Dynamic Modeling Forms}

\section{Verbal Models}

Verbal descriptions are the simplest way of communicating the behavior of the system being studied. As more detail is available, the model is easier to construct. This verbal description is the written form of a mental model and represents a qualitative model of the system being studied. The model is qualitative because no mathematical preciseness is involved. This is exactly the problem with only having a verbal description of the system. No experimentation can take place to cletermine the impact of different variables of the model. The mental model is very intuitive to the one who owns the model, but is subject to misunderstanding to those who are trying to understand the variables involved. Also the mental model does not handle the complexity involved as pointed out earlier with man's inability to handle multiple tracks, particularly with time-series information.

\section{Causal Diagrams}

The causal diagram is the picture of the verbal model described. It is a series of cause-and-effect relationships that display the interactions between key variables in analyzing how the system works. The system dynamics causal diagramming 
convention explained below is the one used in this research. This methodology utilizes classes of variables to indicate the function of a specific variable in the finalized causal diagram. The types of variables are as follows and diagrammed in Figures 4.4 and 4.5:

Level variables accumulate a physical process and represent the level, condition, or state of a system. Levels are a function of the rates and appear at the head of a solid arrow. In Figure 4.4, the physically sufficient highway, $\mathrm{PSH}$, is the level variable that will accumulate the lane-miles of physically sufficient highway.

Rate variables define information flows to the level variables and define the amount by which the levels change over an interval of time. Rates are functions of levels and auxiliary variables and appear at the tail of a solid arrow. In Figure 4.4, the highway ordinary maintenance, HOM, is the rate variable that defines the rate of change in the level variable over time.

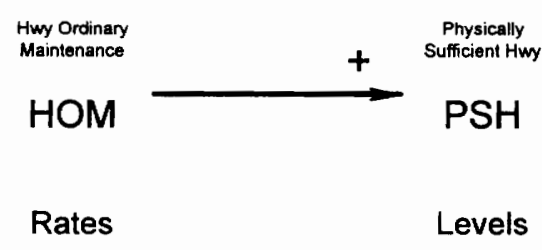

Figure 4.4: Levels and Rates

Auxiliary variables are intermediate variables on the path from a level variable to a rate variable or are outside input into a rate variable. Auxiliary variables further disaggregate the rate variables and provide additional information in the feedback loops. In Figure 4.5, the ordinary maintenance cost, OMC, fraction of expenditure for ordinary maintenance, FEOM, and 
the highway maintenance expenditure, HME, are auxiliary variables that provide input or additional information about the rate of highway ordinary maintenance, HOM.

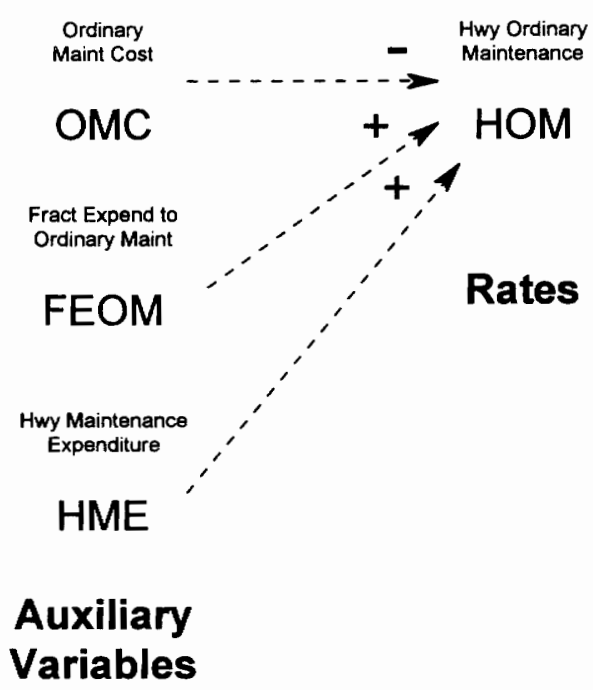

Figure 4.5: Auxiliary Variables

The following definitions also help explain additional system dynamics functions and naming conventions used in this research.

Table functions are a way to represent a non-linear relationship where the exact function may not be known. Linear interpolation is used between known or hypothesized points.

Initial variables assign an initial value to the level variables. These values can either be assigned or computed based on other auxiliary variables.

Constants are assigned values that will not change throughout a simulation.

Decision variables are variables that are under the control of the decision makers and define the policies to be reviewed. 
Measures of effectiveness are variables that will define the effect of the decision variables on the system and help indicate the outcome of the policy decisions made.

The signs on the causal links in Figures 4.4 and 4.5 indicate the nature of the relationship between variables. A " + means that the two variables move in the same direction, that is an increase in the parameter at the tail of the arrow will result in an increase in the variable at the head of the arrow or a decrease in the parameter at the tail of the arrow will result in an decrease in the variable at the head of the arrow. Similarly, a "-" means that the two variables move in opposite directions. An increase in the parameter at the tail of an arrow will result in a decrease in the variable at the head of the arrow or a decrease in the parameter at the tail of an arrow will result in an increase in the variable at the head of the arrow. Loops that can be traced continuously through the levels and rates in a causal diagram are called feedback loops which give rise to behavior in the model.

A positive loop, structurally indicated by exponential growth or decline, is determined by an even number of negative signs around a feedback loop. A negative loop, structurally indicated by movement toward an equilibrium point, is formed from an odd number of negative signs around a feedback loop.

\section{Mathematical Formulation}

Integration is the basis for the level and rate structure in the system dynamics methodology. Level variables, $\mathrm{L}(\mathrm{t})$, accumulate a physical entity at time $t$. Rate variables indicate the change in the level variable over the interval from time $t-1$ to $t$. In a mathematical sense, this relationship can be written as: 


$$
\mathrm{L}_{\mathrm{t}}=\mathrm{L}_{0}+\int_{0}^{\mathrm{t}}(\mathrm{RI}-\mathrm{RO}) \mathrm{dt}
$$

where:

$\mathrm{L}_{\mathrm{t}}=$ the value of the Level at any time $t$

$\mathrm{L}_{0}=$ initial value of the Level at time $=0$

$\mathrm{RI}=$ rate being added or rate in

$\mathrm{RO}=$ rate being subtracted or rate out.

Solution of the mathematical formulation by a computer simulation is accomplished using a difference equation form instead of the integration form:

$$
\text { L.K }=\text { L.J + (DT) }(\text { RI.JK }- \text { RO.JK })
$$

where:

L.K = the value of the Level at any time $t$

L.J $=$ the value of the Level at time $t-1$

$\mathrm{RI} . \mathrm{JK}=$ rate being added or rate in from time $t-1$ to $t$

RO.JK $=$ rate being subtracted or rate out from time $t-1$ to $t$

DT $=$ time interval of time $t-1$ to $t$.

The difference equation indicates that the Level at any time $t$ is equal to the Level at time $t-1$ plus the change over the time interval from $t-1$ to $t$ due to the rate in and rate out. Substitution of the auxiliary variables that add information about the rates into the Level equation will allow solution of the model in an analytical sense. The model behavior can be determined from the solution and the impact of a change in the decision variable can be graphed over time.

\section{Computer Simulation}

DYNAMO (DYNAmic MOdeling) is a computer simulation language intended for use in modeling real-world systems so the behavior of a problem can be traced through time. A problem is first identified and verbalized. The verbal model gives rise to a causal (visual) diagram which is then iteratively and sequentially formulated 
into a mathematical model. The mathematical model allows formal quantification of the dynamic relationships.

DYNAMO equations represent the causal diagram in the mathematical sense.

Since the simulation equations are written to express movements of the level, rate, and auxiliary variables over time, a naming convention was established to handle the computer computations. The values of the variables are at discrete moments in time and are postscripted to indicate that position in time, either the present time, $t,(. \mathrm{K})$, the first past interval of time, $t-1,(. \mathrm{J})$, or the first future interval of time, $t+1,(. \mathrm{L})$. Combinations of postscripts refer to time intervals, either past to present time $t-1$ to $t$, (.JK), or present to future time $t$ to $t+1,(. \mathrm{KL})$.

The types of equations also represent the state of the system (Level equations, L), the change in the system (Rate equations, $\mathrm{R}$ ) or additional information affecting the change in the system (Auxiliary equations, A, Constants, C, Initial values, N). The solution time interval for the level equations, DT, is for computational purposes and converts the system change rates into a system state value.

\section{Level Equation}

L $\quad$ PSH.K $=$ PSH.J +(DT)(HOM.JK +HMR.JK-HA.JK)

The physically sufficient highway, PSH, at time $t$ equals the physically sufficient highway at time $t-1$ plus the change due to the highway ordinary maintenance, HOM, the highway maintenance replacement, HMR, and the highway aging, HA, over the time interval from $t-1$ to $t$.

\section{Rate Equation}

$\mathrm{R} \quad \mathrm{HOM} . \mathrm{KL}=\mathrm{HME} * \mathrm{FEOM} / \mathrm{OMC}$ 
The highway ordinary maintenance, HOM, rate is equal to the highway maintenance expenditure, HME, multiplied by the fraction of expenditure for ordinary maintenance, FEOM, divided by the ordinary maintenance cost, OMC.

\section{Auxiliary Equation}

A $\quad$ LOI.K $=(1-F H D M P Y . K) * R Q I . K$

The Level of Operation Index, LOI, at time $t$ equals the fraction of highway down for maintenance, FHDMPY, multiplied by the road quality index, RQI.

\section{Decision Variable}

\section{A $\quad \mathrm{HME}=\mathrm{UMHE}{ }^{*} \mathrm{HWYT}$}

The total highway maintenance expenditure, HME, is the unit maintenance expenditure, UMHE, multiplied by the total system highway miles, HWYT. The decision variable is the unit maintenance highway expenditure with is under the control of the decision makers. The policy for expenditure is controlled by those that will decide how much to expend. By varying the unit maintenance highway expenditure, the effect of that decision can be viewed without having the wait several years to see the impact.

\section{Measure of Effectiveness}

A $\quad$ RLE.K $=$ HRG.K-UMHE

A HRG.K $=$ QKL.K*CFTAT*LLKL*TPG/(AFE*HWYT)

The revenues less expenditures, RLE, indicate the amount of highway revenues generated by the traffic, HRG, less the maintenance expenditures made, UMHE. The highway revenues generated, HRG, are based on the traffic volume, QKL, the travel distance, LLKL, the tax per gallon, TPG, the average fuel efficiency, AFE, and the total highway lane-miles maintained, HWYT. To convert the hourly traffic to yearly 
traffic, a conversion factor for two-way annual traffic, CFTAT, is needed. As more traffic can use the roads, the revenues generated will increase. The traffic generated is based on the capacity and maintenance condition of the highway which is based on the highway maintenance expenditure which is based on the revenues generated. The feedback loop is closed. This is how the verbal model is mapped to mathematical equations that will allow explicit definitions of the system and allow experimentation with the decision variables.

\section{Summary}

Most problems facing society today are too complex to be understood in their entirety. Looking for relationships between two variables fails to consider the whole system and the aspect of feedback loops that are inherent in most social, technical, economic, and political systems. By incorporating the aspect of feedback and studying the system behavior, much can be learned and then applied to controlling the system. While most social science methodologies are oriented towards gathering and testing data, system dynamics is directed towards serving as a guide to action. The models are based on two major types of variables, levels and rates. The levels represent the state of the system and rates define the change in that system over an interval of time. The chains of levels and rates are the feedback loops that generate either continued growth or decline in positive loops or eventual equilibrium from negative loops. The increasing complexities of the systems make it necessary to use a computer simulation to determine the response of the system.

The verbalization of a problem is translated into a causal diagram that explicitly defines the interactions between the variables. This leads to a mathematical model for simulation. The generally implicit verbal form of a model is transformed into a 
detailed mathematical model that can be revised, criticized, changed, and discussed iteratively and sequentially where a verbal model is often misunderstood between groups of interested people. The major goal of understanding can be achieved when a model is open for discussion and resolution. 


\section{CHAPTER 5: \\ DEVELOPMENT OF SYSTEM DYNAMICS MODELS}

\section{Introduction}

This chapter describes the development of the system dynamics model derived to simulate the impact of deferred maintenance and/or obsolescence of a highway system using the Comprehensive Level of Service concept. The Maintenance Level of Operation model was developed to define the relationships between maintenance activities and traffic volume. The model then develops the utilization of trafficgenerated highway revenues to maintain the Level of Operation of the road surface. A simulation model was similarly developed based on the format of the maintenance model to simulate the Level of Availability for the Comprehensive Level of Service.

\section{Development of Maintenance Level of Operation Simulation Model}

For the Level of Operation model, the road surface is considered to be in one of three physical states, physically sufficient highway, physically deficient highway, or physically deteriorated highway. The road surface ages over time and physically sufficient highway will become physically deficient highway. Similarly, for a highway deteriorating rate, physically deficient highway will become physically deteriorated highway. Maintenance efforts, either ordinary maintenance or maintenance replacement as defined by the Virginia Department of Transportation (VDOT), will upgrade the road surface from physically deficient highway to physically sufficient highway, in the case of ordinary maintenance, or from physically deteriorated highway to physically sufficient highway, in the case of maintenance replacement. The causal diagram for this model is shown in Figure 5.1. The DYNAMO equations for the Highway Levels are as follows: 


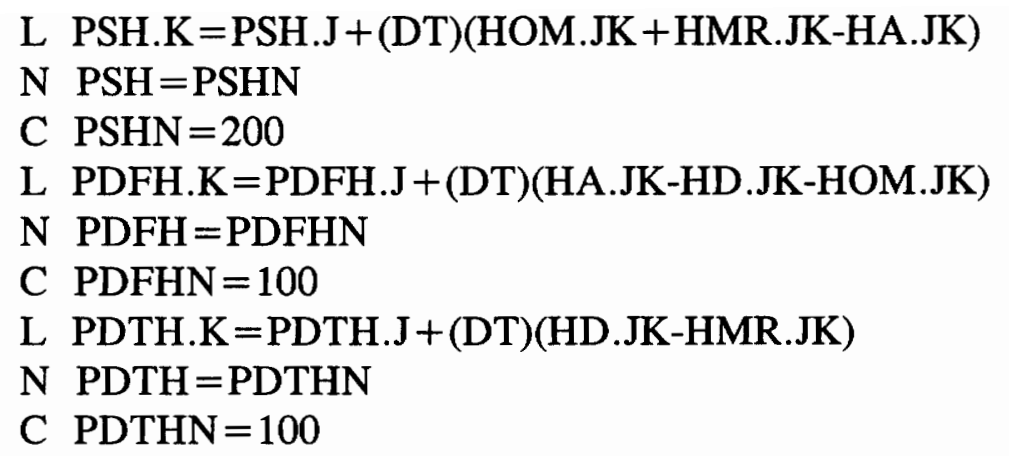
PSH - Physically Sufficient Highway (lane-miles)
PSHN - Initial Quantity of Physically Sufficient Highway (lane-miles)
PDFH - Physically Deficient Highway (lane-miles)
PDFHN - Initial Quantity of Physically Deficient Highway (lane-miles)
PDTH - Physically Deteriorated Highway (lane-miles)
PDTHN - Initial Quantity of Physically Deteriorated Highway (lane-miles)
HA - Highway Aging Rate (lane-miles/year)
HD - Highway Deteriorating Rate (lane-miles/year)
HOM - Highway Ordinary Maintenance Rate (lane-miles/year)
HMR - Highway Maintenance Replacement Rate (lane-miles/year)

The total lane-miles of highway is the sum to the three levels of roadway quality. Since this is a maintenance model, the number of lane-miles of highway to maintain will not increase or decrease, but will remain constant. Thus, this is a conserve system and the total number of lane-miles initially will be the same total number of lane miles at any time. The DYNAMO equation for the Highway Total is as follows:

A HWYT.K=PSH.K+PDFH.K+PDTH.K

HWYT - Highway Total (lane-miles)

PSH - Physically Sufficient Highway (lane-miles)

PDFH - Physically Deficient Highway (lane-miles)

PDTH - Physically Deteriorated Highway (lane-miles)

The highway aging rate is directly proportional to the physically sufficient highway and inversely proportional to the highway aging time. The highway 


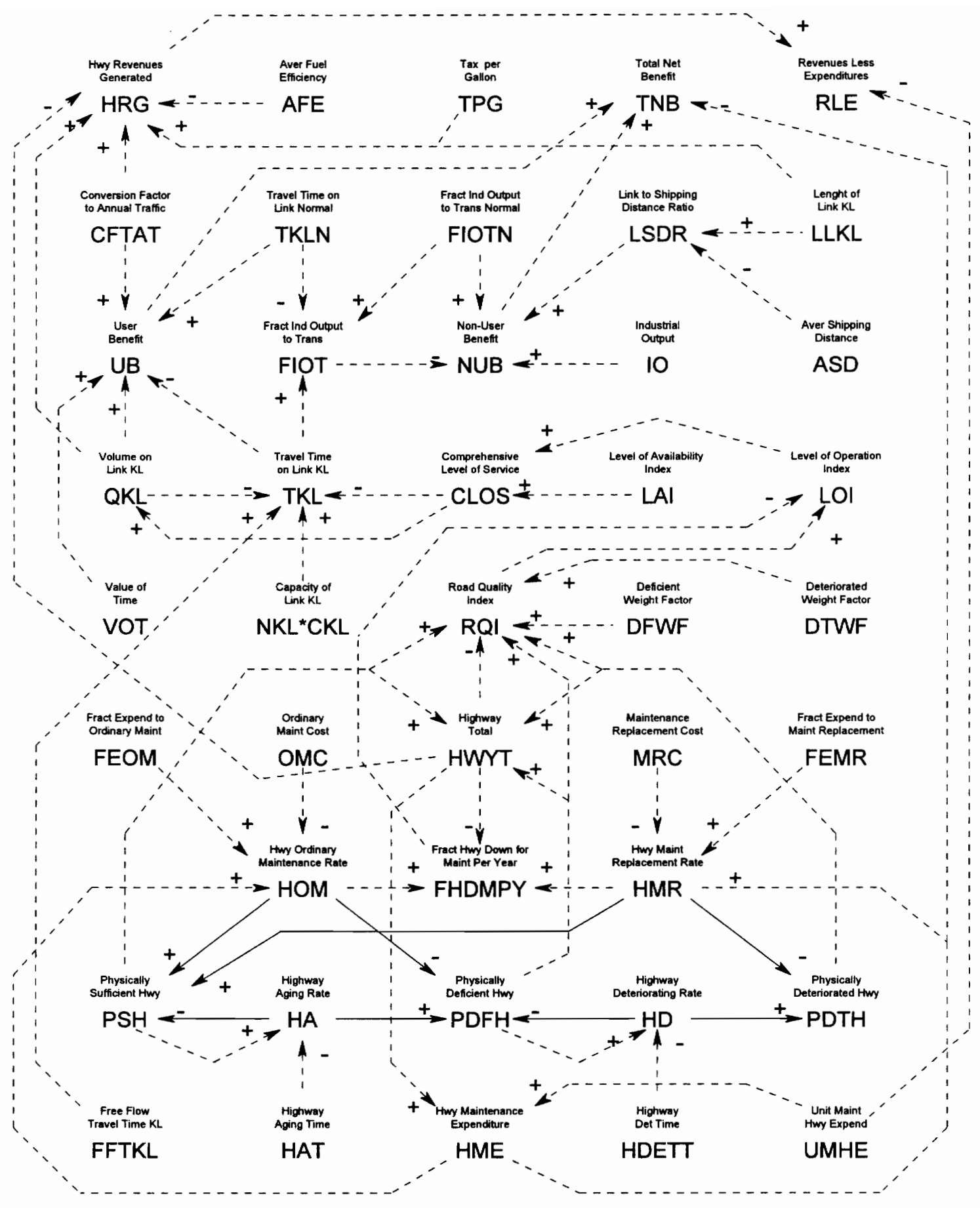

Figure 5.1: Causal Diagram for Highway Maintenance Model 
deteriorating rate is also directly proportional to the physically deficient highway and inversely proportionally to the highway deterioration time. This means that the number of lane-miles of roadway that will age is dependent on both the number of lane-miles at a particular level and the aging or deteriorating time. As the physically sufficient highway increases, the highway aging rate increases, that is, more lane-miles will age. As the highway aging time increases, the highway aging rate decreases. The same is true for the highway deteriorating rate. The DYNAMO equations for the Highway Aging and the Highway Deteriorating rates are as follows:
R HA. $\mathrm{KL}=\mathrm{PSH} . \mathrm{K} / \mathrm{HAT}$
C $\mathrm{HAT}=5$
R HD.KL $=$ PDFH.K/HDETT
C HDETT $=10$
HA - Highway Aging (lane-miles/year)
PSH - Physically Sufficient Highway (lane-miles)
HAT - Highway Aging Time (years)
HD - Highway Deteriorating Rate (lane-miles/year)
PDFH - Physically Deficient Highway (lane-miles)
HDETT - Highway Deteriorating Time (years)

The number of lane-miles of pavement that can be maintained each year is dependent on the maintenance rate. For ordinary maintenance, the highway ordinary maintenance rate varies directly with the highway maintenance expenditure and the fraction of expenditure to ordinary maintenance. The highway ordinary maintenance rate is inversely proportional to the ordinary maintenance cost. As the highway ordinary maintenance cost increases, the number of lane-miles that can be maintained will decrease. As the highway maintenance expenditure increases, the number of lanemiles that can be maintained increases. Similarly, as the fraction expended on ordinary 
maintenance increases, the highway ordinary maintenance rate increases. The DYNAMO equations for the Highway Ordinary Maintenance rate are as follows:

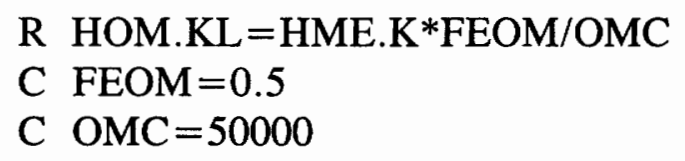

HOM - Highway Ordinary Maintenance (lane-miles/year)

HME - Highway Maintenance Expenditure (\$/year)

FEOM - Fraction Expenditure to Ordinary Maintenance (dimensionless)

OMC - Ordinary Maintenance Cost (\$/lane-mile)

For maintenance replacement, the highway maintenance replacement rate varies directly with the highway maintenance expenditure and the fraction of expenditure to maintenance replacement. The highway maintenance replacement rate is inversely proportional to the maintenance replacement cost. As the highway maintenance replacement cost increases, the number of lane-miles that can be maintained will decrease. As the highway maintenance expenditure increases, the number of lane-miles that can be maintained increases. Similarly, as the fraction expended on maintenance replacement increases, the highway maintenance replacement rate increases. The fraction expended on maintenance replacement is directly proportional to the fraction expended on ordinary maintenance. As the fraction expended on ordinary maintenance increases, the fraction expended on maintenance replacement decreases. The DYNAMO equations for the Highway Maintenance Replacement rate are as follows:

R HMR.KL $=$ HME.K*FEMR.K/MRC

A FEMR.K=1-FEOM

C $\mathrm{MRC}=200000$

HMR - Highway Maintenance Replacement (lane-miles/year)

HME - Highway Maintenance Expenditure (\$/year)

FEMR - Fraction Expenditure to Maintenance Replacement (dimensionless) 
MRC - Maintenance Replacement Cost (\$/lane-mile)

FEOM - Fraction Expenditure to Ordinary Maintenance (dimensionless)

The highway maintenance expenditure is directly related to the unit highway maintenance expenditure and the number of lane-miles of roadway. As the unit maintenance expenditure increases, the highway maintenance expenditure increases. As the number of lane-miles increases, the highway maintenance expenditure also increases. The unit maintenance highway expenditure is a decision variable that is controlled by the decision makers. The DYNAMO equations for the Highway Maintenance Expenditure are as follows:

A HME.K=UMHE*HWYT.K

C $\mathrm{UMHE}=($ Values varied from $\$ 2,000$ to $\$ 17,000$ during simulation)

HME - Highway Maintenance Expenditure (\$/year)

UMHE - Unit Maintenance Highway Expenditure (\$/year/lane-mile)

HWYT - Highway Total (lane-miles)

The fraction of highway down for maintenance each year, FHDMPY, is dependent on the highway ordinary maintenance rate, the highway maintenance replacement rate, and the total number of lane-miles of highway. As the ordinary replacement rate and/or the maintenance replacement rate increases, the fraction of highway down for maintenance increases. As the total number of lane-miles of highway increases, the fraction of highway down for maintenance per year decreases. The DYNAMO equation for the Fraction of Highway Down for Maintenance per Year is as follows:

A FHDMPY.K=(HOM.KL+HMR.KL)/HWYT.K

FHDMPY - Fraction Highway Down for Maintenance per Year (1/year)

HOM - Highway Ordinary Maintenance Rate (lane-miles/year)

HMR - Highway Maintenance Replacement Rate (lane-miles/year) 
HWYT - Total Highway (lane-miles)

The Road Quality Index, RQI, is a measure of the overall physical condition of the highway system. It is dependent on the states of the highway, physically sufficient, physically deficient, and physically deteriorated. The roadway states are weighted by a deficient weight factor and a deteriorated weight factor. As the level of physically deficient highway or physically deteriorated highway increases, the Road Quality Index decreases. The DYNAMO equations for the Road Quality Index are as follows:
A RQI.K=(PSH.K+DFWF*PDFH.K+DTWF*PDTH.K)/HWYT.K
C DFWF $=0.5$
C DTWF $=0$

RQI - Road Quality Index (dimensionless)

PSH - Physically Sufficient Highway (lane-miles)

DFWF - Deficient Weighting Factor (dimensionless)

PDFH - Physically Deficient Highway (lane-miles)

DTWF - Deteriorated Weighting Factor (dimensionless)

PDTH - Physically Deteriorated Highway (lane-miles)

HWYT - Total Highway (lane-miles)

The highway Level of Operation is defined by the Road Quality Index and the fraction of highway down for maintenance per year. As the Road Quality Index increases, the Level of Operation increases. As the fraction of highway down for maintenance per year increases, the Level of Operation decreases. The DYNAMO equations for the Level of Operation are as follows:
A LOI.K=(1-FHDMPY.K)*RQI.K
LOI - Level of Operation Index (dimensionless)
FHDMPY - Fraction Highway Down for Maintenance per Year (1/year)
RQI - Road Quality Index (dimensionless) 
For the maintenance model, the Level of Availability is considered to be a constant, so the impact of maintenance alone can be considered. With both the Level of Operation and Level of Availability defined, the Comprehensive Level of Service is then available. As the Level of Operation increases, the Comprehensive Level of Service increases. Similarly, as the Level of Availability increases, the Comprehensive Level of Service increases. The table function allows a non-linear mapping of the product of the LOI and the LAI to a Comprehensive Level of Service Factor to be used in subsequent model equations. The DYNAMO equations for the Comprehensive Level of Service are as follows:

A CLOS.K=LAI.K*LOI.K

A CLSF.K $=$ TABLE(CLSFT,CLOS.K,0,1,0.1)

T CLSFT $=0 / 0.63 / 0.72 / 0.78 / 0.83 / 0.87 / 0.90 / 0.93 / 0.96 / 0.98 / 1.00$

CLOS - Comprehensive Level of Service (dimensionless)

CLSF - Comprehensive Level of Service Factor (dimensionless)

CLSFT - Table Values for Comprehensive LOS Factor

LOI - Level of Operation Index (dimensionless)

LAI - Level of Availability Index (dimensionless)

Travel time on a road system is dependent on the Comprehensive Level of Service, the capacity of the highway, the free flow travel time and the volume of traffic initially on a link of highway. The travel time formula incorporates a queuing mechanism into the speed-flow relationship because delays arise from faster vehicles catching up with slower vehicles and being required to change lanes to pass or wait until a passing lane is clear. In the case of a single lane or a congested condition, the passing may not be available. A queuing mechanism is at work and has been introduced into the traffic flow equation in the form of the following equation (Drew, 1993): 


$$
\begin{aligned}
& \mathrm{T}=\mathrm{T}_{\mathrm{f}} * \frac{1-(1-\mathrm{j}) * \rho}{1-\rho} \\
& \text { Where: } \mathrm{T} \quad=\text { travel time (minutes) } \\
& \mathrm{T}_{\mathrm{f}}=\text { free flow travel time (minutes) } \\
& 1-\mathrm{j}=\text { Level of Service factor (dimensionless) } \\
& \rho \quad=\mathrm{q} / \mathrm{Q}=\text { volume on link / capacity of link (dimensionless) } \\
& \mathrm{Q} \quad=\mathrm{n} * \mathrm{c} \text { (vehicles/hour) } \\
& \mathrm{n} \quad=\text { number of lanes } \\
& \mathrm{c} \quad=\text { capacity of single lane (vehicles/hour) }
\end{aligned}
$$

The DYNAMO equations for the Travel Time are as follows:
A TKL.K $=$ FFTKL ${ }^{*}\left(1-\left(\mathrm{CLSF} . \mathrm{K}^{*} \mathrm{QKL} \cdot \mathrm{K}\right) /\left(\mathrm{NKL}{ }^{*} \mathrm{CKL}\right)\right) /(1-$ $\left.\mathrm{QKL} . \mathrm{K} /\left(\mathrm{NKL}{ }^{*} \mathrm{CKL}\right)\right)$
C FFTKL $=1$
C $\mathrm{NKL}=2$
C $\mathrm{CKL}=2400$

TKL - Travel Time on Link KL (minutes/mile)

FFTKL - Free Flow Travel Time from K to L (minutes/mile)

CLSF - Comprehensive Level of Service Factor

NKL - Number of Lanes from $K$ to $L$ (lanes)

CKL - Lane Capacity on Link K to L (vehicles/hour)

QKL - Volume on Link from K to L (vehicles/hour)

The volume of traffic on a link of highway, $\mathrm{KL}$, will vary depending on the Comprehensive Level of Service Factor at any time and the initial Comprehensive Level of Service Factor. As the Comprehensive Level of Service Factor decreases from the initial, the volume of traffic decreases. The DYNAMO equations for the Volume of Traffic are as follows:
A $\mathrm{QKL} \cdot \mathrm{K}=\mathrm{QKLN} *(\mathrm{CLSF} \cdot \mathrm{K} / \mathrm{CLSFN})$
C $\mathrm{QKLN}=2500$
QKL - Volume on Link from $\mathrm{K}$ to $\mathrm{L}$ (vehicles/hour)
QKLN - Volume on Link from K to L Normal (vehicles/hour) 


\section{CLSF - Value of Comprehensive LOS Factor (dimensionless) \\ CLSFN - Initial Comprehensive LOS Factor (dimensionless)}

The highway revenues generated on a per-mile basis are dependent on the volume of traffic on the highways, the length of link, the tax per gallon on fuel, the average fuel efficiency of the vehicles, and the total miles of highway in the system. As the volume of traffic increases, the revenues generated will also increase. As the length of travel increases, the revenues generated will increase. As the tax per gallon charged the motoring public increases, the revenues generated will again increase. However, as the average fuel efficiency of the vehicles increases, the revenues generated will decrease. The highway revenues generated on a per mile of highway system will decrease as the number of miles of road increases. The DYNAMO equations for the Highway Revenues Generated are as follows:
A HRG.K $=$ QKL.K*CFTAT*LLKL*TPG/(AFE*HWYT.K)
C $\mathrm{AFE}=20$
C $\quad$ TPG $=0.3$

HRG - Highway Revenues Generated (\$/year/lane-mile)

QKL - Volume on Link from K to L (vehicles/hour)

CFTAT - Conversion Factor to 2-way Annual Traffic (hours/year)

LLKL - Length of Link K to L (miles)

TPG - Tax per Gallon (\$/gallon)

AFE - Average Fuel Efficiency (miles/gallon)

HWYT - Total Highway (lane-miles)

Revenues less expenditures is a measure of effectiveness that can be utilized to determine effectiveness of the maintenance effort. Since the Comprehensive Level of Service directly affects the volume of traffic on the highway system, and the maintenance expenditures affect the Comprehensive Level of Service, this variable, i.e., RLE, would give an indication of the effect of maintenance or deferring of the 
maintenance required. The revenues less expenditures is dependent on the highway revenues generated and the unit maintenance highway expenditures. As the revenues increase, the revenues less expenditures increase. As the unit maintenance highway expenditures increase, the revenues less expenditures decrease. The DYNAMO equations for the Revenues Less Expenditures are as follows:

A RLE.K=HRG.K-UMHE

RLE - Revenues Less Expenditures (\$/year/lane-mile)

HRG - Highway Revenues Generated (\$/year/lane-mile)

UMHE - Unit Maintenance Highway Expenditure (\$/year/lane-mile)

\section{Development of a Construction Level of Availability Simulation Model}

The system dynamics model for the maintenance simulation was constructed with the assumption that the Level of Availability due to new construction, highway improvements or upgrading was constant. This however is not generally the case. As need requires or funding permits, new roads are constructed or existing roads improved to allow better traffic flow.

The road system is considered to be in one of three traffic volume states, an uncongested highway, a partially congested highway, or a fully congested highway. The highway system will grow more congested over time as the population increases, businesses move or new businesses are added to an area and uncongested highways will become partially congested highways. Similarly, partially congested highways will become fully congested highways. Construction efforts, either new construction, improvements, or upgrading will increase the ability of the system to carry more traffic. Highway upgrading would be considered increasing lane widths or reducing road gradients. Highway improvement would include improvement on highway alignments or improved construction standards that would allow smoother and faster 
traffic-flow rates. Highway expansion would include new roads or additional lanes in congested areas that would increase the capacity of the system. The causal diagram for this section is shown in Figure 5.2. The DYNAMO equations for the three highway levels are as follows:

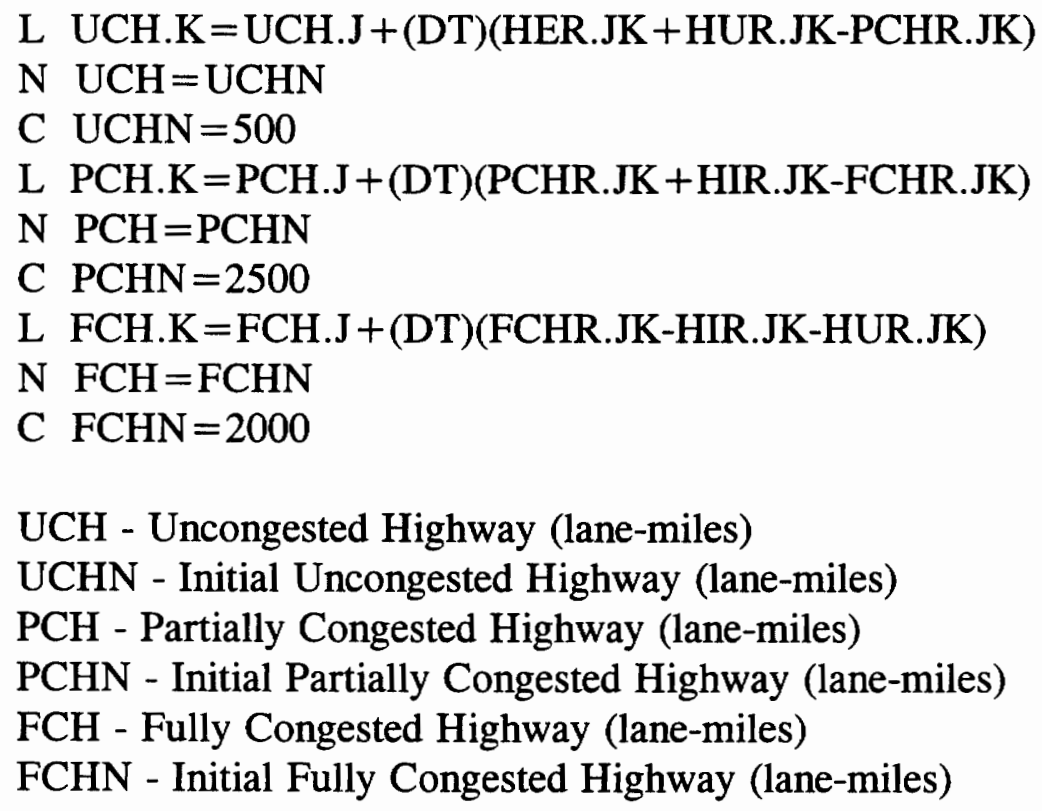

The total lane-miles of highway is the sum to the three levels of congested roadway. Since this is a construction model, the number of lane-miles of highway will increase according the amount of roadway constructed each year. Thus, this is different from a conserve system as the total number of lane-miles will increase each year as new roads are constructed. The DYNAMO equations for the Highway Total are as follows:
A HWYT.K $=$ UCH.K + PCH.K + FCH.K
A $\mathrm{HWYTN}=\mathrm{UCHN}+\mathrm{PCHN}+\mathrm{FCHN}$
HWYT - Highway Total (lane-miles)
UCH - Uncongested Highway (lane-miles)
PCH - Partially Congested Highway (lane-miles)
FCH - Fully Congested Highway (lane-miles) 


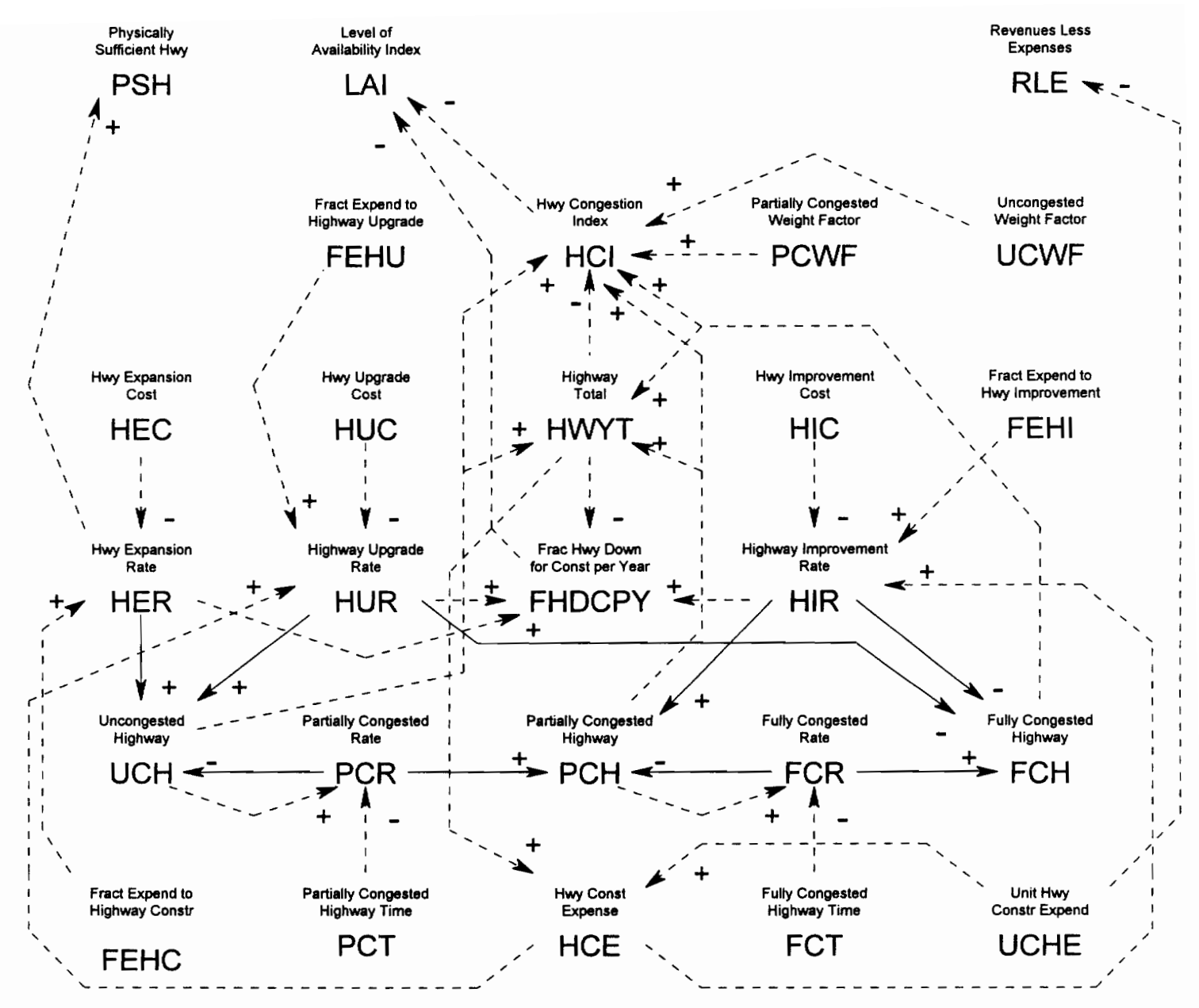

Figure 5.2: Causal Diagram for Highway Construction Model

HWTYN - Initial Highway Total (lane-miles)

UCHN - Initial Uncongested Highway (lane-miles)

PCHN - Initial Partially Congested Highway (lane-miles)

FCHN - Initial Fully Congested Highway (lane-miles)

The highway congestion rates are based on the current rate of traffic increase in the United States. Traffic has grown at an approximate $3 \%$ rate each year for the past ten years (FHWA 1993). The uncongested highway will become partially congested at the partially congested rate. The partially congested highway will become fully congested at the fully congested rate. The congestion rates are directly proportional to 
the lane-miles of highway at a congestion level and inversely proportional to the congestion time. As the number of lane-miles of roadway increases, the congestion rate increases. As the congestion time increases, the congestion rate decreases. The DYNAMO equations for the congestion rates are as follows:
R PCHR.KL $=\mathrm{UCH} . \mathrm{K} / \mathrm{HPCT}$
C $\mathrm{HPCT}=5$
R FCHR.KL $=$ PCH.K/HFCT
C $\mathrm{HFCT}=10$
PCHR - Partially Congested Highway Rate (lane-miles/year)
UCH - Uncongested Highway (lane-miles)
HPCT - Highway Partial Congestion Time (years)
FCHR - Fully Congested Highway Rate (lane-miles/year)
PCH - Partially Congested Highway (lane-miles)
HFCT - Highway Fully Congested Time (years)

The highway construction expenditure is dependent on the unit construction highway expenditure and the total highway lane-miles. As the unit construction highway expenditure increases, the highway construction expenditure increases. As the total number of highway lane-miles increases, the highway expenditure also increases. The DYNAMO equations for the Highway Construction Expenditure are as follows:
A HCE.K $=$ UCHE*HWYT.K
C $\mathrm{UCHE}=$ (Values Varied from $\$ 2,000$ to $\$ 24,000$ during simulations)
HCE - Highway Construction Expenditure (\$/year)
UCHE - Unit Construction Highway Expenditure (\$/year/lane-mile) HWYT - Highway Total (lane-miles)

The highway expansion rate is dependent on the fraction of expenditure to highway construction, the amount of highway construction expenditure, and the highway expansion cost. As the fraction of expenditure to highway construction 
increases, the highway expansion rate increases. Similarly, as the highway construction expenditure increases, the highway expansion rate increases. However, as the highway expansion cost increases, the highway expansion rate will decrease. The DYNAMO equations for the Highway Expansion Rate are as follows:
R HER.KL $=$ HCE.. $*$ FEHE/HEC
C $\mathrm{FEHE}=0.3$
C $\mathrm{HEC}=2000000$

HER - Highway Expansion Rate (lane-miles/year)

HCE - Highway Construction Expenditure (\$/year)

FEHE - Fraction Expenditure to Highway Expansion (dimensionless)

HEC - Highway Expansion Cost (\$/lane-mile)

The highway upgrade rate is dependent on the fraction of expenditure to highway upgrade, the highway construction expenditure, and the highway upgrade cost. As upgrading is accomplished on the highways, fully congested lane-miles will move to uncongested lane-miles. As the highway construction expenditure increases, the highway upgrade rate will increase. As the fraction expenditure to highway upgrade increases, the highway upgrade rate will also increase. However, as the highway upgrade cost increases, the highway upgrade rate will decrease. The DYNAMO equations for the Highway Upgrade Rate are as follows:
R HUR.KL $=$ HCE.K $*$ FEHU/HUC
C HUC $=500000$
C $\mathrm{FEHU}=0.35$

HUR - Highway Upgrade Rate (lane-miles/year)

HCE - Highway Construction Expenditure (\$/year)

FEHU - Fraction Expenditures to Highway Upgrade (dimensionless)

HUC - Highway Upgrade Cost (\$/lane-mile) 
The highway improvement rate is the rate that fully congested highways are improved to a partially congested highway condition. The highway improvement rate is dependent on the fraction of expenditure to highway improvement, the highway construction expenditure, and the highway improvement rate. The fraction of expenditure to highway improvement will also depend on the fraction of expenditure to highway expansion and the fraction of expenditure to highway upgrade. As the fraction of expenditure in the two other areas increases, the fraction of expenditure to highway improvement will decrease. As the fraction expenditure to highway improvement increases, the highway improvement rate increases. Also, as the highway construction expenditure increases, the highway improvement rate will increase. As the highway improvement cost increases, however, the highway improvement rate will decrease. The DYNAMO equations for the Highway Improvement Rate are as follows:

\section{$\mathrm{R}$ HIR.KL $=$ HCE.K*FEHI.K/HIC \\ C $\mathrm{HIC}=250000$ \\ A FEHI.K=1-FEHE-FEHU}

HIR - Highway Improvement Rate (lane-miles/year)

HEC - Highway Construction Expenditure (\$/year)

FEHI - Fraction Expenditure to Highway Improvement (dimensionless)

HIC - Highway Improvement Cost (\$/lane-mile)

FEHE - Fraction Expenditures to Highway Expansion (dimensionless)

FEHU - Fraction Expenditures to Highway Upgrade (dimensionless)

The fraction of highway down for construction per year is dependent on the highway expansion rate, the highway upgrade rate, the highway improvement rate, and the total number of lane-miles of highway. As the expansion, improvement and/or the upgrade rate increases, the fraction of highway down for construction increases. As the total number of lane-miles of highway increases, the fraction of highway down for 
construction per year decreases. The DYNAMO equation for the Fraction of Highway Down for Construction per Year is as follows:

\section{A FHDCPY.K=(HUR.KL+HIR.KL+HER.KL)/HWYT.K}

FHDCPY - Fraction Highway Down for Construction per Year (dimensionless) HIR - Highway Improvement Rate (lane-miles/year)

HUR - Highway Upgrade Rate (lane-miles/year)

HER - Highway Expansion Rate (lane-miles/year)

HWYT - Highway Total (lane-miles)

The Highway Congestion Index, $\mathrm{HCI}$, is a measure of the overall functional condition of the highway system. It is dependent on the congestion states of the highway, uncongested, partially congested, and fully congested. The roadway states are weighted by a partially congested weight factor and an uncongested weight factor. As the level of uncongested highway or partially congested highway increases, the highway congestion index decreases. The DYNAMO equations for the Highway Congestion Index are as follows:
A $\mathrm{HCI} . \mathrm{K}=(\mathrm{UCH} . \mathrm{K} * \mathrm{UCWF}+\mathrm{PCH} . \mathrm{K} * \mathrm{PCWF}+\mathrm{FCH} . \mathrm{K}) / \mathrm{HWYT} . \mathrm{K}$
C $\mathrm{PCWF}=0.5$
C $\mathrm{UCWF}=0.5$

HCI - Highway Congestion Index (dimensionless)

UCH - Uncongested Highway (lane-miles)

UCWF - Uncongested Highway Weighting Factor (dimensionless)

PCH - Partially Congested Highway (lane-miles)

PCWF - Partially Congested Highway Weighting Factor (dimensionless)

FCH - Fully Congested Highway (lane-miles)

HWYT - Highway Total (lane-miles)

The Level of Availability is then dependent on the highway congestion index and the fraction of highway down for construction per year. As the highway congestion index increases, the Level of Availability decreases because of the increased 
congestion. As the fraction of highway down for construction, improvement or upgrade per year increases, the Level of Availability also decreases, because of the increased lane-miles barricaded for construction purposes. The DYNAMO equation for the Level of Availability is as follows:

\section{A $\mathrm{LAI} . \mathrm{K}=(1-\mathrm{HCl} . \mathrm{K}) *(1-\mathrm{FHDCPY} . \mathrm{K})$}

LAI - Level of Availability Index (dimensionless)

HCI - Highway Congestion Index (dimensionless)

FHDCPY - Fraction Highway Down for Construction per Year (dimensionless)

\section{Development of Comprehensive Level of Service Simulation Model}

The Comprehensive Level of Service simulation model was then developed by integrating both the physical Level of Operation and the functional Level of Availability models. The changes required for the integration of the two models are described below.

The physically sufficient highway is increased by the addition of highway through the highway expansion rate. As highway lane-miles are increased, the physically sufficient highway increases. The DYNAMO equation for the Physically Sufficient Highway was changed as follows to reflect the addition of the highway expansion rate:

L PSH.K $=$ PSH.J +(DT) $($ HOM.JK + HMR.JK + HER.JK-HA.JK)

PSH - Physically Sufficient Highway (lane-miles)

HOM - Highway Ordinary Maintenance Rate (lane-miles/year)

HMR - Highway Maintenance Replacement Rate (lane-miles/year)

HER - Highway Expansion Rate (lane-miles/year)

HA - Highway Aging Rate (lane-miles/year)

The total highway lane-miles will be taken from the Level of Availability model since the total number of lane-miles will increase as new lane-miles are added each 
year. As the highway total is increased, additional lane-miles of highway will require maintenance. The revised DYNAMO equation is as follows:
A HWYT.K=UCH.K+PCH.K+FCH.K
HWYT - Highway Total (lane-miles)
UCH - Uncongested Highway (lane-miles)
PCH - Partially Congested Highway (lane-miles)
FCH - Fully Congested Highway (lane-miles)

The revenues less expenditures for the complete system will depend on both the unit maintenance highway expenditures and the unit construction highway expenditures. As the expenditures increase, the revenues less expenditures will decrease from the total highway revenues generated. The revised DYNAMO equation is as follows:
A RLE.K=HRG.K-UMHE-UCHE
RLE - Revenues Less Expenditures (\$/year/lane-mile)
HRG - Highway Revenues Generated (\$/year/lane-mile)
UMHE - Unit Maintenance Highway Expenditures (\$/year/lane-mile)
UCHE - Unit Construction Highway Expenditures (\$/year/lane-mile)

\section{DYNAMO Simulation of Comprehensive Level of Service Model}

With the Comprehensive Level of Service model completed (Appendix C), combinations of the unit maintenance, UMHE, and unit construction, UCHE, were simulated to determine the effect on the measure of effectiveness, Revenues Less Expenditures. With highway expansion being allowed, and the possibility of decision makers being able to determine the amount of expenditures for construction and maintenance, the measure of effectiveness will provide an indication of the combined affect of maintenance and construction on the Comprehensive Level of Service for the highway system. 


\section{Model Parameters and Initial Conditions}

The parameters shown in Tables 5.1 through 5.3 were utilized for the model simulation to visualize the impact of maintenance and construction on the Revenues Less Expenditures. The model values for the interstate and population were taken to simulate a hypothetical State of Virginia region with approximate 100 miles of interstate (400 lane-miles) and a population of 200,000 people, such as the Blacksburg, Christiansburg area of Montgomergy County to Roanoke in Roanoke County.

Table 5.1: Initial Construction Variable Values for Comprehensive Level of Service Model

\begin{tabular}{|c|c|c|}
\hline \multicolumn{3}{|c|}{ Construction, Improvement, Upgrading } \\
\hline Variable & Variable Description & Parameter Value \\
\hline HIC & Highway Improvement Cost & $\$ 250,000 /$ lane-mile \\
\hline HUC & Highway Upgrade Cost & $\$ 500,000 /$ lane-mile \\
\hline FEHI & $\begin{array}{l}\text { Fraction Expenditure for } \\
\text { Highway Improvement }\end{array}$ & 0.35 \\
\hline FEHU & $\begin{array}{l}\text { Fraction Expenditure for } \\
\text { Highway Upgrade }\end{array}$ & 0.35 \\
\hline HPCT & $\begin{array}{c}\text { Highway Partially } \\
\text { Congested Time }\end{array}$ & 5 years \\
\hline HFCT & $\begin{array}{l}\text { Highway Fully } \\
\text { Congested Time }\end{array}$ & 10 years \\
\hline UCWF & $\begin{array}{c}\text { Uncongested } \\
\text { Weighting Factor }\end{array}$ & 0.5 \\
\hline PCWF & $\begin{array}{l}\text { Partially Congested } \\
\text { Weighting Factor }\end{array}$ & 0.5 \\
\hline HEC & Highway Expansion Cost & $\$ 2,000,000$ lane-mile \\
\hline FEHE & $\begin{array}{c}\text { Fraction Expenditure for } \\
\text { Highway Expansion }\end{array}$ & 0.3 \\
\hline UCHN & Uncongested Highway Initial & 50 lane-miles \\
\hline PCHN & $\begin{array}{l}\text { Partially Congested } \\
\text { Highway Initial }\end{array}$ & 250 lane-miles \\
\hline FCHN & $\begin{array}{l}\text { Fully Congested } \\
\text { Highway Initial }\end{array}$ & 100 lane-miles \\
\hline
\end{tabular}


Table 5.2: Initial Maintenance Variable Values for Comprehensive Level of Service Model

\begin{tabular}{|c|c|c|}
\hline \multicolumn{3}{|c|}{ Maintenance } \\
\hline \hline Variable & Variable Description & Parameter Value \\
\hline OMC & Ordinary Maintenance Cost & $\$ 50,000 /$ lane-mile \\
\hline MRC & Maintenance Replacement Cost & $\$ 200,000 /$ lane-mile \\
\hline FEOM & $\begin{array}{c}\text { Fraction Expenditure } \\
\text { for Ordinary Maintenance }\end{array}$ & 0.5 \\
\hline FEMR & $\begin{array}{c}\text { Fraction Expenditure } \\
\text { for Maintenance Replacement }\end{array}$ & 0.5 \\
\hline HAT & Highway Aging Time & 5 years \\
\hline HDETT & Highway Deteriorating Time & 10 years \\
\hline DFWF & Deficient Weighting Factor & 0.5 \\
\hline DTWF & Deteriorating Weighting Factor & 0 \\
\hline PSHN & Physically Sufficient Highway Initial & 200 lane-miles \\
\hline PDFHN & Physically Deficient Highway Initial & 100 lane-miles \\
\hline PDTHN & $\begin{array}{c}\text { Physically Deteriorated } \\
\text { Highway Initial }\end{array}$ & 100 lane-miles \\
\hline
\end{tabular}

Table 5.3: Initial Model Parameters for Comprehensive Level of Service Model

\begin{tabular}{|c|c|c|}
\hline \multicolumn{3}{|c|}{ Model Parameters } \\
\hline \hline Variable & Variable Description & Initial Value \\
\hline QKLN & Traffic Volume & 2500 vehicles/hour \\
\hline TPG & Tax per Gallon & \$0.30 per gallon \\
\hline AFE & Average Fuel Efficiency & 20 miles per gallon \\
\hline NKL & Number of Lanes & 2 \\
\hline CKL & Capacity of Lanes & 2400 vehicles/hour \\
\hline CFTAT & $\begin{array}{c}\text { Conversion Factor } \\
\text { for Two-way Traffic }\end{array}$ & 4000 hours \\
\hline LLKL & Length of Link & 100 miles \\
\hline
\end{tabular}




\section{Simulation Results and Analysis}

The graphs in Figures 5.3, 5.4, and 5.5 were taken from the DYNAMO simulation at 10,15 , and 20 years. The peaking values of the measure of effectiveness, Revenues Less Expenditures, suggest that there is a point where maintenance and construction are complementary and that it is possible to overspend and/or underspend construction and maintenance dollars with the effect of not providing an optimum volume of traffic. The Revenues Less Expenditures equation in the model is a function of the volume of traffic which is a function of the

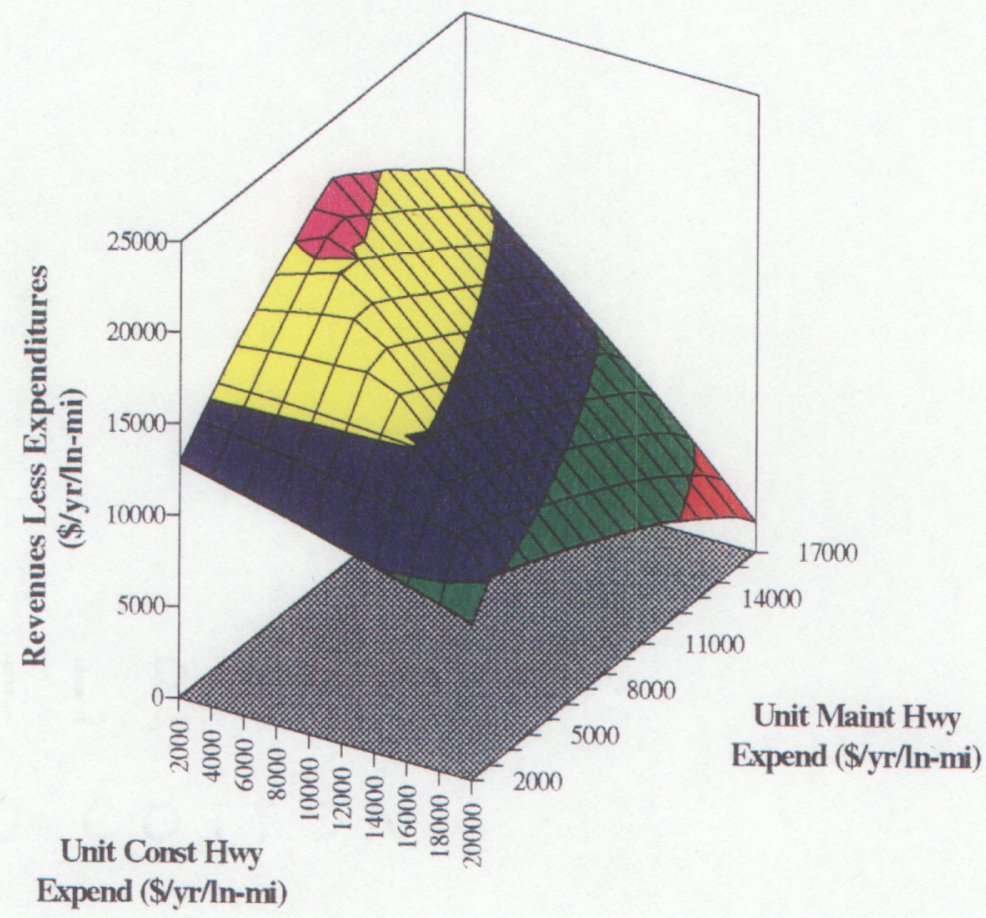

Figure 5.3: Revenues Less Expenditures vs UMHE and UCHE Simulated over 10 Years 
Comprehensive Level of Service. The effect of reducing the volume of traffic on the highway is not providing additional revenues for maintenance and/or construction purposes and reducing the Comprehensive Level of Service. Increasing the expenditures can increase the CLOS, but may not be as cost effective, meaning more expenditures for a small increase in traffic volume. The movement from the optimum traffic could be from either increasing deterioration or increasing congestion, both of which will increase user costs by increasing travel time and/or driver discomfort and inconvenience.

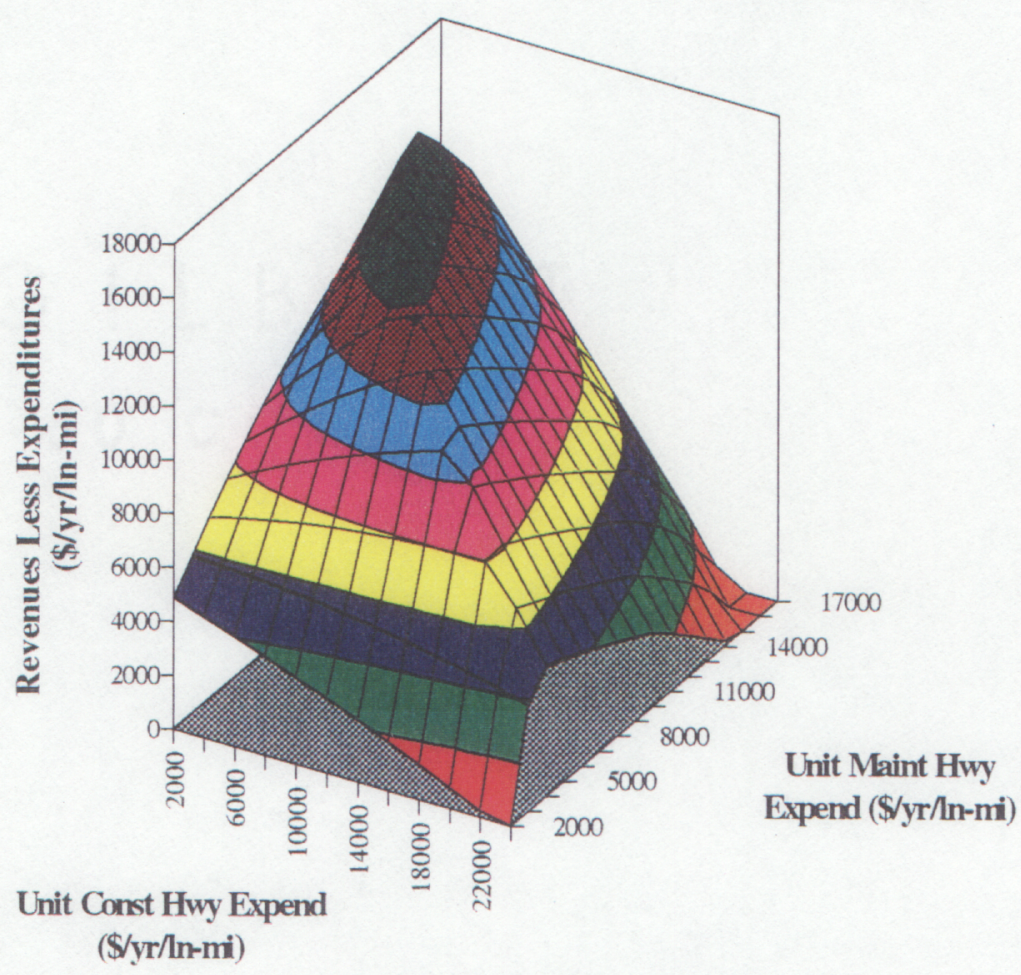

Figure 5.4: Revenues Less Expenditures vs UMHE and UCHE Simulated over 15 Years 


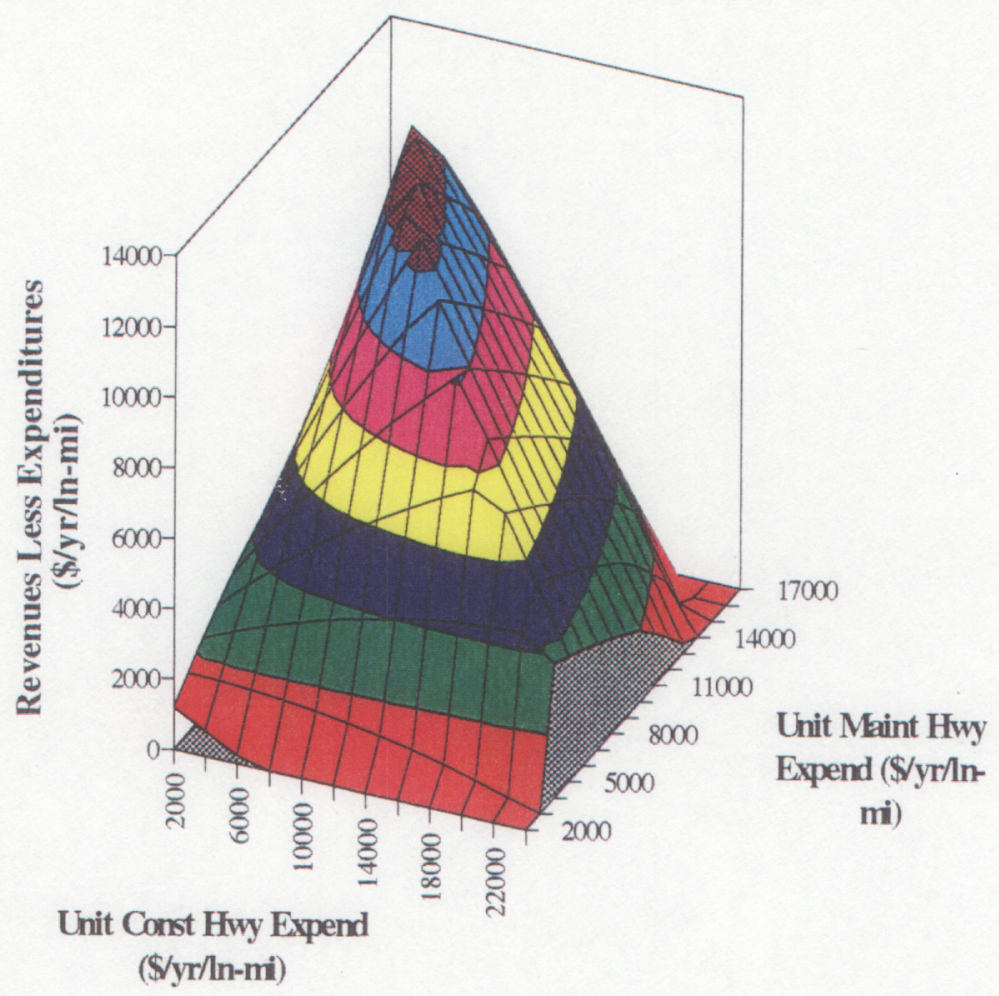

Figure 5.5: Revenues Less Expenditures vs UMHE and UCHE Simulated over 20 Years

\section{Summary}

This chapter has developed the theory and relationships concerning the variables affecting the decision to maintain and/or to improve, upgrade or expand a highway system. System dynamics was used as the modeling tool to build and test these relationships. This technique allowed iteratively building and testing the relationships until the model was developed. With the variables and relationships amplified, the basis for a Management Information System has been established for collecting data and calibrating the model. Building and specifying the relationships can also bring to 
the forefront new ideas for discussion, criticisms, and revision for new approaches to the continuing problem of how to effectively and efficiently utilize the scarce financial resources available. 


\section{CHAPTER 6: EQUILIBRIUM ANALYSIS OF SYSTEM DYNAMICS MODELS}

\section{Introduction}

This chapter describes the analytical analysis of the system dynamics models developed in Chapter 5. The equilibirium analysis provides insight into the model behavior and simulation for the impact of deferred maintenance and obsolescence of a highway system.

\section{Equilibrium Analysis of Level of Operation Model}

With the maintenance model causal diagram and model equation available, an equilibrium analysis was accomplished to determine the model behavior and suitability for policy analysis. For equilibrium analysis, the rate of change for a level variable must be zero, that is, no change in rates would take place over time in an equilibrium or steady state. The steady state also allows mathematical analysis of the model for quantification of the measures of effectiveness based on the decision variables. For the maintenance model, the unit maintenance highway expenditure, UMHE, is a decision variable in that the amount to be expended is under the direct control of the decision maker. The measure of effectiveness, MOE, is the revenues less expenditures, RLE, because the revenues generated from the motoring public through the maintenance and construction of highway lane-miles are used to maintain the road surface and/or construct or improve the highway system. As more traffic is utilizing the highways, more revenues will be generated. The ability of the highway to accommodate more vehicles is directly related to the Comprehensive Level of Service which is affected by the Level of Availability and the Level of Operation. For the maintenance model, the 
Level of Availability is kept constant so the impact on the revenues less expenditures is totally from the maintenance of the road surface.

The equilibrium analysis is made with the rate of change over time being zero. For example, from the maintenance model level equation for physically deteriorated highway, PDTH:

PDTH.K = PDTH.J +(DT)(HD.JK - HMR.JK)

for PDTH.K to equal PDTH.J, HD.JK must equal HMR.JK, or the rate of highway deteriorating, HD, must equal the rate of highway maintenance replacement, HMR, at equilibrium or:

$$
\mathrm{HD}_{\mathrm{e}}=\mathrm{HMR}_{\mathrm{e}} \text {. }
$$

Substituting into both sides from the maintenance model equations in Appendix A:

$$
\frac{\text { PDFH }_{e}}{\text { HDETT }}=\frac{\text { HME }^{*} \text { FEMR }}{\text { MRC }}
$$

Solving for $\mathrm{PDFH}_{\mathrm{e}}$ :

$$
\mathrm{PDFH}_{\mathrm{e}}=\frac{\text { HME }^{*} \text { FEMR }^{*} \text { HDETT }}{\text { MRC }} \text { (lane-miles). }
$$

From the model level equation for $\mathrm{PDFH}_{\mathrm{e}}$ :

$$
\mathrm{HA}_{\mathrm{e}}=\mathrm{HD}_{\mathrm{e}}+\mathrm{HOM}_{\mathrm{e}} .
$$

Substituting into both sides from the maintenance model equations in Appendix A and solving for $\mathrm{PSH}_{\mathrm{e}}$ :

$$
\mathrm{PSH}_{\mathrm{e}}=\mathrm{HME}^{*} \mathrm{HAT}^{*}\left(\frac{\text { FEMR }}{\mathrm{MRC}}+\frac{\text { FEOM }}{\mathrm{OMC}}\right) \text { (lane-miles). }
$$


The total number of lane-miles of highway will not change for the maintenance model as no expansion is considered. This is a conserve system which means that at any time, the total number of lane-miles will be the same as the initial number of lanemiles. At equilibrium:

$$
\begin{aligned}
& \mathrm{HWYT}=\mathrm{PSH}_{\mathrm{e}}+\mathrm{PDFH}_{\mathrm{e}}+\mathrm{PDTH}_{\mathrm{e}} \text { or } \\
& \mathrm{PDTH}_{\mathrm{e}}=\mathrm{HWYT}-\mathrm{PSH}_{\mathrm{e}}-\mathrm{PDFH}_{\mathrm{e}} .
\end{aligned}
$$

Substituting Equations 6.1 and 6.2 into Equation 6.3:

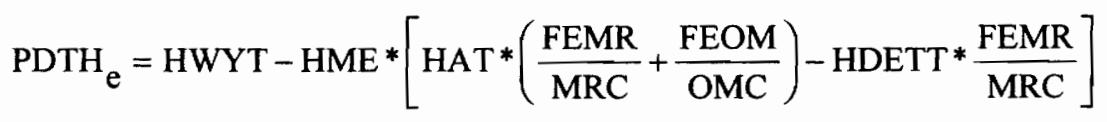

By defining a unit maintenance highway expenditure as the highway maintenance expenditure divided by the total highway lane-miles or:

$$
\mathrm{UMHE}=\frac{\mathrm{HME}}{\mathrm{HWYT}}(\$ / \text { lane-mile }),
$$

then each of the highway levels can be defined in terms of the unit maintenance highway expenditure.

From Equation 6.1, dividing both sides by HWYT:

$$
\frac{\text { PDFH }_{\mathrm{e}}}{\text { HWYT }}=\frac{\text { HME }}{\text { HWYT }} * \frac{\text { FEMR } * \text { HDETT }_{\text {MRC }}}{\text { M }}
$$

Letting $\mathrm{PDFH}_{\mathrm{e}}=\mathrm{HWYT}$ and solving for UMHE, UMHE is the expenditure required on a per year basis for all lane-miles to be upgraded to a physically sufficient highway state after the road has become completely deteriorated. Any unit maintenance highway expenditure less than the equilibrium solution of Equation 6.5 would result in pavement being in one of the three defined physical states, physically sufficient, physically deficient or physically deteriorated.

$$
\mathrm{UMHE}=\frac{\mathrm{MRC}}{\mathrm{FEMR} * \mathrm{HDETT}}(\$ / \text { lane-mile }) .
$$


Similarly for Equation 6.2, dividing both sides by HWYT:

$$
\frac{\mathrm{PSH}_{\mathrm{e}}}{\mathrm{HWYT}}=\frac{\mathrm{HME}_{\mathrm{HWYT}}}{\mathrm{HWAT}} *\left(\frac{\mathrm{FEMR}}{\mathrm{MRC}}+\frac{\text { FEOM }}{\mathrm{OMC}}\right) \text {. }
$$

Letting $\mathrm{PSH}_{\mathrm{e}}=\mathrm{HWYT}$ and solving for UMHE, UMHE is the maximum maintenance expenditure rate for all lane-miles to be upgraded to the physically sufficient highway state from any initial state.

$$
\mathrm{UMHE}=\frac{\mathrm{MRC}^{*} \mathrm{OMC}}{\left(\mathrm{FEMR}^{*} \mathrm{OMC}+\mathrm{FEOM}^{*} \mathrm{MRC}\right) * \mathrm{HAT}}(\$ / \text { lane-mile }) .
$$

The road quality index at equilibrium can now be determined in terms of the unit maintenance highway expenditure.

$$
\mathrm{RQI}_{\mathrm{e}}=\frac{\mathrm{PSH}_{\mathrm{e}}+\mathrm{DFWF}^{*} \mathrm{PDFH}_{\mathrm{e}}+\mathrm{DTWF}^{*} \mathrm{PDTH}_{\mathrm{e}}}{\mathrm{HWYT}}
$$

Substituting Equations 6.1, 6.2, and 6.4 into $\mathrm{RQI}_{\mathrm{e}}$ yields:

$$
\mathrm{RQI}_{\mathrm{e}}=\frac{\mathrm{HME}}{\mathrm{HWYT}} *\left[\mathrm{HAT} *\left(\frac{\text { FEMR }}{\text { MRC }}+\frac{\text { FEOM }}{\text { OMC }}\right) *(1-\mathrm{DTWF})+\frac{\text { FEMR } * \text { HDETT }}{\text { MRC }} *(\text { DFWF }- \text { DTWF })\right]+\text { DTWF }
$$

To simplify, let the deteriorated weighting factor equal zero, or DTWF $=0$, then:

$$
\mathrm{RQI}_{\mathrm{e}}=\mathrm{UMHE}^{*}\left[\mathrm{HAT} *\left(\frac{\text { FEMR }}{\text { MRC }}+\frac{\text { FEOM }}{\text { OMC }}\right)+\frac{\text { FEMR }^{*} \text {HDETT}^{*} \text { DFWF }}{\text { MRC }}\right]
$$

Letting:

$$
\begin{aligned}
& \mathrm{C}_{1}=\frac{\text { FEMR }}{\mathrm{MRC}}+\frac{\text { FEOM }}{\mathrm{OMC}} \text { and } \\
& \mathrm{C}_{2}=\mathrm{HAT}^{*} \mathrm{C}_{1}+\frac{\text { FEMR }^{*} \mathrm{HDETT}^{*} \mathrm{DFWF}}{\mathrm{MRC}},
\end{aligned}
$$

then:

$$
\mathrm{RQI}_{\mathrm{e}}=\mathrm{UMHE}^{*} \mathrm{C}_{2}
$$

The Level of Operation at the steady state would be a measure of the maintenance level of the highway network. From the maintenance model developed: 


$$
\mathrm{LOI}_{\mathrm{e}}=(1-\mathrm{FHDMPY}) * \mathrm{RQI}_{\mathrm{e}}
$$

Substituting into this equation from Eq. 6.8. and the model equations in Appendix A:

$$
\mathrm{LOI}_{\mathrm{e}}=\left[1-\mathrm{UMHE}^{*}\left(\frac{\text { FEMR }}{\mathrm{MRC}}+\frac{\text { FEOM }}{\mathrm{OMC}}\right)\right] * \mathrm{UMHE}^{*} \mathrm{C}_{2}
$$

Simplifying using $C_{1}$ (Eq. 6.8) and $C_{2}$ (Eq. 6.9) as previously defined:

$$
\mathrm{LOI}_{\mathrm{e}}=\mathrm{UMHE}^{*} \mathrm{C}_{2}-\mathrm{UMHE}^{2} * \mathrm{C}_{1} * \mathrm{C}_{2}
$$

For the maintenance only model runs, the initial values in Table 6.1 were used for solution of the steady state equations. This allows graphing of the Level of Operation at equilibrium for varying unit maintenance expenditures with the initial values. Figure 6.1 indicates the model behavior for the Level of Operation.

Table 6.1: Initial Values for Level of Operation Index vs Unit Maintenance Highway Expenditure

\begin{tabular}{|c|c|c|}
\hline Variable Name & Variable Description & Initial Value \\
\hline \hline OMC & Ordinary Maintenance Cost & $\$ 50,000$ \\
\hline MRC & Maintenance Replacement Cost & $\$ 200,000$ \\
\hline FEOM & $\begin{array}{c}\text { Fraction Expenditure } \\
\text { for Ordinary Maintenance }\end{array}$ & 0.5 \\
\hline FEMR & $\begin{array}{c}\text { Fraction Expenditure } \\
\text { for Maintenance Replacement }\end{array}$ & 0.5 \\
\hline HAT & Highway Aging Time & 5 years \\
\hline HDETT & Highway Deteriorating Time & 10 years \\
\hline DFWF & $\begin{array}{c}\text { Deficient Highway } \\
\text { Weighting Factor }\end{array}$ & 0.5 \\
\hline DTWF & $\begin{array}{c}\text { Deteriorated Highway } \\
\text { Weighting Factor }\end{array}$ & 0 \\
\hline $\mathrm{C}_{1}$ & Equation 6.8 & 0.0000125 \\
\hline $\mathrm{C}_{2}$ & Equation 6.9 & 0.000075 \\
\hline
\end{tabular}




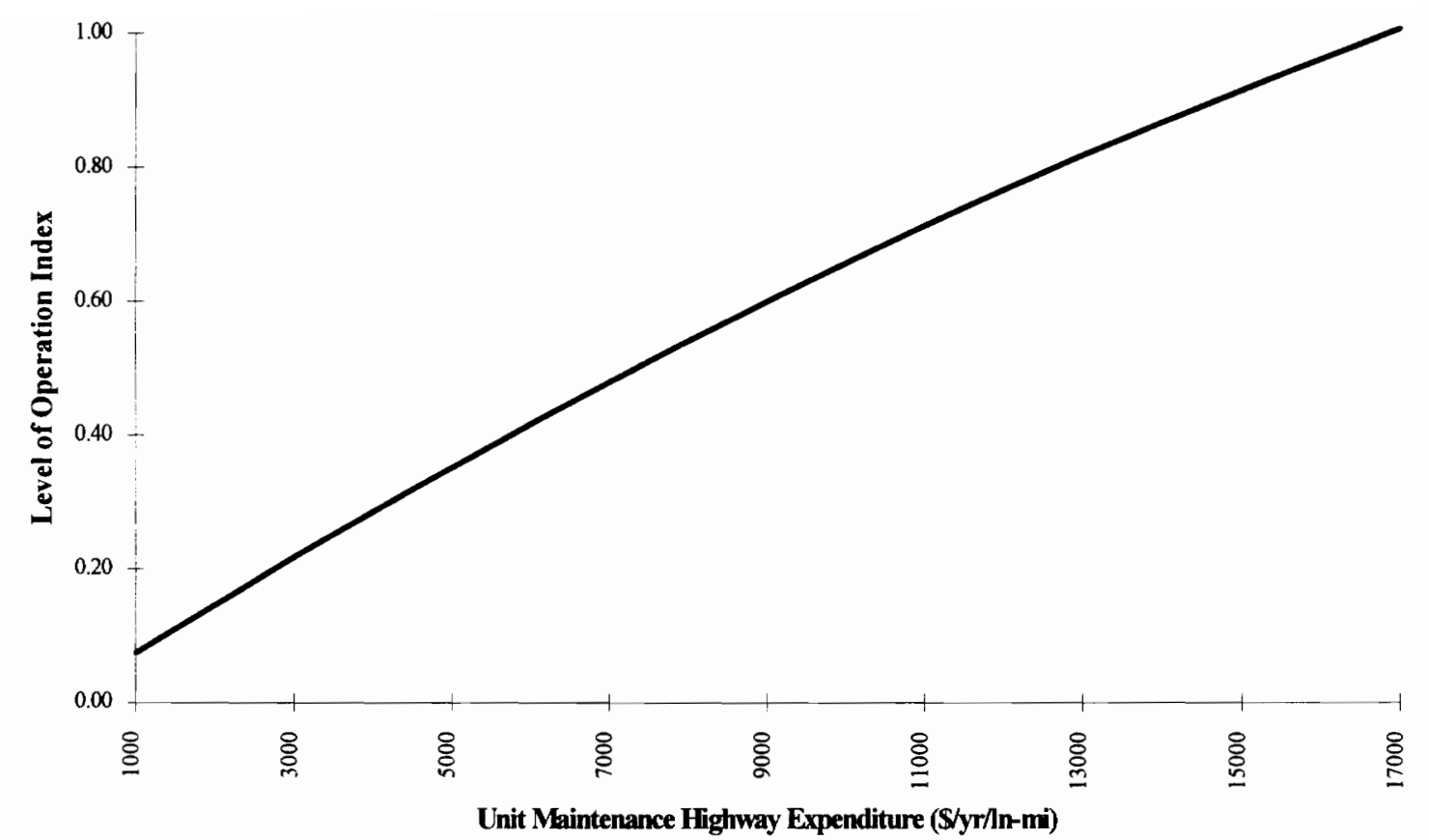

Figure 6.1: Level of Operation vs Unit Maintenance Highway Expenditure for Steady State Analysis

The measure of effectiveness for the maintenance model is the Revenues Less Expenditures, RLE. This is an indication of how well maintenance is providing a physically sufficient travel way for motorists as the key variable for the revenues generated is the traffic volume, QKL. From the maintenance model, the measure of effectiveness is RLE:

$$
\begin{aligned}
& \mathrm{RLE}_{\mathrm{e}}=\mathrm{HRG}_{\mathrm{e}}-\mathrm{UMHE} \\
& \mathrm{HRG}_{\mathrm{e}}=\frac{\mathrm{QKL}_{\mathrm{e}}{ }^{*} \mathrm{CFTAT}^{*} \mathrm{LLKL}^{*} \mathrm{TPG}}{\mathrm{AFE}^{*} \mathrm{HWYT}_{\mathrm{e}}}
\end{aligned}
$$

Substituting into this equation and letting

$$
\mathrm{C}_{3}=\frac{\mathrm{QKLN}^{*} \mathrm{CFTAT}^{*} \mathrm{LLKL}{ }^{*} \mathrm{TPG}}{\mathrm{AFE}{ }^{*} \mathrm{HWYT}},
$$


then:

$$
\mathrm{RLE}_{\mathrm{e}}=\mathrm{C}_{3} * \frac{\mathrm{CLOS}_{\mathrm{e}}}{\mathrm{CLOSN}}-\mathrm{UMHE}
$$

with:

$$
\mathrm{CLOS}_{\mathrm{e}}=\mathrm{LAI}^{*} \mathrm{LOI}_{\mathrm{e}} \text { and } \mathrm{CLOSN}=\mathrm{LAIN} * \mathrm{LOIN} .
$$

The "N" on the end of these variables indicates the initial value of the Level of Availability and Level of Operation as determined by the beginning physical state of the total highway lane-miles. Substituting LOI $_{\mathrm{e}}$ from Equation 6.12 with $\mathrm{LOIN}=\mathrm{RQIN}$ from the model equations in Appendix A into Equation 6.14 yeilds:

$$
\mathrm{RLE}_{\mathrm{e}}=\mathrm{C}_{3} *\left[\frac{\mathrm{LAI} *\left(\mathrm{UMHE}^{*} \mathrm{C}_{2}-\mathrm{UMHE}^{2} * \mathrm{C}_{1} * \mathrm{C}_{2}\right)}{\mathrm{LAIN} * \mathrm{RQIN}}\right]-\mathrm{UMHE}
$$

This also allows graphing at the equilibrium or steady state to envision the effect of increasing maintenance expenditure on the Revenues Less Expenditures, realizing that the main variable is the traffic since:

$$
\mathrm{QKL}_{\mathrm{e}}=\mathrm{QLKN}^{*} \frac{\mathrm{CLOS}_{\mathrm{e}}}{\mathrm{CLOSN}}
$$

As the Comprehensive Level of Service increases above the initial CLOS, the traffic volume increases. The additional initial parameters in Table 6.2 were utilized to graph RLE vs UMHE. 
Table 6.2: Initial Values for Revenues Less Expenditures vs Unit Maintenance Highway Expenditure

\begin{tabular}{|c|c|c|}
\hline Variables & Variable Descriptions & Initial Value \\
\hline \hline QKLN & Initial Traffic Volume & 2500 vehicles/hour \\
\hline CFTAT & $\begin{array}{c}\text { Conversion Factor for Two- } \\
\text { Way Annual Traffic }\end{array}$ & 4000 hours \\
\hline TPG & Tax per Gallon & $\$ 0.30$ \\
\hline AFE & Average Fuel Efficiency & 20 miles per gallon \\
\hline HWYT & Total Highway Miles & 400 lane-miles \\
\hline LLKL & Length of Link & 100 miles \\
\hline LAI & Level of Availability & 0.5 \\
\hline LAIN & Initial Level of Availability & 0.5 \\
\hline RQIN & Initial Road Quality Index & .625 \\
\hline C 3 & Equation 6.12 & 37500 \\
\hline
\end{tabular}

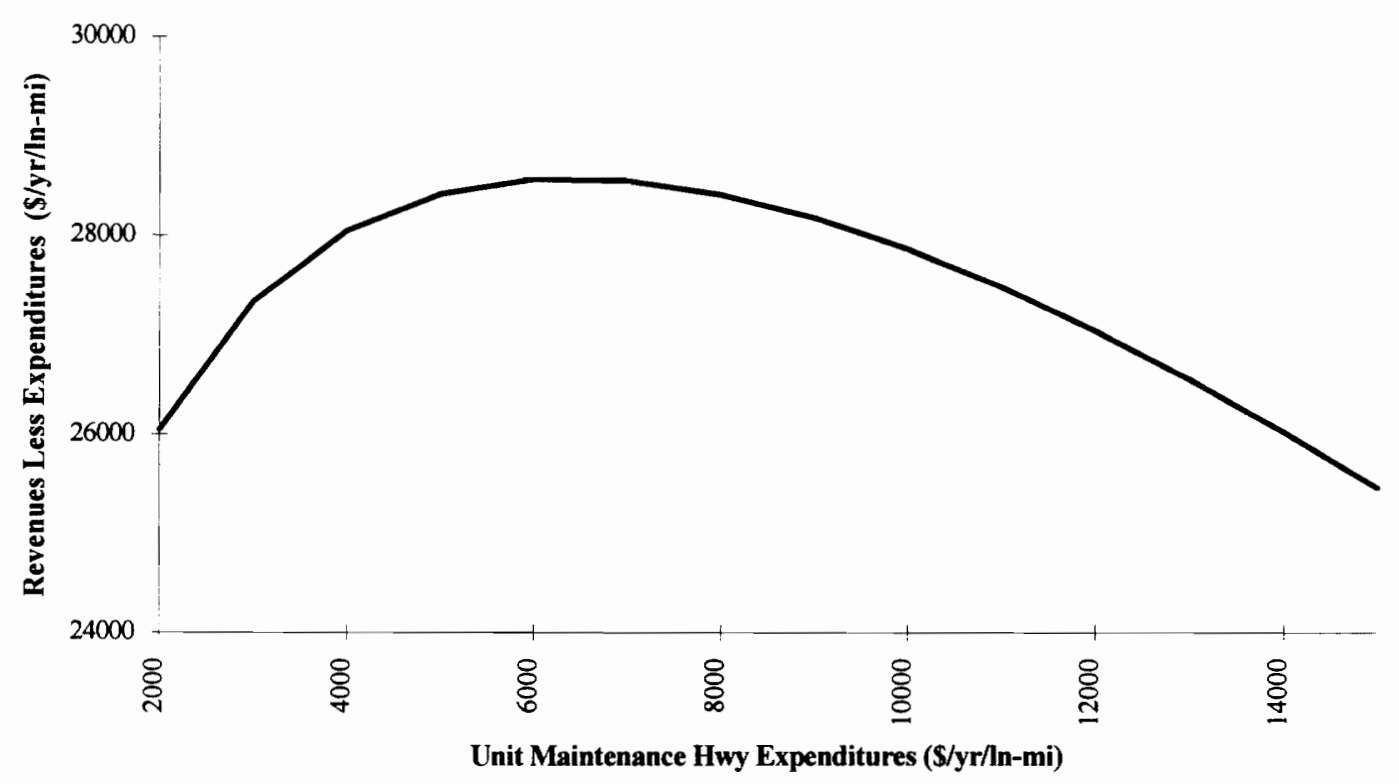

Figure 6.2: Revenues Less Expenditures vs Unit Maintenance Highway Expenditures for Steady State Analysis 


\section{DYNAMO Maintenance Model Results}

With the maintenance model described above, several simulation runs were accomplished to determine the time-related results. The same initial values were utilized as listed in Table 6.2 with the Level of Availability remaining constant. The Revenues Less Expenditures were simulated for every five (5) years for thirty years. Figure 6.3 is the graph for time $=25$ years.

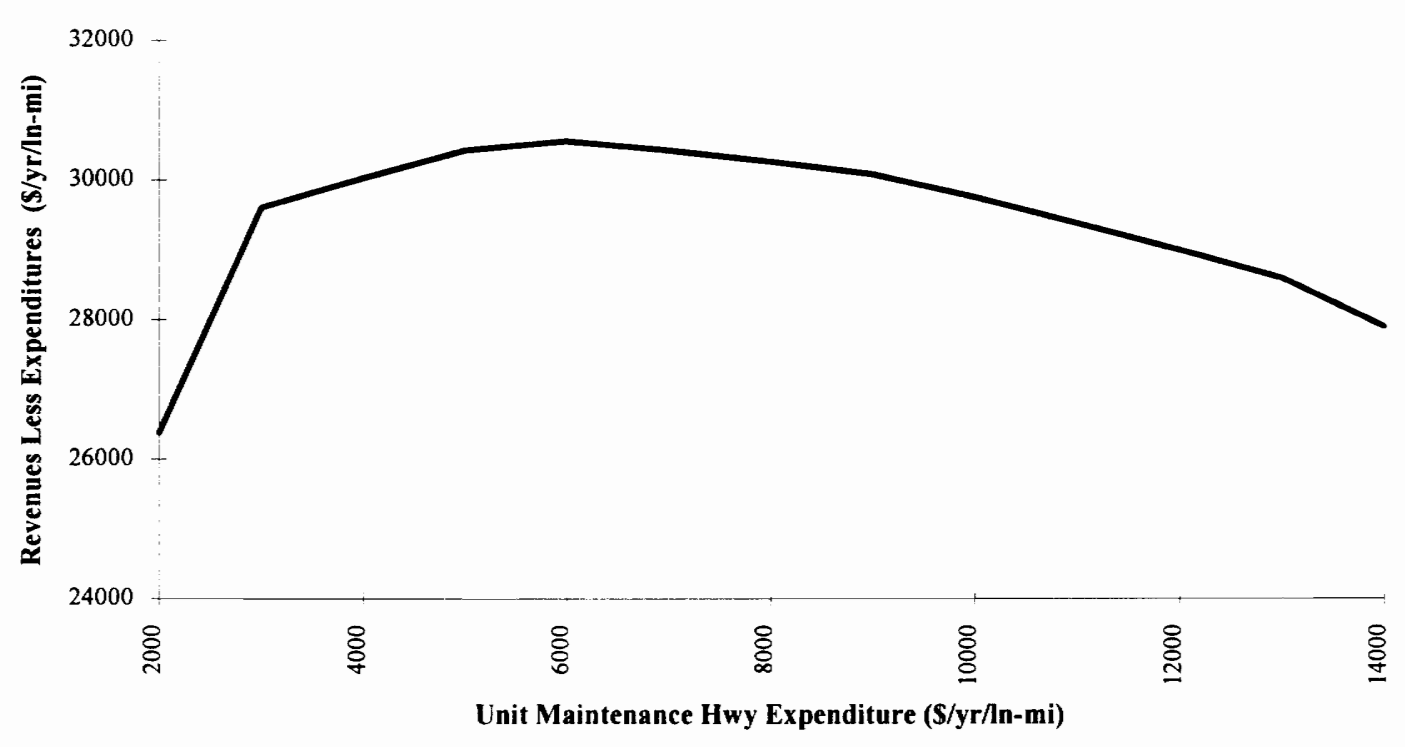

Figure 6.3: Revenues Less Expenditures vs Unit Maintenance Highway Expenditures Simulated over 25 Years Using DYNAMO Simulation

As can be seen from Figures 6.2 and 6.3, the shape of the graphs are essentially the same. The results are not exactly equal because the table values used to determine the Level of Operation in the DYNAMO simulation are not exact as in the mathematical solution. This is a confirmation that the DYNAMO simulation will provide results that are equivalent to the equilibrium analysis. This is important for a complete system analysis, which could contain additional highway lane-miles, because 
an equilibrium or steady state will not be reached, and the results of the simulation must bear a reasonable appearance to what would be expected to happen in reality.

\section{Equilibrium Analysis for Level of Availability Model}

The equilibrium analysis for the construction model could only be accomplished with the assumption that no highway expansion was accomplished, that is, additional lane-miles of road would not be constructed. With new lane-miles of road being constructed, a steady state could not be reached. Improvement and upgrades would be accomplished, but no new roads are constructed for a steady state analysis. This was accomplished by making the fraction of expenditure to highway expansion, FEHE, equal to zero (0).

For the steady state analysis again, the rates of change must equal zero (0). Substituting in the Level of Availability model equations and solving: For partially congested highway, $\mathrm{PCH}_{\mathrm{e}}$ :

$$
\mathrm{PCH}_{\mathrm{e}}=\mathrm{HCE} *\left(\frac{\mathrm{FEHI}}{\mathrm{HIC}}+\frac{\text { FEHU }}{\mathrm{HUC}}\right) * \text { HFCT (lane-miles), }
$$

For uncongested highways, $\mathrm{UCH}_{\mathrm{e}}$ :

$$
\mathrm{UCH}_{\mathrm{e}}=\frac{\mathrm{HCE}^{*} \mathrm{FEHU}^{*} \mathrm{HPCT}}{\mathrm{HUC}} \text { (lane-miles), }
$$

For fully congested highways, $\mathrm{FCH}_{\mathrm{e}}$ :

$$
\mathrm{FCH}_{\mathrm{e}}=\mathrm{HWYT}-\mathrm{HCE} *\left[\frac{\text { FEHU } * \text { HPCT }}{\text { HUC }}-\mathrm{HFCT}^{*}\left(\frac{\text { FEHI }}{\mathrm{HIC}}+\frac{\text { FEHU }}{\mathrm{HUC}}\right)\right] .
$$

Dividing both sides of Equations 6.16 and 6.17 by HWYT, a unit cost per lanemile for construction can be defined which can then be used to determine the effect of the unit construction cost on the Level of Availability. 
From Equation 6.16:

$$
\frac{\mathrm{PCH}_{e}}{\mathrm{HWYT}}=\frac{\mathrm{HCE}}{\mathrm{HWYT}} *\left(\frac{\text { FEHI }}{\mathrm{HIC}}+\frac{\text { FEHU }}{\mathrm{HUC}}\right) * \text { HFCT } .
$$

Letting $\mathrm{PCH}_{\mathrm{e}} / \mathrm{HWYT}=1$ and solving for UCHE:

$$
\mathrm{UCHE}=\frac{\mathrm{HIC}^{*} \mathrm{HUC}}{\left(\mathrm{FEHI}{ }^{*} \mathrm{HUC}+\mathrm{HIC}^{*} \mathrm{FEHU}\right) * \mathrm{HFCT}}(\$ / \mathrm{yr} / \mathrm{ln}-\mathrm{mi}) .
$$

From Equation 6.17:

$$
\frac{\mathrm{UCH}_{\mathrm{e}}}{\mathrm{HWYT}}=\frac{\mathrm{HCE}}{\mathrm{HWYT}} * \frac{\mathrm{FEHU}^{*} \mathrm{HPCT}}{\mathrm{HUC}} \text {. }
$$

Letting $\mathrm{UCH}_{\mathrm{e}} / \mathrm{HWYT}=1$ and solving for UCHE:

$$
\mathrm{UCHE}=\frac{\mathrm{HUC}}{\mathrm{FEHU}^{*} \mathrm{HPCT}}(\$ / \mathrm{yr} / \mathrm{ln}-\mathrm{mi}) .
$$

The Highway Congestion Index is a measure of the amount of congestion on the highway system with approaching 1 being a very congested system and approaching 0 as uncongested. Substituting Equations 6.19 and 6.21 into the model equations from Appendix B for the Highway Congestion Index, HCI, the Level of Availability can be related to the unit construction highway expenditure.

From the model equations:

$$
\mathrm{HCI}_{\mathrm{e}}=\frac{\left(\mathrm{UCH}_{\mathrm{e}}{ }^{*} \mathrm{UCWF}+\mathrm{PCH}_{\mathrm{e}}{ }^{*} \mathrm{PCWF}+\mathrm{FCH}_{\mathrm{e}}\right)}{\mathrm{HWYT}}
$$

For the steady state with no expansion, $\mathrm{FCH}_{\mathrm{e}}=\mathrm{HWYT}-\mathrm{UCH}_{\mathrm{e}}-\mathrm{PCH}_{\mathrm{e}}$, therefore:

$$
\mathrm{HCI}_{e}=1-\frac{\mathrm{UCH}_{\mathrm{e}}}{\mathrm{HWYT}} *(1-\mathrm{UCWF})-\frac{\mathrm{PCH}_{\mathrm{e}}}{\mathrm{HWYT}} *(1-\mathrm{PCWF}) .
$$

Substituting Equations 6.19 and 6.21 yields:

$$
\mathrm{HCI}_{\mathrm{e}}=1-\mathrm{UCHE} *\left[\frac{\mathrm{FEHU} * \mathrm{HPCT}}{\mathrm{HUC}} *(1-\mathrm{UCWF})+\left(\frac{\mathrm{FEHI}}{\mathrm{HIC}}+\frac{\mathrm{FEHU}}{\mathrm{HUC}}\right) * \mathrm{HFCT}^{*}(1-\mathrm{PCWF})\right] \text {. }
$$


Letting:

$$
\begin{aligned}
& \mathrm{C}_{4}=\frac{\text { FEHI }}{\mathrm{HIC}}+\frac{\text { FEHU }}{\mathrm{HUC}} \text { and } \\
& \mathrm{C}_{5}=\frac{\mathrm{FEHU}^{*} \mathrm{HPCT}}{\mathrm{HUC}} *(1-\mathrm{UCWF})+\mathrm{C}_{4} * \mathrm{HFCT}^{*}(1-\mathrm{PCWF}),
\end{aligned}
$$
then:

$$
\mathrm{HCI}_{\mathrm{c}}=1-\mathrm{UCHE}^{*} \mathrm{C}_{5} .
$$

The Level of Availability Index (LAI) is a measure of how much capacity is still available for the highway system. A LAI approaching 1 would mean that the highway has almost full capacity available while approaching 0 would mean very little capacity left. The Level of Availability Index is a function of both the Highway Congestion Index and the fraction of highway down for construction per year. At equilibrium:

$$
\mathrm{LAI}_{\mathrm{e}}=\left(1-\mathrm{HCI}_{\mathrm{e}}\right) *(1-\mathrm{FHDCPY}) .
$$

Substituting Equation 6.26 and the model equations for FHDCPY into Equation 6.27 yields:

$$
\mathrm{LAI}_{\mathrm{e}}=\left(\mathrm{UCHE}^{*} \mathrm{C}_{5}\right) *\left[1-\frac{\mathrm{HCE}}{\mathrm{HWYT}} *\left(\frac{\mathrm{FEHU}}{\mathrm{HUC}}+\frac{\mathrm{FEHI}}{\mathrm{HIC}}\right)\right]
$$

or:

$$
\mathrm{LAI}_{\mathrm{e}}=\left(\mathrm{UCHE} * \mathrm{C}_{5}\right) *\left(1-\mathrm{UCHE}^{*} \mathrm{C}_{4}\right) .
$$

Expanding this equation yields:

$$
\mathrm{LAI}_{e}=\mathrm{UCHE}^{*} \mathrm{C}_{5}-\mathrm{UCHE}^{2} \mathrm{C}_{5} * \mathrm{C}_{4} .
$$

Similarly, Equation 6.29 allows graphing of the Level of Availability at equilibrium for varying unit construction expenditures with the initial values. Figure 6.4 indicates the model behavior for the Level of Availability using the initial values from Table 6.3. 
Table 6.3: Parameter Values for Level of Availability Index Steady State Analysis

\begin{tabular}{|c|c|c|}
\hline Variable & Variable Description & Parameter Value \\
\hline \hline HIC & Highway Improvement Cost & $\$ 250,000 /$ lane-mile \\
\hline HUC & Highway Upgrade Cost & $\$ 500,000 /$ lane-mile \\
\hline FEHI & $\begin{array}{c}\text { Fraction Expenditure for } \\
\text { Highway Improvement }\end{array}$ & 0.5 \\
\hline FEHU & $\begin{array}{c}\text { Fraction Expenditure for } \\
\text { Highway Upgrade }\end{array}$ & 0.5 \\
\hline HPCT & $\begin{array}{c}\text { Highway Partial } \\
\text { Congestion Time }\end{array}$ & 5 years \\
\hline HFCT & $\begin{array}{c}\text { Highway Fully } \\
\text { Congested Time }\end{array}$ & 10 years \\
\hline UCWF & $\begin{array}{c}\text { Uncongested Highway } \\
\text { Weighting Factor }\end{array}$ & 0.5 \\
\hline PCWF & $\begin{array}{c}\text { Partially Congested Highway } \\
\text { Weighting Factor }\end{array}$ & 0.5 \\
\hline $\mathrm{C}_{4}$ & Equation 6.21 & 0.000003 \\
\hline $\mathrm{C}_{5}$ & Equation 6.22 & 0.0000175 \\
\hline
\end{tabular}

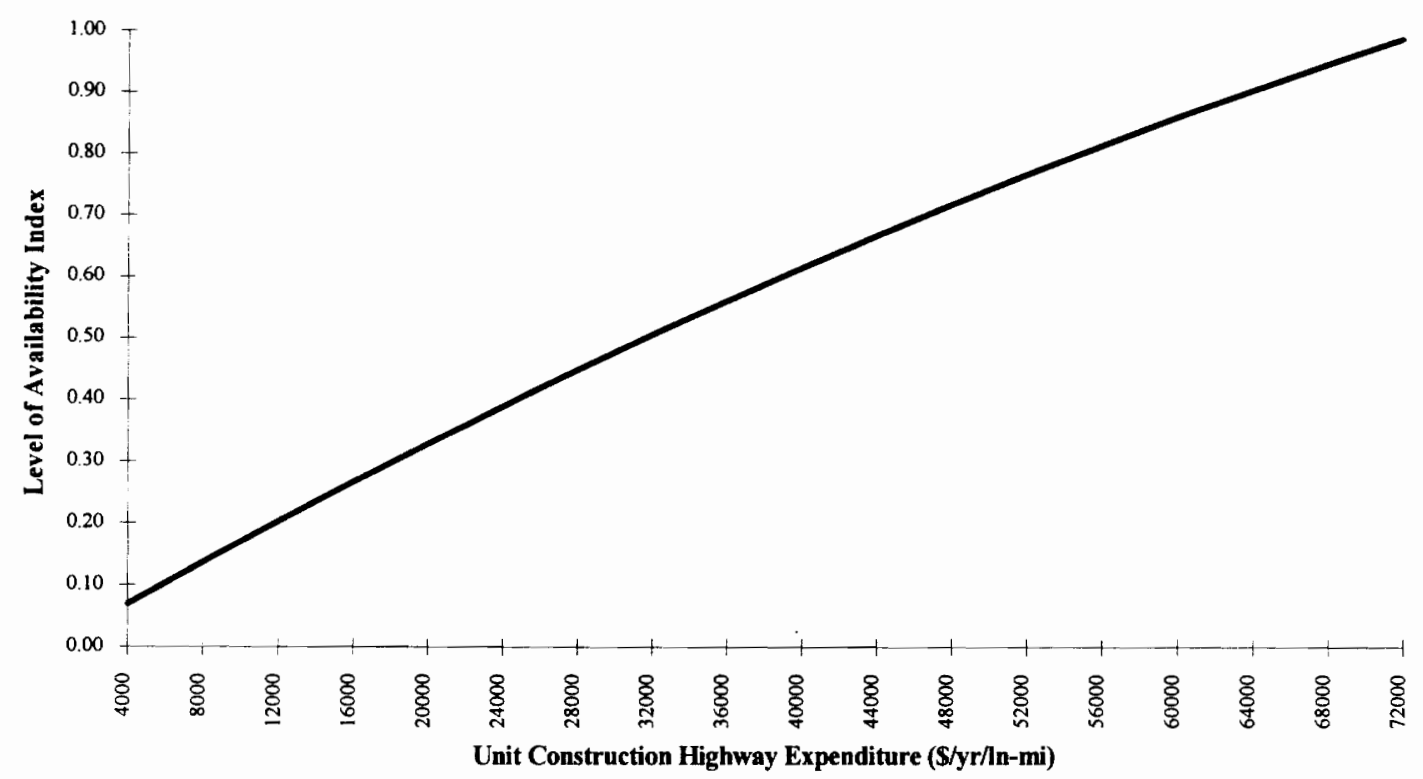

Figure 6.4: Level of Availability vs Unit Construction Highway Expenditure for Steady State Analysis 


\section{Comprehensive Level of Service}

Having solved both the Level of Operation model and Level of Availability model in an equilibrium state as a function of unit highway expenditures, the Comprehensive Level of Service can now be visualized as a function of both maintenance and construction. With the initial values in Tables 6.2 and 6.3 , the steady state Comprehensive Level of Service (CLOS) was graphed. The graph of the CLOS, Figure 6.5 , provides a visual idea of the concept that a trade-off exists between maintenance and construction expenditures to provide a desired Level of Service to the motoring public.

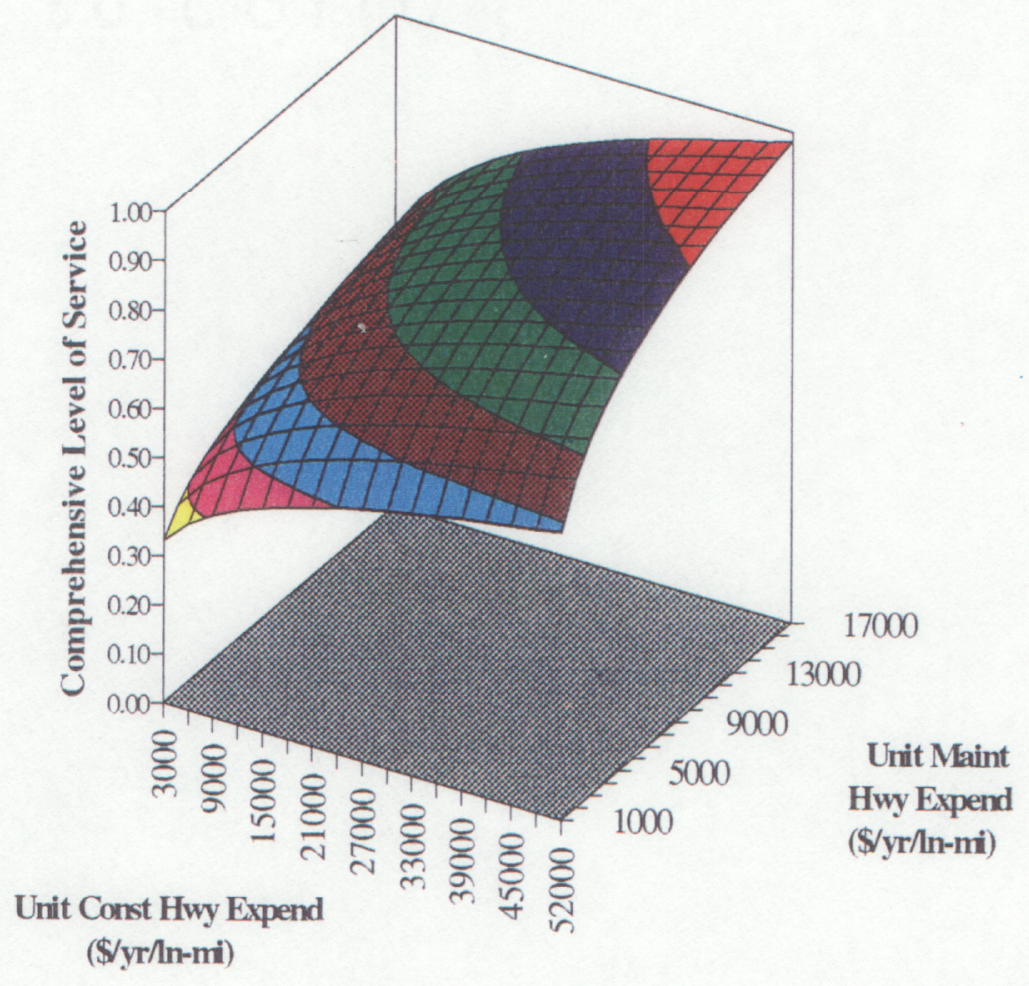

Figure 6.5: Comprehensive Level of Service vs Unit Construction Highway Expenditures vs Unit Maintenance Highway Expenditures 
To emphasize, the steady state analysis depicted in Figure 6.5 was accomplished without additional lane-miles being constructed. In contrast, the DYNAMO simulations shown in Figures 5.3, 5.4 and 5.5 in Chapter 5 provided the results of the measure of effectiveness, Revenues Less Expenditure vs Unit Highway Expenditures, for a continually expanding highway system.

\section{Summary}

The equilibrium analyses for the maintenance and construction models provide important insight and understanding of the inter-relationships between maintenance and construction. For example, from the maintenance model level equations (Equations 6.1, 6.2, and 6.3), insight is available into the equilibrium amount of highway lanemiles at any particular physical condition, i.e., physically sufficient or physically deficient, depending on the maintenance expenditure made. Varying the unit maintenance highway expenditure would determine the final condition of the highway system. For a negative feedback loop, which is the feedback relationship in these models, a system will move to equilibrium regardless of the initial state values. A graph similar to Figure 6.6, based on an equilibrium analysis, could provide a quick visual reference of the system condition under various maintenance expenditures.

The value of the steady state analysis is the insight that is gained on the relationships between the system's structure and behavior. These relationships can shed light on the system behavior in the context of the growth or decline of the system, based on the feedback loops developed and analyzed. 


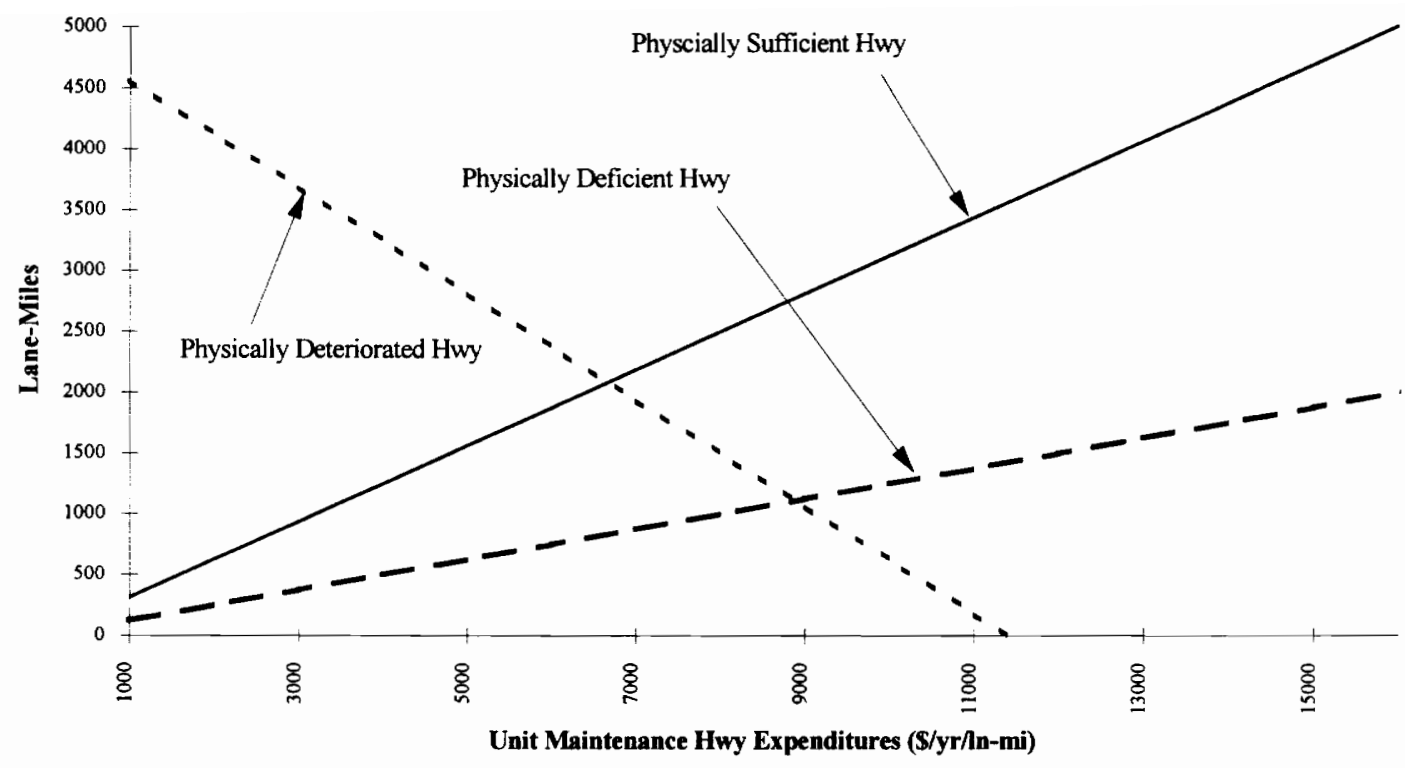

Figure 6.6: Lane-Mile Condition vs Unit Maintenance Highway Expenditure at Equilibrium 


\section{CHAPTER 7: \\ USER AND NON-USER BENEFIT ANALYSIS}

\section{Introduction}

This chapter describes a methodology to implement a user and non-user benefit analysis using the Comprehensive Level of Service models outlined in Chapters 5 and 6. This methodology forms the framework for determining the impact of deferring maintenance and/or obsolescence on user and non-user benefits.

\section{Background}

Most highway infrastructure in the United States has been primarily constructed and maintained with public money. As government has grown, the need to have a method to ensure efficient use of public money led to the creation of a benefit-to-cost rationale to indicate whether the benefits to be derived by the public exceeded the cost in tax dollars to be expended. The benefit-cost ratio has been used almost exclusively since 1952 to determine the economic benefit of highway construction (Winfrey 1969). This benefit-cost ratio is expressed as follows (Thuesen 1993):

$$
\mathrm{BC}(i)=\frac{\text { Benefits to the Public }}{\text { Cost to the Government }} \text {. }
$$

The benefits are considered to be the advantages that accrue to the public less the expenditures required to maintain that advantage. The costs are considered to be the disbursements necessary to make the improvements being considered. The easiest way to state the benefits and costs is in monetary terms, although not always possible, as in the case of benefits such as security, the environment, or the aesthetics of an area.

The user benefits, as defined by the American Association of State Highway and Transportation Officials' (AASHTO) manual, Analysis of Highway and Bus-Transit 
Improvements 1977 (known as the Redbook), are the "advantages, privileges, and/or cost reductions that accrue to highway motor vehicle users (drivers or owners) ...through the use of a particular transportation facility as compared with the use of another. Benefits are generally measured in terms of a decrease in user costs" (AASHTO, 1978, pg. 6). These benefits are usually defined as a reduction in travel time, reduced vehicle operating costs, and improved safety. As travel time and/or vehicle operating costs are reduced, user benefits will increase. As safety is improved, user benefits will also increase.

Non-user benefits are those benefits that accrue to the community at large, based on the increased transportation activities. These benefits can be increasing economic activities, population, land values and business opportunities. One method of determining the effect of transportation on the non-users is to examine the impact of reduced travel time on the fraction of transportation costs in the total industrial output. As the travel time is reduced, the fraction of transportation cost would decrease, increasing the ability of industry to reinvest those dollars in business expansion.

\section{Benefit-Cost Ratio Analysis}

The following discussion is condensed from Fabrycky, 1991, Thuesen, 1993, AlDawood, 1990.

The benefit-cost ratio allows the comparison of revenues or benefits received to the cost required to gain the benefit. In order to compare benefits and costs on an equivalent basis, the amounts must be compared on an equal basis, either through a present worth, $\mathrm{PW}(i)$, or annual equivalence, $\mathrm{AE}(i)$, at an interest rate, $i$, that reflects the appropriate time value of money. For public work, this interest rate should at least be the government's cost of borrowed money. 
To convert a present value, $\mathrm{P}$, to its future worth, $\mathrm{F}$, at time $n$, assuming an interest rate, $i$, and an annual compounding at that rate:

$$
\mathrm{F}=\mathrm{P}(1+\mathrm{i})^{\mathrm{n}}
$$

This is considered the single payment compound-amount factor, $(F / P, i, n)$, allowing the introduction of inflation into the model development. Costs will increase over time due to inflation in the economy. Maintenance and construction costs have increased over time and will continue to increase, decreasing the amount of maintenance or construction work that can be accomplished with the same amount of funds.

Solving Equation 7.1 for the present worth of a future amount yields:

$$
P=\frac{F}{(1+i)^{n}} \text {. }
$$

This is the single payment present-worth factor, $(P / F, i, n)$ allowing the comparison of future user and non-user benefits on an equivalent present-worth basis. The benefits accrued will be worth less in the future as the interest rate increases.

A future amount can also be represented as a series of equal amounts deposited at the end of each interest period and is represented as follows:

$$
F=\sum_{j=0}^{n-1} A(1+i)^{j}=A\left[\frac{(1+i)^{n}-1}{i}\right] .
$$

This is the equal payment series compound-amount factor, $(F / A, i, n)$.

Solving Equation 7.3 for A yields:

$$
A=F\left[\frac{i}{(1+i)^{n}-1}\right] \text {. }
$$


This is the equal payment series sinking-fund factor $(A / F, i, n)$ allowing the comparison of future benefits on an equal annual basis. This has appeal because the future amount can be annualized for annual budgetary or planning purposes.

Substituting Equation 7.1 for $F$ in Equation 7.4 yields:

$$
A=P(1+i)^{n}\left[\frac{i}{(1+i)^{n}-1}\right]=P\left[\frac{i(1+i)^{n}}{(1+i)^{n}-1}\right] .
$$

This is the equal payment series capital-recovery factor $(A / P, i, n)$ that allows defining a present construction cost on an annual basis for comparison with annual benefits and/or revenues.

Solving Equation 7.5 for P yields:

$$
P=A\left[\frac{(1+i)^{n}-1}{i(1+i)^{n}}\right] .
$$

This is the equal payment series present-worth factor $(P / A, i, n)$ and allows the comparison of annualized benefits on a present-worth basis. Revenues and/or maintenance expenditures that are recurring from year to year can be calculated on a present-worth basis for comparison with the present worth of construction costs.

To compare outflows and inflows of different amounts on an equivalent basis, the present worth or annual equivalence of all amounts can be determined, using the above equations. Since the benefits that are derived from an improvement generally require a maintenance expenditure to maintain those benefits, the annual benefits less the annual maintenance expenditure required, $\left(B_{a}-E_{a}\right)$, can be substituted into Equation 7.6 for $A$ and yield the present worth of the annual benefits.

$$
B_{P W}=\left(B_{a}-E_{a}\right)\left[\frac{(1+i)^{n}-1}{i(1+i)^{n}}\right] .
$$


If the annual benefits less annual maintenance expenditures are defined on a present worth basis, then subtracting the project cost from the benefits would provide the present worth of any project alternative under review or:

$$
\mathrm{PW}_{\mathrm{Alt}}=\left(\begin{array}{c}
(\mathrm{P} / \mathrm{A}, \mathrm{i}, \mathrm{n}) \\
\mathrm{B}_{\mathrm{a}}-\mathrm{E}_{\mathrm{a}}
\end{array}\right)-\mathrm{C} \text { or } \mathrm{PW}_{\mathrm{Alt}}=\mathrm{B}_{\mathrm{PW}}-\mathrm{C} \text {. }
$$

This allows all potential projects that are competing for funding to be reviewed and a selection made on the same economic basis.

To allow the same economic comparisons to be made on an annual equivalent basis, the construction cost must be expressed as an annual expenditure by using Equation 7.5. Then, Equation 7.8 is revised as follows:

$$
\mathrm{AE}_{\mathrm{Alt}}=\left(\mathrm{B}_{\mathrm{a}}-\mathrm{E}_{\mathrm{a}}\right)-{ }^{(A / P, i, n)}
$$

To see how the benefit-cost ratio is formulated, it is apparent from either Equation 7.8 or 7.9 , that if the benefits less expenditures equals the investment cost, then the present worth or annual equivalent would be zero. In order for the project alternative to be worth the investment, the benefits less maintenance expenditures must be greater than the investment cost. Rearranging Equations 7.8 and 7.9 yields the common Benefit-Cost ratio as:

$$
\begin{aligned}
& \mathrm{BC}(i)_{\mathrm{PW}}=\frac{\mathrm{B}_{\mathrm{a}}-\mathrm{E}_{\mathrm{a}}}{\mathrm{C}} \text { or } \\
& \mathrm{BC}(i)_{\mathrm{AE}}=\frac{\mathrm{B}_{\mathrm{a}}-\mathrm{E}_{\mathrm{a}}}{(A / P / P, n)} .
\end{aligned}
$$

This indicates a benefit-cost ratio greater than 1 is required to ensure the benefits outweigh the investment cost to achieve the desired benefits. 


\section{Continuously Compounded Benefit-Cost Ratio}

The above time-value equations are based on an annual compounding period of the interest rate. As the number of compounding periods would increase, approaching infinity $(\infty)$, a continuous compounding factor is introduced. If the benefits generated from the time $t$ to $t+\Delta t$ are noted as $\mathrm{B}_{\mathrm{t}} \Delta \mathrm{t}$, then the present worth of the future benefits (Equation 7.2) would be:

$$
\mathrm{B}_{\mathrm{PW}}=\sum_{\mathrm{t}=0}^{\mathrm{n}} \frac{\mathrm{B}_{\mathrm{t}} \Delta \mathrm{t}}{\left(1+\frac{\mathrm{r}}{\mathrm{c}}\right)^{\mathrm{ct}}}
$$

where $B_{t}=$ benefits

$\mathrm{r}=$ annual interest rate

$c=$ number of times interest is compounded per year

$\mathrm{n}=$ project life in years.

Taking the limit as $\Delta t$ approaches zero yields the continuous formulation of Equation 7.12:

$$
\mathrm{B}_{\mathrm{PW}}=\int_{0}^{\mathrm{n}} \frac{\mathrm{B}_{\mathrm{t}} \mathrm{dt}}{\left(1+\frac{\mathrm{r}}{\mathrm{c}}\right)^{\mathrm{ct}}} .
$$

The benefits at any time $t, B_{t}$, are the annual user and non-user benefits, $B_{a}$, less the annual maintenance expenditures, $E_{a}$. Then Equation 7.13 can be written as:

$$
B_{p W}=\left(B_{a}-E_{a}\right) \frac{d t}{\int_{0}^{n}\left[\left[1+\frac{r}{c}\right]^{c / r}\right]^{n}} .
$$

Since:

$$
\lim _{c \rightarrow \infty}\left[1+\frac{r}{c}\right]^{c / r}=e
$$


Equation 7.14 can be written as follows:

$$
\mathrm{B}_{\mathrm{PW}}=\left(\mathrm{B}_{\mathrm{a}}-\mathrm{E}_{\mathrm{a}}\right) \int_{0}^{\mathrm{n}} \mathrm{e}^{-\mathrm{rt}} \mathrm{dt} .
$$

Integrating and applying the limits of integration yield:

$$
\mathrm{B}_{\mathrm{PW}}=\left(\mathrm{B}_{\mathrm{a}}-\mathrm{E}_{\mathrm{a}}\right) \frac{1-\mathrm{e}^{-\mathrm{rm}}}{\mathrm{r}} .
$$

From Equations 7.8 and 7.16, the present worth of an alternative can be rewritten as:

$$
\mathrm{B}_{\mathrm{PW}}=\left(\mathrm{B}_{\mathrm{a}}-\mathrm{E}_{\mathrm{a}}\right) \frac{1-\mathrm{e}^{-\mathrm{m}}}{\mathrm{r}}-\mathrm{C} .
$$

This puts the annual benefits and maintenance expenditures in the same present worth as the investment cost.

Realizing again that if the benefits less the maintenance expenditures equal the investment cost, then the present worth would be zero, or:

$$
\left(\mathrm{B}_{\mathrm{a}}-\mathrm{E}_{\mathrm{a}}\right) \frac{1-\mathrm{e}^{-\mathrm{m}}}{\mathrm{r}}=\mathrm{C} \text {. }
$$

Making Equation 7.18 into the normal benefit-cost ratio by dividing both sides by the investment cost yields:

$$
B C=\frac{\left(B_{a}-E_{a}\right)}{C}\left(\frac{1-e^{-m}}{r}\right) .
$$

If a normal infrastructure life is considered twenty-five to forty years, the term (1-e-rn) approaches unity for representative values of $r$ and $n$. This would allow the benefit-cost ratio to be simplified to:

$$
\mathrm{BC}=\frac{\mathrm{B}_{\mathrm{a}}-\mathrm{E}_{\mathrm{a}}}{\mathrm{Cr}}
$$


where: $\mathrm{B}_{\mathrm{a}}=$ user and non-user benefits (annual)

$\mathrm{E}_{\mathrm{a}}=$ maintenance expenditures (annual)

$\mathrm{C}=$ investment or construction cost (present worth)

$r=$ interest rate.

\section{Maintenance, Obsolescence and User/Non-User Benefits}

Highway maintenance is a major function of state and local government. The impact of deferring maintenance activities is reflected on both users and non-users in the cost of operation of the transportation utilized. Deteriorating roads and bridges can increase travel time, as rough roads tend to slow traffic, and increase vehicle operating costs, as additional vehicle repairs could be required. The ride is uncomfortable and the motorist may look for a different route to by-pass a rough road. Poor roads could lead businesses to look to other areas that better support the highway system and provide more cost-effective fleet operations.

Congestion, a manifestation of obsolescence, will also cause increased vehicle operating costs and increased travel time. Business-related drivers that spend time in bumper-to-bumper traffic waste productive time and increase the transportation costs for shipping goods. The newer just-in-time manufacturing plants depend on a reliable transportation network to deliver the needed parts and supplies. Shipments that are delayed could stop an entire plant from operating, which is a substantial loss in productivity. Escalating vehicle operating costs from increased fuel expenses remove dollars that could be spent in other places, thus decreasing the business opportunities for more individuals.

\section{Model Approach to the Simulation of User/Non-User Benefits}

The user benefits for this model are based on AASHTO's Redbook (AASHTO 1978). User benefits are based on vehicle operating costs, due to the maintenance 
condition of the road, and travel time, due to the traffic conditions. The form of the equation from the AASHTO manual is a follows:

$$
\mathrm{UB}=\left(\mathrm{U}_{0}-\mathrm{U}_{1}\right)\left(\frac{\mathrm{V}_{0}+\mathrm{V}_{1}}{2}\right)
$$

where: $U_{0}=$ User cost per unit of traffic (vehicles) at time $t_{0}$

$\mathrm{U}_{1}=$ User cost per unit of traffic at later time $\mathrm{t}_{1}$

$\mathrm{V}_{0}=$ Volume of traffic at time $\mathrm{t}_{0}$

$V_{1}=$ Volume of traffic at later time $t_{1}$

User benefits, $U$, are represented by basic section costs and accident costs. For this framework, basic section costs include a unit time value and a vehicle operating cost associated with the volume of traffic and the condition of the road section. Accident costs will not be considered in this analysis.

Figure 7.1 graphically illustrates the principles involved in the user cost and benefit relationships. Consider, for example, motorists in a region that use a highway regularly for commuting to work. The users will create a traffic demand curve implying that as the time to commute decreases, the volume of traffic using the highway will increase. The supply from the existing highway, or the capacity curve, will indicate the traffic volume and travel time. The intersection point of the existing facility supply and traffic demand curves, point $P$, will determine the traffic volume, V0, and travel time, UB0. When a new highway is constructed or the existing highway expanded or improved, a new supply (capacity curve) is determined. The new intersection point on the existing demand curve and the improved facility supply curve, point $\mathrm{M}$, determines a revised traffic volume, V1, and travel time, UB1. The difference between the existing travel time (UB0) and the travel time (UB1) for the new or expanded facility corresponds to $\left(\mathrm{U}_{0}-\mathrm{U}_{1}\right)$. To calculate the user benefits derived from the reduction in user costs, the $\left(\mathrm{U}_{0}-\mathrm{U}_{1}\right)$ difference is multiplied by the average 
traffic volume between the existing highway (V0) and the improved facility (V1). The average is used because an increase in traffic is assumed to occur over time and the average will more closely approximate the traffic growth rather than a single unchanged traffic volume.

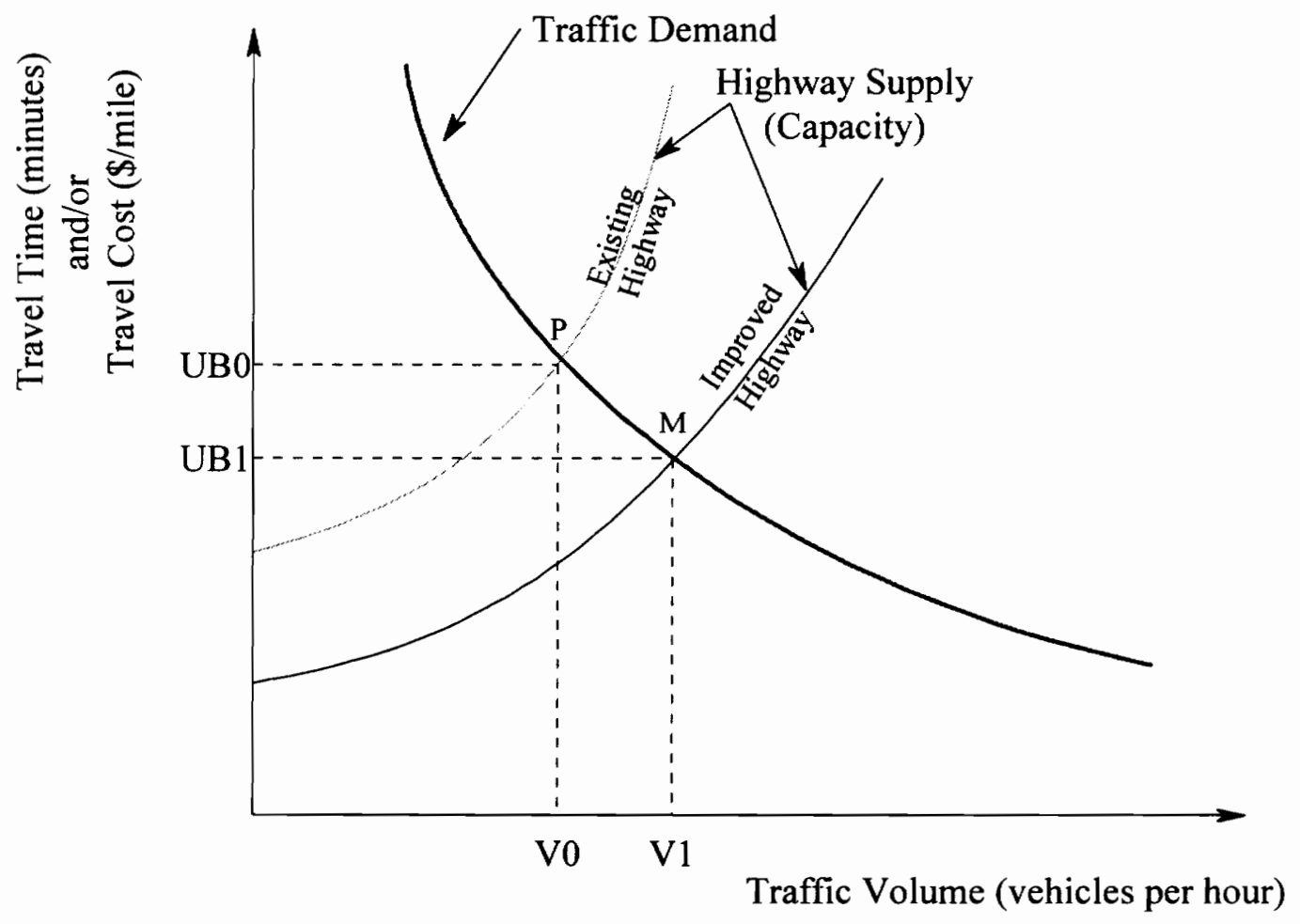

Figure 7.1: Highway User Cost and Benefit Relationships Single Facility

The complexities of the user-benefit relationships can be seen from the graph in Figure 7.2 that depicts the user cost and benefit relationships when two different routes are available to the same location. Consider, for example, an existing two-lane road between two population centers. The existing highway supply and the traffic demand intersect at point $\mathrm{P}$, establishing the original travel time UB0 and traffic volume V0. A new four-lane road is constructed between the two population centers giving the users 
two alternate routes to travel from home to work and back. The new travel time will now be a slightly better travel time, UB2, than either of the two alternatives as the users will tend to equalize the travel time, thus improving traffic volume to V2. This is shown as point $Q$ in Figure 7.2. The equilibrium traffic volume will increase because the supply of traffic on the existing two-lane road will be added to the supply of traffic for the four-lane road. The form of the user-benefit equation though remains the same as shown in Equation 7.21.

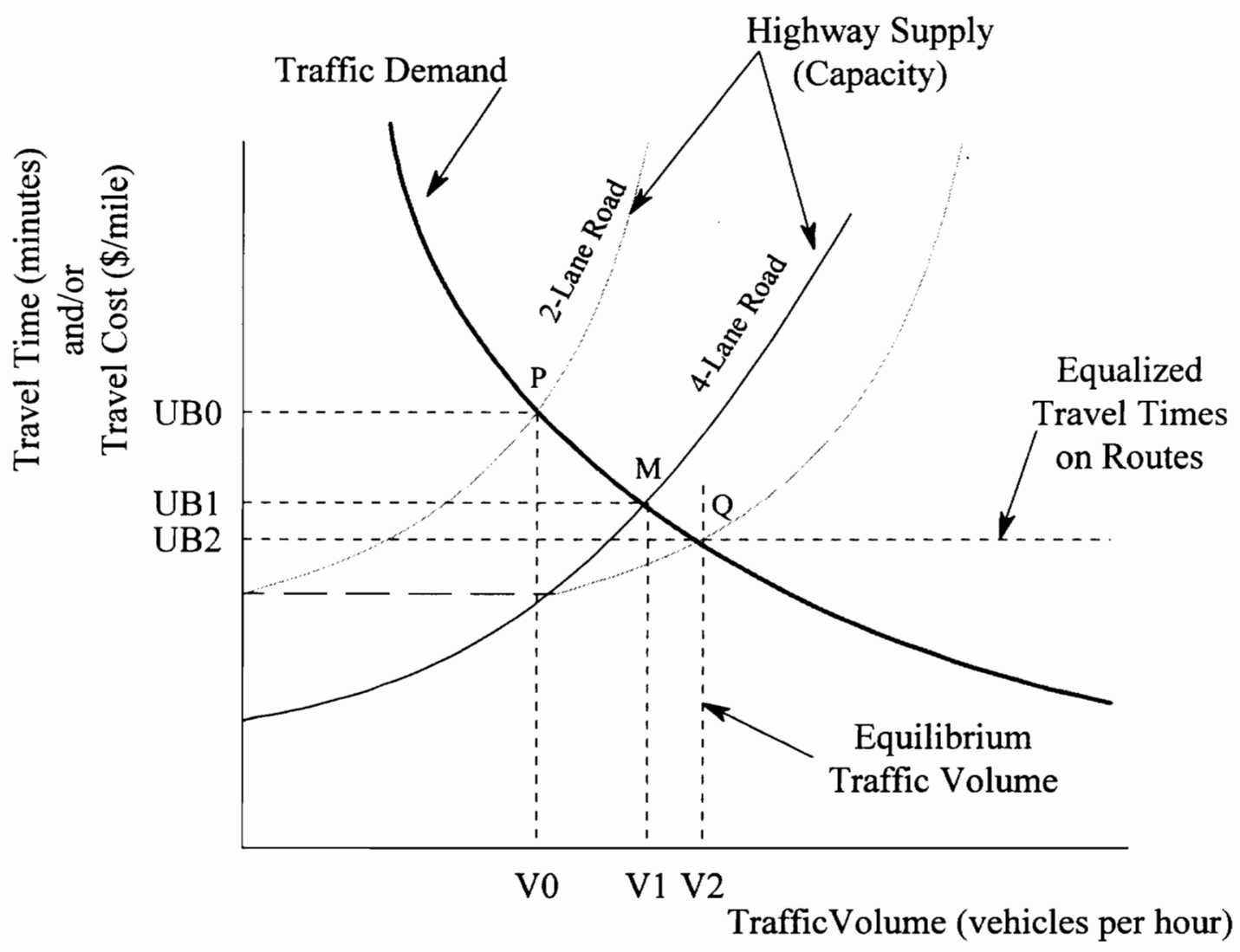

Figure 7.2: Highway User Cost and Benefit Relationships Alternate Facilities 


\section{Model Development for User/Non-User Benefits}

The vehicle operating costs are represented by a table function to indicate the various costs of operating a vehicle based on the Level of Operation of the highway. As the Level of Operation decreases, the vehicle operating costs increase. The use of the table values allow mapping a non-linear function for the relationship between vehicle operating costs and the Level of Operation as shown in Figure 7.3. The DYNAMO equations for the Vehicle Operating Costs are as follows:

$\mathrm{N}$ VOCN $=$ TABLE(VOCNT,LOIN, $0,1,0.2)$

$T$ VOCNT $=0.40 / 0.30 / 0.22 / 0.18 / 0.16 / 0.15$

A VOC.K=TABLE(VOCT,LOI.K, $0,1,0.2$ )

$\mathrm{T}$ VOCT $=0.40 / 0.30 / 0.22 / 0.18 / 0.16 / 0.15$

VOCN - Vehicle Operating Cost Normal ( $\$ / \mathrm{mile})$

VOCNT - Table Values for Vehicle Operating Costs Normal

LOIN - Level of Operation Index Initial (dimensionless)

VOC - Vehicle Operating Costs ( $\$ / \mathrm{mile})$

VOCT - Table Values for Vehicle Operating Costs ( $\$ / \mathrm{mile})$

LOI - Level of Operation Index (dimensionless)

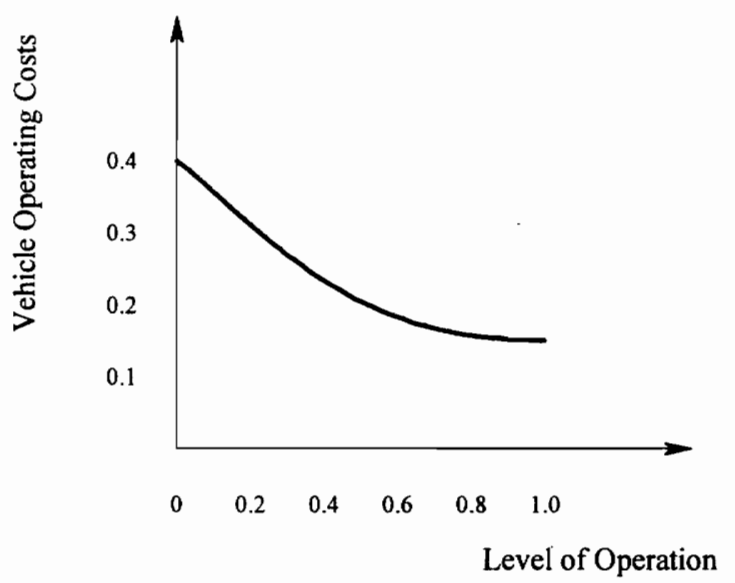

Figure 7.3: Vehicle Operating Costs vs Level of Operation 
User benefits depend on the volume of traffic, the normal travel time on link KL, the new travel time on link KL, the normal vehicle operating costs on link KL, and the new vehicle operating costs on link $\mathrm{KL}$. As the vehicle operating costs decrease, the user benefits will increase. As the travel time decreases, the user benefits will increase because the user costs are decreasing. The average volume of traffic will also affect the user benefits. The value of time for the user is assumed to be $\$ 12.00$ per hour per vehicle. The DYNAMO equations for the User Benefits are as follows:

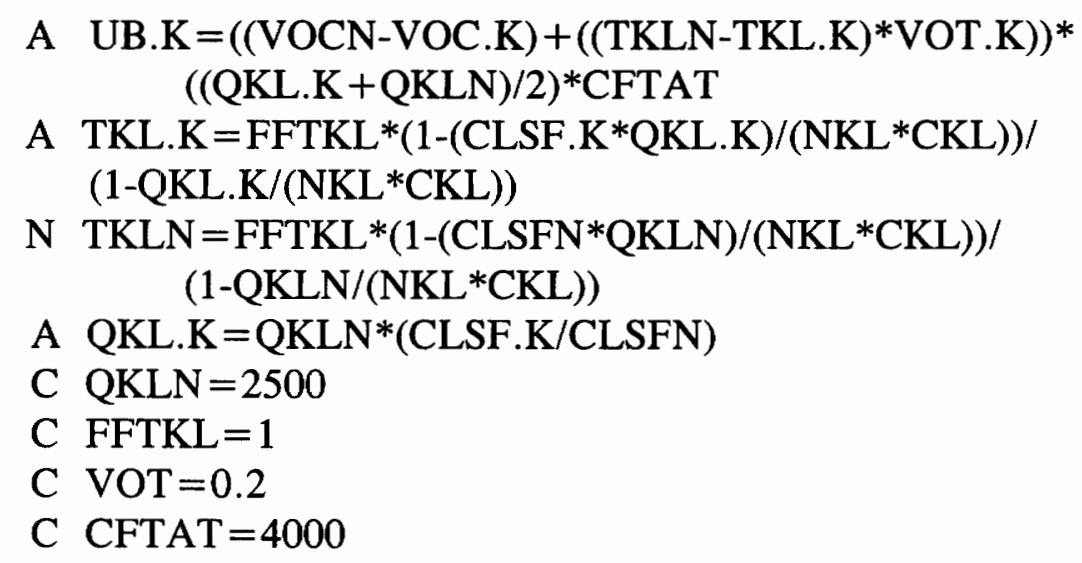

UB - User Benefits (\$/year/mile)

VOCN - Vehicle Operating Costs Normal $(\$ / \mathrm{mile})$

VOC - Vehicle Operating Costs $(\$ / \mathrm{mile})$

TKLN - Travel Time Link K to L normal (minutes/mile)

TKL - Travel Time Link K to L (minutes/mile)

QKL - Volume on Link from $\mathrm{K}$ to $\mathrm{L}$ (vehicles/hour)

QKLN - Volume on Link from K to L Normal (vehicles/hour)

VOT - Value of Time ( $\$$ /minute)

CFTAT - Conversion Factor to Two-way Annual Traffic (hours/year)

FFTKL - Free Flow Travel Time from K to L (minutes/mile)

CLSF - Value of Comprehensive LOS Factor (dimensionless)

NKL - Number of Lanes from K to L (lanes)

CKL - Lane Capacity on Link KL (vehicles/hour) 
The non-user benefits are dependent on the fraction of transportation costs compared to the total industrial output. As the fraction decreases, the non-user benefits increase. This fraction is dependent on the travel time of the shipping distance within the area under study. As the shipping travel time decreases from the normal travel time, the fraction of transportation costs compared to the total industrial output will also decrease.

Non-user benefits are also a function of the industrial output of a region which is dependent on the population, the per capita income, and the fraction of industrial input to output. The fraction of industrial input to output is a measure of the efficiency of industry. For this research, we will assume that the industrial input to output normal, FIOIN is 0.7 . As the fraction of industrial input to output increases, the industrial output increases. As the industrial output increases, the non-user benefits increase.

Non-user benefits are also a function of the link to shipping distance ratio which is a measure of an industry's dependence on the transportation system. The link is the travel distance within the region under study. The link to shipping distance ratio is dependent on the length of the link and the average shipping distance. As the length of link increases, the link to shipping distance ratio will increase. As the average shipping distance increases, the link to shipping distance ratio will decrease. As the link to shipping distance ratio increases, the non-user benefits increase. The DYNAMO equations for the Non-User Benefits are as follows:
A NUB.K=(FIOTN-FIOT.K)*IO*LSDR
$\mathrm{N}$ FIOT $=$ FIOTN
C FIOTN $=0.5$
A FIOT.K $=$ FIOTN $*$ SQRT(TKL.K/TKLN)
$\mathrm{N}$ IO $=(\mathrm{PCI} * \mathrm{POP}) /(1-\mathrm{FIOIN})$
C $\mathrm{PCI}=20000$
C $\mathrm{POP}=200000$ 

C FIOIN $=0.7$
$\mathrm{N} \quad \mathrm{LSDR}=\mathrm{LLKL} / \mathrm{ASD}$
C $\mathrm{LLKL}=100$
C $\mathrm{ASD}=400$

NUB - Non-User Benefits ( $\$ /$ year/mile)

FIOTN - Fraction Industrial Output to Transportation Normal (dimensionless)

FIOT - Fraction Industrial Output to Transportation (dimensionless)

IO - Industrial Output (\$/year)

LSDR - Link to Shipping Distance Ratio (dimensionless)

TKL - Travel Time Link K to L (minutes/mile)

TKLN - Travel Time Link K to L normal (minutes/mile)

POP - Population (persons)

PCI - Per Capita Income (\$/year/person)

FIOIN - Fraction Industrial Output to Input Normal (dimensionless)

LLKL - Length of Link $\mathrm{K}$ to $\mathrm{L}$ (miles)

ASD - Average Shipping Distance (miles)

The total net benefits due to maintenance and construction activities are dependent on the user benefits, the non-user benefits, the unit maintenance highway expenditures, and the unit construction highway expenditures. As the user benefits increase, the total net benefits will increase. As the non-user benefits increase, the total net benefits will increase. However, as the highway maintenance expenditures and/or the highway construction expenditures increase, the total net benefits will decrease. The DYNAMO equation for the Total Net Benefits is as follows:

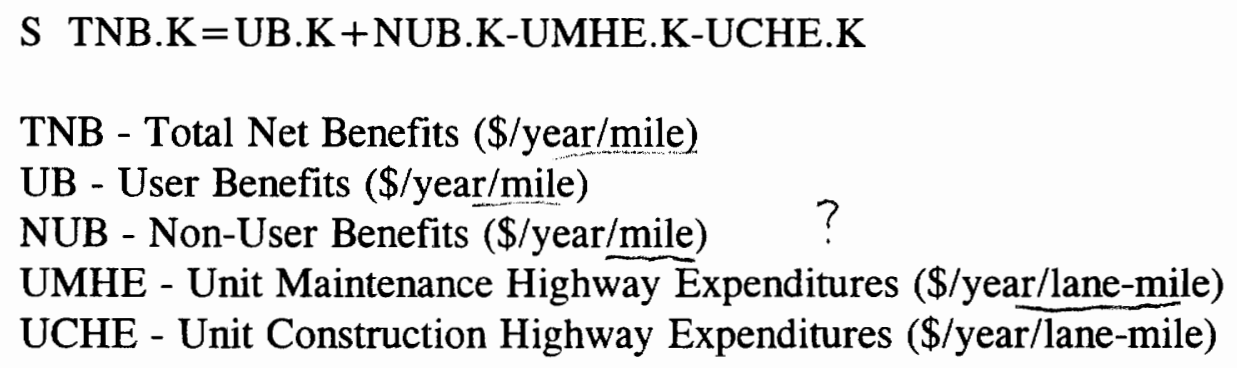

The total net benefits can be used to simulate the effect of various maintenance and construction expenditure rates and visualize the effect of these activities on a 
system basis. For example, Figures 7.4, 7.5, and 7.6 are an illustration of the effects of the various unit maintenance and construction expenditures on the total net benefits over a twenty-year simulation time-frame.

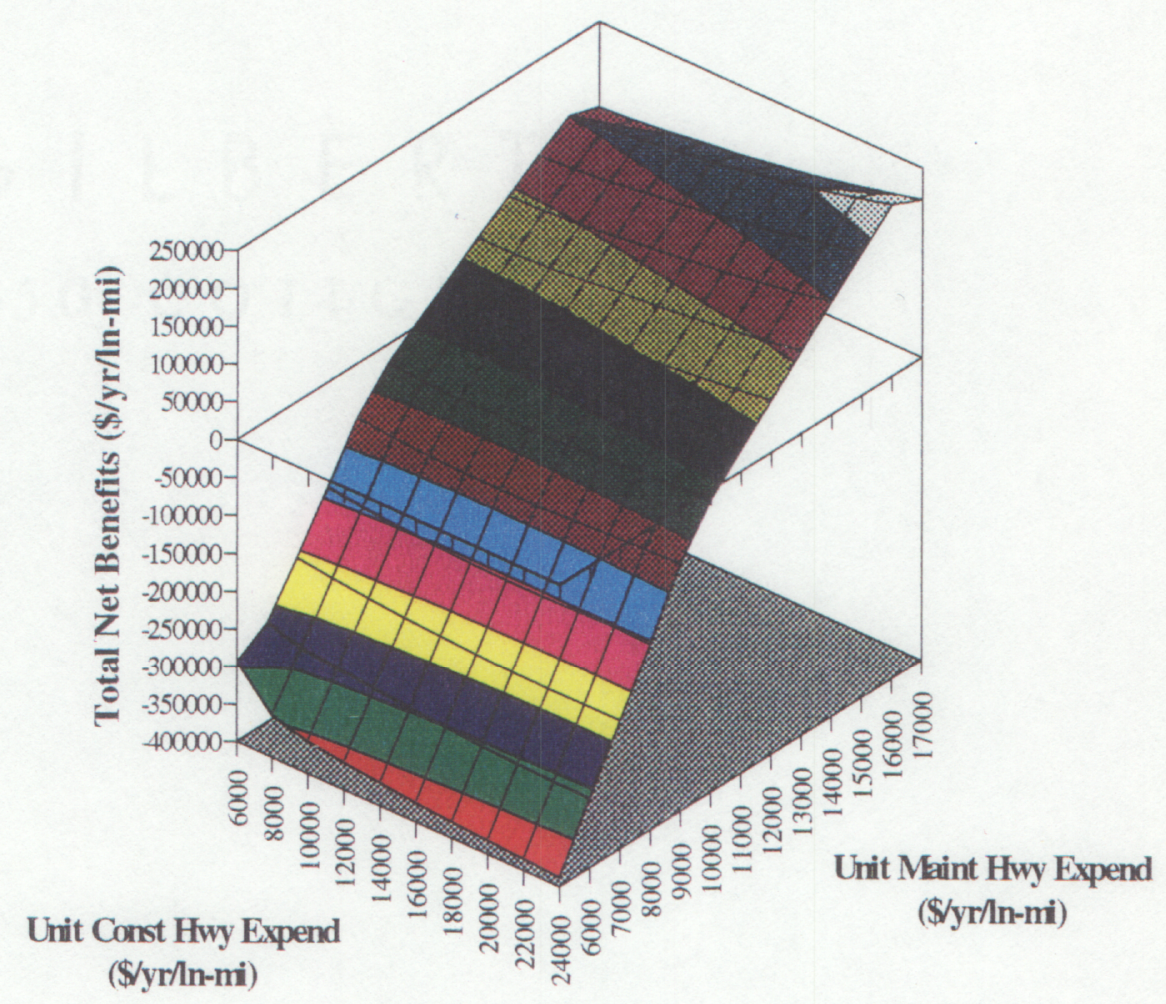

Figure 7.4: Total Net Benefits vs UMHE and UCHE Simulated over 10 Years

The total net benefits can also be determined on a per capita basis by recalculating the total net benefits by multiplying by the number of lane-miles in a region and dividing by the population. As the number of lane-miles increases, the per capita benefits would increase. As the population increases, the per capita benefits 


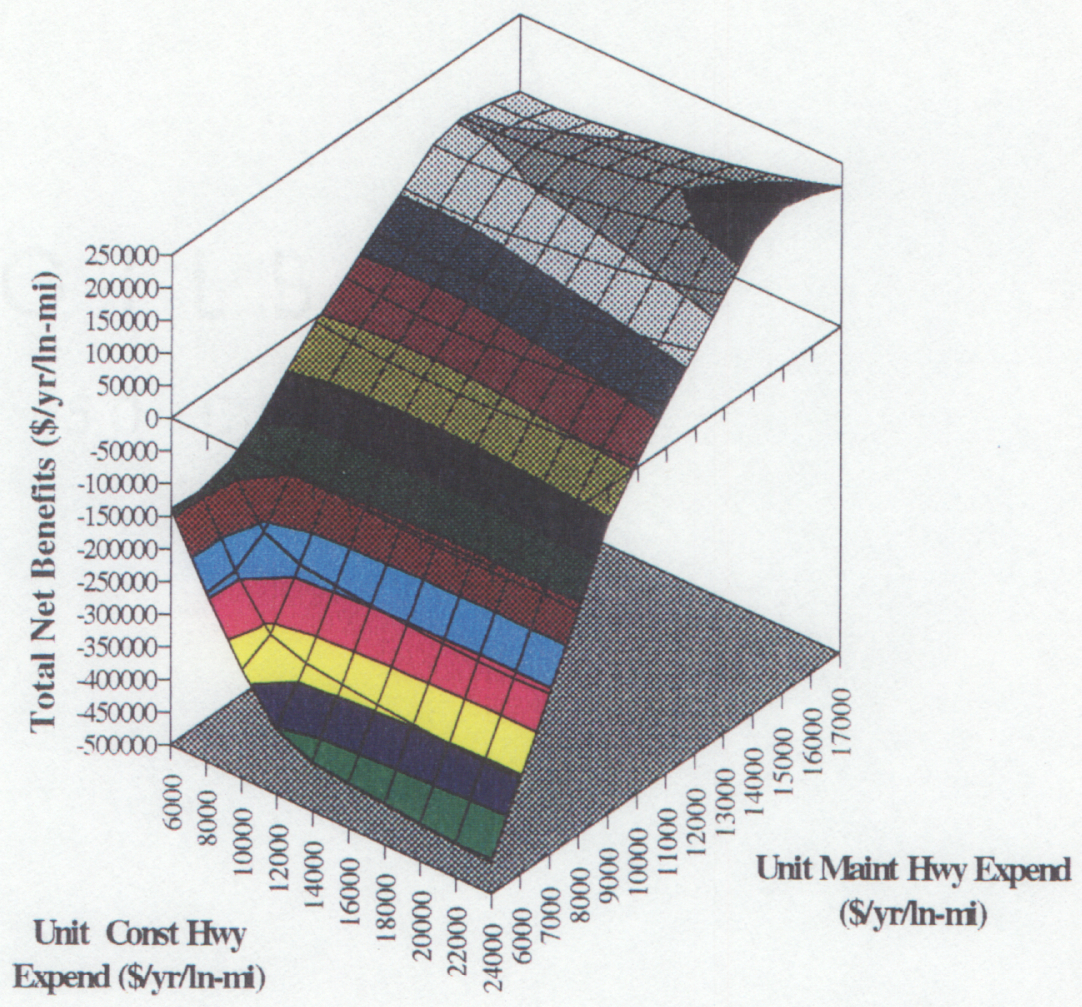

Figure 7.5: Total Net Benefits vs UMHE and UCHE Simulated over 15 Years

would decrease. The DYNAMO equation for the Total Net Benefits per Capita is as follows:

\section{S TNBPC.K=TNB.K*HWYT.K/POP}

TNBPC - Total Net Benefits per Capita (\$/year/person)

TNB - Total Net Benefits (\$/year/lane-mile)

HWYT - Total Highway Miles (lane-miles)

POP - Population (persons) 


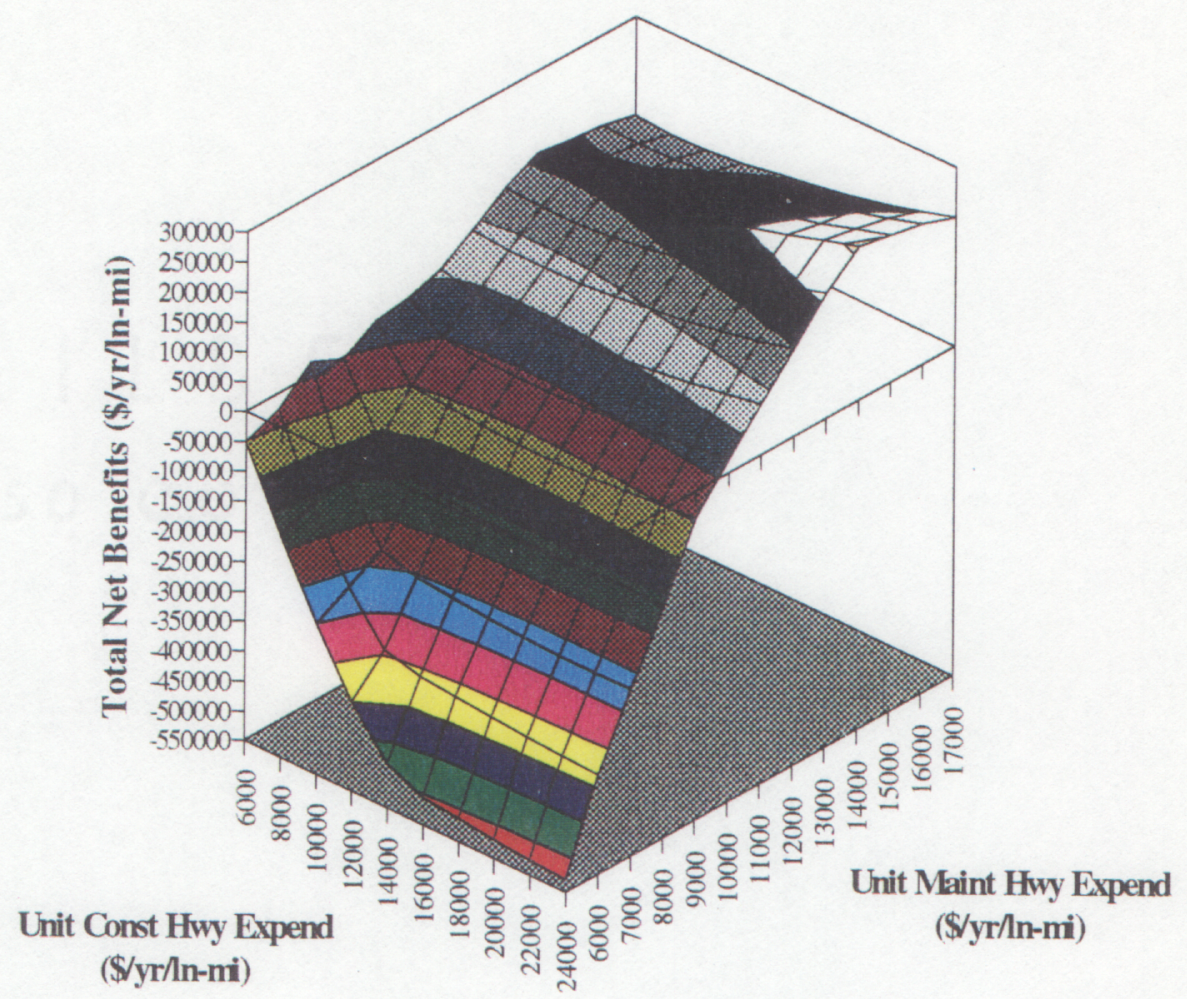

Figure 7.6: Total Net Benefits vs UMHE and UCHE Simulated over 20 Years

Figures 7.7 through 7.9 illustrate the revised surface graphs relating highway maintenance and construction expenditures to the net benefits to the population of aregion. This would provide an indication of the total effect of highway expenditures on both the users and non-uses alike.

\section{Model Development for Benefit-Cost Analysis of User/Non-User Benefits}

The benefit-cost ratio was developed to indicate a rationale for highway expenditures. The purpose of highway maintenance and construction expenditures is to 


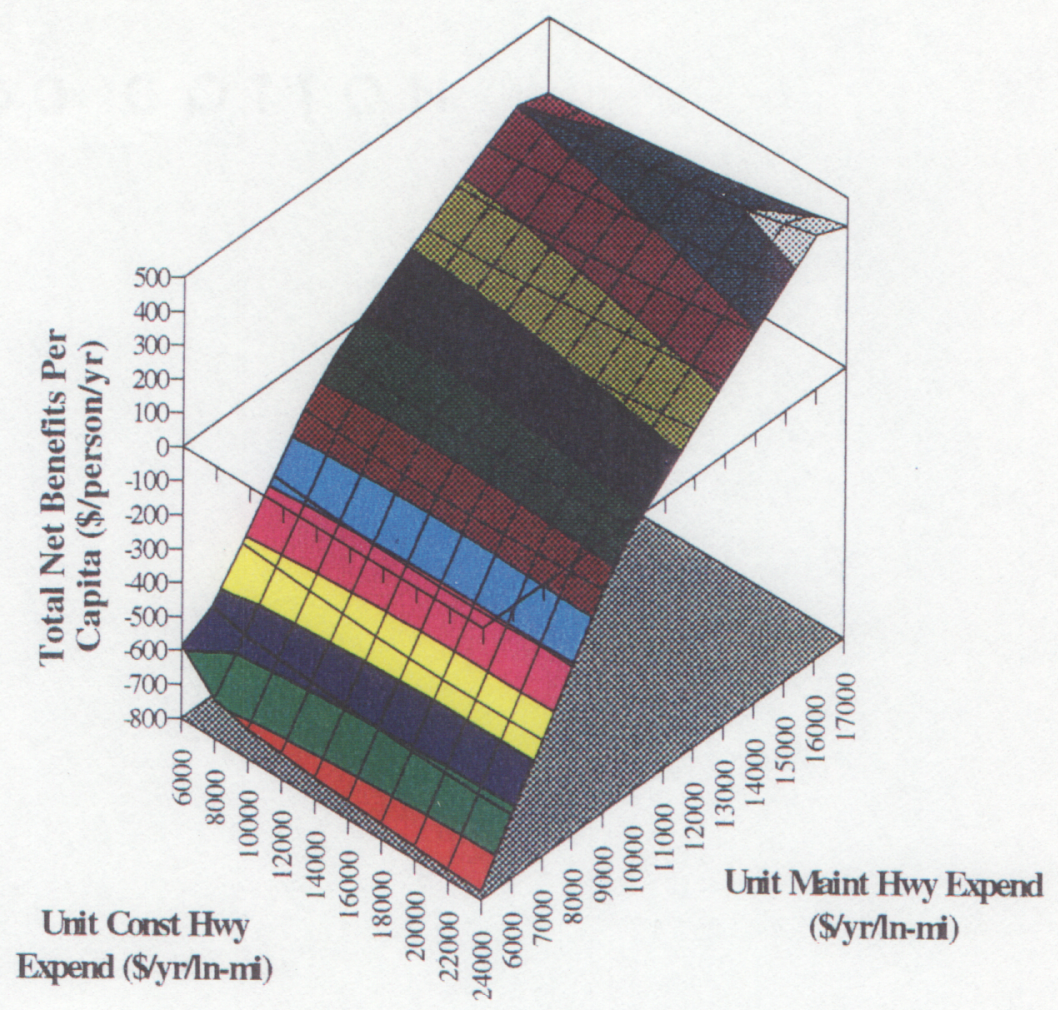

Figure 7.7: Total Net Benefits per Capita vs UMHE and UCHE Simulated over 10 Years

provide a system that will allow the efficient and effective movement of goods and people. The benefits derived for users and non-users alike are dependent upon both the roadway condition (Level of Operation) and the freedom of travel, reliability of travel and the ease of movement (Level of Availability). The benefit-cost ratio will give an indication of the expenditure rate that will provide the most benefits for the expenditures on the system.

The benefits are a combination of the user and non-user benefits as determined previously. Since the simulation will generate yearly benefits, the user and non-user benefits will be summed over a period of time and then an annual equivalence 


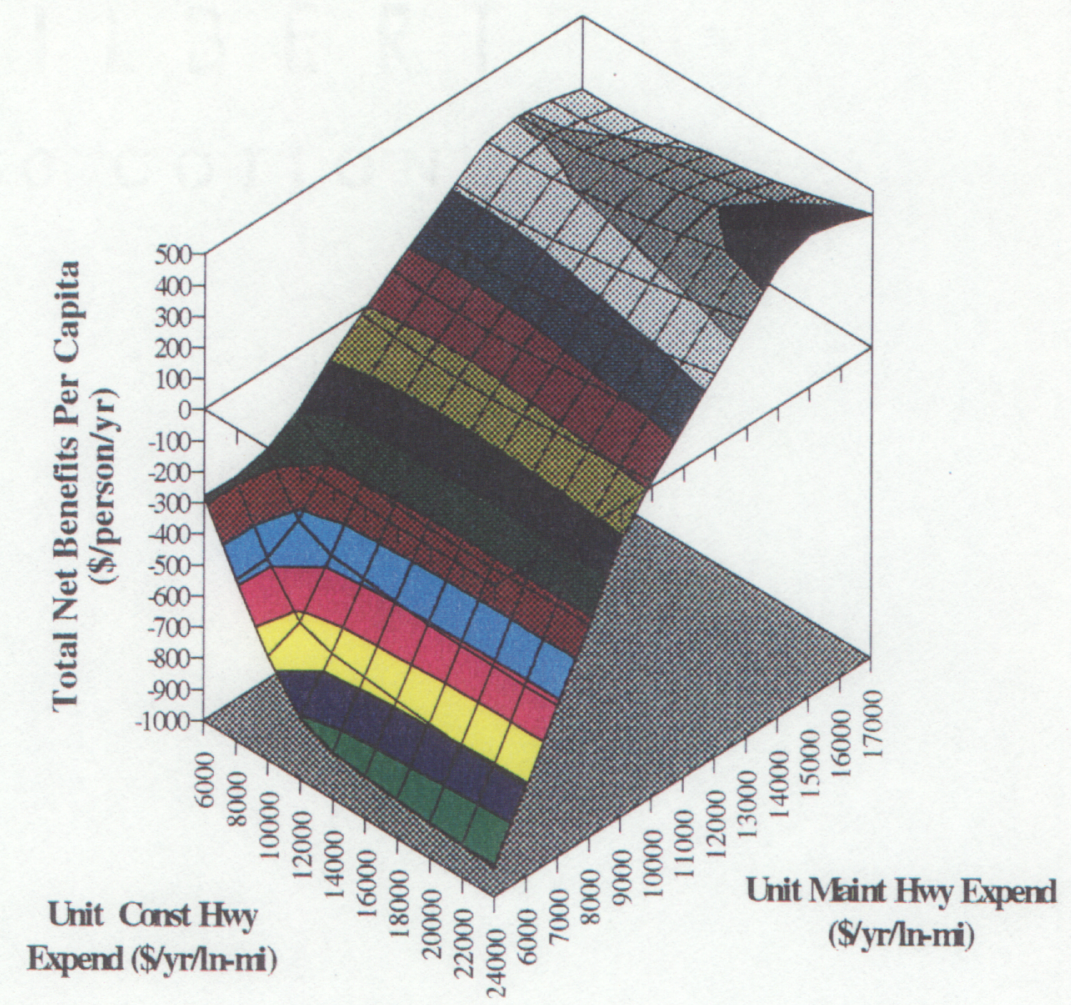

Figure 7.8: Total Net Benefits per Capita vs UMHE and UCHE Simulated over 15 Years

determined. The DYNAMO equations for the Annual Equivalence for User Benefits are as follows:

R PWUB. KL $=$ UB. $K *$ SPPWF.K

A SPPWF.K $=1 /((1+\mathrm{R}) * *$ TIME. $\mathrm{K})$

L CPWUB.K $=$ CPWUB.J $+(\mathrm{DT})($ PWUB.JK)

$\mathrm{N}$ CPWUB $=$ CPWUBN

C $\mathrm{CPWUBN}=0$

A AEUB. $K=$ CPWUB. $K *$ EPSCRF. $K$

A EPSCRF. $\mathrm{K}=((\mathrm{R} *(1+\mathrm{R}) * *$ TIME. $\mathrm{K})) /(((1+\mathrm{R}) * *$ TIME.K $)-.9999)$ 


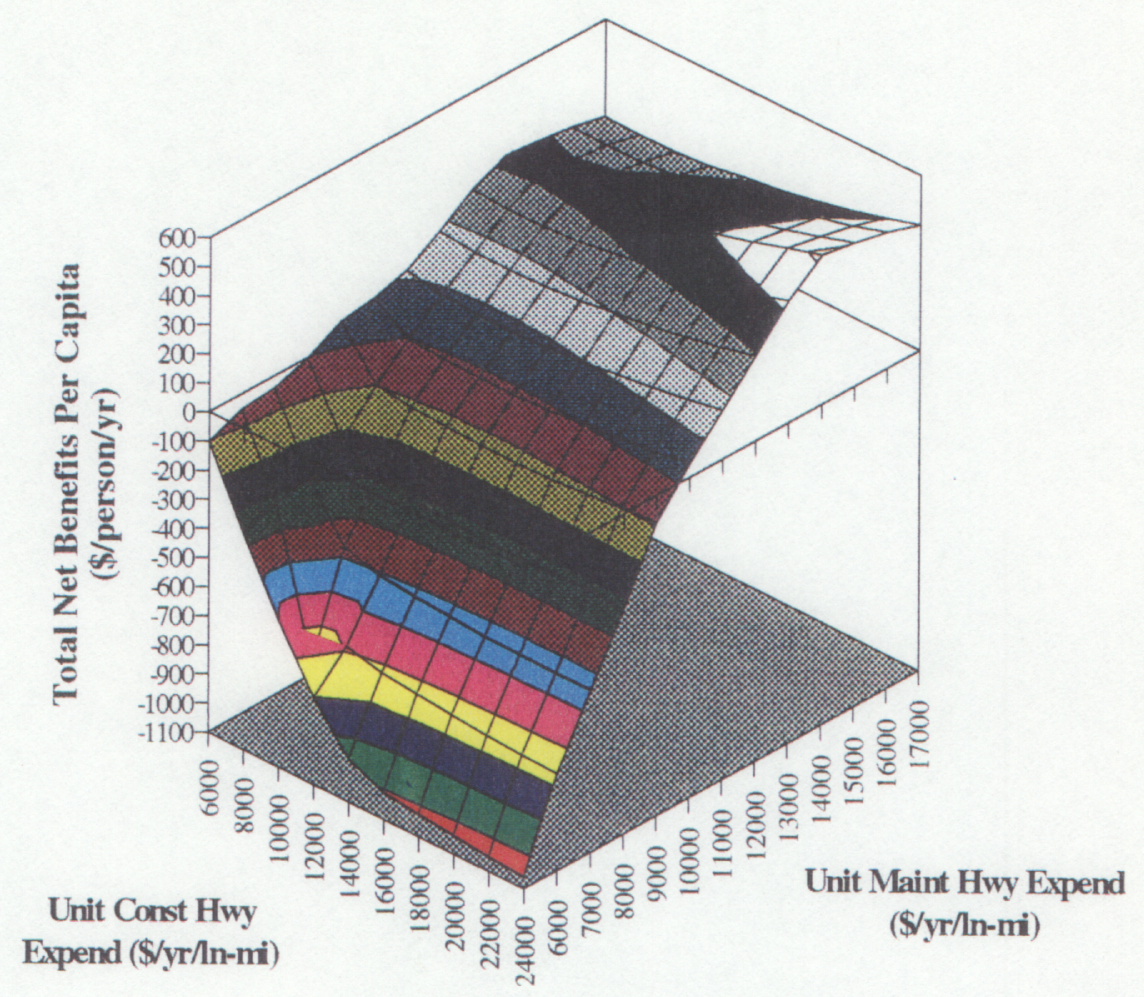

Figure 7.9: Total Net Benefits per Capita vs UMHE and UCHE Simulated over 20 Years

PWUB - Present-Worth User Benefits (\$/lane-mile)

UB - User Benefits (\$/year/mile)

SPPWF - Single Payment Present-Worth Factor $(P / F, i, n)$

$\mathrm{R}$ - Interest Rate (dimensionless)

CPWUB - Cumulative Present-Worth User Benefits (\$/lane-mile)

CPWUBN - Initial Value of Cumulative Present-Worth User Benefits (\$/lane-mile)

AEUB - Annual Equivalence User Benefits (\$/year/lane-mile)

EPSCRF - Equal Payment Series Capital Recovery Factor $(A / P, i, n)$

The DYNAMO equations for the Annual Equivalence for Non-User Benefits are as follows: 
R PWNUB.KL $=$ NUB. $K *$ SPPWF.K

L CPWNUB.K $=$ CPWNUB.J $+(\mathrm{DT})(\mathrm{PWNUB} . \mathrm{JK})$

$\mathrm{N}$ CPWNUB $=$ CPWNUBN

C $C P W N U B N=0$

A AENUB. $\mathrm{K}=\mathrm{CPWNUB} . \mathrm{K} *$ EPSCRF. $\mathrm{K}$

PWNUB - Present-Worth Non-User Benefits (\$/lane-mile)

NUB - Non-User Benefits (\$/lane-mile)

SPPWF - Single Payment Present-Worth Factor $(P / F, i, n)$

CPWNUB - Cumulative Present-Worth Non-User Benefits ( $\$ / \mathrm{mile})$

CPWNUBN - Initial Value for Cumulative Present Worth Non-User Benefits (\$/mile)

AENUB - Annual Equivalence of Non-User Benefits (\$/year/lane-mile)

EPSCRF - Equal Payment Series Capital Recovery Factor $(A / P, i, n)$

The benefit-cost ratio (Equation 7.19) can be simulated as the user benefits plus the non-user benefits less the annual maintenance expenditures divided by the construction investment. As is typical with most maintenance and construction work, prices increase over time due to inflationary pressures. To capture the results of this inflation, an inflation factor was added to the unit maintenance highway expenditure (UMHE) and unit construction highway expenditure (UCHE) to allow for the increasing of the yearly expenditures to match inflation if desired. As the inflation increases, the unit expenditure rates will increase. The DYNAMO equations for the Annual Equivalence for Unit Maintenance and Unit Construction Expenditures are as follows:

C $\mathrm{UMHE}=$ (Variable varied from $\$ 2,000$ to $\$ 17,000$ during simulations)

R RUMHE.KL = UMHE*INFF.K

A INFF.K $=(1+$ INFR $) * *$ TIME.K

C INFR $=0.00$

R PWRUMHE.KL $=$ RUMHE.KL $*$ SPPWF.K

L CPRUMH.K $=$ CPRUMH.J +(DT)(PWRUMHE.JK)

N CPRUMH $=$ CPRUMHN

C CPRUMHN $=0$

A AEUMHE. $\mathrm{K}=$ CPRUMH. $\mathrm{K} *$ EPSCRF. $\mathrm{K}$ 
UMHE - Unit Maintenance Highway Expenditure (\$/year/lane-mile) RUMHE - Actual Unit Maintenance Highway Expenditure (\$/year/lane-mile) INFF - Inflation Factor (dimensionless)

INFR - Inflation Rate (dimensionless)

PWRUMHE - Present-Worth Actual Unit Maintenance Highway Expenditure (\$/lane-mile)

SPPWF - Single Payment Present-Worth Factor $(P / F, i, n)$

CPRUMH - Cumulative Present-Worth Real Unit Maintenance Highway Expenditure (\$/lane-mile)

CPRUMHN - Initial Value of Cumulative Present-Worth Real Unit Maintenance Highway Expenditure (\$lane-mile)

AEUMHE - Annual Equivalence Unit Maintenance Highway Expenditure (\$/year/lane-mile)

EPSCRF - Equal Payment Series Capital Recovery Factor $(A / P, i, n)$

C $\mathrm{UCHE}=$ (Variable varied from $\$ 2,000$ to $\$ 24,000$ during simulations)

A RUCHE.KL $=$ UCHE*INFF.K

R PWRUCHE.KL $=$ RUCHE.KL*SPPWF.K

L CPRUCH.K $=$ CPRUCH.J +(DT)(PWRUCHE.JK)

$\mathrm{N}$ CPRUCH $=\mathrm{CPRUCHN}$

C $\mathrm{CPRUCHN}=1$

A AEUCHE.K=CPRUCH.K*EPSCRF.K

UCHE - Unit Construction Highway Expenditure (\$/lane-mile)

RUCHE - Actual Unit Construction Highway Expenditure (\$/lane-mile)

INFF - Inflation Factor (dimensionless)

PWRUCHE - Present-Worth Actual Unit Construction Highway Expenditure (\$/lane-mile)

SPPWF - Single Payment Present-Worth Factor $(P / F, i, n)$

CPRUCH - Cumulative Present-Worth Actual Unit Construction Highway Expenditure (\$/lane-mile)

CPRUCHN - Initial Value of Cumulative Present-Worth Actual Unit

Construction Highway Expenditure (\$/lane-mile)

AEUCHE - Annual Equivalence for Present-Worth Unit Construction Highway

Expenditure (\$/year/lane-mile)

EPSCRF - Equal Payment Series Capital Recovery Factor $(A / P, i, n)$

As the benefits increase, the benefit-cost ratio will increase. As the annual maintenance expenditures increase, the benefit-cost ratio will decrease. As the 
construction investment expenditures increase, the benefit-cost ratio will also decrease. The DYNAMO equations for the Benefit-Cost Analysis using an annual equivalent basis is as follows:

\section{A BENCOST.K=(AEUB.K + AENUB.K-AEUMHE.K)/(AEUCHE.K)}

BENCOST - Annual Equivalent Benefit-Cost Ratio (dimensionless)

AEUB - Annual Equivalence of User Benefits (\$/year/lane-mile)

AENUB - Annual Equivalence of Non-User Benefits (\$/year/lane-mile)

AEUMHE - Annual Equivalence of Unit Maintenance Highway Expenditure (\$/year/lane-mile)

AEUCHE - Annual Equivalence of Unit Construction Highway Expenditure (\$/year/lane-mile)

The benefits derived from maintenance and construction expenditures increase as expenditures increase. From a DYNAMO simulation, Figures 7.10 and 7.11 reveal that a satisfactory benefit-cost ratio will be derived only after a substantial commitment to maintenance expenditures. For example, both figures show the benefit-to-cost ratio is greater than one (1) after $\$ 12,000$ per year per lane-mile is expensed in highway maintenance. Figure 7.11 is the result of a 20 year simulation. If this time were considered to be the length of time for investment purposes, the graph indicates that a point exists where the expenditure rate exceeds the benefits gained by those expenditures. After a maintenance expenditure rate of $\$ 15,000$ per year per lane-mile, the benefit-cost ratio begins to level out and even decrease at higher expenditure rates.

From Figure 7.11, the benefit-cost ratio is continuing to increase from year 15 to year 20. This methodology allows accumulation of user and non-user benefits on a yearly basis for annualizing instead of estimating an annual benefit to be used for each year in the benefit-cost calculations. Consequently, the annual equivalent user and non-user benefits will be increasing each year. From this additional information, it can 


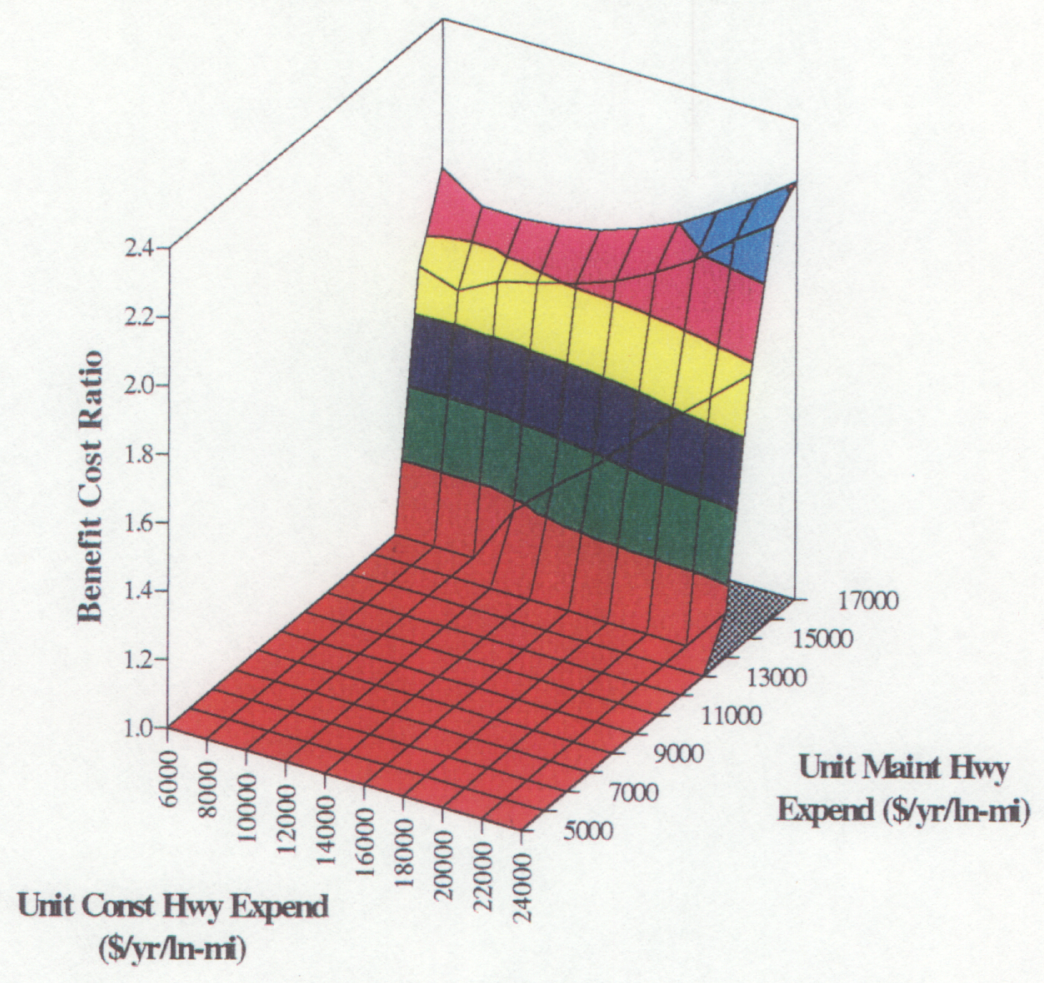

Figure 7.10: Benefit-Cost Ratio (Annual Equivalence) vs UMHE and UCHE Simulated over 15 Years

also be determined when the total benefits become positive, giving an indication of how far into the future it may be before a project will start being beneficial to the motoring public. An example of this is shown below in Figure 7.12 by graphing the total benefits for a unit maintenance highway expenditure of $\$ 15,000$ per year per lane-mile and a unit construction highway expenditure of $\$ 12,000$ per year per lane-mile. The initially low total benefits are primarily due to the vehicle operating costs being above normal for the first few years. The initial deficit takes several years to overcome in the overall analysis. This again indicates that maintenance expenditures are important to keeping the user and non-user benefits at a higher level. 


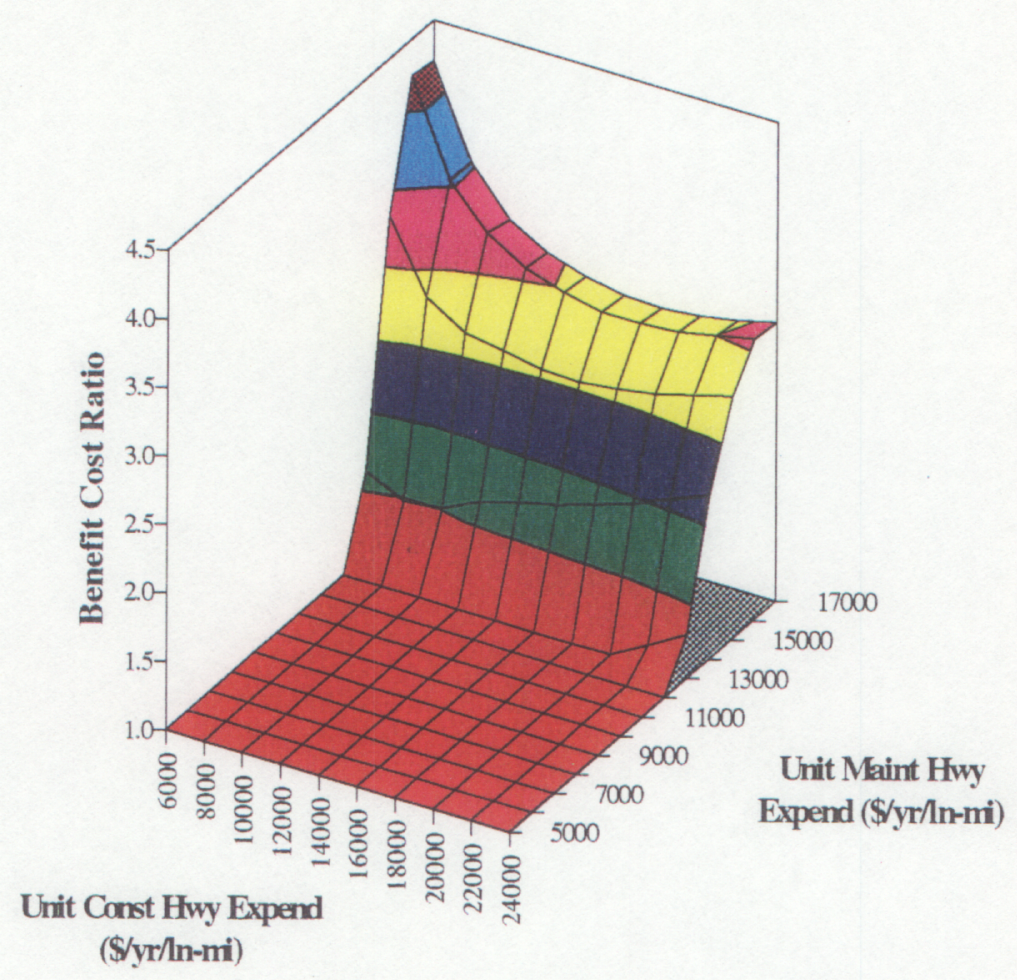

Figure 7.11: Benefit-Cost Ratio (Annual Equivalence) vs UMHE and UCHE Simulated over 20 Years

A simplified form of the benefit-cost ratio (BCR) was developed in Equation 7.20. This form of the BCR allows the use of a construction investment cost per lanemile if preferred by the decision makers instead of an annual per lane-mile investment cost. The construction investment cost would be the cost for the actual improvement or upgrade project instead of a system-wide expenditure rate. The benefit-cost ratio still determines the benefits less the maintenance expenditures derived from the investment expenditure decision. As before, an increase in benefits will increase the benefit-cost ratio. An increase in maintenance expenditures will decrease the benefit-cost ratio. An increase in the construction investment will decrease the benefit-cost ratio. The 


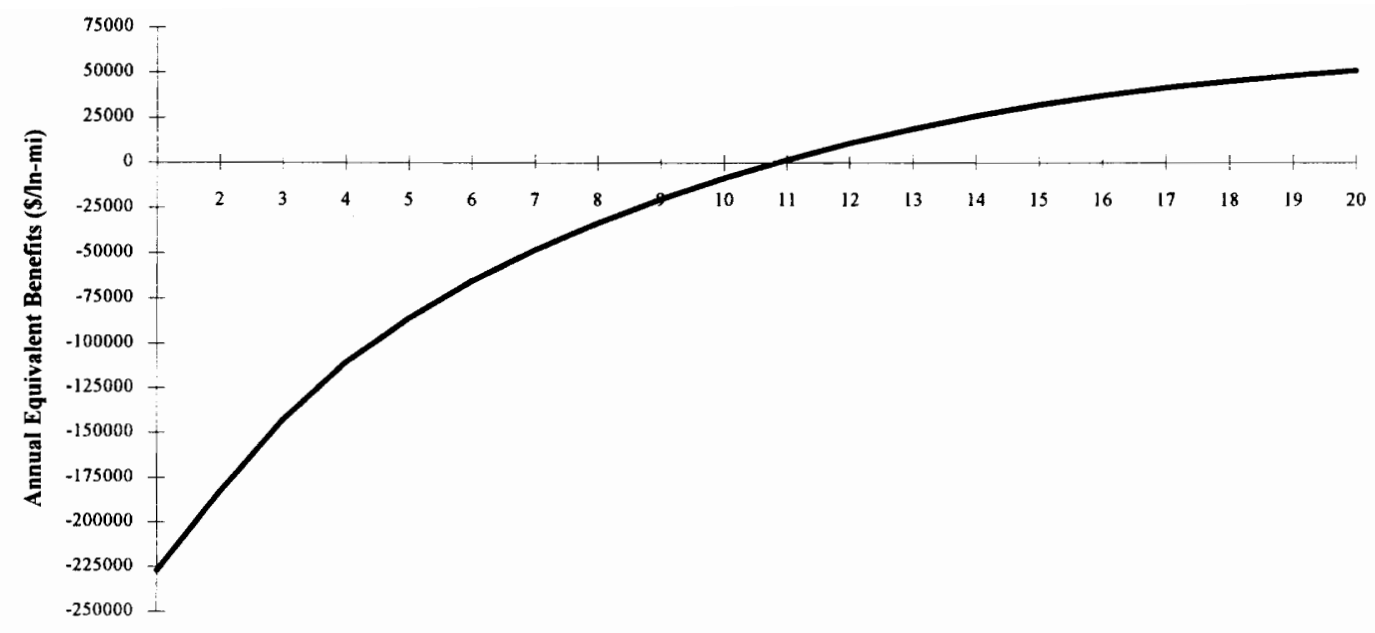

Years

Figure 7.12: Annual Equivalent Total Benefits

DYNAMO equations for the Benefit-Cost Ratio analysis using the continuous compounding basis are as follows:
A CBENCST.K $=\left((\right.$ AEUB. $K+$ AENUB.K-RUMHE.KL $) /{ }^{\wedge}$
C $\mathrm{YEARS}=7$
(RUCHE.KL*R*YEARS) $) *\left(1-E X P\left(-R^{*}\right.\right.$ ECONLIFE) $)$
C $\mathrm{R}=.10$
C ECONLIFE $=25$

CBENCST - Continuous Compounding Benefit-Cost Ratio (dimensionless) AEUB - Annual Equivalence of User Benefits (\$/year/lane-mile) AENUB - Annual Equivalence of Non-User Benefits (\$/year/lane-mile) RUMHE - Actual Unit Maintenance Highway Expenditures (\$/year/lane-mile) RUCHE - Actual Unit Construction Highway Expenditures (\$/year/lane-mile) YEARS - Years before Rehabilitation (years) $\mathbf{R}$ - Interest Rate (dimensionless)

ECONLIFE - Economic Life of Project (years)

A simulation was accomplished with no inflation and no increase in lane-miles to demonstrate the benefit-cost analysis during maintenance or rehabilitation of an existing 
system. For the model developed, the construction accomplished is for increasing lane widths, adding shoulders, rehabilitating existing roads, and reconstructing highways to improve alignment. The maintenance encompasses both ordinary maintenance activities, such as spot patching or crack sealing, and maintenance replacement activities such as seal coats and overlays. Figures 7.13 and 7.14 reveal that an increase in both maintenance and construction investments will increase the benefit-cost ratio suggesting that increasing expenditures for both maintenance and construction will increase the user and non-user benefits derived from the expenditures. Also, it is noted, that a positive BCR does not start until a substantial commitment of maintenance funding is provided, over $\$ 12,000$ per year per lane-mile.

\section{Summary}

Benefits that are derived from the maintenance and construction activities for a highway system are the basis for determining what types of expenditures should be undertaken. Users and non-users alike are concerned with the Comprehensive Level of Service of a highway since it is a measure of their direct benefits as indicated by the freedom to maneuver, the travel reliability of the system, and the expense for movement of goods and personal travel. The ability to quantify these types of benefits, such as vehicle operating costs and travel time reductions, and then relate these benefits to the costs for maintenance and construction expenditures will greatly enhance the decision-makers' ability to effectively and efficiently use the resources available to them.

The framework developed provides the opportunity to determine expenditure rates for maintenance and/or construction and visualize the impact of those decisions. User benefits were modeled to relate the Comprehensive Level of Service to a 


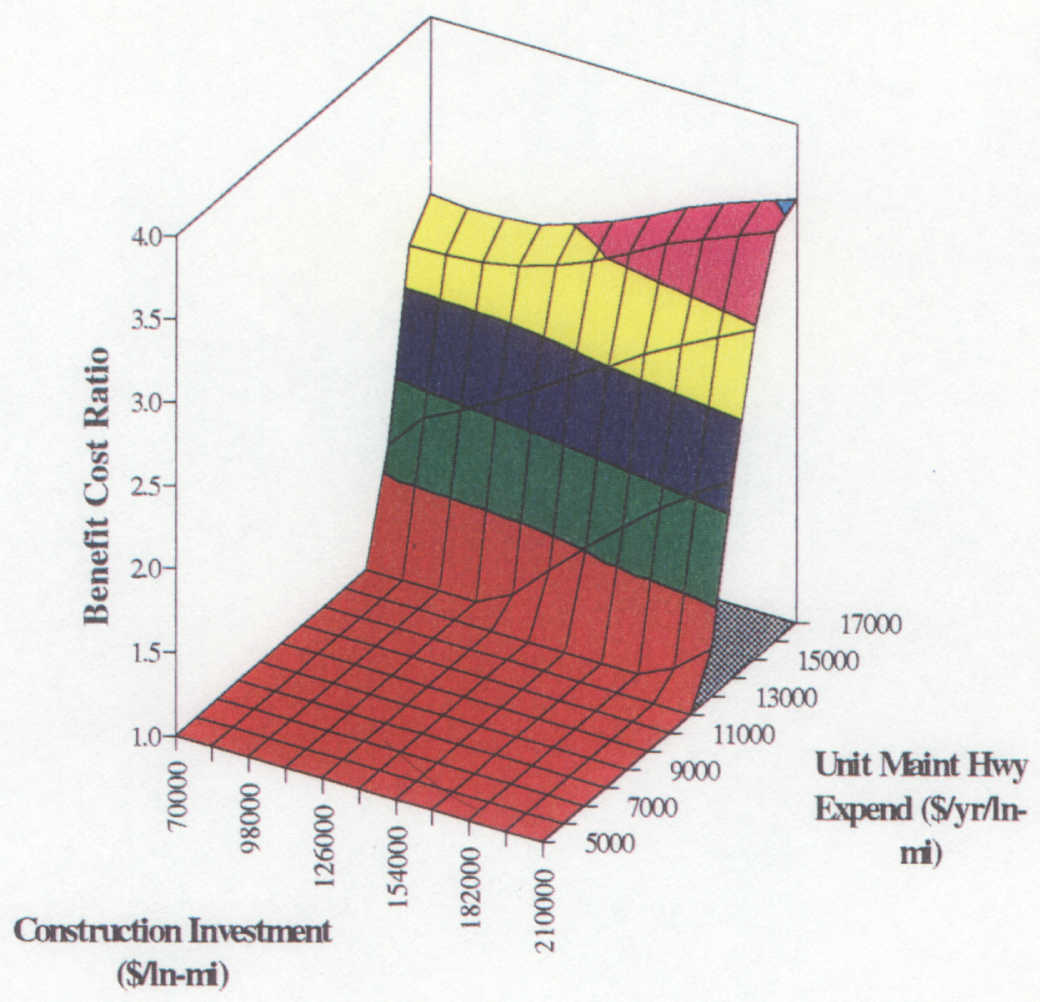

Figure 7.13: Benefit-Cost Ratio (Continuous Compounding) vs UMHE and Construction Investment Simulated over 15 Years

reduction or increase in travel time, and to relate the Level of Operation (maintenance) to vehicle operating costs. Non-user benefits were related to the Comprehensive Level of Service and the increase or decrease in travel time, an important factor for business owners. From the simulation model, the total net benefits (the user and non-user benefits less the maintenance and construction expenditures) generally increase as the expenditures increase. However, the model suggests that a point exists where the net benefits start decreasing even though the expenditures continue to increase. This is an important point to understand and consider in the final decision process. 


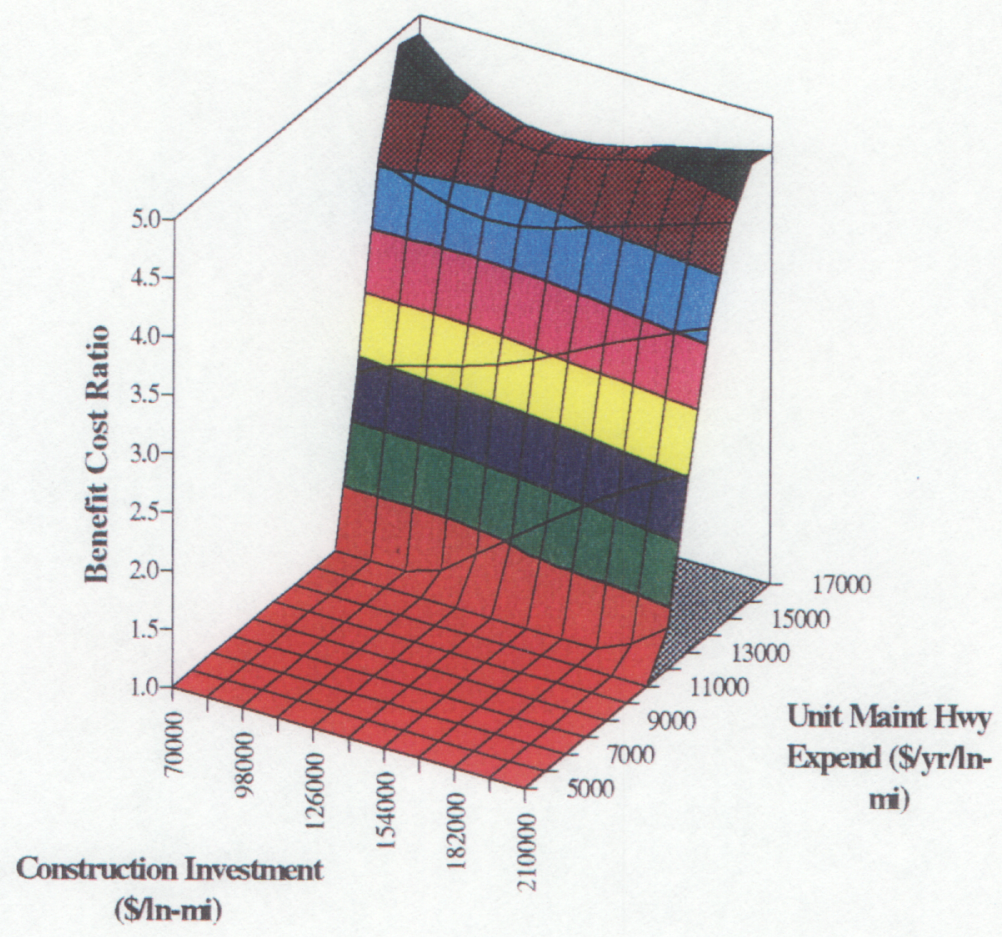

Figure 7.14: Benefit-Cost Ratio (Continuous Compounding) vs UMHE and Construction Investment Simulated over 20 Years

Finally, the benefit-cost ratio was modeled to show how the benefits derived for the expenditure rates could be used to help determine how to better utilize the available resources. Increasing expenditures increased the benefit-cost ratio, but a point seems to exist where the expenditures outweigh the benefits derived. This point is suggested from the model and resultant surface graphs. The benefit-cost ratio is an easily understood concept that is used extensively in the transportation sector. By utilizing this approach in the model framework, the end product will be more useful to the decision makers. 


\section{CHAPTER 8: \\ MODEL VALIDATION}

\section{Introduction}

This chapter describes the process used to establish confidence in the soundness and usefulness of the system dynamics models developed. The model validation consists of dimensional consistency analysis, parameter sensitivity, and extreme conditions tests.

\section{System Dynamics Model Validation}

Validation of system dynamics models is a topic of frequent discussion. The following is taken from Richardson (1981) and Bala (1994) as to the purpose and rationale behind the system dynamics question of validity.

Model building in the system dynamics area is to provide insight into the dynamics and inter-relationships of a complex problem and to answer a reasonably, well-defined set of questions. The model should be suitable for the purpose proposed and the problem addressed and be consistent with the slice of reality it is trying to capture. While these two ideas are subjective, several objective tests can be utilized to judge a model's utility and effectiveness. The most obvious test would be if policies implemented through the use of the model produced the results predicted in the real world. Since the time-frame of prediction is long after the adoption of policies, the purpose of the validation step is to instill confidence in the model regarding its soundness and usefulness. This will be addressed through validation, sensitivity analysis and policy analysis.

Table 8.1 was adapted from Richardson (1981) and is a concise chart that indicates the tests that were used to help guide the model building and provide the level 
of confidence placed in the model behavior. "Any one of these tests by itself is certainly adequate as an indicator of model validity. Taken together, they are a formidable filter, capable of trapping and weeding out weaker models and allowing passage only to those most likely to reflect something close to the truth" (Richardson 1981, p. 313).

Table 8.1: Summary Table of Tests for Building Confidence in System Dynamics Models (Richardson 1981)

\begin{tabular}{|l||l|l|}
\hline & Focus on STRUCTURE & Focus on BEHAVIOR \\
\hline \hline $\begin{array}{l}\text { Testing SUITABILITY } \\
\text { for purpose }\end{array}$ & Dimensional Consistency & $\begin{array}{l}\text { Parameter (in)sensitivity } \\
\text { - behavior characteristics } \\
\text { - policy conclusions }\end{array}$ \\
$\begin{array}{l}\text { (tests focusing inward } \\
\text { on the model) }\end{array}$ & Extreme conditions & \\
\hline $\begin{array}{l}\text { Testing CONSISTENCY } \\
\text { with reality }\end{array}$ & $\begin{array}{l}\text { Face validity } \\
\text { - rates and levels } \\
\text { (tests comparing the } \\
\text { model with information } \\
\text { about the real system) }\end{array}$ & information feedback \\
\hline $\begin{array}{l}\text { Contributing to the } \\
\text { UTILITY and } \\
\begin{array}{l}\text { EFFECTIVENESS of a } \\
\text { suitable, consistent model }\end{array}\end{array}$ & $\begin{array}{l}\text { Extreme condition behavior } \\
\text { - aggregation/detail }\end{array}$ & \\
\hline
\end{tabular}




\section{Testing Confidence in a System Dynamics Model}

\section{Tests for Model Structure and Behavior Suitability}

Structure verification relates the structure of the model to the structure of the real system. The model statements should be well argued in relation to what is known and described about the system being modeled. The structure of the model should also match observable information and constraints of the system. For example, additional maintenance expenditures should generate better system road quality and decrease travel time on a highway link. As indicated by Figures 6.1 and 6.6, increasing maintenance expenditures does indeed provide a better quality road system in terms of the Level of Operation and the number of physically sufficient lane-miles in the system. Figure 8.1 below, also from the maintenance model, indicates that as maintenance expenditures are increased, travel time on a per mile basis does decrease, which is what is anticipated to occur.

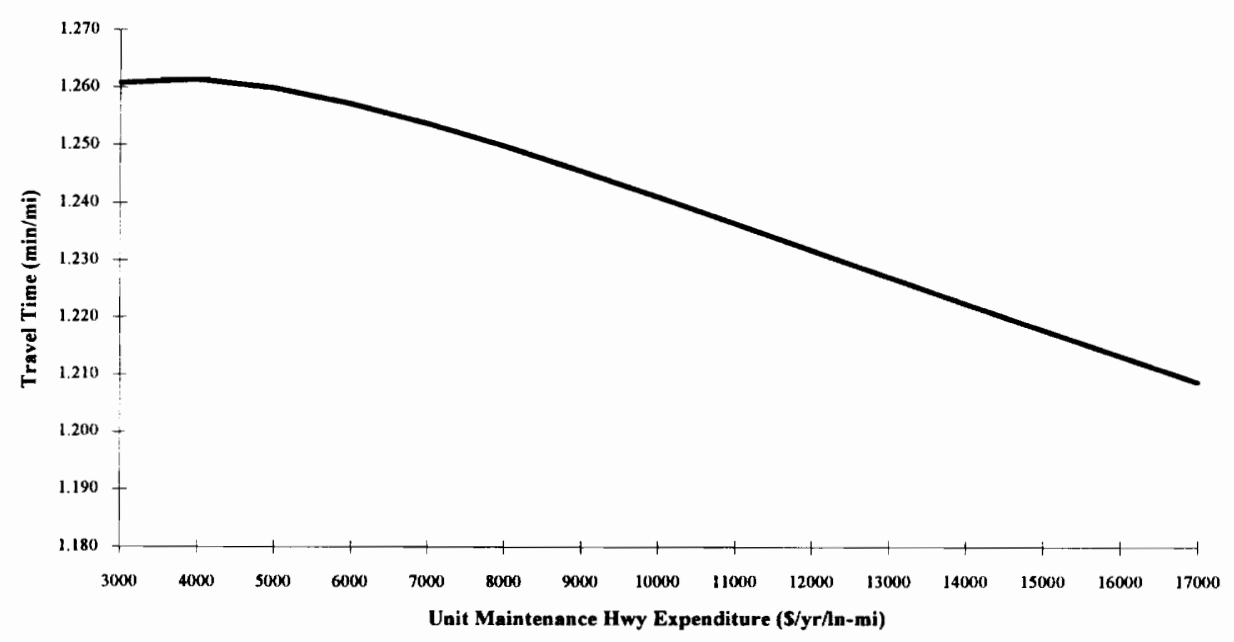

Figure 8.1: Effect of Unit Maintenance Highway Expenditures on Travel Time 


\section{Dimensional Consistency Verification}

Dimensional consistency entails a dimensional analysis of the model's rate equations to verify if the right hand and left hand side of the equation match dimensionally. This ensures that the units are proper, thus strengthening the confidence in the model structure. This also relates to a parameter consistency as the parameters in the model should have a correlation to observable constants in real life. The choice of initial values for the level equations and values of constants is directly related to model description and should relate to observable values.

A dimensional consistency check was accomplished on all rates in the models to verify the consistency of the model equations. As an example, the following dimensional analysis of the rate equation for Highway Ordinary Maintenance, HOM, is provided to show the procedure used.

R HOM.KL $=$ HME.K*FEOM/OMC

A HME.K=UMHE*HWYT.K

C $\mathrm{UMHE}=$ (Variable varied from $\$ 2,000$ to $\$ 17,000$ during simulations)

C $\mathrm{FEOM}=0.5$

C $\mathrm{OMC}=50000$

HOM - Highway Ordinary Maintenance (lane-miles/year)

HME - Highway Maintenance Expenditure (\$/year)

FEOM - Fraction Expenditure to Ordinary Maintenance (dimensionless)

OMC - Ordinary Maintenance Cost (\$/lane-mile)

UMHE - Unit Maintenance Highway Expenditure (\$/year/lane-mile)

HWYT - Highway Total (lane-miles)

$$
\operatorname{HOM}\left(\frac{\text { lane }- \text { miles }}{\text { year }}\right)=\frac{\operatorname{HME}\left(\frac{\$}{\text { year }}\right) * \operatorname{FEOM}(\text { dimensionless })}{\text { OMC }\left(\frac{\$}{\text { lane }- \text { miles }}\right)}
$$

Substituting UMHE*HWYT.K for HME in the rate equation and canceling yields: 
$\operatorname{HOM}\left(\frac{\text { lane }- \text { miles }}{\text { year }}\right)=\frac{\operatorname{UMHE}\left(\frac{\$ / \text { year }}{\text { lane }- \text { mile }}\right) * \text { HWYT }(\text { lane }- \text { miles }) * \text { FEOM }}{\operatorname{OMC}\left(\frac{\$}{\text { lane }- \text { mile }}\right)}=\left(\frac{\text { lane }- \text { miles }}{\text { year }}\right)$

The rate equation is consistent on both sides of the equations in lane-miles per year. The rate also has consistency in a real world situation since a maintenance work rate could be considered on a basis of how many lane-miles of maintenance were accomplished per year. The maintenance rate would depend on the rate of maintenance expenditure and the total highway expenditure available.

\section{Model Behavior and Parameter Sensitivity}

This test for confidence deals with the model behavior and the sensitivity of the model to parameter variation. Typically, the behavior of a system dynamics model will not be affected by reasonable changes in most parameter values. As parameter values are changed through a plausible range, the behavior of the model should not be dramatically affected. However, real systems and models are sensitive to a few variables. Finding a sensitive variable enhances the worth of a model as more emphasis can be placed on data gathering or testing to determine a more suitable value for the model.

The following graphs reflect a parameter sensitivity analysis reflecting a change of $\pm 50 \%$ of the initial values for ordinary maintenance cost (OMC), maintenance replacement cost (MRC), highway aging time (HAT), and highway deteriorating time (HDETT). Table 8.2 indicates the parameters, initial parameter values and the values as varied for the maintenance model. 
Table 8.2: Parameter Sensitivity Analysis for Maintenance Model

\begin{tabular}{|c|c|c|c|c|c|}
\hline Parameter & $\begin{array}{c}\text { Parameter } \\
\text { Description }\end{array}$ & $\begin{array}{c}\text { Initial } \\
\text { Value }\end{array}$ & $\begin{array}{c}\mathbf{5 0 \%} \\
\text { Decrease }\end{array}$ & $\begin{array}{c}\mathbf{5 0 \%} \\
\text { Increase }\end{array}$ & Figure \\
\hline \hline OMC & $\begin{array}{c}\text { Ordinary } \\
\text { Maintenance Cost }\end{array}$ & $\$ 50,000$ & $\$ 25,000$ & $\$ 75,000$ & 8.2 \\
\hline MRC & $\begin{array}{c}\text { Maintenance } \\
\text { Replacement Cost }\end{array}$ & $\$ 200,000$ & $\$ 100,000$ & $\$ 300,000$ & 8.3 \\
\hline HAT & Highway Aging Time & 5 & 2.5 & 7.5 & 8.4 \\
\hline HDETT & $\begin{array}{c}\text { Highway } \\
\text { Deteriorating Time }\end{array}$ & 10 & 5 & 15 & 8.5 \\
\hline
\end{tabular}

Figures 8.2 through 8.5 show the effect of the parameter variation on the travel time as defined in the maintenance model, Appendix A. This test for parameter sensitivity helps the modeler to understand the implication of parameter variation. As each parameter was varied with all other parameters being held constant, the impact on travel time was used to determine how the model behaves since travel time is important to the understanding of user and non-user benefits. The general insensitivity of the parameters indicates a stable model. For example in Figure 8.2, when the ordinary maintenance cost is varied from $\$ 25,000$ to $\$ 75,000$, the travel time still decreases. However, at lower expenditures rates, the travel time increases because the road quality would be deteriorating due to the higher cost of maintenance and lower expenditure rate. This is reasonable. A similar structure is noted for Figure 8.3 with the maintenance replacement cost.

The highway deterioration rates in Figures 8.4 and 8.5 provide similar information. As the highway aging time decreases, more lane-miles of road will need repair on an annual basis. A lower maintenance expenditure rate would allow the road quality to deteriorate, increasing the travel time. With a more rapid highway aging time, a greater maintenance expenditure rate would be required to keep the quality of 

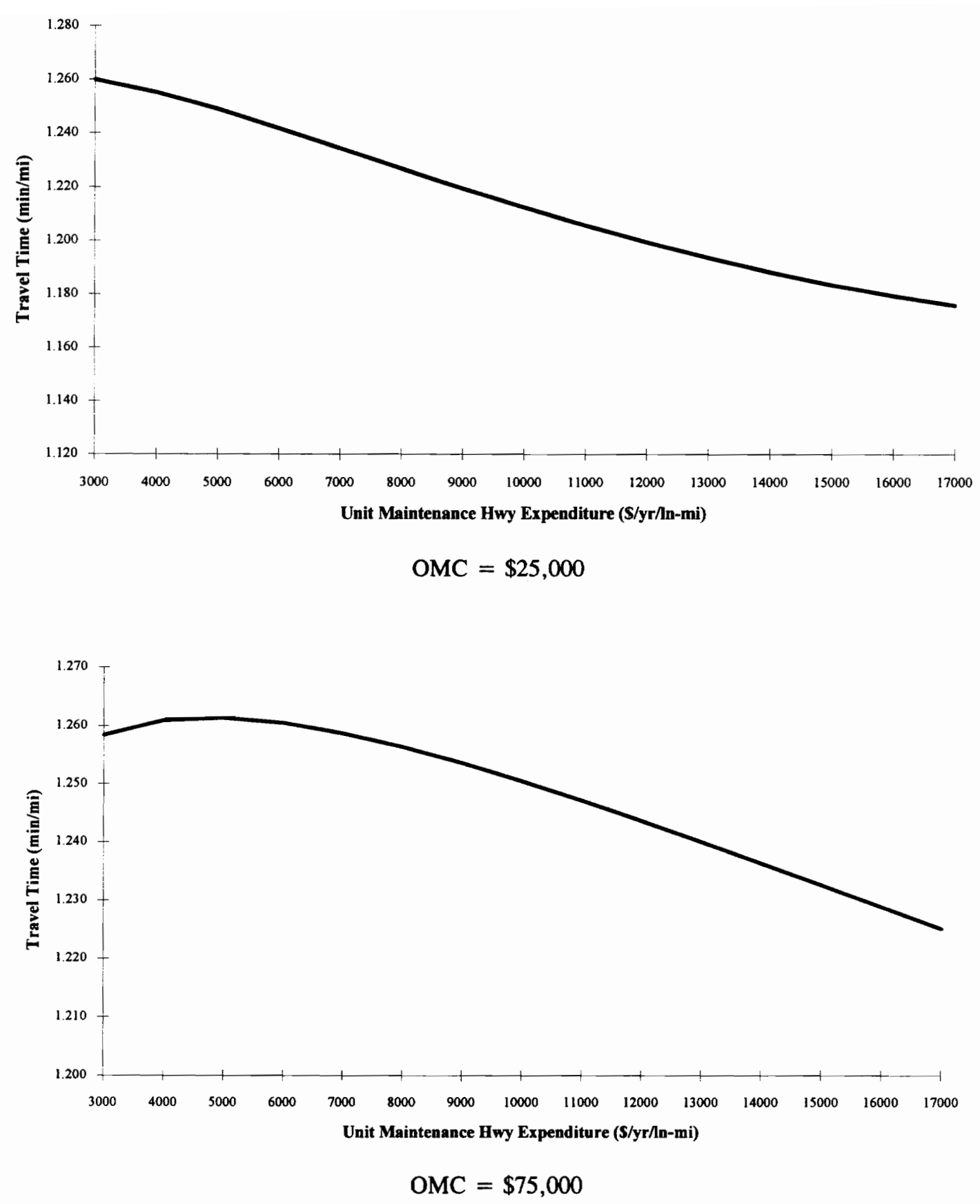

Figure 8.2: Parameter Sensitivity for Ordinary Maintenance Cost in the Maintenance Model 


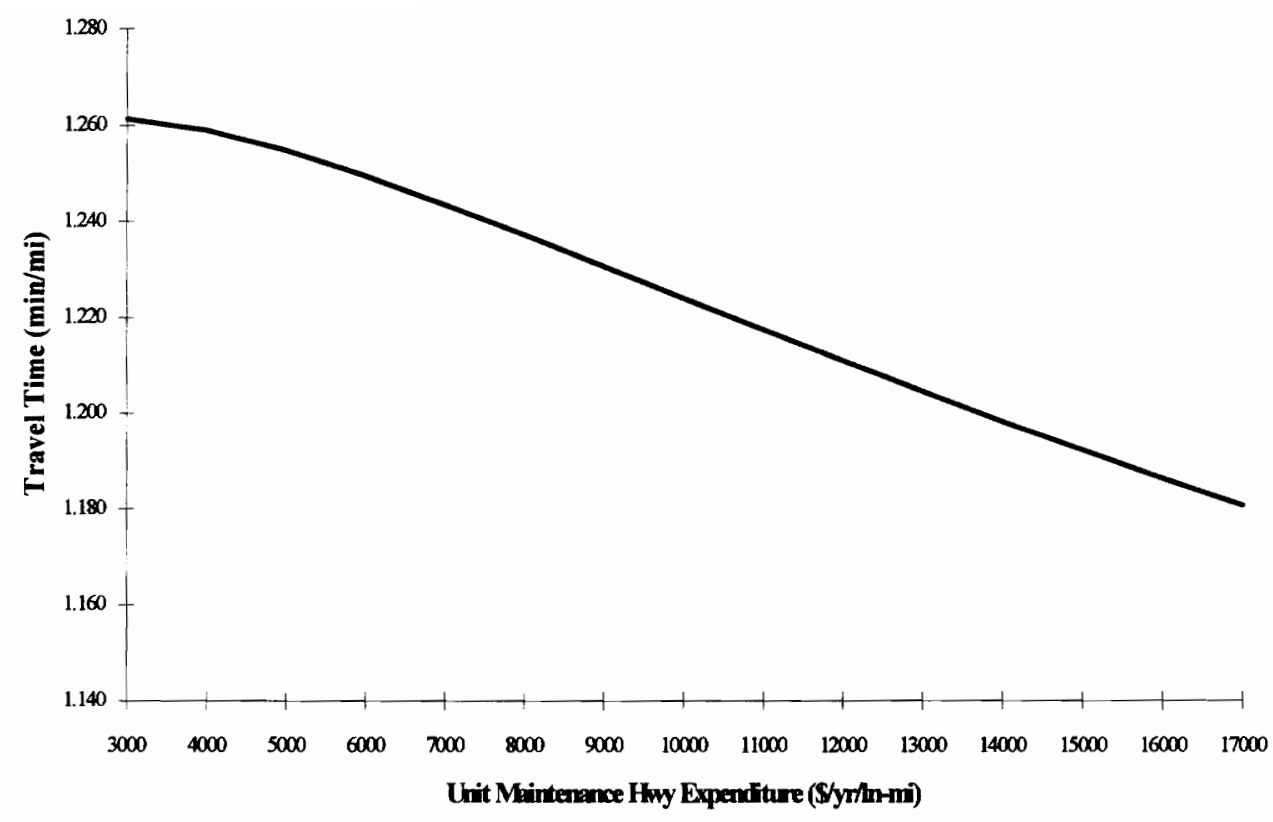

$\mathrm{MRC}=\$ 100,000$

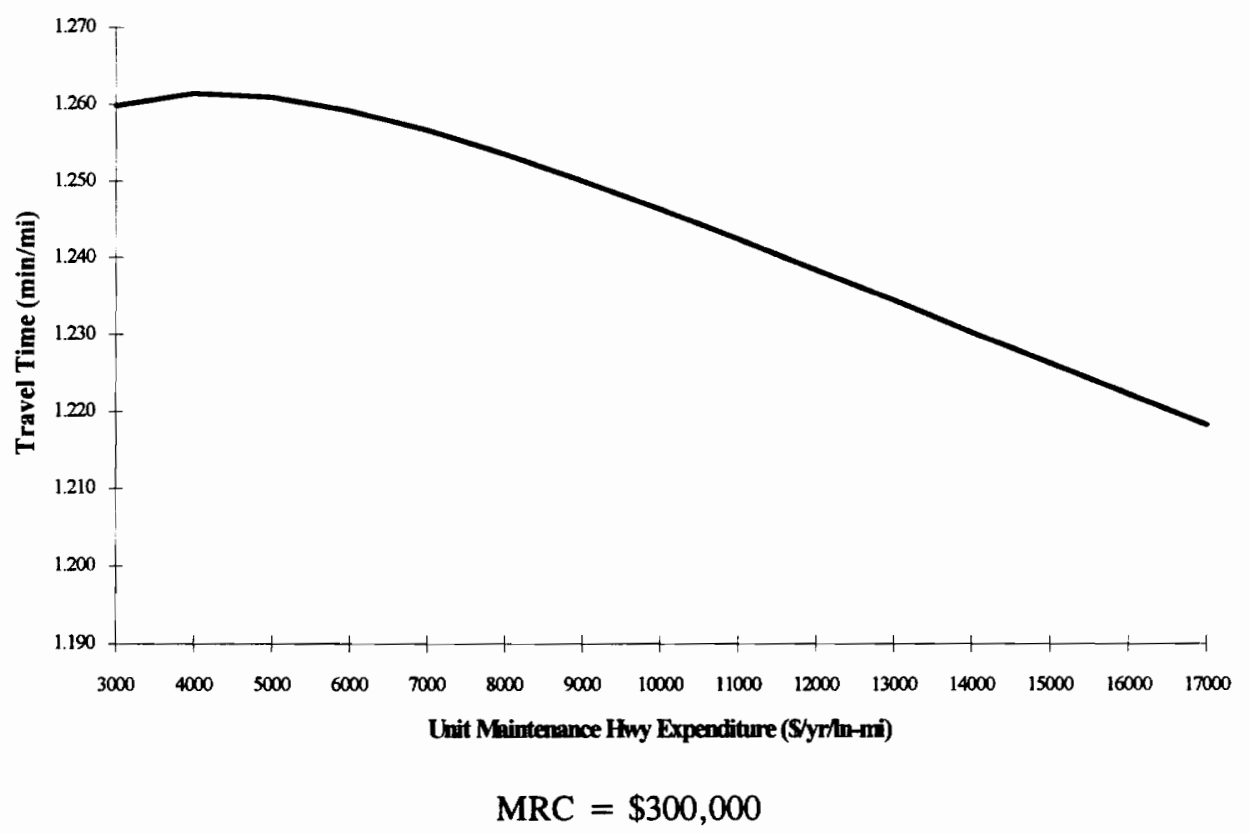

Figure 8.3: Parameter Sensitivity for Maintenance Replacement Cost in the Maintenance Model 


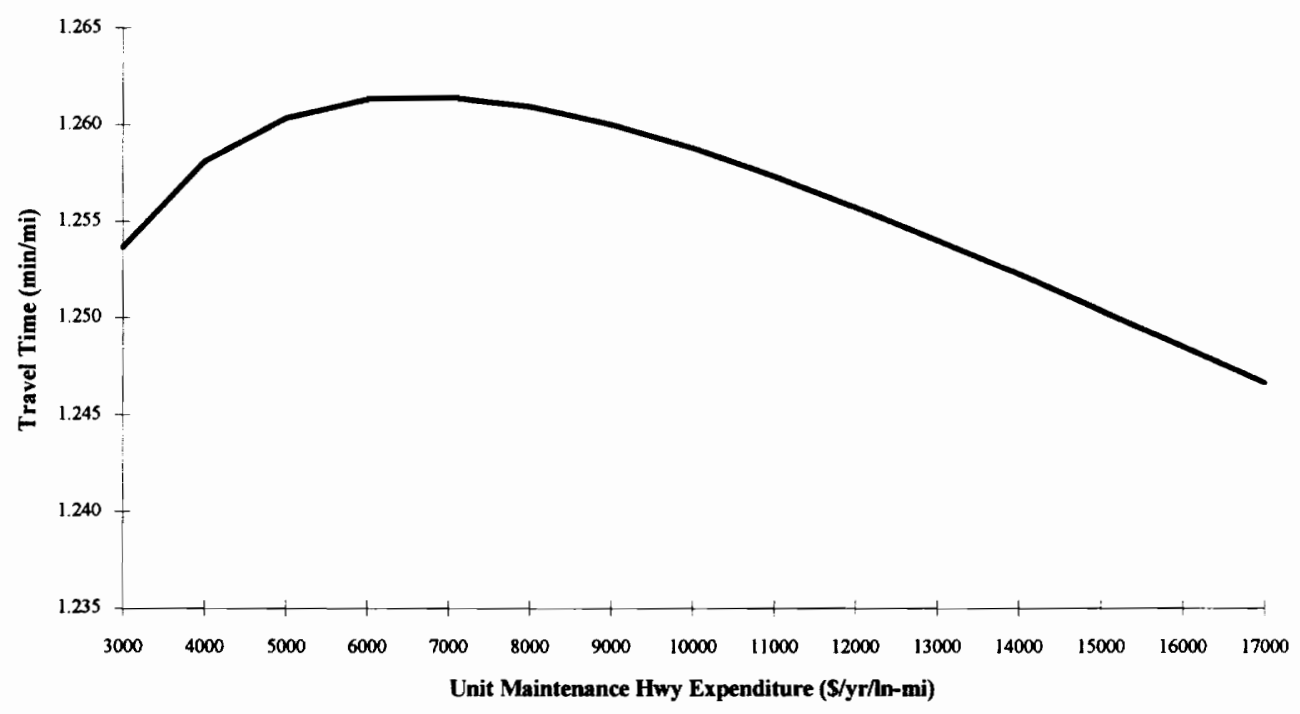

$\mathrm{HAT}=2.5$ years

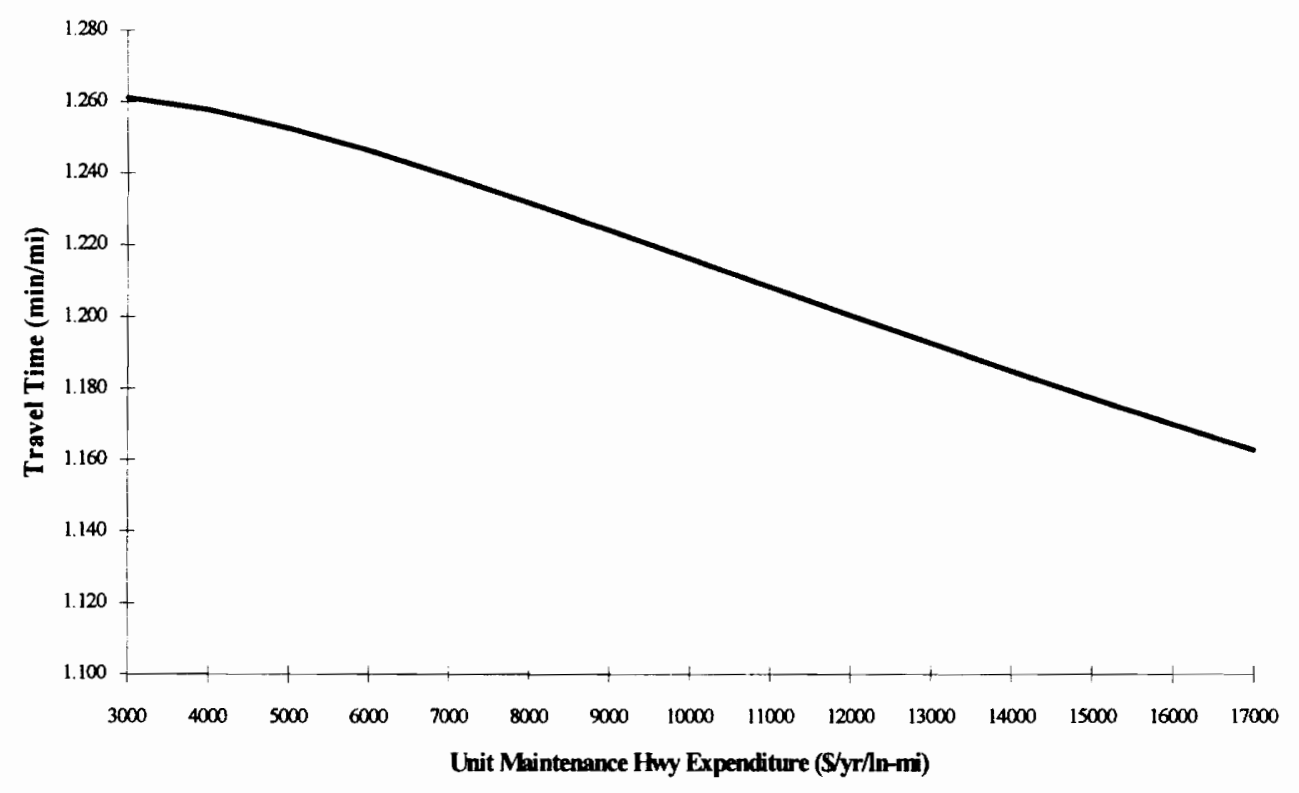

$\mathrm{HAT}=7.5$ years

Figure 8.4: Parameter Sensitivity for Highway Aging Time in the Maintenance Model 

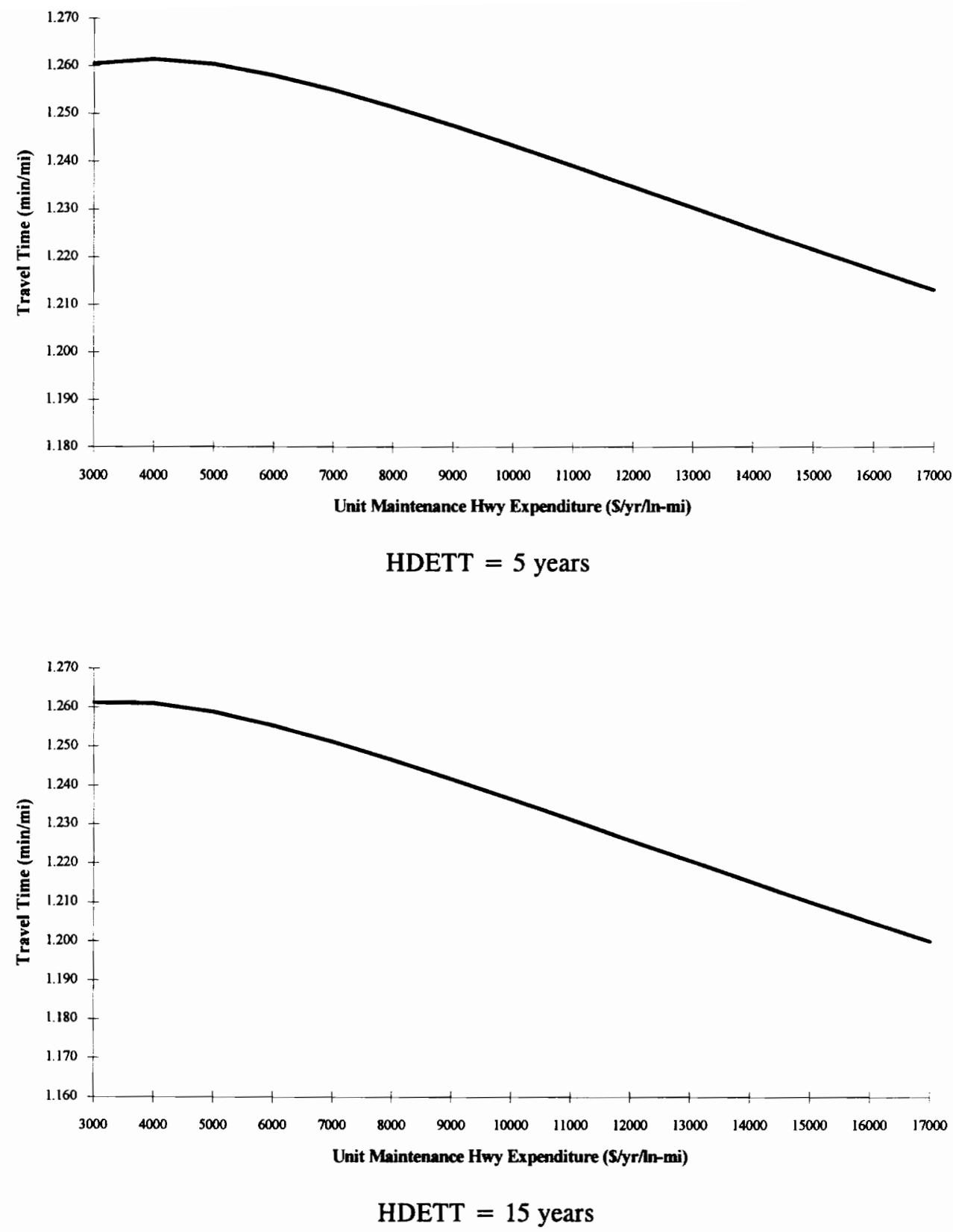

Figure 8.5: Parameter Sensitivity for Highway Deteriorating Time in the Maintenance Model 
the road surface higher and reduce travel time. The model implication is that deterioration rates play an important part in determining expenditure rates for higher quality roadway surfaces.

\section{Tests for Model Consistency}

Tests for model consistency examine the validity of the values for the rates and levels in the model and the validity of the model behavior under extreme conditions. The final validity of the rates and initial values of the levels would be determined by specific calibration of a model for a particular region. For this model, the rates and levels were assumed from previous work done by Huang, Moussavi, and Drew (Drew 1993). The initial total highway value (400 lane-miles) used for this model is similar to what would be found for the interstate highways in an area such as the Salem District of the Virginia Department of Transportation.

Extreme conditions, such as an initial level value of highway sufficiency as either all physically sufficient or all physically deteriorated, allow further testing of the model for confidence. An extreme condition test is useful as it can detect a defect in a model and enhance the usefulness of a model to analyze policies that may cause a system to operate outside historically normal regions of behavior. For example, how does the maintenance model operate if all the roads in a region are initially in a physically sufficient condition, a Level of Availability of 1, meaning that traffic is free flowing, and only varying rates of ordinary maintenance work is accomplished? We would expect the travel time to be nearly the free flow travel time and the initial Comprehensive Level of Service to be high. The travel time should increase at different rates depending on the expenditure rate selected because the road quality will degenerate unless enough monies are spent to maintain the initial physically sufficient 
conditions. As the simulated time increases, the Comprehensive Level of Service should decrease based on the different maintenance expenditure rates, unless sufficient funds are expended to maintain the system at the physically sufficient level.

Figures 8.6 and 8.7 are simulations under these extreme conditions for all physically sufficient roads. The model behaves as expected. At an expenditure rate of $\$ 10,000$ per year per lane-mile, the initial conditions are maintained. The Comprehensive Level of Service is maintained and the travel time does not decrease. Varying expenditures rates of less than the $\$ 10,000$ per year per lane-mile allow the Comprehensive Level of Service to decline and the travel time to increase.

An anomaly that needs to be addressed is the reason for the different travel times and Comprehensive Levels of Service for each unit maintenance highway expenditure rate at time $t=0$. This is due to the initialization routine that DYNAMO accomplishes for each expenditure rate. Recall from Chapter 4, System Dynamics Modeling, the level equations are determined from time $t-1$ to $t$ (p. 79). This means that the initial quantities assumed for the model, for example the initial quantity of physically sufficient highway as 200 lane-miles, was in essence for time $t=-1$. The first simulation run uses the initial values to set all the model variables for time $t=0$. Recall also from Chapter 6, Equilibrium Analysis, that the road quality index is based on the level values of the physical condition of the highway (Equation 6.11), and that the Level of Operation, based on the road quality index, was solved in terms of the unit maintenance highway expenditure (Equation 6.12). The Comprehensive Level of Service is based on the Level of Operation, consequently each simulation run with different unit maintenance highway expenditures will calculate a different value of CLOS at time $t=0$. A similar occurrence happens for the travel time values since the travel time is based on the Comprehensive Level of Service. The model confidence 


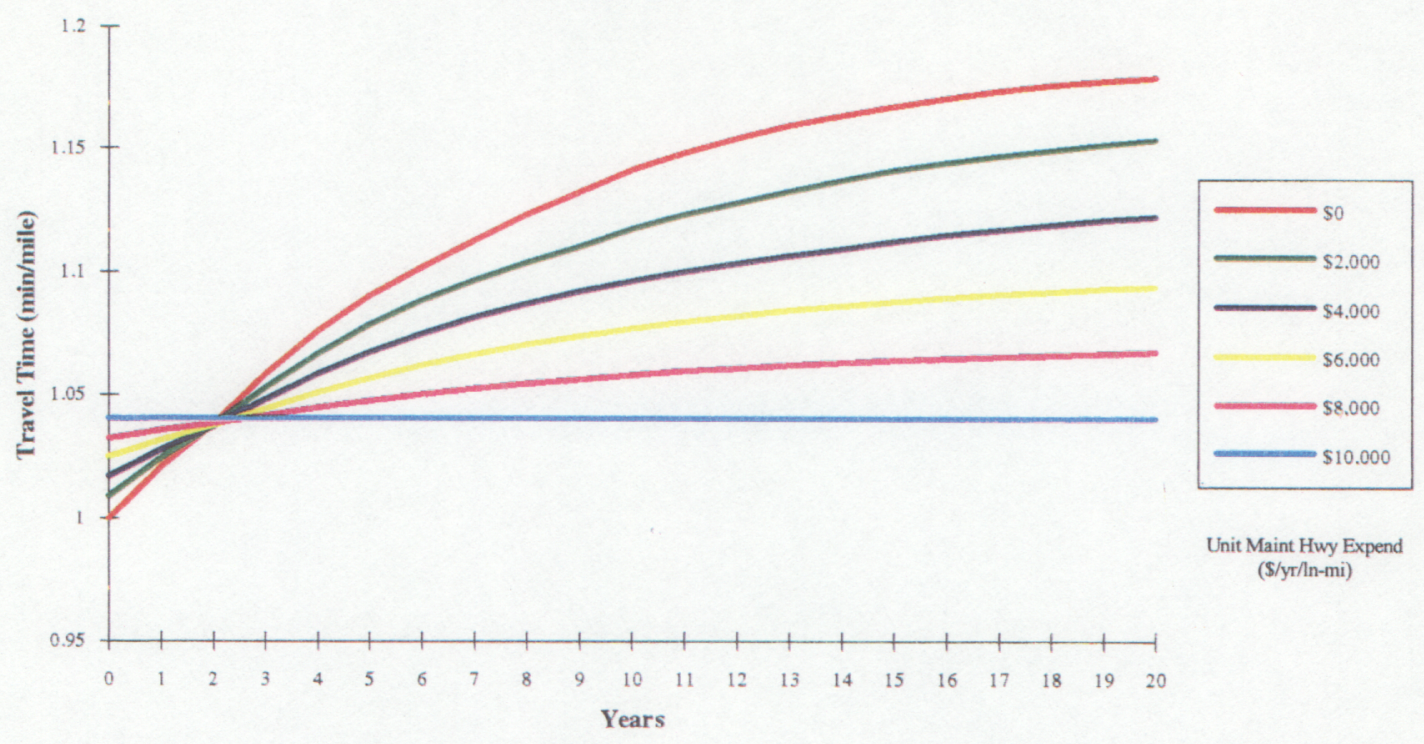

Figure 8.6: Extreme Condition Test for Maintenance Model Travel Time on Physically Sufficient Roads

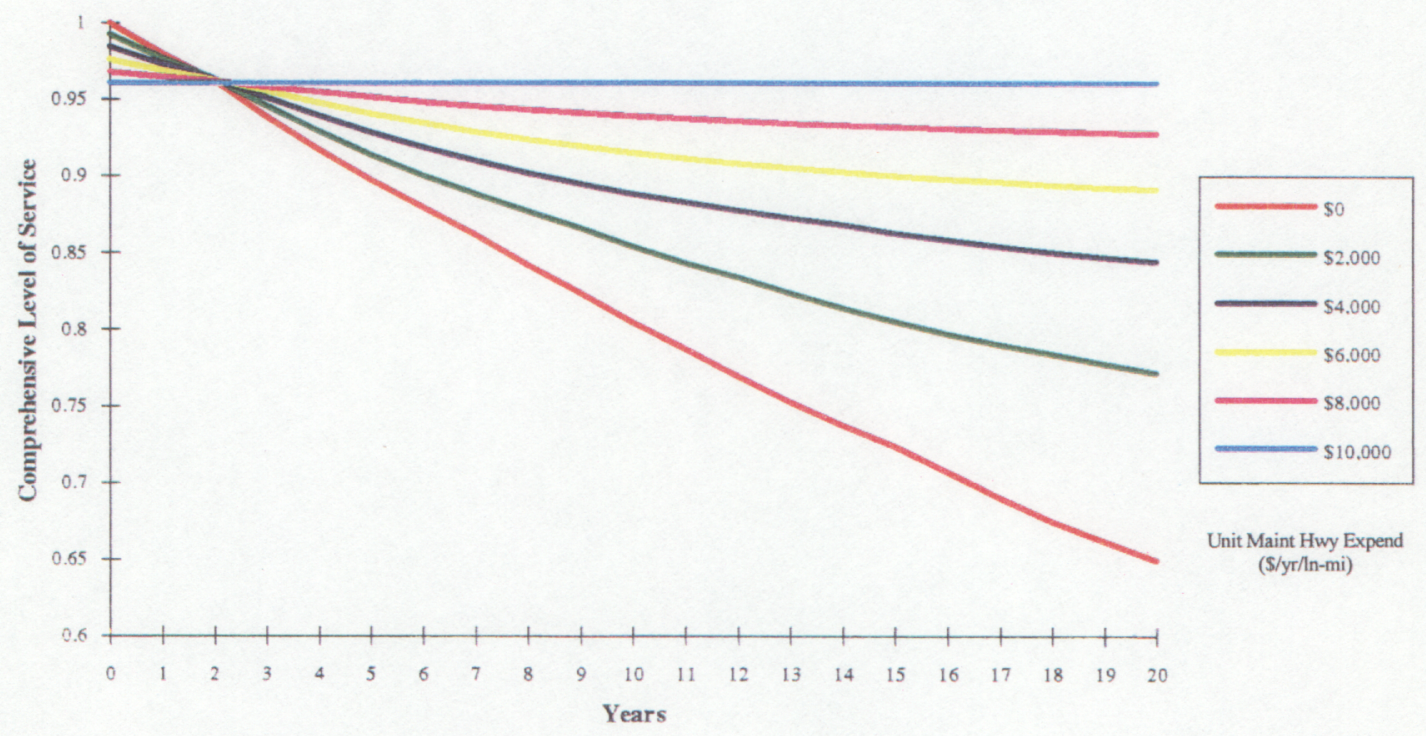

Figure 8.7: Extreme Condition Test for Maintenance Model Comprehensive Level of Service for Physically Sufficient Road 
should not be encumbered with this slight calculating anomaly as the behavior is still as we would expect. The exact values are not as important now as the structure and model behavior. The values will be enhanced when calibrated to a specific location.

The other extreme condition is addressed by examining how the maintenance model operates if all the roads in a region are in an initial physically deteriorated condition. For this test, the Level of Availability is again set at 1, meaning that traffic is free flowing, and only varying rates of maintenance replacement work is accomplished. We would expect the initial Comprehensive Level of Service to be low and the travel time to be the highest. The travel time should decrease at different rates with an increasing maintenance replacement expenditure rate because the road quality will improve as funds are expended to improve the initial conditions. As the simulated time increases, the Comprehensive Level of Service should increase based on increasing maintenance expenditure rates. Figures 8.8 and 8.9 are simulations under these extreme conditions for all physically deteriorated roads. Again, the model behaves as expected. As the maintenance replacement expenditure increases from $\$ 4,000$ to $\$ 14,000$ per year per lane-mile, the travel time decreases accordingly, faster for higher maintenance replacement expenditures and slower for lower expenditure rates. Similarly, the Comprehensive Level of Service, over the same expenditure range of $\$ 4,000$ to $\$ 14,000$ per year per lane-mile, increases at varying rates. It must be remembered that the Level of Availability is 1, meaning free flow conditions. The model behavior is the important part of this test, not the specific CLOS value.

\section{Summary}

A system dynamics model is a valuable tool for gaining insight and understanding into complex relationships that confront many decision-making efforts. The confidence 


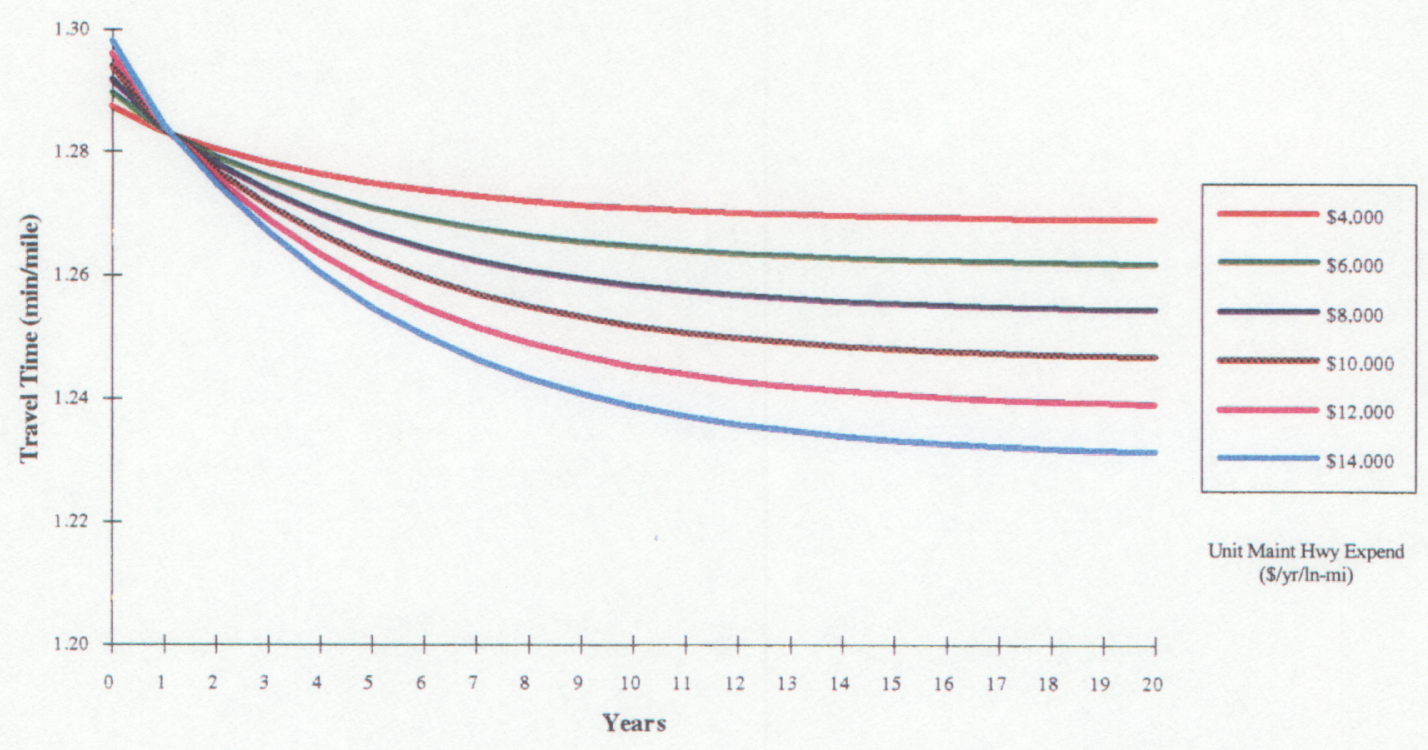

Figure 8.8: Extreme Condition Test for Maintenance Model Travel Time on Physically Deteriorated Roads

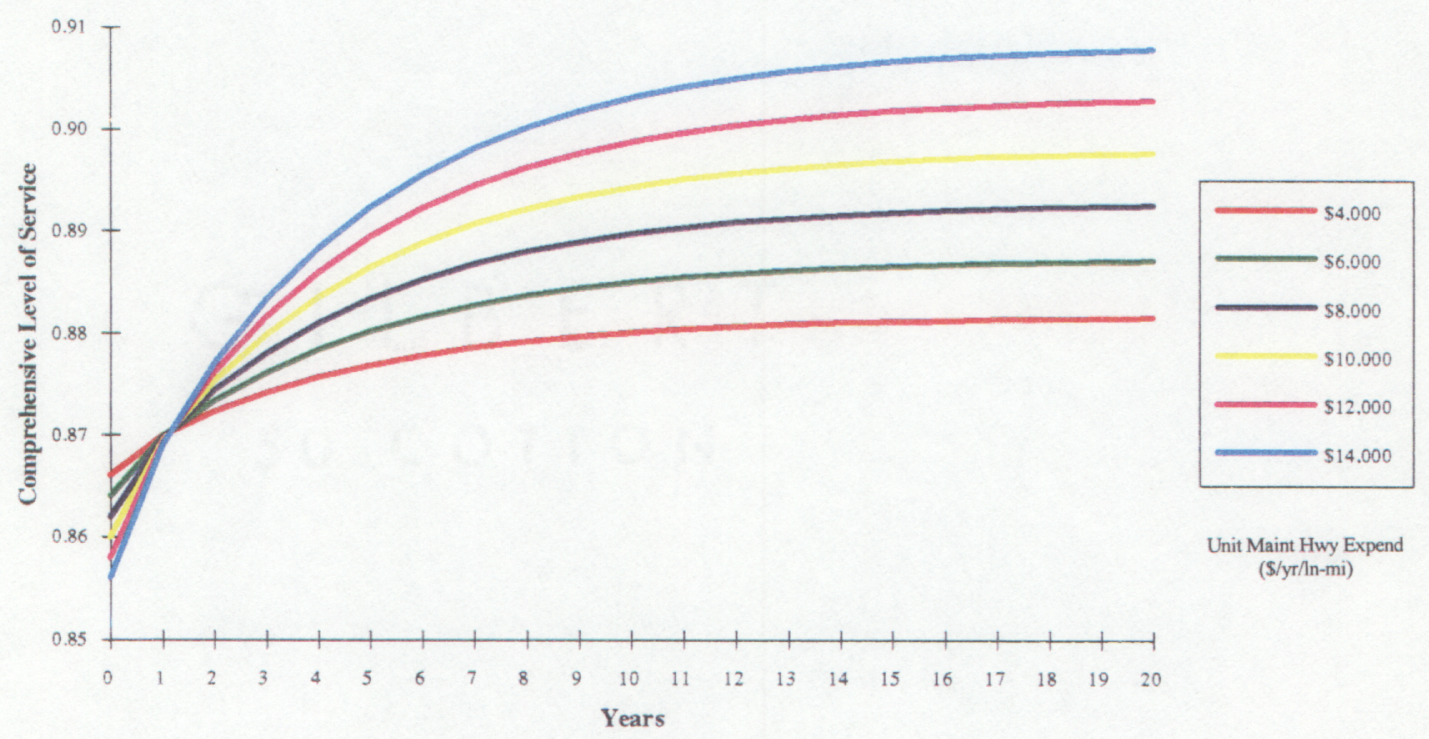

Figure 8.9: Extreme Condition Test for Maintenance Model Comprehensive Level of Service for Physically Deteriorated Roads 
in a proposed model comes from the structure and behavior of the model to capture the essence of how a system is observed to perform. The best validation of any model would be the ability to predict what will happen in the future. However, decision makers cannot wait for several years to correlate the output with the actual results. When the confidence in the model structure and behavior can be demonstrated with input that is reasonable, then the data collection effort required to calibrate the model for a particular purpose can be accomplished with a more structured approach and with more focused results. 


\section{CHAPTER 9: \\ MODEL IMPLEMENTATION}

\section{Introduction}

The implementation of this methodology to determine the impact of maintenance and/or construction expenditures on a highway system is suited for various policy analysis scenarios that would provide decision makers the insight into the future consequences of the decisions made. This chapter will be presented in two parts; first, a discussion of implementing a management information system to provide the data necessary for model calibration and second, potential policy scenarios that would be of importance to transportation officials.

\section{Management Information Systems}

The methodology described is based on a systems approach that is designed to be a guide to action. Most approaches to a problem are oriented towards gathering and testing data to try to find some relationship between two or more variables. The system dynamics approach is to identify variables based on system operation and then model those variables so as to allow experimentation with the system, cognizant of the feedback attributes of the problem. Once the mathematical model has been developed, the variables identified lend to the establishment of information-gathering tools that are focused on determining what data needs to be collected and make the collection of that data more cost effective.

Systems change over time and policies that are instituted affect how the system will change. Policies of an organization are decision rules that affect the rates of flow in a system. Those policies are imbedded in the goals of the organization and dictate what information is used to make those decisions. Information that is available is used 
to generate those decision rules, but is it the best or right information to use? By first developing a mathematical model that will define a system, the variables form a target data-collection set that will enhance the collection effort and the rationale for collecting the data required. For example, the developed models indicate several parameters that would be needed for understanding the interaction between maintenance and construction activities. These parameters can be tested in a sensitivity analysis to indicate what data is important and what resources and time should be expended to collect the necessary data, instead of collecting data and then trying to determine what to do with the collected data. This is the major philosophical difference between this methodology and usual data-collection schemes. By first determining the structure of the problem under study and modeling the system, the types of data needed can be more easily identified.

This management information system is not stagnant, but always improving and providing new, updated information. The iterative nature of this methodology is ideal for continual updating and revision as additional data is provided. Variables and parameters can be updated regularly and the impact of the revised information put to use immediately through the system models. This will allow the decision makers the opportunity to see the importance of the information provided and make more timely and structured decisions.

\section{Scenario for Maintenance Expenditure Rates}

One question relative to the maintenance of a region's highways could be the distribution of funding for maintenance options. The framework maintenance model was developed in Chapter 5 and is coded in Appendix A. The model reflects two types of maintenance options, ordinary maintenance and maintenance replacement. Ordinary 
maintenance is considered as spot patching, crack sealing, or slurry patching. This type of work would be typical of in-house maintenance work. Maintenance replacement activities would include seal coats or overlays, the type of work accomplished by contract forces. What is the effect of applying more funding to contract work with a reduction of in-house work forces as a result of reduced government budgets with an inflation factor added?

Using the maintenance model and assuming the initial level and cost conditions shown in Table 9.1, Figures 9.1, 9.2, and 9.3 were developed. They indicate the type of framework information and visual-aids that could be available for the decision makers in the areas of revenues, net benefits, and benefit-cost ratios on the impact of reducing ordinary maintenance, which in effect is deferring maintenance until road deterioration is more severe before making repairs.

Table 9.1: Initial Values for Maintenance Effects Scenario

\begin{tabular}{|c|c|c|}
\hline Parameter & Parameter Description & Initial Value \\
\hline \hline PSH & Physically Sufficient Highway & 200 lane-miles \\
\hline PDFH & Physically Deficient Highway & 100 lane-miles \\
\hline PDTH & Physically Deteriorated Highway & 100 lane-miles \\
\hline OMC & Ordinary Maintenance Cost & $\$ 50,000 /$ lane-mile \\
\hline MRC & Maintenance Replacement Cost & $\$ 200,000 /$ lane-mile \\
\hline INF & Inflation Rate & $3 \%$ \\
\hline LAI & Level of Availability Index & 0.375 \\
\hline
\end{tabular}

This type of model provides information for the decision makers in a format that allows quick comparison of several conflicting types of indicators. For example, the maintenance expenditure rate where the greatest total net benefit per capita is available 
is $\$ 14,000$ per year per lane-mile with $50 \%$ being used for ordinary maintenance. The benefit-cost ratio at the same expenditure rate is approximately 5.0, which is not the expenditure rate for the best available benefit-cost ratio. Similarly, the revenues less expenditures, at approximately $\$ 18,000$ per year per lane-mile, are at a decreasing point indicating that less traffic is moving on the highway system. With this information available, a conscious decision can be made as to the best use of available resources.

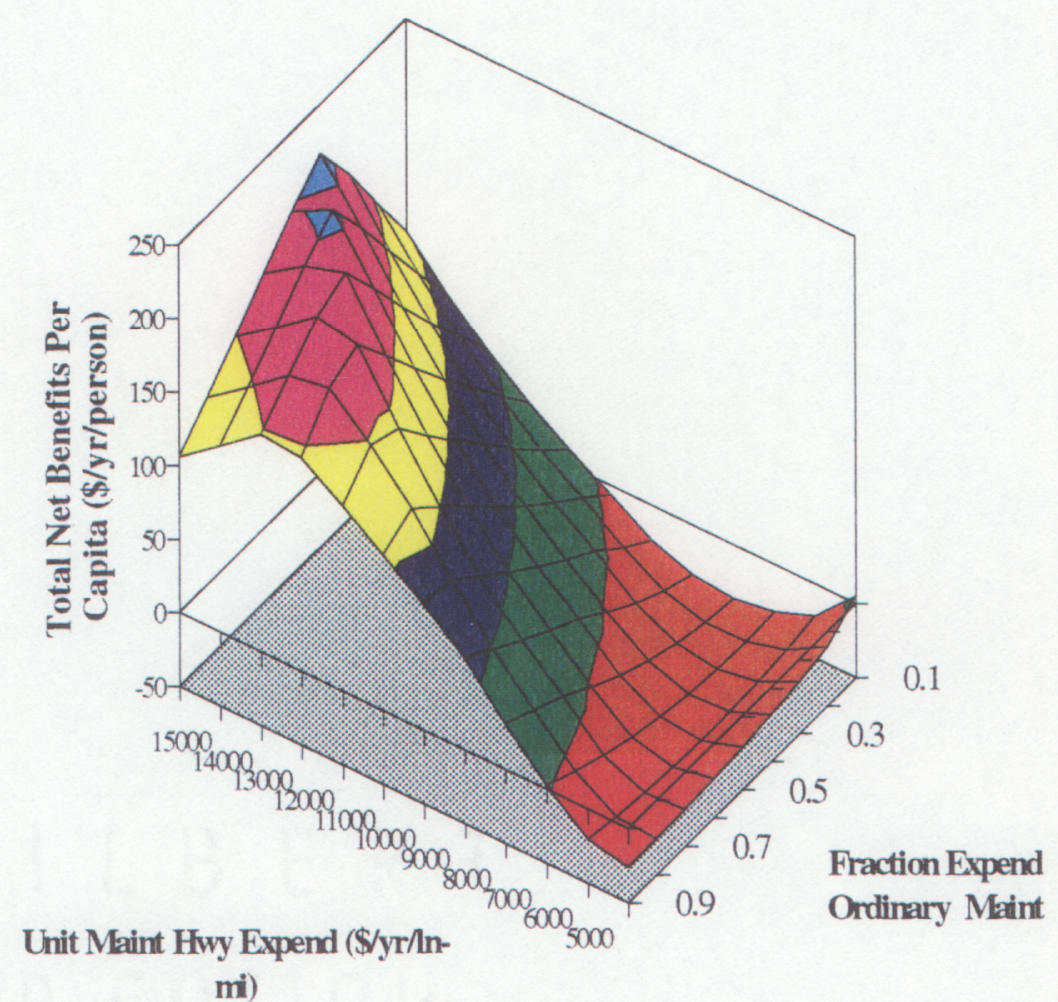

Figure 9.1: Total Net Benefits per Capita vs UMHE vs FEOM Simulated over 20 Years 


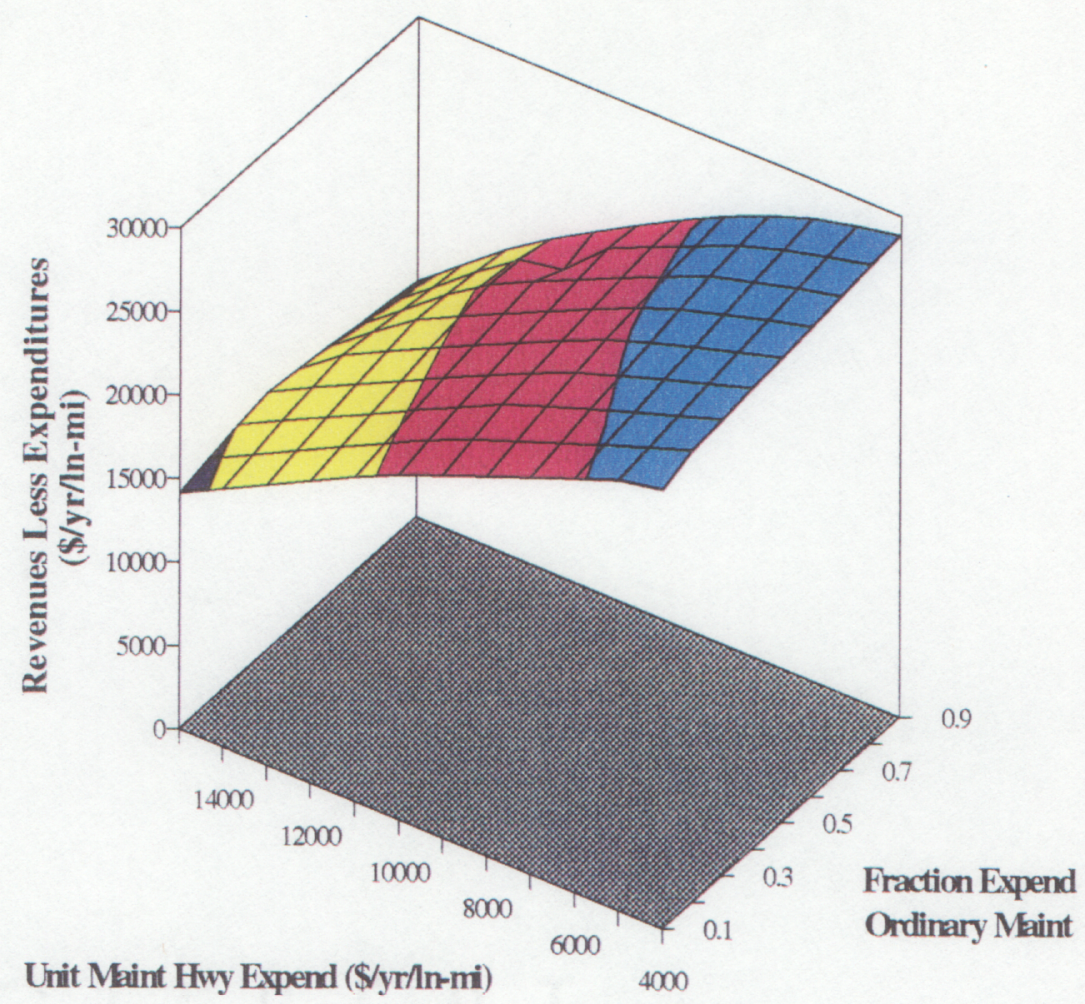

Figure 9.2: Revenues Less Expenditures vs UMHE vs FEOM Simulated over 20 Years

\section{Analysis of Maintenance Effects Simulation Results}

An analysis of the graphs indicates that as ordinary maintenance expenditures decrease, which is a defacto deferring of maintenance since less routine maintenance is accomplished and a larger contract maintenance expenditure is required, the total net benefits per capita and the benefit-cost ratio will decrease. This indicates that the benefits for the users and non-users will be lessened, potentially from a positive to a negative value. Also, as the benefit-cost ratio decreases, the benefits derived from the 


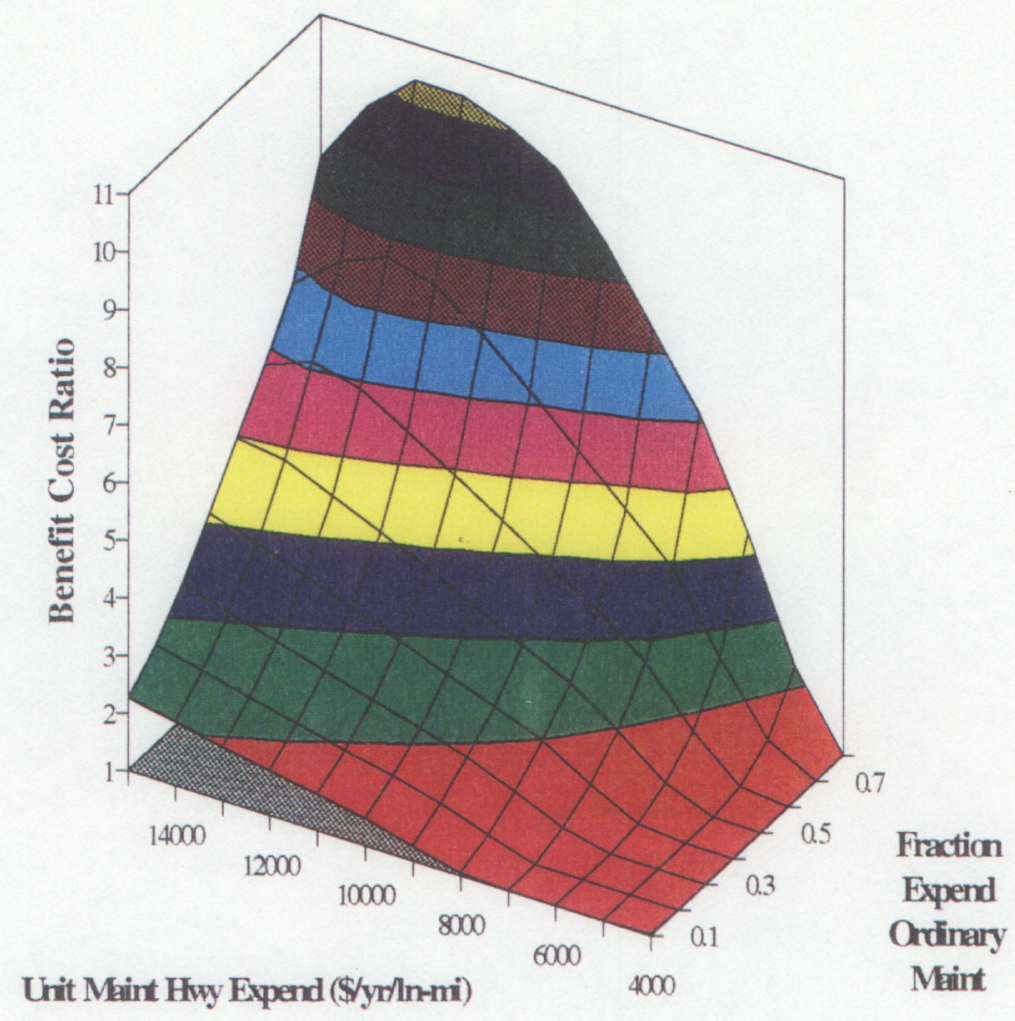

Figure 9.3: Benefit-Cost Ratio vs UMHE vs FEOM Simulated over 20 Years

expenditures that are made are not as effective. In Figure 9.2, the declining revenues less expenditures graph results because the increased maintenance expenditure rate reduces the RLE by a greater amount than the increased highway revenues generated. This quantification of the impact of deferring maintenance would be beneficial to decision makers as they can quickly and visually assimilate the impact of deferring maintenance expenditures on the highway system. 


\section{Scenario for Highway Maintenance vs Highway Improvement}

Another possible scenario that could be applicable to a highway department is the funding for maintenance and highway improvement. Highway improvement for the maintenance and construction model (Appendix C) that was developed in Chapter 5, is considered to include increased lane-width or reconstruction for improved alignment or reduced gradient. How does the increased or decreased funding for maintenance impact the operation of the highway? What is the impact of inflation on the highway system? Table 9.2 lists the initial highway conditions and maintenance costs used for the simulation. This scenario is for maintenance and construction improvement and upgrade only and does not consider any new construction for additional lane-miles of highway expansion.

Table 9.2: Initial Values for Highway Maintenance vs Highway Improvement Scenario

\begin{tabular}{|c|c|c|}
\hline Parameter & Parameter Description & Initial Value \\
\hline \hline PSH & Physically Sufficient Highway & 200 lane-miles \\
\hline PDFH & Physically Deficient Highway & 100 lane-miles \\
\hline PDTH & Physically Deteriorated Highway & 100 lane-miles \\
\hline UCH & Uncongested Highway & 50 lane-miles \\
\hline PCH & Partially Congested Highway & 250 lane-miles \\
\hline FCH & Fully Congested Highway & 100 lane-miles \\
\hline OMC & Ordinary Maintenance Cost & $\$ 50,000 /$ lane-mile \\
\hline MRC & Maintenance Replacement Cost & $\$ 200,000 /$ lane-mile \\
\hline HUC & Highway Upgrade Cost & $\$ 500,000 /$ lane-mile \\
\hline HIC & Highway Improvement Cost & $\$ 250,000 /$ lane-mile \\
\hline INF & Inflation Rate & $3 \%$ \\
\hline
\end{tabular}


Figures 9.4 through 9.6 are possible indicators and visual-aids that could be provided to decision makers for their use. The expenditure rates for the best total net benefits per capita is a UMHE of $\$ 14,000$ per year per lane-mile, a UCHE of $\$ 24,000$ per year per lane-mile, giving a TNBPC of approximately $\$ 850$ per year per person. At the same expenditure rate, the benefit-cost ratio is approximately 3.0 , far below the maximum BCR at a UMHE of $\$ 14,000$ per year per lane-mile and a UCHE of $\$ 6,000$ per year per lane-mile. The revenues less expenditures (a possible measure of

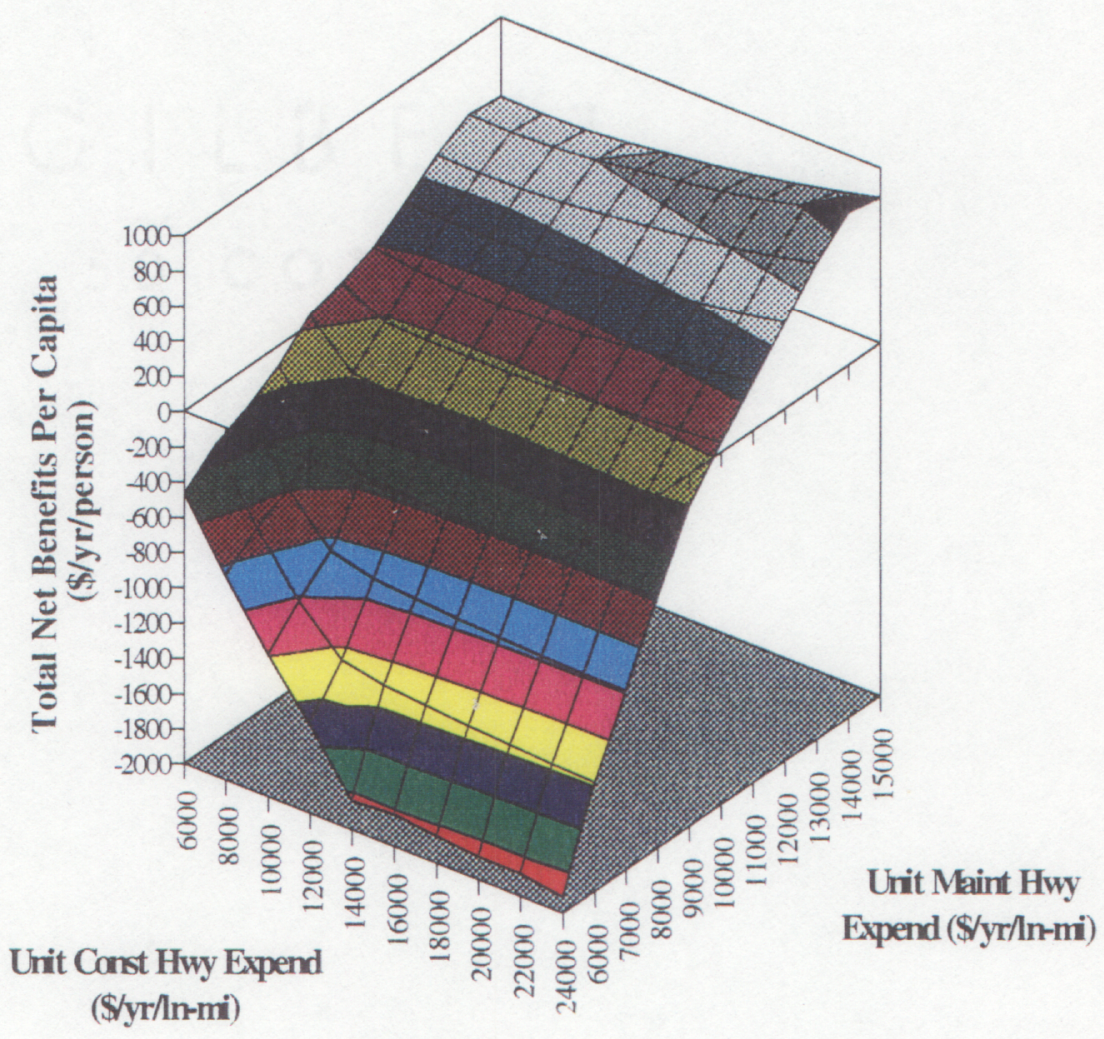

Figure 9.4: Total Net Benefits per Capita vs UMHE vs UCHE Simulated over 20 Years 


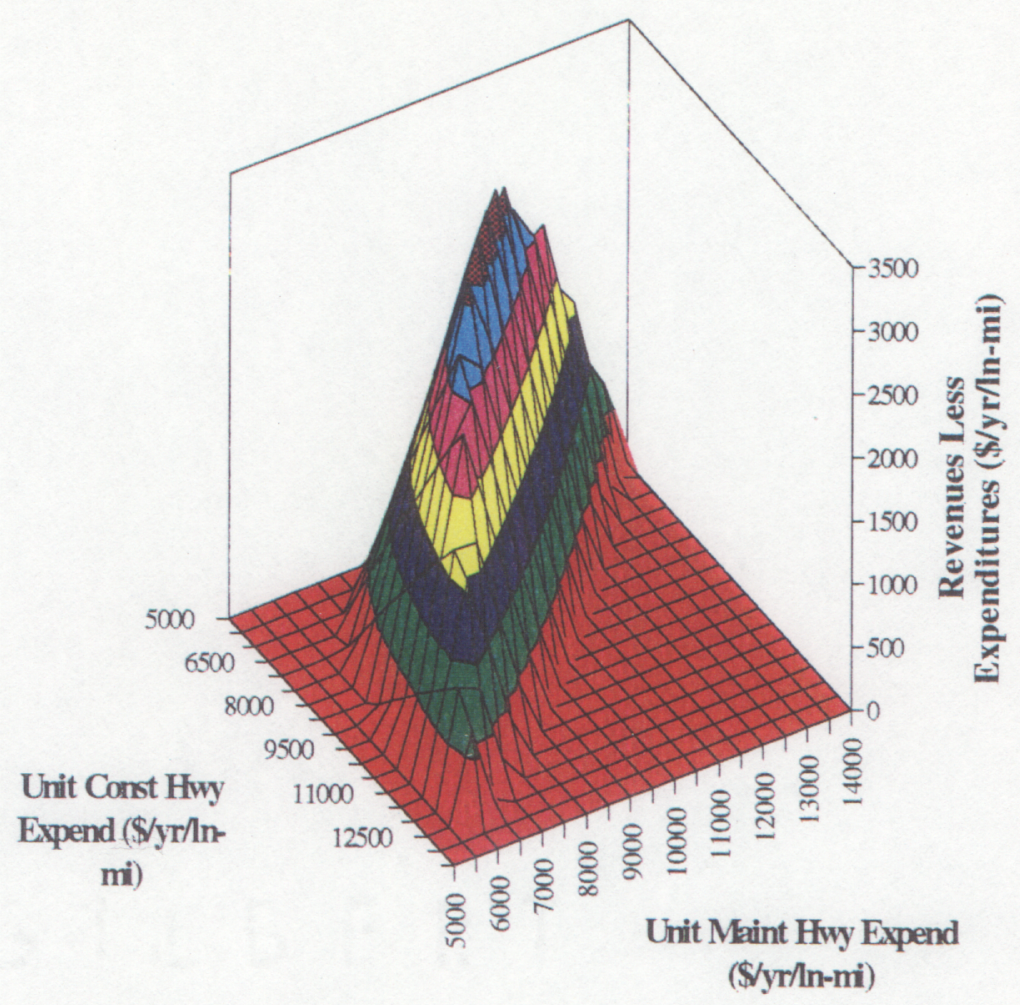

Figure 9.5: Revenues Less Expenditures vs UMHE vs UCHE Simulated over 20 Years

effectiveness for the highway department) has a maximum of approximately $\$ 3300$ per year per lane-mile at a UMHE of $\$ 9,000$ per year per lane-mile and a UCHE of $\$ 8,000$ per year per lane-mile. The expenditure rates which maximize the RLE do not match the expenditure rates for total net benefits per capita (a possible measure of effectiveness of the economic impact in a region) or the benefit-cost ratio (a possible measure of policy effectiveness). Knowing the impact of the different expenditure rates still allows a decision to be made with the possible satisficing of all interests involved. 


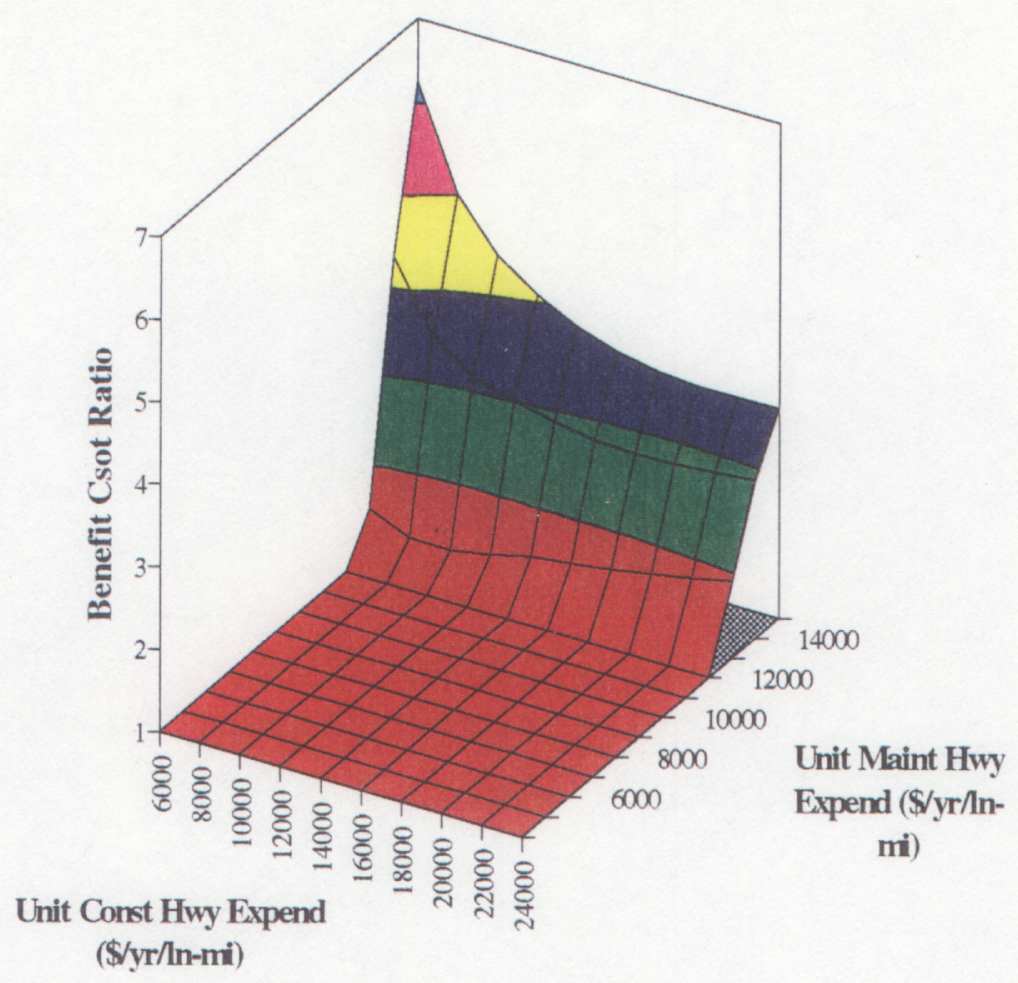

Figure 9.6: Benefit-Cost Ratio vs UMHE vs UCHE Simulated over 20 Years

\section{Analysis of Highway Maintenance vs Highway Improvement Simulation Results}

An analysis of the simulation results for the highway maintenance vs the highway improvement indicates that a decrease in maintenance expenditures, which is a deferring of maintenance as less maintenance work can be accomplished, will impact the total net benefit per capita by decreasing the benefits to the population, even to a negative value. The negative value indicates that no benefit would accrue to the population for the expenditures made. Similarly, decreasing maintenance expenditures will impact the benefit-cost ratio, again indicating that the effectiveness of the 
expenditures is decreasing. The revenues less expenditures graph indicates an expenditure rate that will maximize the traffic flow providing the maximum revenues available for the maintenance of the highway system. Noting that an intersection point does not correlate between the three graphs highlights the hard decisions that face policy-making bodies. Not all interested parties can be satisfied by the expenditure rates. This type of framework will help develop decision aids that will enable those in the decision-making process to make more rational decisions for highway expenditures.

\section{Summary}

Once a system has been modeled, various policies can be viewed in a laboratory setting to conceptualize and visualize the outcome and impact of the policy scenarios. For example, the models developed were viewed from different maintenance and construction expenditure rates to determine the impact on total net benefits per capita, revenues less expenditures, and the benefit-cost ratio. With these three measures of effectiveness, a decision-making board could have a better understanding of the impact of various expenditure rates on the different interest groups being served. The population of a region would like the highest net benefit to be returned for the highway investment. The highway department needs revenues for maintenance and construction activities, and the policy board wants to make the best investment of revenues with maximum benefits obtained. If these desires are in conflict, then a framework such as the one developed will provide information for a more rational and structured approach to the decisions made. Calibrating a model to a specific location or region may generate an optimum point that would provide the maximum benefits to all parties involved. 


\section{CHAPTER 10: SUMMARY AND RECOMMENDATIONS}

\section{Introduction}

This chapter summarizes the results of this research and suggests several directions that could be taken in the future for further study. This research forms a foundation for determining the impact of deferred maintenance and construction investment as measured by the benefits derived by highway users and non-users.

\section{Summary of Research}

The impact of infrastructure deterioration due to deferred maintenance has risen to the forefront of national concern since the problem was publicized in the early 1980 's. The debate has raged on several fronts as to what must be done and how much investment is needed to bring the foundation of society back to the level required to support healthy economic growth. The problem of quantifying the impact of the deferred infrastructure maintenance has not been sufficiently addressed to allow a comparison of maintenance versus construction investment. This research is the foundational step in developing a system's framework for understanding the problems and the interrelationships between maintenance and construction activities in support of civil infrastructure systems. This framework approach will assist budgeting and policymaking personnel in their understanding of the effects of maintenance and construction policy decisions on the benefits and/or consequences for users and non-users alike.

Previously, maintenance and construction activities have been examined separately, without having considered these two major functions as complementary to the quality of life in a region. This research proposed the concept of a Comprehensive Level of Service based on a Level of Operation, a physical level of service indicating 
the degree of deterioration or the physical condition of a system, and a Level of Availability, a functional level of service indicating the degree of obsolescence or the amount available for increased future requirements. For this research, the Level of Operation defined the physical level of maintenance of a highway system indicating the road's physically maintained quality. The Level of Availability defined the functional or capacity level of the highway, indicating the degree of congestion or the remaining available capacity within the system. This research also assumed that the Level of Service for bridges, as part of a highway system, are maintained at the same physical and functional Level of Service as the rest of the highway. It is understood that the expenditures to maintain or upgrade a bridge and/or bridge deck in dollars per lanemile are significantly higher than the costs assumed for pavement maintenance or rehabilitation. A bridge structure, like a bottleneck, could impact a portion of a highway system so as to rendered that portion unusable with a physically deteriorated bridge. The effect of the bridges on a system could be added as an additional input factor, but were not considered as part of this research.

The Comprehensive Level of Service was then integrated into a systems model to mathematically describe relationships between maintenance work, construction activities and user and non-user benefits. Improving maintenance will increase the Level of Operation. Increasing capacity will improve the Level of Availability. Both will affect the Comprehensive Level of Service and increase the amount of user and non-user benefits for the region under study. The mathematical model formed the basis for a computer simulation that demonstrated how the effects of maintenance and construction expenditures on user and non-user benefits could be quantified. This quantification will help visualize the impact of those expenditures on decision-maker defined measures of effectiveness such as total net benefits per capita or a benefit-cost ratio. 
The mathematical model developed provides the foundation for a focused, relevant data collection effort that could form the basis for a management information system. The variables used to develop the mathematical model provide insight into what information is relevant to the model. The manipulative properties of a mathematical model help pinpoint what variables are sensitive to variation allowing increased research efforts on those variables.

The computer simulation produced graphic aids to visually illustrate the impact of specific policy decisions. Increasing or decreasing expenditures will increase or decrease user and non-user benefits. The ability to quantify the impact of those decisions will improve understanding and provide a guide to action for policy-making groups. Together, they aid in an enhanced understanding of the decision-making process concerning the impact of deferring maintenance and/or allocating the additional funding required for new construction.

Major philosophical differences regarding the incorporation of data are also pointed out by this research. Collection of data without a model in mind for guidance and reference is not the most expedient use of scarce labor or financial resources. By first developing a verbal model of what is happening and then translating that verbal model into a mathematical model, the variables driving a system can be identified, thus directing the resources where the most beneficial information will be developed that will assist in policy decisions. Critical data needs can be targeted and obtained. Once the data is identified and collected, policy scenarios can be developed and simulated in a laboratory setting to demonstrate the implications of various policy decisions.

Secondly, the lack of precise data does not need to delay model development nor lessen the confidence that can be placed in the proposed mathematical model. A model can be developed with variables that are available and reasonable, knowing that 
variables can be dynamically refined and/or expanded as more information becomes available through data collection efforts or new research findings. The confidence in the model comes not in the preciseness of the variables, but in the structure and behavior of the model. As additional information becomes available, the accuracy of the model predictions should improve, but the confidence of the model should not change.

\section{Recommendations for Future Research}

This research, as presented, is the foundation for developing a framework for understanding the impact of deferring maintenance and/or obsolescence on civil infrastructure systems. The modeling methodology leads to development of the basis for a management information system in support of a state's or region's infrastructure system. A first future research project would gather targeted data identified within this framework for development and calibration of a model for a specific district, state or highway, such as I-81 in Virginia.

Secondly, a different type of infrastructure system could be modeled. The framework and methodology provide a starting place for other infrastructure component modeling, such as water and waste systems, electric or natural gas operations, or even in a broader context, building construction. Any infrastructure system that requires maintenance, in order to sustain the Level of Operation, and necessitates additional construction, to maintain a Level of Availability, could benefit from this concept and form the basis for a guide to action to keep the infrastructure at a desired Comprehensive Level of Service.

A third approach to future research would be to expand the model framework and incorporate additional factors that impact user and non-user benefits, such as 
environmental considerations such as the congestion effects on smog, regulatory constraints such as budget cuts or speed limit changes, or technological improvements such as new fuel-efficient automobiles. The inclusion of the impact of deteriorating bridges could also be added as a factor that has great affect on both users and nonusers. While the current model is based on an interstate highway system, a fourth research project could be to include the primary and secondary highway systems for a larger system context.

A fifth research undertaking could be improving the construction and Level of Availability model and its impact on user and non-user benefits. The improvement could consist a more rigorous modeling of the urban transportation planning process (UTPP) to conceptualize the forecast of socio-economic activity. This forecast results in trip generations by the population in a region which ultimately determines user and non-user transportation demand. The linking of economic activity and traffic demand would enhance the understanding of the traffic congestion rates that drive the Level of Availability Index. Construction activity could then be based on anticipated demand and the impact of deferring the maintenance of new highways could be better visualized.

A sixth area of research that could be developed from this framework would be the quantification of a Comprehensive Level of Service. A graph, resembling Figure 6.5 , would be labeled to identify on a generated surface, the current Levels of Service A through $\mathrm{F}$ as defined in the Highway Capacity Manual. Level of Service is still an important measurement tool in the transportation field as a way of indicating road service. By combining both the maintenance and construction indicators into one index, the quantification of the Level of Service would be the next step in determining the economic impact on user and non-user benefits. 
A final area of research would be to extend this concept to the design phase. This research assumes deterioration rates and maintenance and/or rehabilitation efforts for existing highway systems. The same foundational approach could be utilized for a lifecycle cost analysis during the design stage for different design alternatives, i.e., concrete pavement versus asphalt pavement. One design parameter that should be considered during design is the concept of maintainability, which deals with the projected times, costs, and techniques of maintenance. Maintainability for infrastructure systems would deal with more maintenance-free materials, special application or repair techniques, installation equipment and material disposal requirements. Alternative designs will recommend different maintenance actions at different time frames at different costs. The final design, based on the desired design parameters, will affect the initial construction cost and will determine the subsequent maintenance criteria. For example, full-depth asphalt pavement requires different maintenance actions than the more conventional asphalt pavement over aggregate base course material. The lifecycle cost analysis then assumes that the maintenance actions programmed during design will be accomplished as detailed in the lowest life-cycle cost. The questions that could then be asked are: What if the life-cycle maintenance is deferred and not performed as originally projected during design? What is the difference of the impact of deferred maintenance between existing highway systems and alternative life-cycle designs? What is the impact of deferred maintenance on the future Comprehensive Level of Service and repair costs of the alternative highway designs? How does deferred maintenance on the different designs impact user and non-user benefits? This approach could be utilized to point out the trade-offs between the initial construction investment, the cost of maintainability, and the impact of deferring the life-cycle maintenance determined by the design alternatives. 


\section{REFERENCES}

AASHTO (1977). A Manual on User Benefit Analysis of Highway and Bus-Transit Improvements. American Association of State Highway and Transportation Officials, Washington, D.C.

Agee, W. J. (1993). "Genuine Investment, Not Just Spending." Construction Business Review, 3(2), pp. 46-49.

Al-Dawood, A. S. (1990). Transportation and Economic Development Evaluation Model, Ph.D. Dissertation, Virginia Polytechnic Institute and State University, Blacksburg, VA.

Al-Suleiman, T. I., Sinha, K. C., and Riverson, J. D. (1991). "Effects of Pavement Age and Traffic on Maintenance Effectiveness." Journal of Transportation Engineering, ASCE, 117(6), pp. 644-659.

Allen, M. T. and Floyd, C. F. (1991). "Alternative Financing Techniques in Funding Major Highway Reconstruction Projects." Transportation Quarterly, Eno Transportation Foundation, Inc., Westport, CN, 45(1), pp. 357-368.

Bala, B. K., (c. 1994). Principles of System Dynamics. Bangladseh Agricultural University, Mymensingh 2202, Bangladesh.

Baladi, G. Y. (1991). "Analysis of Pavement Distress Data Pavement Distress Indices and Remaining Service Life," IN Course Notes, CE 5984, Pavement Management Systems, Virginia Polytechnic Institute and State University, Blacksburg, VA, Fall, 1993.

Banks, J. H. (1989). "Freeway Speed-Flow-Concentration Relationships: More Evidence and Interpretations." IN Highway Capacity, Flow Measurement, and Theory, Transportation Research Record 1225, Transportation Research Board, National Academy of Sciences, Washington, D.C., 1989, pp. 53-60.

Barker, M., ed., (1984). Rebuilding America's Infrastructure, An Agenda for the 1980's. Duke University Press, Durham, NC.

Butler, S. E., Gazda, W. E., Horn, R. J., Smith, R. T., Ismail, H. and Webster, A. L. (1984), "Highway Investment and the National Economy." Economic Analysis of Transportation Investments and Economic Developments, Transportation Research Record 984, Transportation Research Board, National Research Board, Washington, D.C., pp. $42-51$. 
Choate, P. (1981) "The Case for a National Capital Budget." Public Budgeting and Finance, Winter, 1981, pp. 21-26.

Cleveland, D. E. (1987). "Effect of Resurfacing on Highway Safety," IN Relationship Between Safety and Key Highway Features, A Synthesis of Prior Research, Transportation Research Board, National Research Council, Washington D.C., 1987, pp. 78-95.

Cranford, J. (1989). Budgeting for America, 2nd Ed. Congressional Quarterly, Inc., Washington, D.C.

Croft, F. M. and Clark, J. E. (1985). "Quantitative Measures of Level of Service." IN Highway Capacity, Traffic Characteristics, and Flow Theory, Transportation Research Record 1005, Transportation Research Board, National Research Council, Washington, D.C., 1985, pp. 11-20.

DHS (1987) Deloitte Haskins \& Sells. Final Report on Recommendations to Improve Public Works Decision-Making. National Council on Public Works Improvement, November, 1987.

Dowling, R. G. (1989). "Controlling Growth with Level-of-Service Policies." IN Congestion, Land Use, Growth Management, and Transportation Planning, Transportation Research Record 1237, Transportation Research Board, National Research Council, Washington, D.C., 1989, pp. 39-46.

Doyle, R. and McCaffery, J. (1991). "The Budget Enforcement Act of 1990: The Path to No Fault Budgeting," Public Budgeting and Finance, Spring, 1991, pp. 24-40.

Drew, D. R. (1968). Traffic Flow Theory and Control, McGraw-Hill, New York, NY, 1968.

Drew, D. R. (1984). "An Infrastructure-Based Strategy for Guiding Reconstruction, Development and Reconciliation in Lebanon." Rebuilding America: Infrastructure Rehabilitation, ASCE, Metropolitan Association of Urban Designers and Environmental Planners (MAUDED), San Francisco, CA, August 22-24, 1984, pp. 128-139.

Drew, D. R. (1989) "Modeling Transportation and Economic Development at Regional Level," Final Report for Phase I of Research U.S. DOT/VDOT Center's Program, Mid-Atlantic Universities Transportation Center, (1989).

Drew, D. R. (1993). System Dynamics: Modeling and Applications. ENGR 5104, Applied Systems Engineering, Virginia Polytechnic Institute and State University, Blacksburg, VA, Spring 1993. 
Drummond, J. T. (1991). "A New Era in Road Policy." Nation's Business, September, 1991, pp. 20-26.

Ewing, R. (1993). "Transportation Service Standards - As If People Matter." IN Planning and Programming, Land Use, Public Participation, and Computer Technology in Transportation, Transportation Research Record 1400, Transportation Research Board, National Research Council, National Academy Press, Washington, D.C., 1993, pp. 1017.

Fabrycky, W. J. and Blanchard, B. S. (1991). Life-Cycle Cost and Economic Analysis. Prentice Hall, Englewood Cliffs, NJ.

FHWA (1993). The Status of the Nation's Highway, Bridge, and Transit: Conditions and Performance, A Summary. Federal Highway Administration, Publication No. FHWA-PL-93-017, 1993.

FHWA (1993a). ISTEA: Intermodal Surface Transportation Efficiency Act of 1991, Selected Fact Sheets. Federal Highway Administration, Washington, D.C.: U.S. Government Printing Office, January, 1993.

Flanagan, D. V., Jr. (1993). "Infrastructure Investment and the New Risk Sharing." Construction Business Review, 3(2), pp. 50-53.

Friedman, D. (1991). "The High Price of Potholes." U.S. News and World Report, April 15, 1991, pp. 55-56.

Fwa, T. F. and Sinha, K. C.(1986). "Routine Maintenance and Pavement Performance." Journal of Transportation Engineering, ASCE, 112(4), pp. 329-344.

Fwa, T. F. and Sinha, K. C.(1991). "Pavement Performance and Life-Cycle Cost Analysis." Journal of Transportation Engineering, ASCE, 117(1), pp. 33-46.

Fwa, T. F., and Sinha, K. C.(1992). "Quantification of Agency and User Values of Pavement Performance." Journal of Transportation Engineering, ASCE, 118(1), pp. 84-97.

Gleckman, H. (1988). "Suddenly, Voters Look at Taxes and See Schools and Roads," Business Week. November 28, 1988, p.33.

Grigg, N. S. (1988). Infrastructure Engineering and Management. John Wiley and Sons, New York, NY. 
Grigg, N. S. (1993). "Infrastructure and Economic Development: Civil Engineering Perspective." Journal of Professional Issues in Engineering Education and Practice, ASCE, 119(1), pp. 51-61.

Hage, D. (1992). "Paving over the Pain." U. S. News \& World Report, October 12, 1992, pp. 59-62.

Hall, F. L. and Agyemang-Duah, K. (1991). "Freeway Capacity Drop and the Definition of Capacity." IN Freeway Operations, Highway Capacity, and Traffic Flow 1991, Transportation Research Record 1320, Transportation Research Board, National Academy of Sciences, Washington, D.C., 1991, pp. 91-98.

Hinkling Corporation (1993). Research Strategies for Improving Highway User CostEstimating Methodologies, Draft Final Report, NCHRP 2-18, National Cooperative Highway Research Program, Transportation Research Board, National Research Council, Washington, D.C., Feb. 1993.

Huang, G. (1990). Methodology for Evaluating Economic Impacts on Transportation, $\mathrm{Ph}$.D. Dissertation, Virginia Polytechnic Institute and State University, Blacksburg, VA.

Humphrey, T. F. (1981). Evaluation Criteria and Priority Setting for State Highway Programs, National Cooperative Highway Research Program, Synthesis of Highway Practice 84, Transportation Research Board, Washington, D.C., November, 1981.

Hurdle, V. F. and Datta, P. K. (1983). "Speeds and Flows on an Urban Freeway: Some Measurements and a Hypothesis." IN Traffic Flow, Capacity and Measurements, Transportation Research Record 905, Transportation Research Board, National Research Council, Washington, D.C., 1983, pp. 127-137.

Janoff, M. S., Nick, J. B., Davit, P. S., and Hayhoe, G. F. (1985). Pavement Roughness and Rideability, National Cooperative Highway Research Program Report 275, Transportation Research Board, Washington, D.C., 1985.

Karan, M. A. and Haas, R.(1976). "Effects of Pavement Roughness on Vehicle Speeds." IN Pavement Design, Evaluation, and Performance, Transportation Research Record 602, Transportation Research Board, National Research Council, Washington, D.C., 1976, pp. 122-127.

Kee, J. E. and Nystrom, S. V. (1991). "The 1990 Budget Package: Redefining the Debate," Public Budgeting and Finance, Spring, 1991, pp. 3-24. 
Kelly, J. F. (1981). Formulating and Justifying Highway Maintenance Budgets, National cooperative Highway Research Program, Synthesis of Highway Practice 80, Transportation Research Board, Washington, D.C.

Kittell, H. J. (1984). Effective Utilization of Data from the Highway Performance Monitoring System, Final Report, VHTRC 85-R12, Virginia Highway and Transportation Research Council, Charlottesville, VA. October, 1984.

Kulkarni, R., Finn, F., Golabi, K., Johnson, R. and Alviti, E. (1980). Maintenance Level-of-Service Guidelines, National Cooperative Highway Research Program Report 223, Transportation Research Board, National Research Council, Washington, D.C., June, 1980.

Larson, T. D. (1990). Highway Statistics, 1990. Federal Highway Administration, Washington, D.C.: U.S. Government Printing Office.

Lewis, D. (1991). Primer on Transportation, Productivity and Economic Development, National Cooperative Highway Research Program Report 342, Transportation Research Board, National Research Council, Washington, D.C., 1991.

Lynden, F. J., and Lindenberg, M. (1983). Public Budgeting in Theory and Practice. Longman, Inc., New York, N.Y.

Mercier, C. R. and Stoner, J. W. (1988). "Sufficiency Ratings for Secondary Roads: An Aid for Allocation of Funds?" IN Transportation Systems Planning and Management, Transportation Research Record 1156, Transportation Research Board, National Academy of Sciences, Washington, D.C., 1988, pp. 35-40.

NB (1990). "The Foundation Must Be Solid." Nation's Business, September, 1990, pp. 31-32.

NCHRP (1979). Consequences of Deferred Maintenance, National Cooperative Highway Research Program, Synthesis of Highway Practice 58, Transportation Research Board, Washington, D.C.

NCPWI (1988) Fragile Foundations: A Report on America's Public Works, National Council of Public Works Improvement, Washington D.C., U. S. Government Printing Office, February, 1988.

Novick, D. (1990). "Life-cycle Considerations in Urban Infrastructure Engineering," Journal of Management in Engineering, ASCE 6(2), pp. 186-195. 
NSF (1993). Civil Infrastructure System Research: The NSF Role - A Self Study and University/Industry/Government Workshop Report (1993). Final Report, National Science Foundation, Washington D.C.

OTA (1990). U.S. Congress, Office of Technology Assessment, Rebuilding the Foundations: A Special Report on State and Local Public Works Financing and Management. OTA-SET-447, Washington, D.C.: U.S. Government Printing Office, March 1990.

OTA (1991). U.S. Congress, Office of Technology Assessment, Delivering the Goods: Public Works Technologies, Management, and Finance. OTA-SET-477, Washington, D.C.: U.S. Government Printing Office, April 1991.

Parker, E. (1991). "Major Proposals to Restructure the Highway Program," Transportation Quarterly, Vol. 45, No. 1, January 1991, Eno Foundation for Transportation, Inc., Westport, Conn., pp. 55-66.

Perez, A. I., and Ardaman, A. K. (1988). "New Infrastructure: Civil Engineer's Role." Journal of Urban Planning and Development, ASCE, 114(2), pp. 61-73.

Perry, N. J. (1989). "Good News About Infrastructure." Fortune, April 10, 1989, pp. 94-98.

Persaud, B. N. and Hurdle, V. F. (1988). "Some New Data That Challenge Some Old Ideas About the Speed-Flow Relationships." IN Traffic Flow Theory and Highway Capacity, Transportation Research Record 1194, Transportation Research Board, National Academy of Sciences, Washington, D.C., 1988, pp. 191-198.

Peterson, D. E. (1985). Life-Cycle Cost Analysis of Pavements, National Cooperative Highway Research Program, Synthesis of Highway Practice 122, Transportation Research Board, Washington, D.C., December, 1985.

Poggemeyer, L. H. (1989). "New Frontiers in Civil Engineering Infrastructure." Journal of Professional Issues in Engineering, ASCE, 115(4), pp. 393-397.

Polus, A., Craus, J., and Livneh, M. (1991). "Flow and Capacity Characteristics on Two-Lane Rural Highways." IN Freeway Operations, Highway Capacity, and Traffic Flow, 1991, Transportation Research Record 1320, Transportation Research Board, National Academy of Sciences, Washington, D.C., 1991, pp. 128-134.

Polus, A. and Tomecki, A. B. (1986). "A Level of Service Framework for Evaluating Transportation System Management Alternatives." IN Urban Traffic Management, 
Transportation Research Record 1081, Transportation Research Board, National Research Council, Washington, D.C., 1986, pp. 47-53.

Rainer, G. (1990). Understanding Infrastructure, A Guide for Architects and Planners. John Wiley and Sons, New York, NY.

Reinke, D. and Curry, D. (1983). "Quantitative Methods for Evaluation and Selection of TSM Project Alternatives." Economic Analysis of Transportation Problems, Transportation Research Record 912, Transportation Research Board, National Academy of Sciences, Washington, D.C., pp. 42-46.

Richardson, G. P., and Pugh, A. L. III. (1981). Introduction to System Dynamics Modeling with DYNAMO. MIT Press, Cambridge, MA.

Roess, R. P., McShane, W. R., and Pignataro, L. J. (1979). "Freeway Level of Service: A Revised Approach." IN Highway Capacity and Level of Service, Transportation Research Record 699, Transportation Research Board, National Research Council, Washington, D.C., 1979, pp. 7-16.

Roess, R. P. (1984). "Level of Service Concepts: Development, Philosophies, and Implications." IN Traffic Capacity and Characteristics, Transportation Research Record 971, Transportation Research Board, National Research Council, Washington, D.C., 1984, pp. 1-6.

Rubin, I. S. (1993). The Politics of Public Budgeting, Getting and Spending, Borrowing and Balancing. Chatham House Publishers, Chatham, N.J.

Schirmer, A. P. (1993), Director of Public Works, Town of Blacksburg, VA. Personal Interview, 8 July, 1993.

Sharaf, E. A., Shahin, M. Y., and Sinha, K. C. (1988), "Analysis of the Effect of Deferring Pavement Maintenance," IN Pavement Maintenance 1988, Transportation Research Record 1205, Transportation Research Board, Washington, D.C., 1988, pp. 29-35.

Smith, R. E. and Nazarian, S. (1992), "Defining Pavement Maintenance and Distress Precursors for Pavement Maintenance Measurements," IN Maintenance of Pavements, Lane Markings, and Roadsides, Transportation Research Record 1334, Transportation Research Board, Washington, D.C., 1992, pp. 16-18.

Taylor, G. A. (1980). Managerial and Engineering Economy, Economic DecisionMaking, Third Edition, Van Nostrand Company, New York. 
Thuesen, G. J., and Fabrycky, W. J. (1993). Engineering Economy, 8th edition, Prenctice Hall, Englewood Cliffs, NJ.

TRB (1985). Special Report 209: Highway Capacity Manual 1985. Transportation Research Board, National Research Council, Washington, D.C., 1985.

TRIP, (1990). Transportation Road Information Program, "The Federal Highway Trust Fund," Transportation Quarterly, Vol. 44, No. 1, January 1990, Eno Foundation for Transportation, Inc., Westport Conn., pp. 23-35.

Vaughn, R. J. (1984a). "Financing the Nation's Infrastructure Requirements." Infrastructure: Maintenance and Repair of Public Works, Annals of the New York Academy of Sciences, New York Conference on the Infrastructure, Dec. 5-7, 1983, New York, NY, pp. 45-53.

Vaughn, R. J., and Pollard, R. (1984b). Rebuilding America, Planning and Managing Public Works in the 1980's, Vol. I. Council of State Planning Agencies, Washington, D.C.

VDOT (1991). Virginia Department of Transportation, "Maintenance Division Policy Manual," Revised August 1991, Commonwealth of Virginia Department of Transportation, Richmond, VA

Vorster, M. C., and de la Garza, J. M. (1991). "Consequential Equipment Costs Associated with the Lack of Availability and Downtime." Journal of Construction Engineering and Management, ASCE, 116(4), pp. 656-669.

Webster's (1986). Webster's New World Dictionary, Second College Edition. Simon and Schuster, New York, NY.

Weyers, R. E., Prowell, B. D., Sprinkel, M. M., and Vorster, M. (1993). Concrete Bridge Protection, Repair, and Rehabilitation Relative to Reinforcement Corrosion: A Methods Application Manual, SHRP-S-XXX, Strategic Highway Research Program, National Research Council, Washington, D.C., 1993.

Williams, A. K. (1993). District Maintenance Engineer, Virginia Department of Transportation, Salem, VA. Personal Interview, 18 June, 1993.

Winfrey, R. (1969). Economic Analysis for Highways, International Textbook Co., Scanton, PA. 
Woo, H. T. and Hoel, L. A. (1991). "Toll Plaza Capacity and Level of Service." IN Freeway Operations, Highway Capacity, and Traffic Flow 1991, Transportation Research Record 1320, Transportation Research Board, National Academy of Sciences, Washington, D.C., 1991, pp. 119-127. 


\section{BIBLIOGRAPHY}

Allen, B. L., Hall, F. L., and Gunter, M. A. (1985). "Another Look at Identifying Speed-Flow Relationships on Freeways." IN Highway Capacity, Traffic Characteristics, and Flow Theory, Transportation Research Record 1005, Transportation Research Board, National Research Council, Washington, D.C., 1985, pp. 54-64.

Barrie, D. S. and Paulson, B. C. Jr. (1984). Professional Construction Management, 2nd Edition. McGraw Hill, New York, NY.

Becker, G. S. (1988). "Why Potholes and Police get such Short Shrift." Business Week, July 25,1988 , p. 12.

Bieniek, M. P., Griffis, F. H., Gokhale, S., Schwartz, S. I. (1990). "Meeting Issues of Preventive Maintenance for New York City Bridges." Journal of Professional Issues in Engineering, ASCE, 116(4), pp. 323-332.

Blanchard, B. S. (1991). System Engineering Management, John Wiley and Sons, Inc., New York, NY.

Blinder, A. S. (1988). "Are Crumbling Highways Giving Productivity a Flat?" Business Week, August 29, 1988, p. 16.

Brown, R. J., and Yanuck, R. R. (1985). Introduction to Life Cycle Costing. Fairmont Press, Atlanta, GA.

Burns, J. C. (1981). "Roughness and Roadway Safety." IN Pavement Roughness and Skid Properties, Transportation Research Record 836, Transportation Research Board, National Academy of Sciences, Washington, D.C., 1981, pp. 8-14.

Campbell, B. and Humphrey, T. T.(1988). Methods of Cost-Effectiveness Analysis for Highway Projects, National Cooperative Highway Research Program, Synthesis of Highway Practice 142, Transportation Research Board, National Research Council, Washington, D.C.

Carter-Lovejoy, J. (1993). Manager, Planning, Budget and Evaluation, Virginia Department of Transportation, Richmond, VA. Personal Interview, 7 June, 1993.

CE (1994) "Propping Up America: The Critical Need for Infrastructure Improvements." Cost Engineering, Vol. 36/No. 10, October, 1994, pp. 10-13. 
Collura, J., Spring, G., and Black, K. B. (1993). "Service Lives and Costs of Local Maintenance and Rehabilitation Treatments." IN Pavement Management Systems, Transportation Research Record 1397, Transportation Research Board, National Research Council, National Academy Press, Washington, D.C., 1993, pp. 90-95.

Davis, G. A., Nihan, N. L., Hamed, M. M., and Jacobson, L. N. (1990). "Adaptive Forecasting of Freeway Traffic Congestion." IN Traffic Flow, Capacity, Roadway Lighting, and Urban Traffic Systems 1990, Transportation Research Record 1287, Transportation Research Board, National Research Council, Washington, D.C., 1990, pp. 29-33.

Day, M. D. (1990). "Balancing Needs: Growth and Infrastructure Rehabilitation." Water Resources Infrastructure Needs, Economics, and Financing, Proceedings of the Symposium, Apr. 18-20, 1990, Fort Worth, TX, ASCE, pp. 88-91.

Ellis, J. E. (1992). "Rebuilding America: The Mind-Numbing Cost." Business Week/Rebuilding America 1992, pp. 196-198.

Feighan, K. J., Sharaf, E. A., White, T. D., and Sinha, K. C. (1986). "Estimation of Service Life and Cost of Routine Maintenance Activities." IN Highway Maintenance Planning, Transportation Research Record 1102, Transportation Research Board, National Research Council, Washington, D.C., 1986, pp. 13-21.

Fwa, T. F. (1991). "Remaining-Life Consideration in Pavement Overlay Design." Journal of Transportation Engineering, ASCE, 117(6), pp. 685-601.

Fwa, T. F. and Sinha, K. C.(1989). "On the Concept of Total Highway Management." IN Economics, Finance, Planning, and Administration, Transportation Research Record 1229, Transportation Research Board, National Research Council, Washington, D.C., 1989, pp. $79-88$.

Gilchrist, R. S. and Hall, F. L. (1989). "Three-Dimensional Relationships Among Traffic Flow Theory Variables." IN Highway Capacity, Flow Measurement, and Theory, Transportation Research Record 1225, Transportation Research Board, National Academy of Sciences, Washington, D.C., 1989, pp. 99-108.

Gunter, M. A. and Hall, F. L. (1986). "Transitions in the Speed-Flow Relationship, Abridgment." IN Traffic Flow Theory, Characteristics, and Highway Capacity, Transportation Research Record 1091, Transportation Research Board, National Research Council, Washington, D.C., 1986, pp. 18-21. 
Hall, F. L. and Barrow, D. (1988). "Effect of Weather on the Relationship Between Flow and Occupancy on Freeways." IN Traffic Flow Theory and Highway Capacity, Transportation Research Record 1194, Transportation Research Board, National Academy of Sciences, Washington, D.C., 1988, pp. 55-63.

Hall, F. L. and Gunter, M. A. (1986). "Further Analysis of the Flow-Concentration Relationship." IN Traffic Flow Theory, Characteristics, and Highway Capacity, Transportation Research Record 1091, Transportation Research Board, National Research Council, Washington, D.C., 1986, pp. 1-9.

Hanson, R. ed. (1984). Perspectives on Urban Infrastructure. National Academy Press, Washington, D.C.

Hegmon, R. R. (1993). "A Close Look at Road Surfaces," Public Roads, Summer 1993, pp. 4-7.

Hein, R. A. (1990). "Total Life-Cycle Construction (TLC)." Project and Report submitted in partial fulfillment of the requirements for the degree of Masters of Science, Virginia Polytechnic Institute and State University, Blacksburg, VA.

Hoban, T. W. S. (1994) "Cost Effective Road Construction and Maintenance." Highways and Transportation, Vol. 41, No. 1, January 1994, pp. 10-13.

Huddleston, J. R., and Pangotra, P. P. (1990). "Regional and Local Economic Impacts of Transportation Investments," Transportation Quarterly, Vol. 44, No. 4, October 1990, Eno Foundation for Transportation, Inc., Westport, Conn., pp. 579-5974.

Janoff, M. S. (1988). Pavement Roughness and Rideability Field Evaluation, National Cooperative Highway Research Program Report 308, Transportation Research Board, Washington, D.C., 1988.

Karaa, F. A. (1989). "Infrastructure Maintenance Management System Development." Journal of Professional Issues in Engineering, ASCE, 115(4), pp. 422-432.

Koretz, G. (1989). "Crumbling Roads and Bridges: Their Heavy Toll on the Economy." Business Week, August 7, 1989, p. 18.

Kulkarni, R. B., and Van Til, C. J. (1984). Manual for the Selection of Optimal Maintenance Levels of Service, National Cooperative Highway Research Program Report 273, Transportation Research Board, National Research Council, Washington, D.C., December, 1984. 
Larson, T. D. (1993). "ISTEA: Where Are We After a Year?" Public Roads, Vol. 56, No. 4, March, 1993, pp. 135-141.

Lee, Y., Mohseni, A., and Darter, M. I. (1993). "Simplified Pavement Performance Models." IN Pavement Management Systems, Transportation Research Record 1397, Transportation Research Board, National Research Council, Washington, D.C., 1993, pp. 7-14.

Lindley, J. A. (1987). "A Methodology for Quantifying Urban Freeway Congestion." IN Freeway Management and Operations, Transportation Research Record 1132, Transportation Research Board, National Research Council, Washington, D.C., 1987, pp. 1-7.

Mannering, F. L. and Kilareski, W. P. (1990). Principles of Highway Engineering and Traffic Analysis. John Wiley and Sons, New York, NY.

Mar, B. W., and Palmer, R. N. (1989). "Does Civil Engineering Need Systems Engineering?" Journal of Professional Issues in Engineering, ASCE, 115(1), pp. 45-52.

McNeil, S., Markow, M., Neumann, L., Ordway, J., and Uzarski, D. (1992). "Emerging Issues in Transportation Facilities Management." Journal of Transportation Engineering, ASCE, 118(4), pp. 447-495.

Michel, H. L. (1989). "Meeting the Challenge: Working Together on Transportation Infrastructure." Journal of Management in Engineering, ASCE, 5(4), pp. 359-365.

Miller, C. R.(1989). Indicators of Quality in Maintenance, National Cooperative Highway Research Program, Synthesis of Highway Practice 148, Transportation Research Board, National Research Council, Washington, D.C., July, 1989.

Morrall, J. F. and Werner, A. (1990). "Measuring Level of Service of Two-Lane Highways by Overtakings." IN Traffic Flow, Capacity, Roadway Lighting, and Urban Traffic Systems 1990, Transportation Research Record 1287, Transportation Research Board, National Academy of Sciences, Washington, D.C., 1990, pp. 62-69.

Neely, E. S. Jr., and Neathammer, R. D. (1991a). "Life-cycle Maintenance Costs by Facility Use." Journal of Construction Engineering and Management, ASCE, 117(2), pp. 310-320.

Neely, E. S. Jr., and Neathammer, R. D. (1991b). Maintenance Resources by Building Use for U.S. Army Installations. Technical Report P-91/29, Volume I, USACERL. 
Obrien, L. (1989). Evolution and Benefits of Preventive Maintenance Strategies, National Cooperative Highway Research Program, Synthesis of Highway Practice 153, Transportation Research Board, Washington, D.C.

OECD (1983). Traffic Capacity of Major Routes, Report prepared by an OECD Scientific Expert Group, July, 1983.

Parker, D. E., and Dell'Alphonse, J., (1991). Project Budgeting for Buildings. Van Nostrand Reinhold, New York, NY.

Pline, J. L., ed. (1992). Traffic Engineering Handbook, 4th Edition. Prentice-Hall, Englewood Cliffs, NJ.

Radwan, A. E. and Kalevela, S. A. F. (1985). "Investigation of the Effect of Change in Vehicular Characteristics on Highway Capacity and Level of Service." IN Highway Capacity, Traffic Characteristics, and Flow Theory, Transportation Research Record 1005, Transportation Research Board, National Research Council, Washington, D.C., 1985, pp. 65-71.

Rao, K. (1982). Managing State Highway Finance, National Cooperative Highway Research Program, Synthesis of Highway Practice 100, Transportation Research Board, Washington, D.C., December, 1982.

Reilly, W. R., Harwood, D. W., Schoen, J. M., Kuehl, R. O., Bauer, K., and St. John, A. D. (1989). Capacity and Level of Service Procedures for Multilane Rural and Suburban Highways Final Report, NCHRP 3-33, National Cooperative Highway Research Program, Transportation Research Board, National Research Council, Washington, D.C., May, 1989.

Smith, T. M. (1994). "The Impact of Highway Infrastructure on Economic Performance," Public Roads, Spring 1994, pp. 8-14.

Stein, J. M. (1988). Public Infrastructure Planning and Management. Sage Publications, Newbury Park, CA.

Tatom, J. A. (1993). "Is the Infrastructure Crisis a Myth?" Construction Business Review, 3(2), pp. 54-57.

Tourney, P. and Berke, N. (1992). "Put to the Test." Civil Engineering, ASCE, 62(12), pp. 62-63. 
Thompson, G. L., Weller, B., and Terrie, E. W. (1993). "New Perspectives on Highway Investment and Economic Growth." IN Finance, Taxation, Pricing, Economic Analysis, Socioeconomics, Education, and Management, Transportation Research Record 1395, Transportation Research Board, National Research Council, National Academy Press, Washington, D.C., 1993, pp. 81-87.

Uddin, W., and George, K. P. (1993). "User Cost Methodology for Investment Planning and Maintenance: Management of Roads and Highways." IN Finance, Taxation, Pricing, Economic Analysis, Socioeconomics, Education, and Management, Transportation Research Record 1395, Transportation Research Board, National Research Council, National Academy Press, Washington, D.C., 1993, pp. 65-72.

Walters, L. C., Thurgood, G., and Adolphson, D. L. (1993). "New Approach to Integrating Engineering, Managerial, and Political Judgment: Development of the Utah Project Prioritization System." IN Planning and Programming, Land Use, Public Participation, and Computer Technology in Transportation, Transportation Research Record 1400, Transportation Research Board, National Research Council, National Academy Press, Washington, D.C., 1993, pp. 1-9.

Weatherell, R. M. and Ebrahim, A. N. (1986). "Choice of Surface Treatment: Dependency on Level of Road Improvement and Maintenance Budget." IN Highway Maintenance Planning, Transportation Research Record 1102, Transportation Research Board, National Research Council, Washington, D.C., 1986, pp. 1-5.

Zegeer, J. D. (1993). "Updating the 1985 Highway Capacity Manual," Transportation Research News 169, November-December 1993, pp. 18-19+. 


\section{APPENDIX A: \\ LEVEL OF OPERATION MODEL}

HIGHWAY MAINTENANCE MODEL

INTRODUCE COMPREHENSIVE LEVEL OF SERVICE

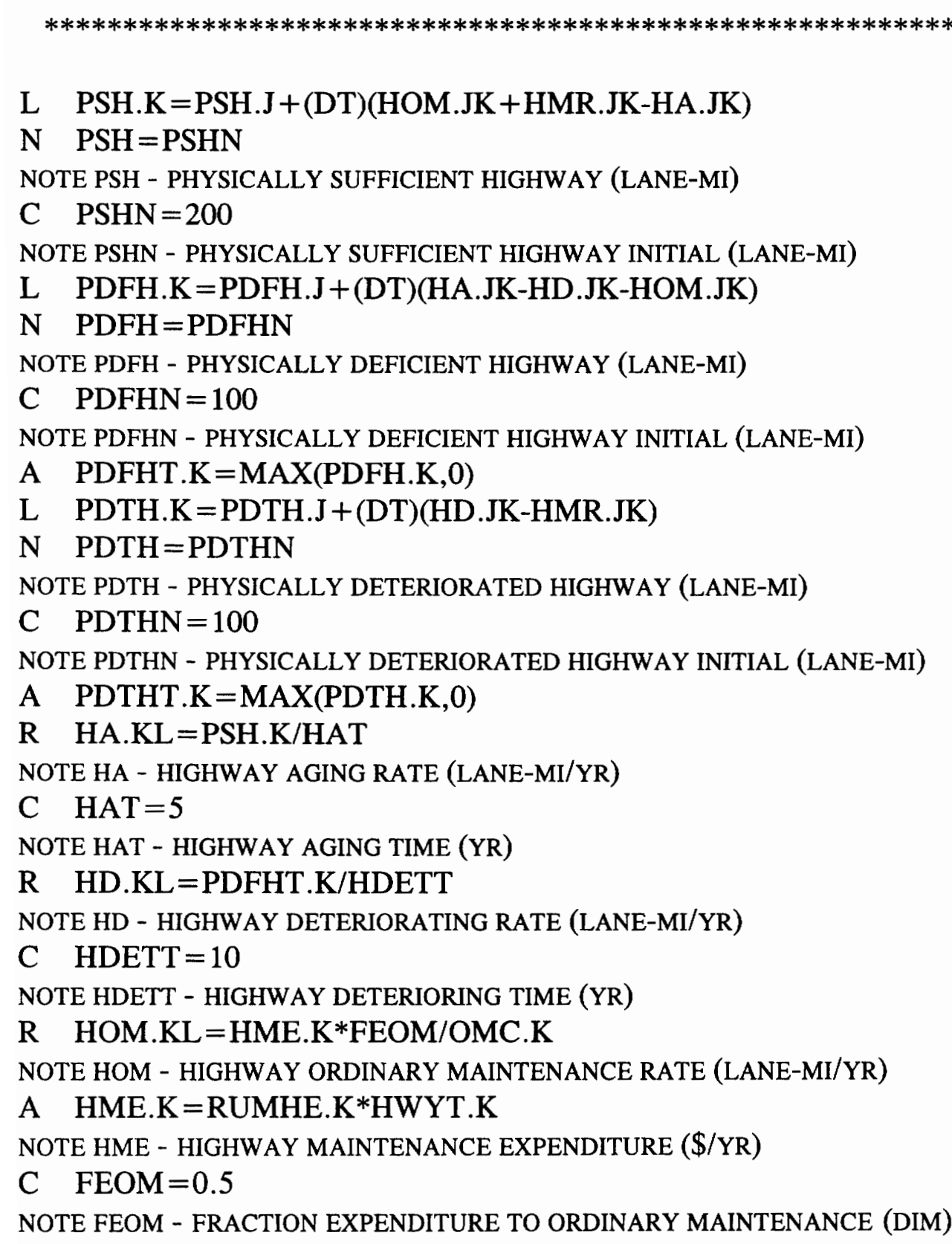


A OMC.K $=50000 *$ INFF.K

NOTE OMC - ORDINARY MAINTENANCE COST (\$/LANE-MI)

R HMR.KL = HME.K*FEMR.K/MRC.K

NOTE HMR - HIGHWAY MAINTENANCE REPLACEMENT (LANE-MI/YR)

A FEMR.K=1-FEOM

NOTE FEMR - FRACT EXPENDITURE TO MAINTENANCE REPLACEMENT (DIM)

A MRC.K $=200000 *$ INFF.K

NOTE MRC - MAINTENANCE REPLACEMENT COST (\$/LANE-MI)

A HWYT.K=PSH.K + PDFH.K+PDTH.K

NOTE HWYT - HIGHWAY TOTAL (LANE-MI)

N $\quad$ HWYTN $=$ PSHN + PDFHN + PDTHN

NOTE HWYTN - INITIAL HIGHWAY TOTAL (LANE-MI)

A FHDMPY.K $=($ HOM.KL +HMR.KL)/HWYT.K

NOTE FHDMPY - FRACT HIGHWAY DOWN FOR MAINTENANCE PER YEAR (1/YR)

A RQI.K $=\operatorname{MIN}((\mathrm{PSH} . \mathrm{K}+$ DFWF*PDFH.K+DTWF*PDTH.K $) /$ HWYT.K, 1.0$)$

NOTE RQI - ROAD QUALITY INDEX (DIM)

C DFWF $=0.5$

NOTE DFWF - DEFICIENT WEIGHING FACTOR (DIM)

C DTWF $=0$

NOTE DTWF - DETERIORATED WEIGHING FACTOR (DIM)

A CLOS.K $=$ LAI $*$ LOI.K

NOTE CLOS - COMPREHENSIVE LEVEL OF SERVICE (DIM)

A CLSF.K =TABLE(CLSFT,CLOS.K,0,1,0.1)

NOTE CFLSF - COMPREHENSIVE LEVEL OF SERVICE FACTOR

$\mathrm{T}$ CLSFT $=0,0.63,0.72,0.78,0.83,0.87,0.90,0.93,0.96,0.98,1.00$

NOTE CLSFT - TABLE VALUES FOR COMPREHENSIVE LEVEL OF SERVICE FACTOR

C LAI $=0.375$

NOTE LAI - LEVEL OF AVAILABILITY INDEX (DIM)

A LOI.K=(1-FHDMPY.K $) *$ RQI.K

NOTE LOI - LEVEL OF OPERATION INDEX (DIM)

A TKL.K $=$ FFTKL $^{*}\left(1-\left(\mathrm{CLSF} . \mathrm{K}^{*} \mathrm{QKL} . \mathrm{K}\right) /(\mathrm{NKL} * \mathrm{CKL})\right) /\left(1-\mathrm{QKL} . \mathrm{K} /\left(\mathrm{NKL}{ }^{*} \mathrm{CKL}\right)\right)$

NOTE TKL - TRAVEL TIME ON LINK KL (MIN/MI)

C $\quad$ FFTKL $=1$

NOTE FFTKL - FREE FLOW TRAVEL TIME ON LINK KL (MIN/MI)

$\mathrm{C} \quad \mathrm{NKL}=2$

NOTE NKL - NUMBER OF LANES ON LINK KL (LANES)

C $\quad \mathrm{CKL}=2400$

NOTE CKL - LANE CAPACITY ON LINK KL (VEH/HR)

A $\mathrm{QKL} . \mathrm{K}=\mathrm{QKLN} *(\mathrm{CLSF} . \mathrm{K} / \mathrm{CLSFN})$

NOTE QKL - VOLUME OF TRAFFIC ON LINK KL (VEH/HR)

C $\quad$ QKLN $=2500$

NOTE QKLN - VOLUME OF TRAFFIC ON LINK KL NORMAL (VEH/HR) 


\section{N CLOSN $=$ LAIN $*$ LOIN}

NOTE CLOSN - COMPREHENSIVE LEVEL OF SERVICE FACTOR INITIAL (DIM)

C $\quad$ LAIN $=0.375$

NOTE LAIN - INITIAL LEVEL OF AVAILABILITY (DIM)

N CLSFN $=$ TABLE(CLSFNT, CLOSN, $0,1,0.1$ )

NOTE CLSFN - INITIAL COMPREHENSIVE LEVEL OF SERVICE FACTOR (DIM)

T CLSFNT $=0,0.60,0.67,0.74,0.80,0.85,0.90,0.93,0.96,0.98,1.00$

NOTE CLSFNT - TABLE VALUES INITIAL COMPREHENSIVE LEVEL OF SERVICE FACTOR

$\mathrm{N} \quad$ LOIN $=$ RQIN

NOTE LOIN - LEVEL OF OPERATION INDEX INITIAL (DIM)

N RQIN $=($ PSHN +DFWF $*$ PDFHN +DTWF $*$ PDTHN $) /$ HWYTN

NOTE RQIN - ROAD QUALITY INDEX INITIAL (DIM)

A UB.K $=((\mathrm{TKLN}-\mathrm{TKL} . \mathrm{K})(\mathrm{QKL} . \mathrm{K}+\mathrm{QKLN}) / 2) * \mathrm{VOT} . \mathrm{K} * \mathrm{CFTAT}$

NOTE UB - USER BENEFIT $(\$ / Y R / M I)$

A VOT.K $=0.2 *$ INFF.K

NOTE VOT - VALUE OF TIME (\$/MIN)

C CFTAT $=4000$

NOTE CFTAT - CONVERSION FACTOR TO TWO-WAY ANNUAL TRAFFIC (HR/YR)

A NUB.K $=($ FIOTN-FIOT.K $) *$ IO $*$ LSDR/HWYT.K

NOTE NUB - NON-USER BENEFIT (\$/YR/MI)

N $\quad$ IO $=($ PCI $*$ POP $) /(1-$ FIOIN $)$

NOTE IO - INDUSTRIAL OUTPUT (\$/YR)

C $\quad \mathrm{PCI}=20000$

NOTE PCI - PER CAPITA INCOME (\$/YR-PERSON)

C $\quad \mathrm{POP}=200000$

NOTE POP - POPULATION (PERSONS)

C $\quad$ FIOIN $=0.7$

NOTE FIOIN - FRACT INDUSTRIAL OUTPUT TO INPUT NORMAL (DIM)

N LSDR $=$ LLKL/ASD

NOTE LSDR - LINK TO SHIPPING DISTRIBUTION RATIO (DIM)

C $\quad$ LLKL $=100$

NOTE LLKL - LENGTH OF LINK KL (MI)

C $\mathrm{ASD}=400$

NOTE ASD - AVERAGE SHIPPING DISTANCE (MI)

A HRG.K=QKL.K*CFTAT*LLKL*TPG.K/(AFE.K*HWYT.K)

NOTE HRG - HIGHWAY REVENUES GENERATED (\$/YR/LANE-MI)

A $\mathrm{AFE} . \mathrm{K}=20$

NOTE AFE - AVERAGE FUEL EFFICIENCY (MI/GAL)

A TPG.K $=0.3$

NOTE TPG - TAX PER GALLON (\$/GAL)

A TNB.K=UB.K+NUB.K-RUMHE.K

NOTE TNB - TOTAL NET BENEFITS (\$/YR/LN-MI) 


\section{A TNBPC. $\mathrm{K}=$ TNB.K*HWYT.K/POP}

NOTE TNBPC - TOTAL NET BENEFITS PER CAPITA (\$/YR/PERSON)

$\mathrm{N} \quad \mathrm{TKLN}=$ FFTKL $*(1-(\mathrm{CLSFN} * \mathrm{QKLN}) /(\mathrm{NKL} * \mathrm{CKL})) /(1-\mathrm{QKLN} /(\mathrm{NKL} * \mathrm{CKL}))$

NOTE TKLN - TRAVEL TIME LINK KL NORMAL (MIN/MILE)

C $\quad$ UMHE $=($ TO BE VARIED DURING SIMULATION $)$

NOTE UHME - UNIT HIGHWAY MAINTENANCE EXPENDITURE (\$/YR/LANE-MI)

A RUMHE.K=UMHE*INFF.K

NOTE RUMHE - ACTUAL UMHE WITH INFLATION FACTOR (\$/YR/LANE-MI)

A INFF.K $=(1+\mathrm{INF})^{* *}$ N.K

NOTE INFF - INFLATION FACTOR

C $\quad \mathrm{INF}=0.03$

NOTE INF - INFLATION RATE (PERCENTAGE)

A N.K=TIME.K

NOTE $N$ - NUMBER OF TIME PERIODS

$\mathrm{R}$ PWUMHE.KL $=$ RUMHE. $\mathrm{K} *$ SPPWF.K

NOTE PWUMHE - PRESENT WORTH OF UNIT MAINT HWY EXPENDITURE (\$/LN-MI)

L CPWUM.K = CPWUM.J+(DT)(PWUMHE.JK)

NOTE CPWUM - CUMULATIVE PRESENT WORTH OF UNIT MAINT HWY EXPEND (\$/LN-MI)

N CPWUM $=$ CPWUMN

C $\quad$ CPWUMN $=1$

NOTE CPWUMN - INITIAL VALUE FOR CUMLATIVE PRESENT WORTH UMHE

A AEUMHE. $K=$ CPWUM. $K *$ EPSCRF. $K$

NOTE PWUMHE - PRESENT WORTH OF UNIT HWY MAINT EXPENDITURES (\$/LN-MI)

A EPSCRF.K $=\left(\mathrm{R}^{*}(1+\mathrm{R}) * * \mathrm{~N} . \mathrm{K}\right) /(((1+\mathrm{R}) * * \mathrm{~N} . \mathrm{K})-.9999)$

NOTE EPSCRF - EQUAL PAYMENT SERIES CAPITAL RECOVER FACTOR $(\mathrm{A} / \mathrm{P}, \mathrm{I}, \mathrm{N})$

A FIOT.K $=$ FIOTN*SQRT(TKL.K/TKLN)

NOTE FIOT - FRACT INDUSTIAL OUTPUT TO TRANSPORTATION (DIM)

$\mathrm{N} \quad \mathrm{FIOT}=$ FIOTN

C $\quad$ FIOTN $=0.5$

NOTE FIOTN - FRACT INDUSTRIAL OUTPUT TO TRANSPORTATION NORMAL (DIM)

R RLE.KL $=$ HRG.K-RUMHE.K

NOTE RLE - REVENUES LESS EXPENDITURES (\$/YR/LANE-MI)

L CRLE.K $=$ CRLE.J $+(D T)(R L E . J K)$

NOTE CRLE - CUMULATIVE REVENUES LESS EXPENDITURES (\$/LANE-MI)

$N$ CRLE $=$ CRLEN

C CRLEN $=0$

NOTE CRLEN - INITIAL VALUE OF REVENUES LESS EXPENDITURES

A SPPWF.K $=1 /\left((1+\mathrm{R})^{* *} \mathrm{~N} . \mathrm{K}\right)$

NOTE SPPWF - SINGLE PAYMENT PRESENT WORTH FACTOR (P/F,I,N)

$\mathrm{R} \quad$ PWUB.KL $=$ UB. $\mathrm{K} *$ SPPWF. $\mathrm{K}$

NOTE PWUB - PRESENT WORTH OF USER BENEFITS (\$/LN-MI) 
L CPWUB.K $=$ CPWUB.J +(DT)(PWUB.JK)

NOTE CPWUB - CUMULATIVE PRESENT WORTH OF USER BENEFITS (\$/LN-MI)

N $\quad$ PPWUB $=$ CPWUBN

C $\quad$ PPWUBN $=0$

NOTE CPWUBN - INITIAL VALUE OF CUMULATIVE PRESENT WORTH OF USER BENEFITS

A $\mathrm{AEUB} . \mathrm{K}=\mathrm{CPWUB} . \mathrm{K} *$ EPSCRF. $\mathrm{K}$

NOTE AEUB.K - ANNUAL EQUIVALENCE USER BENEFITS (\$/LN-MI/YR)

$\mathrm{R}$ PWNUB.KL $=$ NUB.K*SPPWF.K

NOTE PWNUB - PRESENT WORTH OF NONUSER BENEFITS (\$/LN-MI)

L CPWNUB.K $=$ CPWNUB.J+(DT)(PWNUB.JK)

NOTE CPWNUB - CUMULATIVE PRESENT WORTH OF NON-USER BENEFITS (\$/LN-MI)

$\mathrm{N} \quad \mathrm{CPWNUB}=\mathrm{CPWNUBN}$

C $\quad$ CPWNUBN $=0$

NOTE CPWNUB - INITIAL VALUE OF PRESENT WORTH OF NON-USER BENEFITS

A AENUB. $K=$ CPWNUB. $K *$ EPSCRF. $K$

NOTE AENUB - ANNUAL EQUIVALENCE NON USER BENEFITS (\$/YR/LN-MI)

A ANUB.K $=$ NUB. $K *$ EPSCRF. $K$

NOTE ANUB - ANNUAL USER BENEFITS (\$/YR/LN-MI)

C $\quad \mathrm{R}=0.1$

NOTE R - INTEREST RATE

A BENCOST.K $=($ AEUB.K + AENUB.K-AEUMHE.K*FEOM $) /$ ^ (AEUMHE.K*FEMR.K)

NOTE BENCST - ANNUAL EQUIVALENT BENEFIT COST RATIO (DIM)

C $\quad \mathrm{YEAR}=7$

NOTE YEAR - YEAR OF REHABILITATION

A CBENCST.K $=(($ AEUB.K + AENUB.K-AEUMHE.K*FEOM $) /$ $($ RUMHE.K*FEMR.K*YEAR*R))*(1-EXP(-R*N.K))

NOTE CBENCST - CONTINUOUS BENEFIT COST RATIO

C ECONLIFE $=25$

NOTE ECONLIFE - ECONOMIC LIFE OF HIGHWAY.

SPEC DT $=1 /$ LENGTH $=20 /$ SAVPER $=1$

SAVE BENCOST,CBENCST,RLE,CLSF,TNBPC 


\section{APPENDIX B: \\ LEVEL OF AVAILABILITY MODEL}

HIGHWAY CONSTRUCTION MODEL

L UCH.K $=$ UCH.J +(DT)(HER.JK + HUR.JK-PCHR.JK)

$\mathrm{N} \quad \mathrm{UCH}=\mathrm{UCHN}$

NOTE UCH - UNCONGESTED HIGHWAY (LN-MILES)

C $\quad \mathrm{UCHN}=50$

NOTE UCHN - UNCONGESTED HIGHWAY INITIAL (LN-MILES)

L $\quad$ PCH.K $=$ PCH.J +(DT)(PCHR.JK + HIR.JK-FCHR.JK)

N $\quad \mathrm{PCH}=\mathrm{PCHN}$

NOTE PCH - PARTIALLY CONGESTED HIGHWAY (LN-MILES)

C $\quad \mathrm{PCHN}=250$

NOTE PCHN - PARTIALLY CONGESTED HIGHWAY INITIAL (LN-MILES)

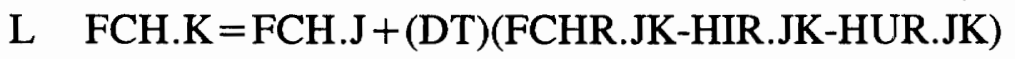

$\mathrm{N} \quad \mathrm{FCH}=\mathrm{FCHN}$

NOTE FCH - FULLY CONGESTED HIGHWAY (LN-MILES)

C $\mathrm{FCHN}=100$

NOTE FCHN - FULLY CONGESTED HIGHWAY INITIAL (LN-MILES)

N $\quad$ HWYTN $=\mathrm{UCHN}+\mathrm{PCHN}+\mathrm{FCHN}$

NOTE HWYTN $=$ INITIAL HIGHWAY TOTAL (LN-MI)

$\mathrm{R} \quad \mathrm{HER} . \mathrm{KL}=\mathrm{HCE} . \mathrm{K} * \mathrm{FEHE} / \mathrm{HEC}$

NOTE HER - HIGHWAY EXPANSION RATE (LN-MILES/YR)

C $\mathrm{FEHE}=0$

NOTE FEC - FRACTION EXPENDITURES TO HIGHWAY EXPANSION (DIM)

C $\mathrm{HEC}=2000000$

NOTE HEC - HIGHWAY EXPANSION COST (\$/LN-MI)

R HUR.KL $=$ HCE.. FEHU/HUC

NOTE HUR - HIGHWAY UPGRADE RATE (LN-MILES/YR)

C $\mathrm{HUC}=500000$

NOTE HUC - HIGHWAY UPGRADE COST (\$/LN-MI)

C $\mathrm{FEHU}=0.5$

NOTE FEHU - FRACTION EXPENDITURES TO HIGHWAY UPGRADE (DIM)

$\mathrm{R}$ HIR.KL $=$ HCE. $\mathrm{K}^{*}$ FEHI.K/HIC

NOTE HIR - HIGHWAY IMPROVEMENT RATE (LN-MILES/YR)

C $\mathrm{HIC}=250000$

NOTE HIC - HIGHWAY IMPROVEMENT COST (\$/LN-MI) 
A FEHI.K=1-FEHU-FEHE

NOTE FEHI - FRACTION EXPENDITURE TO HIGHWAY IMPROVEMENT (DIM)

R PCHR.KL $=$ UCH.K/HPCT

NOTE PCHR - PARTIALLY CONGESTED HIGHWAY RATE (LN-MILES/YR)

C $\quad$ HPCT $=5$

NOTE HPCT - HIGHWAY PARTIAL CONGESTION TIME (YR)

$\mathrm{R} \quad \mathrm{FCHR} . \mathrm{KL}=\mathrm{PCH} . \mathrm{K} / \mathrm{HFCT}$

NOTE FCHR - FULLY CONGESTED HIGHWAY RATE (LN-MILES/YR)

C $\mathrm{HFCT}=10$

NOTE HFCT - HIGHWAY FULLY CONGESTED TIME (YR)

A HWYT.K =UCH.K + PCH.K + FCH.K

NOTE HWYT - HIGHWAY TOTAL (LANE MILES)

A FHDCPY.K $=($ HUR.KL + HIR.KL + HER.KL $) /$ HWYT.K

NOTE FHDCPY - FRACTION HIGHWAY DOWN FOR CONSTRUCTION PER YEAR (DIM)

A HCI.K $=(\mathrm{UCH} . \mathrm{K} * \mathrm{UCWF}+\mathrm{PCH} . \mathrm{K} * \mathrm{PCWF}+\mathrm{FCH} . \mathrm{K}) / \mathrm{HWYT} . \mathrm{K}$

NOTE HCI - HIGHWAY CONGESTION INDEX

A LAI.K $=(1-\mathrm{HCI} . \mathrm{K}) *(1-\mathrm{FHDCPY} . \mathrm{K})$

NOTE LAI - LEVEL OF AVAILABILITY INDEX

C $\quad \mathrm{UCWF}=0.5$

NOTE UCWF - UNCONGESTED WEIGHTING FACTOR

C $\quad P C W F=0.5$

NOTE PCWF - PARTIALLY CONGESTED WEIGHTING FACTOR

C UCHE $=($ TO BE VARIED DURING SIMULATION $)$

NOTE UCHE - UNIT CONSTRUCTION HIGHWAY EXPENDITURE (\$/LN-MI)

A HCE.K $=$ UCHE*HWYT.K

NOTE HCE - HIGHWAY CONSTRUCTION EXPENDITURE (\$)

SPEC DT $=1 /$ LENGTH $=20 /$ SAVPER $=1$

SAVE LAI,HWYT,HCI,FHDCPY,UCH,PCH,FCH 


\section{APPENDIX C: \\ COMPREHENSIVE LEVEL OF SERVICE MODEL}

HIGHWAY CONSTRUCTION AND MAINTENANCE MODEL

INTRODUCE COMPREHENSIVE LEVEL OF SERVICE AND

USER AND NON-USER BENEFIT ANALYSIS

$* * * * * * * * * * * * * * * * * * * * * * *$ MAINTENANCE SECTION $* * * * * * * * * * * * * * * * * * * * * * * *$

L $\quad$ PSH.K $=$ PSH.J +(DT)(HOM.JK + HMR.JK + HER.JK-HA.JK)

N $\quad$ PSH $=$ PSHN

NOTE PSH - PHYSICALLY SUFFICIENT HIGHWAY (LANE-MI)

C $\mathrm{PSHN}=200$

NOTE PSHN - PHYSICALLY SUFFICIENT HIGHWAY INITIAL (LANE-MI)

L PDFH.K =PDFH.J +(DT)(HA.JK-HD.JK-HOM.JK)

$\mathrm{N} \quad \mathrm{PDFH}=\mathrm{PDFHN}$

NOTE PDFH - PHYSICALLY DEFICIENT HIGHWAY (LANE-MI)

C $\quad$ PDFHN $=100$

NOTE PDFHN - PHYSICALLY DEFICIENT HIGHWAY INITIAL (LANE-MI)

A PDFHT.K $=$ MAX(PDFH.K,0)

L $\quad$ PDTH.K $=$ PDTH.J +(DT)(HD.JK-HMR.JK)

N PDTH $=$ PDTHN

NOTE PDTH - PHYSICALLY DETERIORATED HIGHWAY (LANE-MI)

C PDTHN $=100$

NOTE PDTHN - PHYSICALLY DETERIORATED HIGHWAY INITIAL (LANE-MI)

A PDTHT.K=MAX(PDTH.K,0)

R HA.KL $=$ PSH.K/HAT

NOTE HA - HIGHWAY AGING RATE (LANE-MI/YR)

C $\mathrm{HAT}=5$

NOTE HAT - HIGHWAY AGING TIME (YR)

R HD.KL $=$ PDFHT.K/HDETT

NOTE HD - HIGHWAY DETERIORATING RATE (LANE-MI/YR)

C HDETT $=10$

NOTE HDETT - HIGHWAY DETERIORING TIME (YR)

$\mathrm{R}$ HOM.KL $=$ HME.K*FEOM/OMC.K

NOTE HOM - HIGHWAY ORDINARY MAINTENANCE RATE (LANE-MI/YR) 
A HME.K=RUMHE.KL*HWYT.K

NOTE HME - HIGHWAY MAINTENANCE EXPENDITURE (\$/YR)

C UMHE $=($ TO BE VARIED DURING SIMULATION)

NOTE UMHE - UNIT MAINTENANCE HIGHWAY EXPENDITURE (\$/YR/LANE-MI)

R RUMHE.KL $=$ UMHE*INFF.K

NOTE RUMHE - ACTUAL UNIT MAINTENANCE HIGHWAY EXPENDITRE (\$/YR/LANE-MI)

L CRUMHE. $\mathrm{K}=$ CRUMHE.J+(DT)(RUMHE.JK)

NOTE CRUMHE - CUMULATIVE ACTUAL MAINT HWY EXPENDITURE

$\mathrm{N}$ CRUMHE $=$ CRUMHEN

C $\quad$ CRUMHEN $=1$

NOTE CRUMHEN - INITIAL VALUE FOR CUMULATIVE RUMHE

$\mathrm{R}$ PWRUMHE. $\mathrm{KL}=$ RUMHE.KL $*$ SPPWF.K

NOTE PWRUMHE - PRESENT WORTH ACTUAL UNIT MAINT HWY EXPEND (\$/LN-MI)

L CPRUMH.K $=$ CPRUMH.J +(DT)(PWRUMHE.JK)

NOTE CPRUMH - CUMULATIVE PRESENT WORTH REAL UNIT MAINT HWY EXPEND (\$/LN-MI)

N $\quad$ CPRUMH $=$ CPRUMHN

C $\quad$ CPRUMHN $=0$

NOTE CPRUMHE - INITIAL VALUE OF CUM PRESENT WORTH RUMHE

A AEUMHE. $\mathrm{K}=\mathrm{CPRUMH} . \mathrm{K} * \mathrm{EPSCRF} . \mathrm{K}$

NOTE AEUMHE - ANNUAL EQUIVALENCE CUM PRESENT WORTH UMHE

C $\quad$ FEOM $=0.5$

NOTE FEOM - FRACT EXPENDITURE TO ORDINARY MAINTENANCE (DIM)

A OMC.K $=50000 *$ INFF.K

NOTE OMC - ORDINARY MAINTENANCE COST (\$/LANE-MI)

A INFF.K $=(1+$ INFR $) * *$ TIME.K

NOTE INFF - INFLATION FACTOR (DIM)

C INFR $=0.03$

NOTE INFR - INFLATION RATE (PERCENTAGE)

R HMR.KL =HME.K*FEMR.K/MRC.K

NOTE HMR - HIGHWAY MAINTENANCE REPLACEMENT RATE (LANE-MI/YR)

A FEMR.K=1-FEOM

NOTE FEMR - FRACT EXPENDITURE TO MAINTENANCE REPLACEMENT (DIM)

A MRC. $\mathrm{K}=200000 *$ INFF. $\mathrm{K}$

NOTE MRC - MAINTENANCE REPLACEMENT COST (\$LANE-MI)

A FHDMPY.K=(HOM.KL+HMR.KL)/HWYT.K

NOTE FHDMPY - FRACT HIGHWAY DOWN FOR MAINTENANCE PER YEAR (1/YR)

A RQI.K $=$ MIN((PSH.K+DFWF*PDFH.K+DTWF*PDTH.K $) /$ HWYT.K, 1.0)

NOTE RQI - ROAD QUALITY INDEX (DIM)

C $\quad$ DFWF $=0.5$

NOTE DFWF - DEFICIENT WEIGHING FACTOR (DIM)

C $\mathrm{DTWF}=0$

NOTE DTWF - DETERIORATED WEIGHING FACTOR (DIM)

Appendix C: Comprehensive Level of Service Model 
A CLOS.K=LAI.K*LOI.K

NOTE CLOS - COMPREHENSIVE LEVEL OF SERVICE (DIM)

A CLSF.K=TABLE(CLSFT,CLOS.K,0,1,0.1)

NOTE CLSF - COMPREHENSIVE LEVEL OF SERVICE FACTOR

$\mathrm{T}$ CLSFT $=0,0.63,0.72,0.78,0.83,0.87,0.90,0.93,0.96,0.98,1.00$

NOTE CLSFT - TABLE VALUES FOR COMPREHENSIVE LEVEL OF SERVICE FACTOR

A LOI.K=(1-FHDMPY.K $) *$ RQI.K

NOTE LOI - LEVEL OF OPERATION INDEX (DIM)

A TKL.K $=$ FFTKL ${ }^{*}\left(1-\left(\mathrm{CLSF} . \mathrm{K}^{*} \mathrm{QKL} . \mathrm{K}\right) /\left(\mathrm{NKL}{ }^{*} \mathrm{CKL}\right)\right) /\left(1-\mathrm{QKL} . \mathrm{K} /\left(\mathrm{NKL}{ }^{*} \mathrm{CKL}\right)\right)$

NOTE TKL - TRAVEL TIME ON LINK KL (MIN/MI)

C $\quad$ FFTKL $=1$

NOTE FFTKL - FREE FLOW TRAVEL TIME ON LINK KL (MIN/MI)

C $\quad \mathrm{NKL}=2$

NOTE NKL - NUMBER OF LANES ON LINK KL (LANES)

C $\quad \mathrm{CKL}=2400$

NOTE CKL - LANE CAPACITY ON LINK KL (VEH/HR)

A $\mathrm{QKL} . \mathrm{K}=\mathrm{QKLN} *(\mathrm{CLSF} . \mathrm{K} / \mathrm{CLSFN})+\mathrm{QKLT}$

NOTE QKL - VOLUME OF TRAFFIC ON LINK KL (VEH/HR)

C $\quad$ QKLN $=2500$

NOTE QKLN - VOLUME OF TRAFFIC ON LINK KL NORMAL (VEH/HR)

N CLOSN $=$ LAIN $*$ LOIN

NOTE CLOSN - COMPREHENSIVE LEVEL OF SERVICE INITIAL (DIM)

N CLSFN = TABLE(CLSFNT,CLOSN, 0,1,0.1)

NOTE CLSFN - INITIAL COMPREHENSIVE LEVEL OF SERVICE FACTOR (DIM)

$\mathrm{T}$ CLSFNT $=0,0.60,0.67,0.74,0.80,0.85,0.90,0.93,0.96,0.98,1.00$

NOTE CLSFNT - TABLE VALUES INITIAL COMPREHENSIVE LEVEL OF SERVICE FACTOR

$\mathrm{N} \quad$ LOIN $=$ RQIN

NOTE LOIN - LEVEL OF OPERATION INDEX INITIAL (DIM)

$\mathrm{N}$ RQIN $=($ PSHN + DFWF $*$ PDFHN +DTWF $*$ PDTHN $) /$ HWYT

NOTE RQIN - ROAD QUALITY INDEX INITIAL (DIM)

L UCH.K $=$ UCH.J +(DT)(HER.JK + HUR.JK-PCHR.JK)

NOTE UCH - UNCONGESTED HIGHWAY (LN-MILES)

$\mathrm{N} \quad \mathrm{UCH}=\mathrm{UCHN}$

C $\mathrm{UCHN}=50$

NOTE UCHN - INITIAL UNCONGESTED HIGHWAY (LN-MI)

L $\quad$ PCH.K $=$ PCH.J +(DT)(PCHR.JK + HIR.JK-FCHR.JK)

NOTE PCH - PARTIALLY CONGESTED HIGHWAY (LN-MILES) 
N $\mathrm{PCH}=\mathrm{PCHN}$

C $\quad \mathrm{PCHN}=250$

NOTE PCHN - INITIAL PARTIALLY CONGESTED HIGHWAY (LN-MI)

L $\quad$ FCH.K $=$ FCH.J +(DT)(FCHR.JK-HIR.JK-HUR.JK)

NOTE FCH - FULLY CONGESTED HIGHWAY (LN-MILES)

$\mathrm{N} \quad \mathrm{FCH}=\mathrm{FCHN}$

C $\quad \mathrm{FCHN}=100$

NOTE FCHN - INITIAL FULLY CONGESTED HIGHWAY

$\mathrm{N} \quad$ HWYTN $=\mathrm{UCHN}+\mathrm{PCHN}+\mathrm{FCHN}$

NOTE HWYTN $=$ INITIAL HIGHWAY MILE TOTAL (LN-MI)

R HER.KL $=$ HCE.K*FEHE/HEC.K

NOTE HER - HIGHWAY EXPANSION RATE (LN-MILES/YR)

C $\mathrm{FEHE}=0$

NOTE FEHE - FRACT EXPENDITURES TO HIGHWAY EXPANSION (DIM)

A HEC.K $=2000000 *$ INFF.K

NOTE HEC - HIGHWAY EXPANSION COST (\$/LANE-MI)

$\mathrm{R}$ HUR.KL $=$ HCE.K*FEHU/HUC.K

NOTE HUR - HIGHWAY UPGRADE RATE (LN-MILES/YR)

A HUC.K $=500000 *$ INFF.K

NOTE HUC - HIGHWAY UPGRADE COST (\$/LN-MI)

C $\mathrm{FEHU}=0.5$

NOTE FEHU - FRACTION EXPENDITURES TO HIGHWAY UPGRADE (DIM)

R HIR.KL $=$ HCE.K*FEHI.K/HIC.K

NOTE HIR - HIGHWAY IMPROVEMENT RATE (LN-MILES/YR)

A HIC.K $=250000 *$ INFF.K

NOTE HIC - HIGHWAY IMPROVEMENT COST (\$/LN-MI)

A FEHI.K=1-FEHU-FEHE

NOTE FEHI - FRACTION EXPENDITURE TO HIGHWAY IMPROVEMENT (DIM)

$\mathrm{R}$ PCHR.KL $=\mathrm{UCH} . \mathrm{K} / \mathrm{HPCT}$

NOTE PCHR - PARTIALLY CONGESTED HIGHWAY RATE (LN-MILES/YR)

C $\quad \mathrm{HPCT}=5$

NOTE HPCT - HIGHWAY PARTIAL CONGESTION TIME (YR)

R FCHR.KL $=$ PCH.K/HFCT

NOTE FCHR - FULLY CONGESTED HIGHWAY RATE (LN-MILES/YR)

C $\quad \mathrm{HFCT}=10$

NOTE HFCT - HIGHWAY FULLY CONGESTED TIME (YR)

A HWYT.K=UCH.K+PCH.K+FCH.K

NOTE HWYT - TOTAL HIGHWAY MILES (LANE MILES)

A FHDCPY.K $=($ HUR.KL + HIR.KL + HER.KL)/HWYT.K

NOTE FHDCPY - FRACTION HIGHWAY DOWN FOR CONSTRUCTION PER YEAR (DIM)

A HCI.K $=(\mathrm{UCH} . \mathrm{K} * \mathrm{UCWF}+\mathrm{PCH} . \mathrm{K} * \mathrm{PCWF}+\mathrm{FCH} . \mathrm{K}) / \mathrm{HWYT} . \mathrm{K}$

NOTE HCI - HIGHWAY CONGESTION INDEX

Appendix C: Comprehensive Level of Service Model 
A LAI.K $=(1-\mathrm{HCI} . \mathrm{K}) *(1-\mathrm{FHDCPY} . \mathrm{K})$

NOTE LAI - LEVEL OF AVAILABILITY INDEX (FUNCTIONAL LEVEL OF SERVICE)

$\mathrm{N} \quad$ LAIN $=1-\mathrm{HCIN}$

NOTE LAIN - INITIAL LEVEL OF AVAILABILITY INDEX

$\mathrm{N} \quad \mathrm{HCIN}=(\mathrm{UCHN} * \mathrm{UCWF}+\mathrm{PCHN} * \mathrm{PCWF}+\mathrm{FCHN}) / \mathrm{HWYTN}$

NOTE HCIN - HIGHWAY CONGESTION INDEX INITIAL (DIM)

C $\quad$ PCWF $=0.5$

NOTE UCWF - UNCONGESTED WEIGHTING FACTOR

C $\quad \mathrm{UCWF}=0.5$

NOTE FCWF - FULLY CONGESTED WEIGHTING FACTOR

C UCHE $=($ TO BE VARIED DURING SIMULATION $)$

NOTE UCHE - UNIT CONSTRUCTION HIGHWAY EXPENDITURE (\$/LN-MI)

R RUCHE.KL $=$ UCHE $*$ INFF.K

NOTE RUCHE - ACTUAL UNIT CONSTRUCTION HIGHWAY EXPENDITURE

L CRUCHE.K $=$ CRUCHE.J+(DT)(RUCHE.JK)

NOTE CRUCHE - CUMULATIVE ACTUAL UNIT CONST HWY EXPENDITURE

$\mathrm{N}$ CRUCHE $=$ CRUCHEN

C CRUCHEN $=1$

NOTE CRUCHEN - INITIAL VALUE FOR CUM ACTUAL UCHE

$\mathrm{R}$ PWRUCHE.KL $=$ RUCHE.KL*SPPWF.K

NOTE PWRUCHE - PRESENT WORTH ACTUAL UNIT CONST HWY EXPEND (\$/LN-MI)

L CPRUCH.K $=$ CPRUCH.J+(DT)(PWRUCHE.JK)

NOTE CPRUCH - CUMULATIVE PRESENT WORTH ACTUAL UNIT CONST HWY EXPEND

$\mathrm{N} \quad \mathrm{CPRUCH}=\mathrm{CPRUCHN}$

C $\quad$ CPRUCHN $=1$

NOTE CPRUCHN - INITIAL VALUE OF CUM PRESENT WORTH RUCHE

A AEUCHE. $\mathrm{K}=$ CPRUCH. $\mathrm{K} *$ EPSCRF.K

NOTE AEUCHE - ANNUAL EQUIVALENCE FOR PRESENT WORTH UCHE

A HCE.K $=$ RUCHE.KL*HWYT.K

NOTE HCE - HIGHWAY CONSTRUCTION EXPENDITURE (\$)

************************ USER/NON-USER BENEFIT AND********************** $* * * * * * * * * * * * * * * * * * * * * *$ BENEFIT COST ANALYSIS $* * * * * * * * * * * * * * * * * * * * * *$

$\mathrm{N} \quad \mathrm{VOCN}=\mathrm{TABLE}(\mathrm{VOCNT}, \mathrm{LOIN}, 0,1,0.2)$

NOTE VOCN - VEHICLE OPERATING COSTS NORMAL (\$/MI)

$T \quad$ VOCNT $=0.40,0.30,0.22,0.18,0.16,0.15$

NOTE VOCNT - TABLE VALUES FOR VEHICLE OPERATING COSTS

A VOC.K $=$ TABLE(VOCT,LOI.K, $0,1,0.2$ )

NOTE VOC - VEHICLE OPERATING COSTS (\$/MI)

$\mathrm{T} \quad \mathrm{VOCT}=0.40,0.30,0.22,0.18,0.16,0.15$

NOTE VOCT - TABLE VALUES FOR VEHICLE OPERATING COSTS 
A UB.K $=(((\text { VOCN-VOC.K }) *(\text { INFF.K }))+((\text { TKLN-TKL.K }) * \text { VOT.K }))^{*}$ ^ $((\mathrm{QKL} . \mathrm{K}+\mathrm{QKLN}) / 2) * \mathrm{CFTAT}$

NOTE UB - USER BENEFIT (\$/YR/MI)

R PWUB.KL $=$ UB.K*SPPWF.K

NOTE PWUB - PRESENT WORTH USER BENEFITS $(\$ /$ LN-MI) AT TIME $=0$

A SPPWF.K $=1 /((1+\mathrm{R}) * *$ TIME.K $)$

NOTE SPPWF - SINGLE PAYMENT PRESENT WORTH FACTOR (P/F,I,N)

L CPWUB. $\mathrm{K}=$ CPWUB.J $+(\mathrm{DT})($ PWUB.JK)

NOTE CPWUB - CUMULATIVE PRESENT WORTH USER BENEFITS (\$/LN-MI)

N $\quad$ CPWUB $=$ CPWUBN

C $\quad$ CPWUBN $=0$

NOTE CPWUBN - INITIAL VALUE OF CUM PRESENT WORTH USER BENEFITS (\$/LN-MI)

A AEUB. $\mathrm{K}=$ CPWUB. $\mathrm{K} *$ EPSCRF. $\mathrm{K}$

NOTE AEUB - ANNUAL EQUIVALENCE USER BENEFITS (\$/YR/LN-MI)

A VOT.K $=0.2 *$ INFF.K

NOTE VOT - VALUE OF TIME (\$/MIN)

C CFTAT $=4000$

NOTE CFTAT - CONVERSION FACTOR TO TWO-WAY ANNUAL TRAFFIC (HR/YR)

A NUB.K $=($ FIOTN-FIOT.K $) *$ IO*LSDR/HWYT.K

NOTE NUB - NON-USER BENEFIT (\$/YR/MI)

$\mathrm{R}$ PWNUB.KL $=$ NUB.K*SPPWF.K

NOTE PWNUB - PRESENT WORTH NON-USER BENEFITS ( $\$ /$ LN-MI) AT TIME $=0$

L CPWNUB.K $=$ CPWNUB.J + (DT)(PWNUB.JK)

NOTE CPWNUB - CUMULATIVE PRESENT WORTH NON-USER BENEFITS (\$/MI)

$\mathrm{N} \quad \mathrm{CPWNUB}=\mathrm{CPWNUBN}$

C $\quad$ CPWNUBN $=0$

NOTE CPWNUBN - INITIAL VALUE FOR CUMULATIVE PW NON-USER BENEFITS (\$MI)

A AENUB. $K=$ CPWNUB. $K *$ EPSCRF. $K$

NOTE AENUB - ANNUAL EQUIVALENCE OF NON-USER BENEFITS (\$/YR/LN-MI)

$\mathrm{N} \quad \mathrm{IO}=(\mathrm{PCI} * \mathrm{POP}) /(1-\mathrm{FIOIN})$

NOTE IO - INDUSTRIAL OUTPUT (\$/YR)

C $\quad \mathrm{PCI}=20000$

NOTE PCI - PER CAPITA INCOME (\$/YR-PERSON)

C $\quad P O P=200000$

NOTE POP - POPULATION (PERSONS)

C $\quad$ FIOIN $=0.7$

NOTE FIOIN - FRACT INDUSTRIAL OUTPUT TO INPUT NORMAL (DIM)

$\mathrm{N} \quad \mathrm{LSDR}=\mathrm{LLKL} / \mathrm{ASD}$

NOTE LSDR - LINK TO SHIPPING DISTANCE RATIO (DIM)

C $\quad$ LLKL $=100$

NOTE LLKL - LENGTH OF LINK KL (MI)

Appendix C: Comprehensive Level of Service Model 
C $\quad$ ASD $=400$

NOTE ASD - AVERAGE SHIPPING DISTANCE (MI)

R HRG.KL=QKL.K*CFTAT*LLKL*TPG.K/(AFE.K*HWYT.K)

NOTE HRG - HIGHWAY REVENUES GENERATED (\$/YR/LANE-MI)

L CHRG.K $=$ CHRG.J +(DT)(HRG.JK)

NOTE CHRG - CUMULATIVE HIGHWAY REVENUES GENERATED (\$/LN-MI)

$\mathrm{N} \quad \mathrm{CHRG}=\mathrm{CHRGN}$

C $\quad$ CHRGN $=0$

NOTE CHRGN - INITIAL VALUE OF CUMULATIVE HIGHWAY REVENUES GENERATED

A AEHRG. $\mathrm{K}=\mathrm{CHRG} . \mathrm{K} *$ EPSCRF. $\mathrm{K}$

NOTE AEHRG - ANNUAL EQUIVALENCE OF HWY REVENUES GENERATED (\$/YR/LN-MI)

A AFE. $K=20$

NOTE AFE - AVERAGE FUEL EFFICIENCY (MI/GAL)

A TPG.K $=0.3$

NOTE TPG - TAX PER GALLON (\$/GAL)

R TNB.KL =UB.K+NUB.K-RUMHE.KL-RUCHE.KL

NOTE TNB - TOTAL NET BENEFITS $(\$ / Y R / M I)$

A TNBPC.K $=$ TNB.KL*HWYT.K/POP

NOTE TNBPC - TOTAL NET BENEFITS PER CAPITA (\$/YR/PERSON)

L $\quad$ CTNB.K $=$ CTNB.J $+(\mathrm{DT})(\mathrm{TNB} . \mathrm{JK})$

NOTE CTNB - CUMULATIVE TOTAL NET BENEFITS (\$/MI)

$\mathrm{N} \quad \mathrm{CTNB}=\mathrm{CTNBN}$

C $\quad \mathrm{CTNBN}=0$

NOTE CTNBN - INITIAL VALUE FOR CUM TOTAL NET BENEFITS (\$MI)

N TKLN $=$ FFTKL $*(1-(\mathrm{CLSFN} * \mathrm{QKLN}) /(\mathrm{NKL} * \mathrm{CKL})) /\left(1-\mathrm{QKLN} /\left(\mathrm{NKL}{ }^{*} \mathrm{CKL}\right)\right)$

NOTE TKLN - TRAVEL TIME LINK KL NORMAL (MIN/MI)

A FIOT.K=FIOTN*SQRT(TKL.K/TKLN)

NOTE FIOT - FRACT INDUSTIAL OUTPUT TO TRANSPORTATION (DIM)

$\mathrm{N} \quad$ FIOT $=$ FIOTN

C $\quad$ FIOTN $=0.5$

NOTE FIOTN - FRACT INDUSTIAL OUTPUT TO TRANSPORTATION NORMAL (DIM)

R RLE.KL =HRG.KL-RUMHE.KL-RUCHE.KL

NOTE RLE - REVENUES LESS EXPENDITURES (\$/YR/LANE-MI)

L CRLE.K $=$ CRLE.J+(DT)(RLE.JK)

NOTE CRLE - CUMULATIVE REVENUES LESS EXPENDITURES (\$/LN-MI)

$\mathrm{N}$ CRLE $=$ CRLEN

C CRLEN $=0$

NOTE CRLEN - INITIAL VALUE OF CUM REVENUES LESS EXPEND (\$/LN-MI)

A EPSCRF. $\mathrm{K}=((\mathrm{R} *(1+\mathrm{R}) * *$ TIME. $\mathrm{K})) /(((1+\mathrm{R}) * *$ TIME. $\mathrm{K})-.9999)$

NOTE EPSCRF - EQUAL PAYMENT SERIES CAPITAL RECOVERY FACTOR $(\mathrm{A} / \mathrm{P}, \mathrm{I}, \mathrm{N})$

A BENCOST.K=(AEUB.K+AENUB.K-AEUMHE.K)/(AEUCHE.K)

NOTE BENCOST - ANNUAL EQUIV. DISCRETE BENEFIT COST RATIO 
A CBENCST.K $=(($ AEUB.K+AENUB.K-RUMHE.KL $) /$ ^

(RUCHE.KL*R*YEARS))*(1-EXP(-R*ECONLIFE))

NOTE CBENCST - CONTINUOUS BENEFIT COST RATIO

C $\mathrm{YEARS}=7$

NOTE YEARS - YEARS FOR REHABILITATION

C $\mathrm{R}=0.10$

NOTE R - INTEREST RATE

C ECONLIFE $=25$

NOTE ECONLIFE - ECONOMIC LIFE OF PROJECT

SPEC DT $=1 /$ LENGTH $=20 /$ SAVPER $=5$

SAVE BENCOST,CBENCST,RLE,TNBPC 


\section{VITA}

Allan Chasey was born December 12, 1947 in Larned, Kansas. He graduated from Laramie Senior High School in Laramie, Wyoming in May, 1965 and moved with his family to Tempe, Arizona where he graduated from Arizona State University with a Bachelors of Science Degree in Civil Engineering in January, 1971. He entered the United States Air Force at Davis-Monthan Air Force Base in Tucson, Arizona as a Second Lieutenant in April, 1971 and served 2 years in the Civil Engineering Squadron. Following his tour of duty, he joined Federal Civil Service at DavisMonthan Air Force Base and worked for 20 years in various construction and management positions. He was selected by the Air Force to attend the Air Force Institute of Technology in residence at Wright-Patterson Air Force Base in Dayton, Ohio where he received a Masters Degree in Engineering Management in September, 1988.

$\mathrm{He}$ is a registered professional engineer in Arizona and a member of the American Society of Civil Engineers and the American Association of Cost Engineers. $\mathrm{He}$ is married to his wife, Susan, of 25 years and has one daughter, Alisha, a sophomore at Virginia Tech. A son, Sam Rugel, lives in Tucson, Arizona with his wife, Ruth, and two sons, Caleb and Jared.

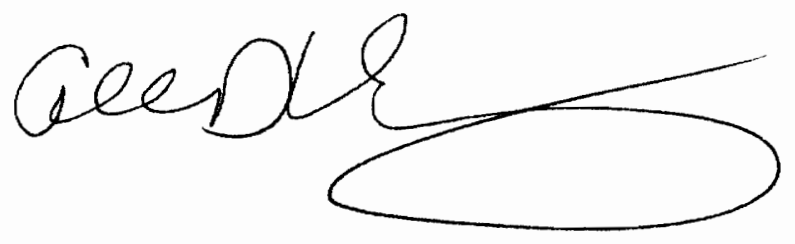

